\title{
Protecting Human Subjects
}

The Adequacy and Uniformity of Federal Rules and their Implementation

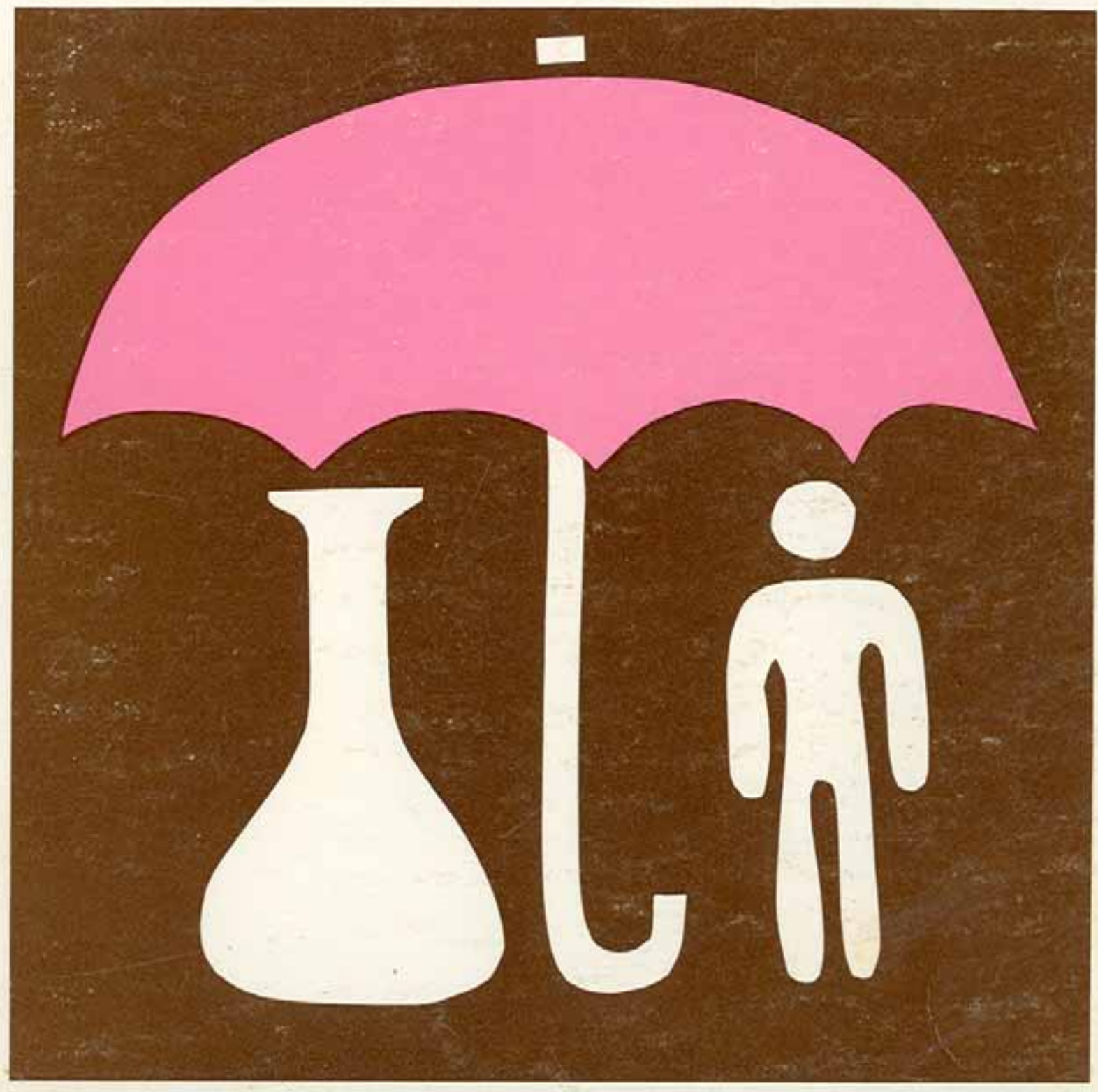

President's Commission for the Study of Ethical Problems in Medicine and Biomedical and Behavioral Research 
Library of Congress card number 81.6001-90

G.P.O. Stock Number 040-000-00452-1

For sale by the Superintendent of Documents, U.S. Government Printing Office Washington, D.C. 20402 


\section{Protecting \\ Human Subjects}

First Biennial Report on the

Adequacy and Uniformity of Federal

Rules and Policies, and their Implementation,

for the Protection of Human Subjects in

Biomedical and Behavioral Research

December 1981

President's Commission for the Study of Ethical Problems in Medicine and

Biomedical and Behavioral Research 


\section{President's Commission for the Study of Ethical Problems in Medicine and Biomedical and Behavioral Research}

Morris B. Abram, M.A., J.D., LL.D., Chairman, New York, N.Y.

Renée C. Fox, Ph.D., D.H.L. Donald N. Medearis, Jr., M.D. University of Pennsylvania Harvard University

Mario García-Palmieri, M.D. Arno G. Motulsky, M.D. Univeristy of Puerto Rico University of Washington

Frances K. Graham, Ph.D. University of Wisconsin

Albert R. Jonsen, Anne A. Scitovsky, M.A. Palo Alto Medical Research Foundation

S.T.M., Ph.D.

Univeristy of California,

San Francisco

Charles J. Walker, M.D. Nashville, Tennessee

Mathilde Krim, Ph.D. * Sloan-Kettering Institute for Cancer Research

Carolyn A. Williams, Ph.D. University of North Carolina, Chapel Hill

* Resignation accepted by President Reagan on December 8 , 1981.

\section{Staff}

Alexander M. Capron, LL.B., Executive Director

Deputy Director

Barbara Mishkin, M.A., J.D.

Assistant Directors

Joanne Lynn, M.D.

Alan J. Weisbard, J.D.

Professional Staff

Mary Ann Baily, Ph.D.

Dan Brock, Ph.D.

Andrew Burness, M.B.A.

Susan Morgan

Marian Osterweis, Ph.D.

Renie Schapiro, M.P.H.

Research Assisants

Michelle Leguay

Jeffrey Stryker

Consultants

Bradford H. Gray, Ph.D.

Dorle Vawter
Administrative Officer

Anne Wilburn

Support Staff

Florence Chertok

Ruth Morris

Clara Pittman

Kevin Powers

Nancy Watson

President's Commission

Commonwealth Fellows and

Student Interns

Joshua Abram (1980)

Deborah Blacker (1980)

Cheryl Cooper (1980)

Jeffrey Katz (1981)

Kathryn Kelly (1981)

Ruth Oratz (1981)

Henry S. Richardson (1981)

Jennifer Seton (1980)

David Tancredi (1981)

William Thompson (1981) 
President's Commission for the Study of Ethical Problems in Medicine and Biomedical and Behavioral Research Sulte 555, 2000 K Street, N.W., Washington, DC 20006 (202) 653-8051

December 30,1981

The President

The White House

Washington, D.C. 20500

Dear Mr. President:

On behalf of the President's Commission for the Study of Ethical Problems in Medicine and Biomedical and Behavioral Research, I am pleased to transmit our Biennial Report on "Protecting Human Subjects." The Commission is directed by $\$ 1802$ (c) of the Public Health Service Act to report every two years on the adequacy and uniformity of the Federal rules and policies, and their implementation, for the protection of human subjects in blomedical and behavioral research. As the Commission began its work in January 1980, this is our first Biennial Report.

The Commission does not propose any major changes in the substance of the rules on human research, although a number of adjustments are recommended to recognize the flexibility needed by research institutions, particularly in responding to allegations of wrongdoing or other problems. We also propose a simple improvement in the reports filed by researchers, to provide information on the number of subjects and on any that are adversely affected by participation in a research project.

The Commission does recommend one major organizational change, namely that a uniform core of regulations be adopted, based upon the present rules of the Department of Health and Human Services, and that HHS become the lead agency in this field. This consolidation would elfminate needless duplication in the rules of the 23 other Federal entities that support or regulate research, thereby simplifying both local compliance with the rules and Federal oversight of the system. Copies of this report are being sent to all affected Federal agencies, with a request for action, pursuant to the Commission's enabling legislation.

We are continuing to examine the important subject of human research and may have further recommendations in our next report on this subject.

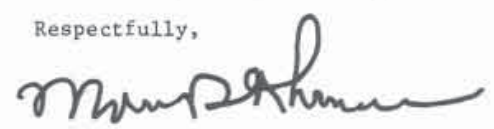

Morris B. Abram

Chairman 

President's Commission for the Study of Ethical Problems

in Medicine and Biomedical and Behavioral Research

Sulto 555, 2000 K Street, N.W., Weshingtion, DC 20006 (202) 653-8051

December 30,1981

The Honorable George Bush

President

Un1ted States Senate

Washington, D.C. 20510

Dear Mr. President:

On behalf of the President's Commission for the Study of Ethical Problems 1n Medicine and Blomedical and Behavioral Research, I am pleased to transmit our Blennial Report on "Protecting Human Subjects." The Commission is directed by 51802 (c) of the Public Health Service Act to report every two years on the adequacy and uniformity of the Federal rules and policies, and their implementation, for the protection of human subjects in blomedical and behavioral research. As the Commission began 1ts work in January 1980, this 1s our f1rst Blennial Report.

The Commission does not propose any major changes in the substance of the rules on human research, although a number of adjustments are recommended to recognize the flexibility needed by research institutions, particularly in responding to allegations of wrongdoing or other problems. We also propose a simple improvement in the reports filed by researchers, to provide information on the number of subjects and on any that are adversely affected by participation in a research project.

The Commission does recommend one major organizational change, namely that aniform core of regulations be adopted, based upon the present rules of the Department of Health and Human Services, and that HHS become the lead agency in this field. Th1s consolidation would eliminate needless duplication in the rules of the 23 other Federal entities that support or regulate research, thereby simplifying both local compliance with the rules and Federal oversight of the system. Copies of this report are being sent to all affected Federal agencies, with a request for action, pursuant to the Commission's enabling legislation.

We are continuing to examine the important subject of human research and may have further recommendations in our next report on this subject.

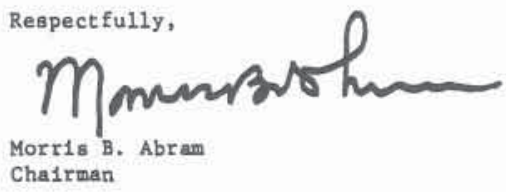



The Honorable Thomas P. O'Neill, Jr. Speaker

U.S. House of Representatives

Washington, D.C. 20515

Dear Mr. Speaker:

On behalf of the President's Commission for the Study of Ethical Problems in Medicine and Biomedical and Behavioral Research, I am pleased to transmit our Biennial Report on "Protecting Human Subjects." The Commission is directed by $\$ 1802$ (c) of the Public Health Service Act to report every two years on the adequacy and uniformity of the Federal rules and policies, and their implementation, for the protection of human subjects $1 \mathrm{n}$ biomedical and behavioral research. As the Commission began its work in January 1980, this is our first Blennial Report.

The Commission does not propose any major changes in the substance of the rules on human research, although a number of adjustments are recommended to recognize the flexibility needed by research institutions, particularly in responding to allegations of wrongdoing or other problems. We also propose a simple improvement in the reports filed by researchers, to provide information on the number of subjects and on any that are adversely affected by participation in a research project.

The Commission does recommend one major organizational change, namely that a uniform core of regulations be adopted, based upon the present rules of the Department of Health and Human Services, and that HHS become the lead agency in this field. This consolidation would eliminate needless duplication in the rules of the 23 other Federal entities that support or regulate research, thereby simplifying both local compliance with the rules and Federal oversight of the system. Copies of this report are being sent to all affected Federal agencies, with a requeat for action, pursuant to the Commission's enabling legislation.

We are continuing to examine the important subject of human research and may have further recommendations in our next report on th1s subject.

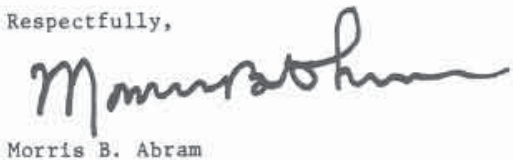

Morris B. Abram Chairman 


\section{Table of Contents}

Page

Summary and Conclusions $\quad 1$

Chapter 1: Introduction 5

The Mandate 5

Initial Recommendations to the Department of Health and Human Services

Summary of the Commission's Activities

Survey of Federal Rules and Procedures Governing

Research with Human Subjects

Review of the Adequacy and Uniformity of the

Rules' Implementation

Attempts to Clarify HHS Policies and Procedures for

Responding to Reports of Misconduct

Case Studies

Commission Hearings

Conferences Attended

Workshop on Whistleblowing in Biomedical

Research

5

Assistance from Liaison Representatives to the Commission

Contacts with the Office of Management and Budget

Report on Compensating for Research Injuries

Extent of Federal Involvement in Research with Human Subjects

Chapter 2: The Adequacy and Uniformity of the Regulations

Methods

Scope of the Survey

Agencies Excluded from Further Review 
Agencies Included in the National Commission

Report that are not Reviewed in this Report

Scope of This Report

The Regulatory System Governing Research Conducted or Supported by the Department of Health and Human Services (HHS)

Applicability

Review Procedures

Review Standards

Consent Provisions

Sanctions

Summary and Analysis of the Regulations of Other Federal Agencies

The Degree of Uniformity: Minor Variations

Agencies Without Formal Regulations 31

Conclusions

Chapter 3: The Adequacy and Uniformity of the Regulations' Implementation

Do Federal Agencies Know How IRBs are Performing?

The Negotiation of "Assurances" by HHS

37

Steps taken by OPRR to Improve Implementation 37

Food and Drug Administration

Other Federal Agencies

Are IRBs Able to Understand and Fulfill Their Obligations?

Initial Review

Continuing Review

Reporting Requirements

How Do Federal Agencies Respond to Reported or Documented Violations of the Regulations or Other Serious Misconduct of Grantees or Contractors?

Case Studies

Questions Posed to the Secretary, HHS

The FDA's Disqualification Procedures 58

Questions Posed to Other Federal Agencies $\quad 59$ 
Chapter 4: Activities of the Commission Extending Into 1982

Site Visits to IRBs: An Exploratory Study $\quad 61$

Guidebook for IRBs

Consideration of the Extension of Federal Regulations and Review Requirements to Research Not Federally Funded

Possible Consideration of the Definition of "Phase 1" Drug Testing in Cancer Chemotherapy

Report on Problems Identified at IRB Workshops

Informed Consent and Problems of Privacy in the

Research Setting

Chapter 5: Recommendations

Recommendations for Improving the Adequacy and Uniformity of Federal Laws and Regulations for the Protection of Human Subjects

1. All Federal Agencies Should Adopt the Regulations of HHS (45 CFR 46)

2. The Secretary, HHS, Should Establish an Office to Coordinate and Monitor Government-Wide Implementation of the Regulations

3. Each Federal Agency Should Apply One Set of Rules Consistently to All Its Subunits and Funding Mechanisms

4. Principal Investigators Should Be Required to Submit Annual Data on the Number of Subjects in Their Research and the Number and Nature of Adverse Effects

5. The National Commission's Recommendations on Research Involving Children and the Mentally Disabled Should Be Acted Upon Promptly

6. "Private" Research Organizations Receiving Direct Federal Appropriations Should Be Required to Follow Regulations for the Protection of Human Subjects

Recommendations for Improving Institutional and Federal Oversight of Research and the Response to Reports of Misconduct

7. Institutions Should Be Free to Use Offices Other than IRBs to Respond to Reports of Misconduct and Should Have Procedures for Prompt Reporting of Their Findings to the Funding Agency 
8. IRBs Should be Required Only to Report to Appropriate Officials of Their Institution (Rather Than to the Funding Agency) When They Learn of Possible Misconduct and to Respond to the Findings of Those Officials

9. There Should be Government-Wide Procedures for Debarring Grantees and Contractors Found Guilty of Serious Misconduct, as well as a Consolidated List of Formal Debarments and Suspensions Actively Shared With Government Agencies, Professional Societies, and Licensing Boards

Appendices

Tables

1. Extent of Biomedical and Behavioral Research Involving Human Subjects Conducted or Supported by Agencies with Statutory Liaisons to the Commission

2. Agencies Excluded from Review and Analysis in This Report

1. Agencies Included in This Report's Review and Analysis

4. Agenc:y Conformity with HHS Regulations

5. Akency Procedures for Monitoring Performance of lixtramural IRBs

1. Summiry of Institutional and HHS Responses to Reporterl Incidents of Research Fraud, Abuse or Violatious of Regulations 



\section{Summary and Conclusions}

Research with human beings plays an essential part in combatting disease and in expanding the frontiers of knowledge. The Commission takes as given that only through research can proven advances be made in the prevention and cure of illness and in the relief of suffering, but in this Report it addresses another goal, which, like progress against disease, is highly valued in our society. For not only is research essential but it is equally essential that this important human activity be carried out without needless risk or distress and with the willing and enlightened cooperation of its subjects. This is an ideal to which the Federal government must be-and for many years, has been-committed. In this Report, the President's Commission responds to the request of the Congress that it report every two years on the degree to which Federal departments and agencies are meeting that high ideal.

The Commission has reviewed the policies of all Federal entities involved in some fashion in research involving human subjects. It is impressed that the officials of these agencies are for the most part concerned about the careful execution of their responsibilities and concludes that the rules and policies of the agencies largely appear adequate for the protection of human subjects if properly implemented. Certain problems in the application and interpretation of the rules, however, have emerged from the Commission's study. This Biennial Report contains the Commission's recommendations to the President, the Congress and the heads of relevant departments and agencies concerning a number of these problems. The Commission intends to make additional proposals in its next Biennial Report on the basis of its continuing examination of this fieid. 
Some of the Commission's conclusions refer to particular federal entities. The Commission points to (1) the need for the Department of Health and Human Services (HHS) either to accept or reject certain recommendations made in 1978 by the National Commission for the Protection of $\mathrm{Hu}-$ man Subjects that were intended to provide additional procedures and standards so that appropriate decisions may be made to protect children and persons institutionalized as mentally disabled when reserchers wish to involve them as subjects; (2) the need for the Department of Housing and Urban Development to establish clear standards by which its social policy research can be categorized and, when appropriate, reviewed; and (3) the urgency that several bodies, including the Department of Transportation, reach decisions on rules that have been "under study" for many years [Recommendations 3 and 5].

Most of what the Commission has to say, however, treats issues that cut across the spectrum of Federal entities involved in research. First, the Commission recommends that the movement toward "uniformity" in the regulations for the protection of human research subjects be carried to its logical conclusion, and that the Department of Health and Human Services and its present regulations become the focus of such uniform rules [Recommendations 1 and 2]. This will advance four important objectives: it will improve the protection of subjects, alleviate an unnecessary burden (and source of confusion) for researchers and their institutions, eliminate the multiplicity of Federal regulations in this field, and simplify Federal oversight.

The first goal will be met as gaps in a few departments' rules to protect research subjects are filled. "Variations" now followed by other departments can be included in the new uniform rules if found useful by the government-wide task force that will formulate these rules. The remaining objectives are closely related. By eliminating more than 200 pages of governmental rules and policies that now largely repeat the HHS regulations, the steps recommended by the Commission would reduce waste and confusion as well as facilitate Federal oversight. The redundancy in agencies' current rules obscures those few variations that are actually important to the respective Federal entities. Under the Commission's recommendations, any special provisions that are needed only by a particular entity could then be highlighted as acceptable exceptions or additions to the "core" provisions of the uniform regulations. And the centralization of responsibility for implementation and oversight in HHS would relieve Federal agencies and research institutions alike of the unnecessary burdens created by multiple inspections and reporting requirements. 
The second major area of Commission recommendations centers on improving the present handling of reports of harm or misconduct involving human subjects. Although such reports are not frequent, the Federal government already has a number of relevant regulations on the books. The Commission examined these regulations to determine whether they provide adequate protection to subjects and other concerned parties in a manner that is clear and simple to apply for Federal officials and research administrators alike. The resulting recommendations fall into three groups.

First, this Report contains recommendations about the responsibilities of the Federal agencies in responding to reports of misconduct. Revisions are needed because of an apparent lack of well-defined standards and an absence of coordination among various Federal entities. The present processes are still relatively new and few cases of misconduct have been reviewed; in fact, it was not until 1981 that

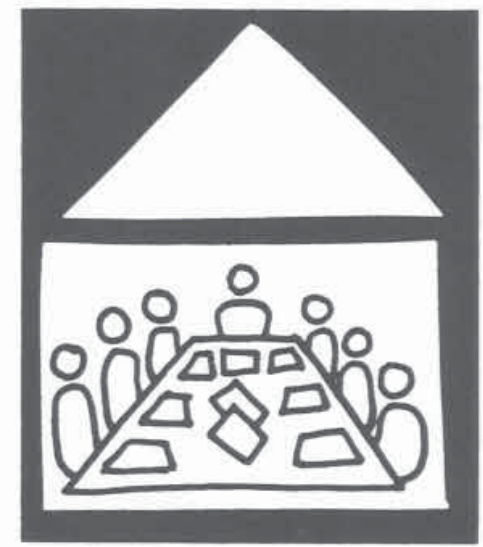
HHS or its predecessors imposed any sanctions against an investigator for misconduct in research funded by the Department that involves human subjects. Cooperation, not merely between Federal agencies but also among them and state and professional boards, is clearly an important goal [Recommendation 9].

Second, several recommendations are made to allow institutions internal flexibility in how they will investigate and adjudicate complaints against researchers. Although perhaps not intended by the Department the present language of the HHS regulations has been interpreted by some as making Institutional Review Boards (IRBs) responsible for resolving allegations of misconduct and for reporting their determinations directly to the Secretary rather than through institutional channels. The IRB must have a place in the process (at a minimum, it must be kept apprised of the outcome), but it need not perform the investigatory/adjudicatory/reporting roles if those are more properly fulfilled by other offices within an institution [Recommendations 7 and 8 ].

Finally, the Commission recommends that the number of subjects involved in, as well as the number adversely affected by, each research project be routinely collected by 
IRBs and reported by them to the sponsoring agencies [Recommendation 4].

In recommending ways in which the federal regulations on research could achieve greater clarity, simplicity and realism, the Commission is not adopting the view that all problems are ultimately soluble by "better" regulations. The Commission took concerns about excessive regulation into account in framing its recommendations and in drawing up its plans for further study of this subject during the coming year. As Plato observed, in esoteric areas, one must rely also on the wisdom of the expert. If society relied totally on written rules,

the arts as we know them would be annihilated and ... could never be resurrected because ... this law [would put] an embargo on all research. The result would be that life which is hard enough as it is, would be quite impossible then and not to be endured. ${ }^{1}$

Just as society must rely on the experts' wisdom, so too must it rely on their consciences - for which reasonable and well-formulated regulations may still provide both instruction and incentive.

1 Plato, Statesman * 229 e (J.B. Skemp trans.), Yale University Press, New Haven (1952) at 208. 


\section{Introduction}

\section{The Mandate}

The Commission's mandate regarding the protection of subjects in research with human beings has two major parts: first, to review the Federal rules and policies governing such reseach ${ }^{1}$ and second, to determine how well those rules are being implemented or enforced. Specifically, Section 1802 (c) of the enabling legislation provides that:

The Commission shall biennially report to the President, the Congress, and appropriate Federal agencies on the protection of human subjects of biomedical and behavioral research. Each such report shall include a review of the adequacy and uniformity (1) of the rules, policies, guidelines, and regulations of all Federal agencies regarding the protection of human subjects of biomedical and behavioral research which such agencies conduct or support, and (2) of the implementation of such rules, policies, guidelines and regulations by such agencies, and may include such recom-

${ }^{1}$ Section 1802 (c) of the Commission's legislation mandates a report on the rules governing research that Federal agencies "conduct or support." The Commission has chosen, pursuant to its authority to study "any other appropriate matter which relates to biomedical or behavioral research," to include within the present study the rules of the Food and Drug Administration (FDA) governing research regulated but not supported by the Federal government. The FDA was singled out because of its preeminent role in regulating biomedical research supported by private funds (under applicable law, materials submitted to obtain FDA approval of drugs and devices must have been produced through research that meets its requirements, including regulations for the protection of human subjects) and because of the close relationship between the FDA regulations and those applicable to research funded by HHS, of which FDA is a component. 
Protecting Human Subjects: Chapter 1

mendations for legislation and administrative action as the the Commission deems appropriate. ${ }^{2}$

The first portion of the mandate expands the survey of Federal agencies that the Commission's predecessor, the National Commission for the Protection of Human Subjects conducted, to a detailed inquiry into the adequacy of the rules of all agencies. The second portion, which adds a new dimension to the inquiry, has emerged as a major focus of this Commission's activities in the wake of the new rules or research promulgated by the Department of Health and Human Services in January 1981.

The first biennium for this Report, which began when the Commission held its first meeting in January 1980, ends in December 1981. (The second "biennium" will end in December 1982 when the Commission's present authority expires.) This report, therefore, represents two years of study and deliberations during which the Commission held three public hearings on this subject, devoted significant portions of twelve meetings to discussion and deliberation, surveyed over 83 Federal agencies to ascertain their involvement in-and rules governing-research with human subjects, requested detailed information from the five agencies having statutory liaisons with the Commission (the Department of Health and Human Services, the Department of Defense, the Central Intelligence Agency, the Veterans Administration, and the National Science Foundation), and participated in Congressional hearings on several issues encompassed within this aspect of the Commission's mandate. ${ }^{3}$ During this period, frequent correspondence and meetings took place between officials of the Department of Health and Human Services (HHS) and the Commission. This introductory chapter briefly describes the Commission's activities relating to this portion of its mandate.

\section{Initial Recommendations to the Department of Health and Human Services}

In September 1980, following a public hearing held in July on social science and behavioral research, the Commission made recommendations to HHS Secretary Patricia R. Harris (see Appendix D) on the Department's proposed revisions to its rules governing research with human subjects (45 CFR 46). The Commission proposed specific exemptions from prior review for most forms of social science re-

${ }^{2}$ Title XVII, Public Health Service Act, 42 USC 300v-1(c).

${ }^{3}$ Commission staff was also in touch with the Commission on the Federal Drug Approval Process, sponsored by Representatives Scheuer and Gore. That body is now reported to have decided not to disturb the status quo regarding the responsibilities of IRBs or other aspects of the regulations to protect human subjects. 
search and some categories of behavioral research that present no risk of physical or psychological harm and no invasion of privacy. These recommendations were in line with the proposals being considered by the Department, but differed from them in that they were organized so as to convey the grounds for each category of exemption to the members of local review boards at research institutions who would have to apply them.

The Commission also informed Secretary Harris of its conclusion that the Department currently lacks statutory authority to require grantee institutions to follow HHS regulations and procedures in reviewing reserch not supported by Departmental funds. The Director of the Office of Management and Budget and the Director of the Office of Science and Technology Policy subsequently endorsed the Commission's position. (Whether such authority should be granted to HHS or other Federal departments is a question the Commission will address in the next Biennial Report.)

The amendments to the HHS rules governing research with human subjects were published on January 26, 1981 to take effect on July $27,1981 .{ }^{4}$ In their final form, the regulations incorporated the recommendation made by the Commission to limit the scope of the regulations by abandoning the proposed applicability to research neither funded by the Department nor subject to the regulatory authority of the Food and Drug Administration (FDA). The Department did not, however, adopt the Commission's formulation of the rationale and organization of the exemptions of certain kinds of social science and behavioral research. (The relevant materials appear in Appendix D.)

\section{Summary of the Commission's Activities}

Survey of Federal Rules and Procedures Governing Research with Human Subjects. The Commission sent letters of inquiry to 83 Federal agencies that might possibly be conducting or supporting research with human subjects. The responsible officials were asked whether their agencies conduct or support research with human subjects and, if so, what regulations or guidelines they follow to assure that such subjects are protected. In all cases, agencies were asked to include copies of applicable regulations, guidelines, or policies with their response.

Chapter Two of this Report contains an analysis of the adequacy and uniformity of the rules and procedures of the 23 Federal entities reporting that they conduct or support research with human subjects, as well as of the rules and procedures of the FDA, which plays the dominant role in the regulation of biomedical research not funded by the

${ }^{4} 46$ Federal Register 8366, reprinted in Appendix A. 
Federal government. Among the agencies, HHS (which supports the largest volume of research and which has devoted the most attention to the subject) is widely regarded as the "lead" agency. A fuller description of the policies and procedures of HHS is set forth in Appendix B, as well as a description of the rules and procedures of each of the other Federal entities, compared with those of HHS.

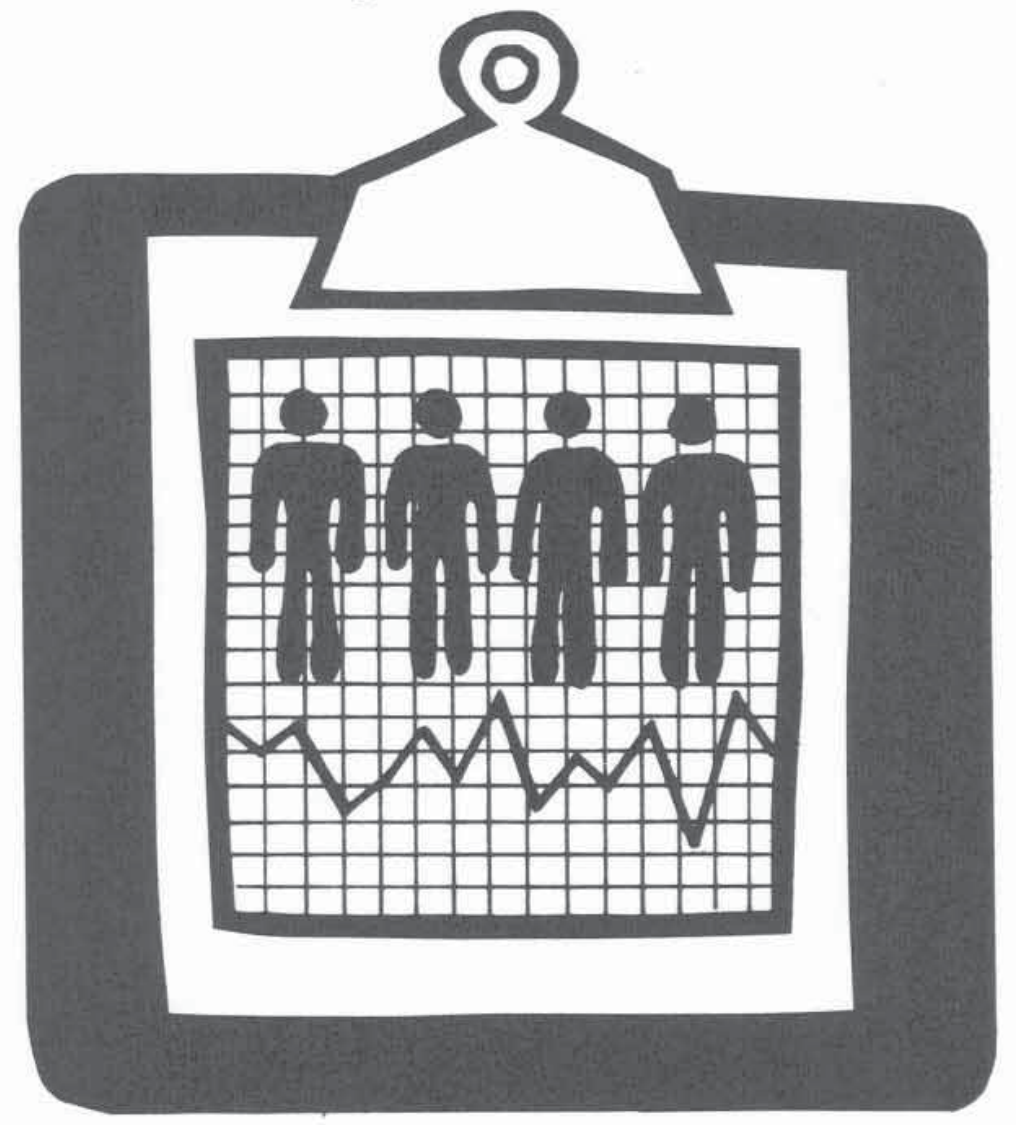

Review of the Adequacy and Uniformity of the Rules' Implementation. The second half of the Commission's charge regarding the protection of human subjects is to determine how adequately the applicable rules are being implemented. This has been a major focus of the Commission's activities in 1981. The Commissioners have tried to learn, from a variety of approaches: (1) how well informed the funding agencies are about institutional compliance with the regulations (an inquiry that led the Commission to conduct a selective examination of grantee institutions' implementation of the regulations); (2) how able institutions are to handle charges of noncompliance, misconduct or in- 
jury; and (3) how the funding agencies respond to reports that the regulations have been violated or human subjects placed at risk through acts of research fraud or other misconduct.

As part of its survey of the rules and procedures of Federal agencies conducting or supporting research with human subjects, the Commission asked each agency about the extent to which it monitors either the actual conduct of research or the performance of the IRBs at grantee and contractor institutions. A summary and analysis of those responses is contained in Chapter Three.

Attempts to Clarify HHS Policies and Procedures for Responding to Reports of Misconduct. The Commission, through its Chairman and senior staff, for more than a year has been, and continues to be, engaged in correspondence and meetings with officials at the Department of Health and Human Services in an attempt to clarify current Departmental policies and procedures for responding to reports of misconduct by grantees and contractors. (See Appendix F.) The Commission is particularly interested in learning about the extent to which standards and procedures exist for: (a) alerting committees that review grants and contracts about serious allegations pending against a scientist; (b) protecting complainants and witnesses from retaliation; (c) protecting the subjects, if research activities must be suspended; (d) protecting the rights of those accused of misconduct; and (e) protecting the public interest by assuring the reliability of research results and the ethical conduct of Federally supported research.

Case Studies. The Commission also examined closely several reported incidents of misconduct in Federally funded research to determine what might be learned from these well-documented cases. Although the cases are few in number, particularly in light of the thousands of research projects conducted each year, the Commission found them instructive. Specifically, the cases indicate areas where procedures for responding to reports of misconduct need improvement at the institutional and the Federal levels. Problems identified in a review of these cases are described in Chapter Three; the cases themselves are described in Appendix E.

Commission Hearings. As an adjunct to its study of cases of misconduct in Federally supported biomedical research, the Commission held hearings during 1981 in Boston and Los Angeles, the locales of two such incidents. The purpose was to learn from administrators and IRB members at the research institutions involved, as well as from principal investigators and those who reported misconduct, how well they believe existing procedures worked and what im- 
provements they would recommend. A number of suggestions regarding the authority of IRBs, institutional mechanisms for investigating and adjudicating reports of misconduct, and Federal procedures for monitoring compliance were received and considered by the Commisssion. Furthermore, in addition to its hearings and deliberations on social and behavioral science research in July and September 1980, the Commission considered aspects of its Biennial Report at its regular meetings in October, November and December 1981, at which time periods were set aside for public comments as well as Commission discussion. (A list of witnesses appears in Appendix I.)

Conferences Attended. Senior professional staff particpated in a number of conferences on the role and responsibilities of IRBs, the need for improved education of investigators and members of IRBs, and the effect that the revised HHS regulations will have on IRB procedures. Such conferences included: a meeting sponsored by HHS of consultants on "Education for IRBs" (December 8, 1980); two conferences sponsored by Public Responsibility in Medicine and Research (PRIMR) on "The New Federal Regulations: What They Do and Do Not Regulate" (Boston, March 26-27, 1981 and Asilomar, November 2-4, 1981); and a workshop sponsored by the Institute for Society, Ethics and the Life Sciences (Hastings Center) on "Institutional Review Boards and Human Subjects Research" (Colorado College, July 12, 1981). In addition, the Commission's director participated in workshop discussions with research administrators and members of IRBs (e.g., the 1981 annual meeting of the National Council of University Research Administrators and the fourth annual University of California conference on IRBs).

Workshop on Whistleblowing in Biomedical Research. Because all Federal agencies rely on private individuals to report incidents of misconduct in research with human beings, the Commission decided to examine the availability of means for making such reports, the adequacy of procedures for evaluating the reports, and the protections afforded both the complainant and the person accused after allegations have been made. The Commission was also interested in the response of the Federal agencies once they receive either an allegation of serious misconduct or a formal finding by an institution that such misconduct has occurred.

To clarify the issues and examine possible modes of response, the Commission held a two-day Workshop on Whistleblowing in Biomedical Research, co-sponsored by the Committee on Scientific Freedom and Responsibility of the American Association for the Advancement of Science and by Medicine in the Public Interest. Participants includ- 
ed physicians engaged in biomedical research; hospital administrators; professors of law, political science, sociology, and educational administration; practicing attorneys; officials of the National Institutes of Health and the Food and Drug Administration, a member of the President's Commission and senior staff of the sponsoring organizations. (See Appendix J.) The conclusions and recommendations of the Workshop were transmitted to members of the Commission and were taken into consideration in developing recommendations on this subject. (Conference papers, discussions and conclusions will be published as a separate volume in 1982.)

Assistance from Liaison Representatives to the Commission. Under section 1801(a)(2) of the Commission's enabling legislation, the heads of six agencies were directed to name officials to act as liaison to the Commission: the Department of Health and Human Services, the Department of Defense, the Central Intelligence Agency, the White House Office of Science and Technology Policy, the Veterans Administration, and the National Science Foundation. ${ }^{5}$ The Commission and its staff wish to thank those who served in this capacity for their conscientious attendance at Commission meetings and their valuable assistance, both formal and informal, in the preparation of this report.

Contacts with the Office of Management and Budget. In response to an OMB proposal for government-wide debarment procedures applicable to Federal contractors, ${ }^{6}$ senior staff of the Commission have discussed with OMB its interest in developing government-wide debarment procedures that would apply to Federal grantees as well. The purpose would be to standardize debarment and sus-

${ }^{5}$ Liaison was provided by: Department of Health and Human Services-Charles R. McCarthy, Ph.D., Director, Office for Protection From Research Risks, Office of the Director, NIH, assisted by Richard Riseberg, Chief, NIH Branch, Office of General Counsel, John C. Petricciani, M.D., Assistant Director for Clinical Research, Bureau of Biologics, FDA, and Stuart Nightingale, M.D., Acting Associate Commissioner for Health Affairs, FDA; Department of Defense-Captain Peter A. Flynn, MC, USN, Special Assistant for Professional Activities, Office of the Assistant Secretary of Defense (Health Affairs); Central Intelligence Agency-Bernard M. Malloy, M.D., Chief of the Psychiatric Division, Office of Medical Services, assisted by Dennis Foreman, Office of General Counsel; Office of Science and Technology Policy-Gilbert S. Ommen, M.D., Ph.D., Associate Director for Human Resources and Social and Economic Services, OSTP, Executive Office of the President, succeeded by John Ball, M.D., J.D., succeeded by Denis Prager, Ph.D.; Veterans Administration-Dorothy C. Rasinski, M.D., J.D., Associate Director, Medical Legal Affairs; and National Science Foundation-Richard T. Louttit, Ph.D., Division Director for Behavioral and Neural Sciences. 
pension procedures so that a scientist, debarred or suspended by one Federal agency (for misconduct in the course of Federally funded research) could be debarred by other agencies without burdening all concerned with additional debarment proceedings. Further, a consolidated list of persons debarred from individual agencies would be available to all Federal agencies. OMB officials have expressed interest in developing such government-wide system applicable to recipients of research grants. (See Appendices G and H.)

\section{Report on Compensating for Research Injuries}

At the urging of the vice-chair of the Ethics Advisory Board in HHS, which was in the process of concluding its activities, the Commission decided at its first meeting to study the problem of providing compensation for researchrelated injuries, a subject closely related to the protection of human subjects.

A starting point was provided by the report of the HEW Secretary's Task Force on Compensation for Injured Research Subjects (1977), which concluded that there is an ethical obligation to provide compensation for persons injured as a result of their participation in Federally sponsored research. The question of how such compensation could be provided was not resolved either by the Task Force or subsequently within HHS. The Commission, therefore, confronted two distinct, but related, questions: (1) whether it agrees that an ethical obligation to provide compensation exists and, if so, the extent of that obligation; and (2) whether feasible mechanisms exist or could be developed that would meet that obligation.

A separate report on the Commission's study of these questions and the conclusions it reached is under preparation and will be released early in 1982 .

\section{Extent of Federal Involvement in Research with Human Subjects}

Annual expenditures for health-related research are now about $\$ 8$ billion, of which the Federal government contributes more than $60 \%$. Three-quarters of this amount comes from the Department of Health and Human Services, primarily through the National Institutes of Health (NIH). ${ }^{7}$ The remaining quarter of Federal support for biomedical and other health-related research is contributed by some 17 other agencies, with major portions provided through the

646 Federal Register 37832 (July 22, 1981).

${ }^{7}$ U.S. Department of Health, Education, and Welfare, Basic Data Relating to the National Institutes of Health: 1980, U.S. Government Printing Office, Washington (1980) at 4. 
Introduction

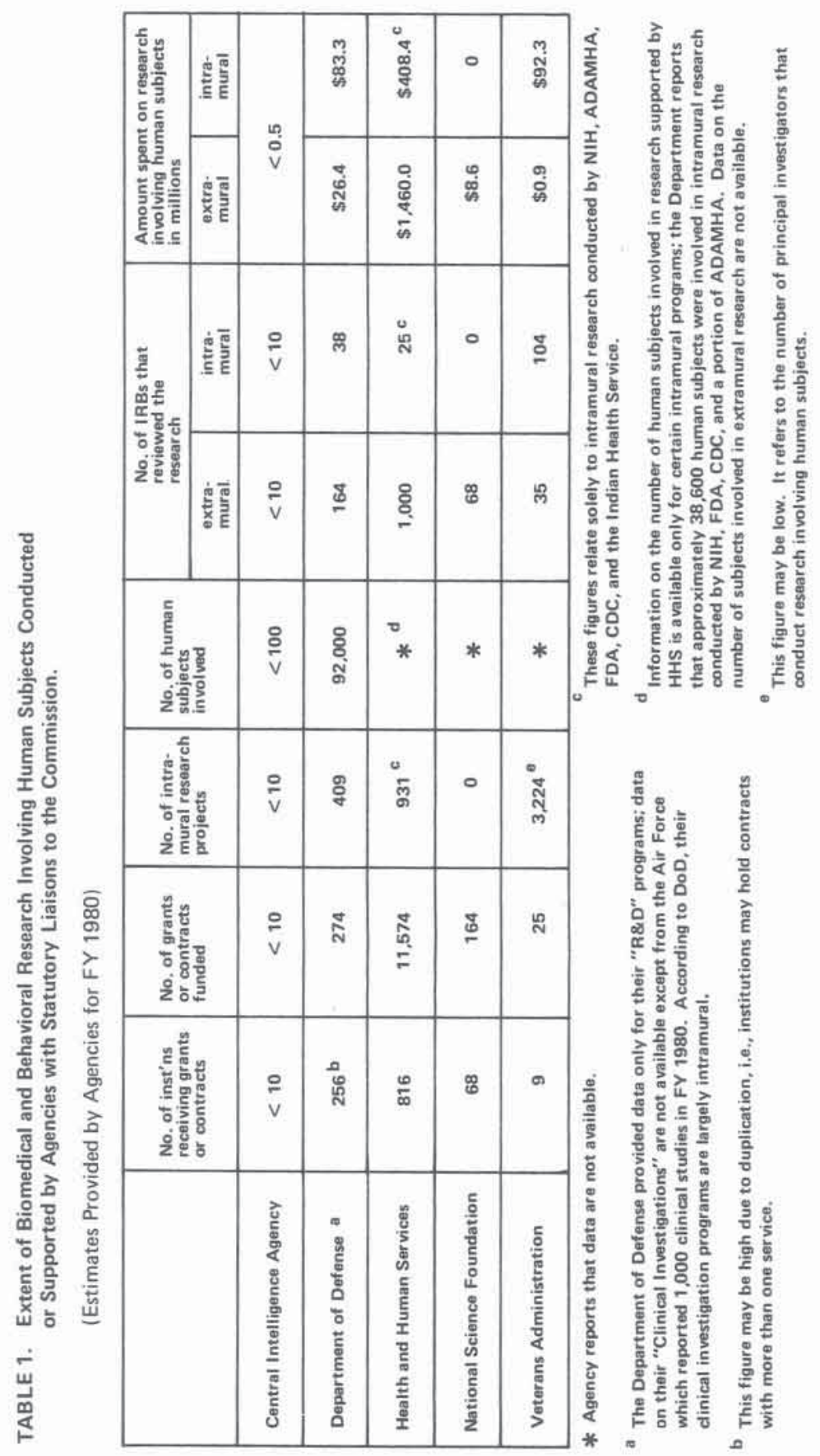


Departments of Agriculture, Defense and Energy and the Veterans Administration. ${ }^{8}$

The amount of such research that involved human subjects is, however, unknown. In fact, the Commission has been hampered in its study of the magnitude of the problem of research injuries because data have not been systematically accumulated on the number of subjects involved in Federally funded research. In an attempt to obtain an impression of the extent of Federal involvement in research with human subjects, the Commission asked the five agencies with official liaisons to the Commission to provide the following information for FY 1980, to the extent obtainable: (1) the number of research projects involving human subjects that were supported by their departments under grants or contracts (extramural research) or that were conducted either by departmental employees or at facilities operated by their departments (intramural research); (2) the number of IRBs that reviewed such research; (3) the amount of money spent; and (4) the number of subjects involved. Table 1 reflects the information provided by the liaison officers.

As the table makes apparent, data are not available on the number of human subjects involved in Federally supported research except for several intramural programs within HHS (e.g., the NIH Clinical Center and the Centers for Disease Control), the R\&D programs (but not the several thousand clinical investigations) conducted by the Department of Defense, and the research conducted by the C.I.A. On the other hand, all five agencies were able to provide the number of grants and contracts they funded for research involving human subjects. In Chapter Five of the Report, the Commission recommends procedures for assuring that all Federal agencies collect and retain in a central location data on the number of subjects participating in research that the agencies conduct or support.

${ }^{8}$ Id. at 5 . 


\section{The Adequacy and Uniformity of the Regulations

A survey of the regulations and policies for the protection of human subjects of Federally funded and regulated research was conducted by the Commission in 1980-81 in response to the legislative mandate that the Commission report biennially to the President, the Congress and the heads of relevant agencies on both the adequacy and the uniformity of the rules and policies of all Federal agencies regarding the protection of human subjects of biomedical and behavioral research. 1

It is generally accepted, among Federal officials and commentators, that the benchmark of "adequacy" is provided by the regulations of the Department of Health and Human Services. Based upon the thorough review of human research regulations of HHS (then, the Department of Health, Education, and Welfare) performed by the National Commission for the Protection of Human Subjects in $1974-78,{ }^{2}$ and the conscientious manner in which HHS has responded to the National Commission's recommendations regarding the review standards and procedures for research involving competent, non-institutionalized adults, the Pres-

"The statutory definition of "Federal agency" excludes the U.S. Courts; therefore, the Commission did not review the activities of the Federal Judicial Center regarding research or experimentation in the justice system. The Commission notes, however, that the Federal Judicial Center has recently received a report on this subject, with recommendations, from an advisory committee on Experimentation in the Law, U.S. Government Printing Office, Washington (1981).

${ }^{2}$ National Commission for the Protection of Human Subjects, Report and Recommendations: Institutional Review Boards, U.S. Government Printing Office, Washington (1978) [hereinafter cited as IRB Report]. 
TABLE 2.

Agencies Excluded from Review and Analysis in this Report

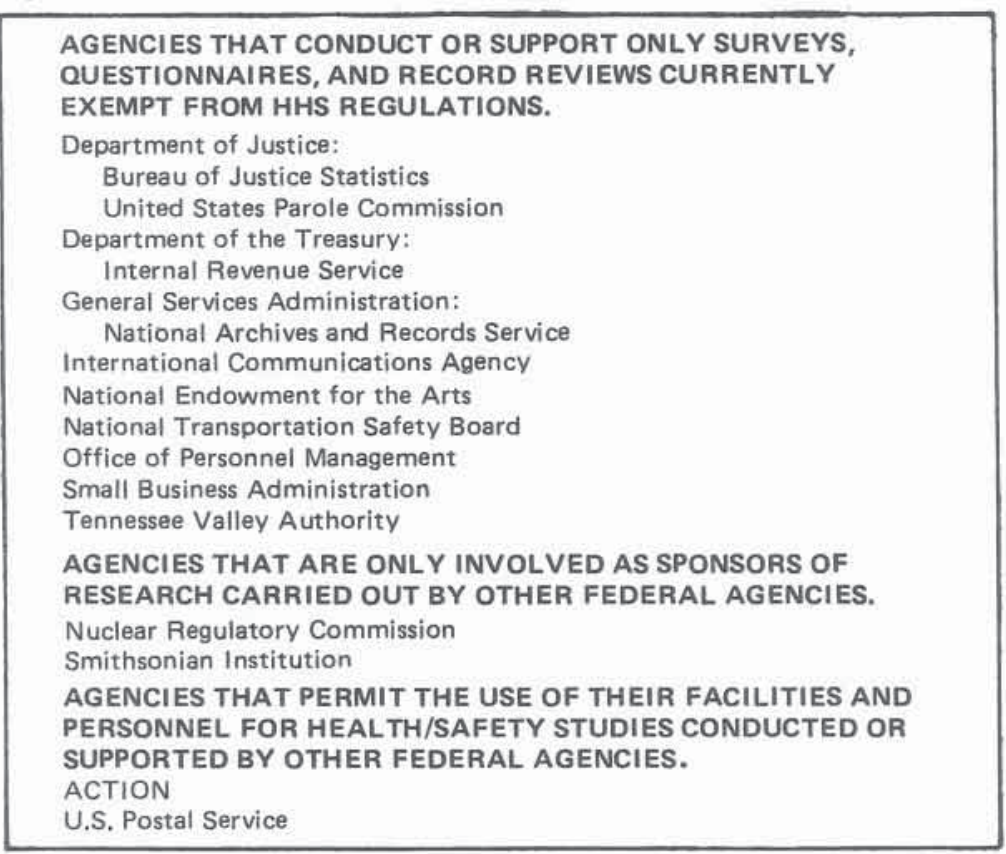

ident's Commission is satisfied that the basic regulations of that Department are adequate if not above improvement. Therefore, the Commission has focused its attention on determining the "uniformity" among other Federal agencies measured by the extent to which their rules conform to the basic regulations of HHS.

\section{Methods}

Scope of the Survey. The methods used to conduct the survey of Federal agencies were similar to those used by the National Commission in 1975 . The 1980 survey was, however, broader in scope, including 11 of the 13 cabinet-level departments, ${ }^{3}$ the Central Intelligence Agency in the Executive Office of the President, and 56 of 87 independent commissions and agencies listed in the Congressional Directory. Agencies were excluded from the survey only when there was reason to be confident that they do not conduct or support research with human subjects. (See Appendix C.)

In March 1980, the twenty still existing Federal agencies which had reported to the National Commission

${ }^{3}$ The Departments of Labor and of the Interior reported in 1976 they do not conduct or support research with human subjects. See letters to Charles U. Lowe, M.D., from John T. Dunlop, Secretary of Labor (October 1, 1975) and from Rayston C. Hughes, Assistant Secretary of the Interior (October 14, 1975). 
TABLE 3.

Agencies Included in this Report's Review and Analysis

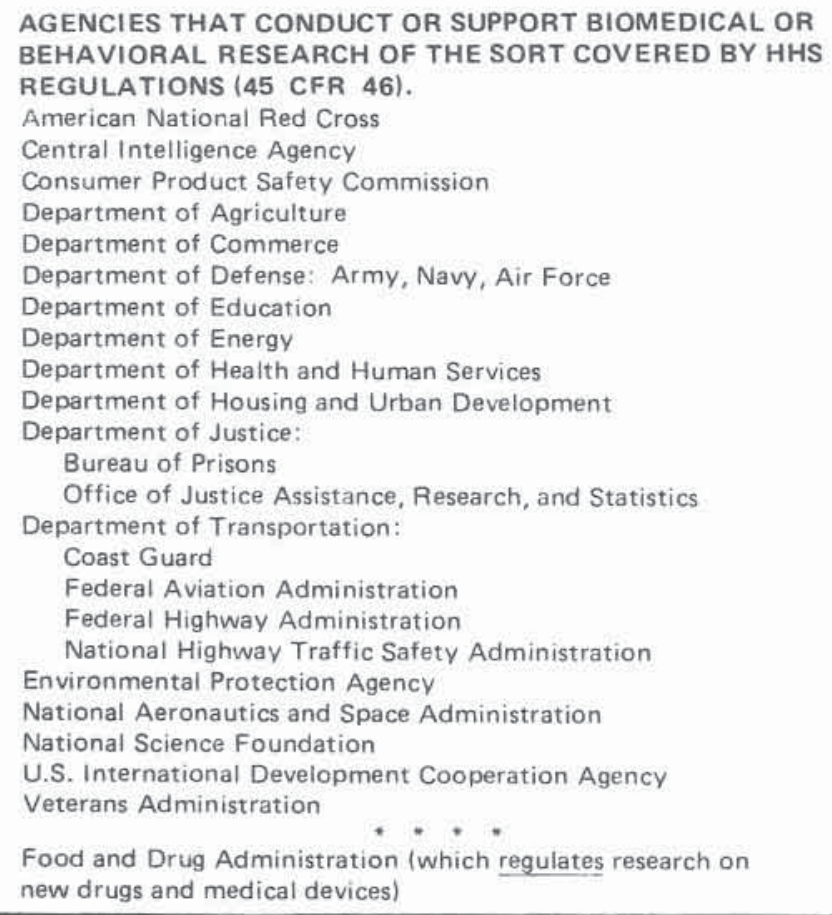

that they support or conduct research involving human subjects were provided with a copy of the 1977 summary of their policies and regulations. They were asked to provide information and supporting documentation regarding any additions or deletions necessary to bring the summary upto-date. Federal agencies not surveyed by the National Commission or who had reported in 1975 that they neither conduct nor support research involving human subjects were asked whether or not they currently conduct or support such research.

In order to improve the consistency of response, agency heads were provided with the following definitions which had been developed by the National Commission:

1. Scientific research is a formal investigation designed to develop or contribute to generalizable knowledge.

Comment: A research project generally is described in a protocol that sets forth explicit objectives and formal procedures designed to reach those objectives. The protocol may include therapeutic and other activities intended to benefit the subjects, as well as procedures to evaluate such activities. Research objectives range from 
understanding normal and abnormal physiological or psychological functions or social phenomena, to evaluating diagnostic, therapeutic or preventive interventions and variations in services or practices. The activities or procedures involved in research may be invasive or non-invasive and include surgical interventions; removal of body tissues or fluids; administration of chemical substances or forms of energy; modification of diet, daily routine or service delivery; alteration of environment; observation; administration of questionnaires or tests; randomization; review of records; etc.

2. Human subject is a person about whom an investigator (professional or student) conducting scientific research obtains (1) data through intervention or interaction with the person, or (2) identifiable private information.

Comment: "Intervention" includes both physical procedures by which data are gathered (e.g., venipuncture), and manipulations of the subject or the subject's environment that are performed for research purposes. "Interaction" includes communiction or interpersonal contact between investigator and subject. "Private information" includes information about behavior that occurs in a context in which an individual can reasonably expect that no observation or recording is taking place, and information which has been provided for specific purposes by an individual and which the individual can reasonably expect will not be made public (e.g., a medical record). Private information must be individually identifiable (i.e., the identity of the subject is or may readily be ascertained by the investigator or associated with the information) in order for obtaining the information to constitute research involving human subjects.

All agencies that conduct or support research involving human subjects, according to the definitions supplied, were asked to provide the following information as well:

(1) A description of the nature and extent of such research;

(2) Copies of the regulations or guidelines that govern the conduct of such research;

(3) An analysis of the extent to which their regulations or guidelines conform to those of the Department of Health, Education, and Welfare (codified at 45 CFR 46, as amended in 43 Federal Register 51559, November 3, 1978);

(4) A description of their procedures for monitoring such research during the course of its conduct, and for assuring that the agency is informed of any untoward or unexpected events; 
(5) A description of the nature and extent of any injuries or of any departures from approved protocols that have been reported or discovered, and the steps taken by their agency to investigate and resolve such problems;

(6) The views of their department or agency regarding recently proposed modifications to the existing HEW regulations; and

(7) Any action taken by their department or agency with respect to the proposed modifications enumerated above.

Agencies Excluded from Further Review. The definition of research involving human subjects supplied to the Federal agencies was compatible with the scope of the then existing HHS regulations which applied to, among other things, the administration of surveys or questionnaires and the review of records. Those regulations were revised January 1981, however, and most research involving only the use of surveys and questionnaires or the review of records is now exempt from the regulations. Therefore, those Federal agencies indicating that they sponsor only research exempt from review under the HHS regulations will be noted but not discussed further in this Report (see Table 2). Only those agencies that support, conduct or regulate biomedical or behavioral research of the type HHS now requires to be reviewed and approved in accordance with 45 CFR 46 are included in this analysis of Federal regulations and policies governing research with human subjects (see Table 3 ).

Also excluded from independent analysis in this $\mathrm{Re}$ port are the Nuclear Regulatory Commission (which, as a matter of policy, does not conduct research involving human subjects except through health agencies, such as HHS, which impose their own regulations), the Smithsonian Institution, which conducts research under grants from HHS and is subject to the regulations of that department, and the U.S. Postal Service and ACTION which permit access to their personnel and facilities by agencies of the Public Health Service (HHS) for research related to health and safety. ${ }^{4}$

Agencies Included in the National Commission Report That are Not Reviewed in This Report. A comparison of this Report with that of the National Commission will reveal various differences, some of them merely superficial. ${ }^{5}$

${ }^{4}$ See letters to Barbara Mishkin from: Robert B. Minogue, Director, Office of Nuclear Regulatory Research (July 23, 1981); S. Dillon Ripley, Secretary, Smithsonian Institution (April 2, 1980); William F. Bolger, Postmaster General (April 4, 1980); and James B. Lancaster, Assistant Director for Administration and Finance, ACTION (April 11, 1980 and December 31, 1980).

${ }^{5}$ Five Federal entities that appeared in the 1977 report of the $\mathrm{Na}$ tional Commission appear under different names in this report 
For example, the Commission on Civil Rights no longer has an Office of Research, and the research responsibilities formerly undertaken by that office have not been reassigned; therefore, the Commission on Civil Rights no longer conducts or supports any research with human subjects. ${ }^{6}$ The National Oceanic and Atmospheric Administration (NOAA) of the Department of Commerce conducts only research involving deep sea diving and other underwater activities; the agency is not involved in research involving humans as subjects in the underwater environment. ${ }^{7}$ The Federal Railroad Administration, within the Department of Transportation, reports that it no longer conducts research with human subjects as described in the report of the National Commission. $^{8}$

The National Academy of Sciences has been deleted from coverage in this Report, at its own request, because it is not a Federal agency and receives no appropriations from Congress. Rather, it is a private institution chartered by Congress as a non-profit organization to provide advice to the government on matters of science and technology. The Academy occasionally conducts or supports research with human subjects at the request of Federal agencies and requires that such research conform to the regulations of the Department of Health and Human Services. ${ }^{9}$

Somewhat differently situated is the Gorgas Memorial Institute of Tropical Diseases and Preventive Medicine, located in Panama. The Institute is a non-profit organization incorporated in Delaware, which receives a significant part

due to reorganization. The Civil Service Commission is now the Office of Personnel Management; it conducts only surveys and questionnaires. The Agency for International Development (AID), formerly part of the Department of State, has become the International Development Cooperation Agency. The Education division of the Department of Health, Education, and Welfare became a separate Department of Education, and HEW became the Department of Health and Human Services. Finally, the Law Enforcement Assistance Administration (LEAA) is now part of the Office of Justice Assistance, Research, and Statistics-still within the Department of Justice.

${ }^{6}$ Letter (March 25, 1980) from Louis Nunez, Staff Director, U.S. Commission on Civil Rights.

${ }^{7}$ Letter (July 31, 1981) from Joseph C. Brown, Acting Director of Personnel, U.S. Department of Commerce.

${ }^{8}$ Memorandum from Acting Associate Administrator for Research and Development, included as attachment to letter (May 27, 1980) from Martin Convisser, Director, Office of Environment and Safety, Office of the Secretary, DOT.

${ }^{9}$ Letter (April 28, 1980) from Robert W. White, Administrator, National Research Council, National Academy of Sciences. 
of its operating budget from direct Congressional appropriations. ${ }^{10}$ In Fiscal 1980, $\$ 1.7$ million of a $\$ 2.5$ million budget came from Congress. Most of the Federal money pays administrative costs such as salaries, field work, maintenance of the plant and equipment, and publications. In FY 1980 , the Institute received an additional $\$ 952,000$ in research grants from NIH, the World Health Organization, the Army, the Navy, and the Pan American Health Organization. Most of the Institute's research is related to tropical diseases; however, the Institute currently has a special assurance on file at NIH's Office for Protection from Research Risks (OPRR) for a grant from the National Cancer Institute to conduct research on cervical cancer. Except for conditions attached to grants from the NIH and the Army, however, there is no specific legal or regulatory provision requiring research involving human subjects conducted by the Gorgas Memorial Institute to undergo IRB review or to comply with provisions for informed consent. Although the direct appropriations from Congress are administered by the Fogarty International Center at NIH, the Center has no authority to attach conditions to such funds. ${ }^{11}$

Scope of This Report. As a result of the foregoing deletions, reorganizations, and modifications, 17 Federal departments or agencies have been identified that currently conduct or support biomedical or behavioral research with human subjects that comes within the definition provided by 45 CFR 46 . Three of those agencies have separate subsidiary components that operate under their own policies or regulations for the protection of human subjects: the Department of Defense (the Army, the Navy, and the Air Force); the Department of Justice (the Bureau of Prisons, and the Office of Justice Assistance, Research, and Statistics); and the Department of Transportation (the U.S. Coast Guard, the Federal Aviation Administration, the Federal Highway Administration, and the National Highway Traffic Safety Administration). Thus, there are a total of 23 separate Federal entities that conduct or support biomedical or behavioral research with human subjects whose rules and procedures are scrutinized in this Report.

The Commission has also chosen to review the rules and procedures of the Food and Drug Administration (FDA), within the Department of Health and Human Services. Under the Federal Food, Drug and Cosmetic Act, the FDA regulates research on new drugs, biologicals, and medical devices. Its basic regulatory scheme was brought into

${ }^{10} 22$ USC 278, 45 Stat. 491 (1928) as subsequently revised.

${ }^{11}$ Personal communication (October 2, 1981) with William Doak, Executive Officer, Fogarty International Center. 
conformity with the regulations governing research conducted and supported by the new rules issued simultaneously with the 1981 HHS revisions. The FDA's method of implementation and monitoring differs from that applicable to grant and contract aspects of HHS, as noted in Chapter Three.

Draft summaries of the regulations and policies of each of these Federal entities were sent to the head of the appropriate departments or agencies in June 1981 for review. Agency heads were asked to confirm the accuracy of the summaries or to indicate necessary modifications. (Agency heads were also asked to provide a description of their procedures for monitoring the implementation of the regulations and investigating and resolving complaints. That material is discussed in Chapter Three of this Report.) The agencies were also asked for documentation to justify significant changes. The material provides the basis for the description and analysis of this chapter.

\section{The Regulatory System Governing Research Conducted or Supported by the Department of Health and Human Services (HHS)}

Since 1966, when the Surgeon General issued an order requiring institutional review to assure ethical acceptability of research with human subjects supported by the Public Health Service (PHS), the PHS policies and procedures have served as a model for other Federal agencies. The history and development of those policies (now embodied in HHS regulations) have been amply chronicled before in the $\mathrm{Na}$ tional Commission's report on IRBs and elsewhere, ${ }^{12}$ and need not be repeated here.

${ }^{12}$ Briefly summarized, the HHS regulations derive from Public Health Service review requirements initiated in 1966 by the Surgeon General. These were expanded and elaborated in the 1971 Institutional Guide to DHEW Policy on Protection of Human Subjects, a description of the grants administration policy which required initial review of proposed research by committees at each institution to assure that the risks were justified by the anticipated benefits or the importance of the knowledge to be gained, and that informed consent would be obtained by methods that are adequate and appropriate. (The required elements of informed consent were defined and explained.) Continuing review of ongoing projects was also required.

Proposed regulations were published in 1973 and final rules were issued in 1974 which converted the earlier grants administration policies into regulations applicable to all research conducted or supported by HEW. An important difference between the new regulations and the old policy was that whereas formerly 
The National Commission found in 1978 that "of the 19 other Federal entities that have formal policies or regulations governing research with human subjects, 17 adopt HEW standards and procedures to a substantial degree, and most of these cite HEW regulations or policy as a reference." 13 Moreover, the National Commission reported that of the departments and agencies lacking formal policies for the protection of human subjects, all but two (the Law Enforcement Assistance Administration and the Department of Housing and Urban Development) conduct or support only surveys, questionnaires or record reviews-activities not universally considered "research with human subjects".

The survey conducted for this Report yielded similar results, both on uniformity and on the preeminence of the

the review requirement attached only to research activities deemed (by the principal investigator) to present risk to human subjects, the new regulations applied to all research with human subjects, leaving it to the review boards to determine the extent of any risk involved.

The proposal and promulgation of regulations by HEW took place against the backdrop of considerable Congressional interest in 1973-74. During this period, hearings were held on legislation intended to address problems with human experimentation that had been the subject of recent publicity, such as the Tuskegee Syphilis Study sponsored by the Public Health Service between 1932 and 1972. The Congressional attention culminated in Title II of the National Research Act of 1974 (Public Law 93-348), which not only required that research institutions have IRBs but also established the National Commission for the Protection of Human Subjects of Biomedical and Behavioral Research, within HEW, to study the ethical principles underlying research and to recommend means of protecting human subjects.

Between 1975 and 1978 the National Commission issued a series of reports and recommendations for amendments to the 1974 regulations, some of which have now been adopted by HHS. The most recent revisions to the regulations (published in January 1981) largely adopted the National Commission's recommendations regarding Institutional Review Boards; earlier revisions incorporated recommendations regarding research with the human fetus and research involving prisoners.

Further descriptions of the history and development of HHS regulations may be found in: Bernard Barber, Informed Consent in Medical Therapy and Research, Rutgers University Press, New Brunswick (1980) at 41-45; Nathan Hershey and Robert D. Miller, Human Experimentation and the Law, Aspen Systems, Rockville (1976) at 1-11; Robert J. Levine, Ethics and Regulation of Clinical Research, Urban and Schwarzenberg, Baltimore (1981) at 207210. See also an extensive history in Chapter Two of The President's Commission's forthcoming Report on Compensating for Research Injuries.

${ }^{13}$ IRB Report, supra note 2, at 94. 
HHS regulations. In order to understand the extent of uniformity of regulations government-wide, however, it is necessary first to describe the policies and procedures of HHS. ${ }^{14}$ The regulations of the other agencies may then be compared to the HHS prototype.

Applicability. The HHS regulations (45 CFR 46), as revised January 26,1981 , apply to all research involving human subjects supported or conducted by HHS, with a few explicit exemptions. "Human subject" is defined as a living individual about whom an investigator conducting research obtains (1) data through intervention or interaction with the individual, or (2) individually identifiable private information.

The following are exempt from the regulations:

(a) Research conducted in established or commonly accepted educational settings, involving normal educational practices;

(b) Research involving the use of educational tests if identities of subjects are not recorded;

(c) All research involving survey or interview procedures when the respondents are elected or appointed public officials or candidates for public office;

(d) Research involving survey and interview procedures or observation of public behavior, unless (1) the subject's identities are recorded and (2) the information, if known outside the research, could reasonably place the subject at risk of legal liability, or be damaging to the subject's employability or financial standing and (3) the research deals with sensitive aspects of the subject's own behavior;

(e) Research involving the collection or study of existing data documents, records, pathological or diagnostic identifiers.

Review Procedures. Each institution that conducts research covered by the regulations must submit an assurance to the department describing its procedures for complying with the requirements of HHS regulations (45 CFR 46). The assurance must contain a statement of principles the institution will follow in discharging its responsibilities for protecting human subjects in research conducted at or sponsored by the institutions (e.g., Nuremberg Code, Helsinki Code), regardless of source of funding. Further, the assurance must identify one or more Institutional Review Boards (IRBs) established by the institution to review and approve all research involving human subjects covered by the HHS

${ }^{14} \mathrm{~A}$ more detailed description of HHS policies and procedures appears in Appendix B to this Report; Appendix A contains the full text of the regulations. 
regulations. An IRB must have at least five members of varying backgrounds, sufficiently qualified to review research proposals and activities commonly conducted by the institution, and include at least one member "whose primary concerns are in a nonscientific area" and at least one individual unaffiliated with the institution. The members of an IRB may not all be of the same gender, nor may the members come from only one professional group. IRB members must be identified to HHS by name, earned degrees, representative capacity, professional (or other) experience, and relationship with the institution.

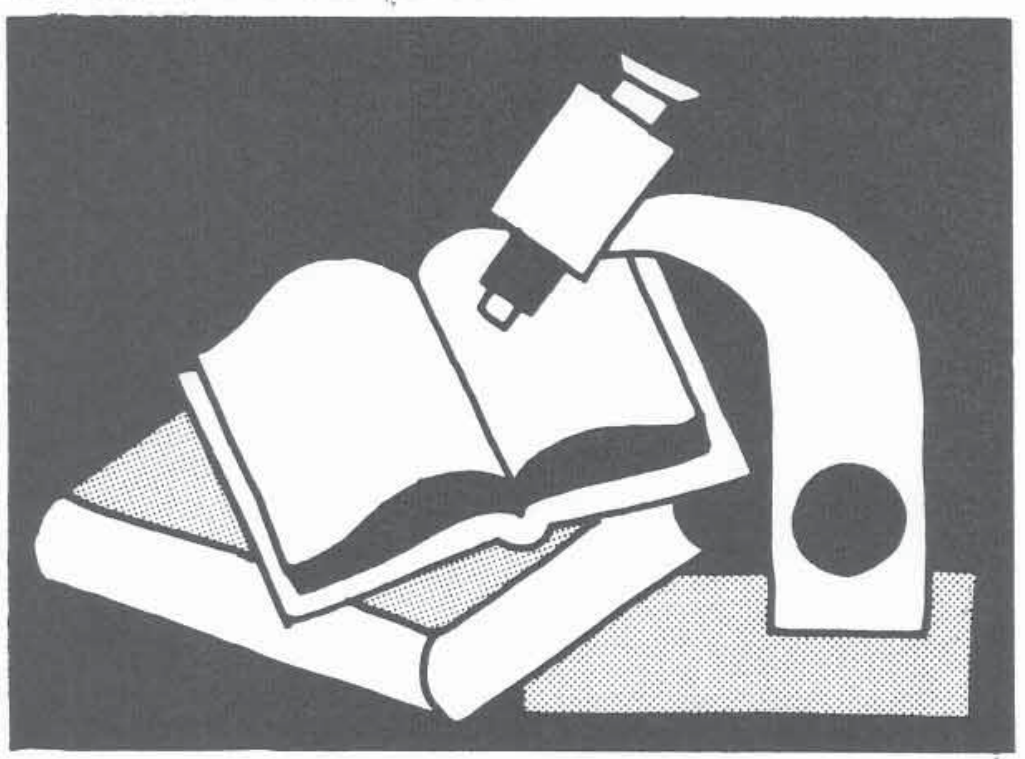

The assurance must also describe IRB procedures: (1) for conducting initial and continuing review of research proposals and activities, (2) for determining which projects require review more often than annually and which require verification from sources other than the investigators that no material changes have occurred since previous IRB review, (3) for assuring that scientists report any proposed changes in a research activity to the IRB, and for assuring that changes are not initiated without IRB sanction except as needed to eliminate immediate hazards to subjects, and (4) for reporting to HHS unanticipated problems involving risks to subjects or others and any serious or continuing noncompliance by the investigator with the HHS regulations or with the requirements and determination of the IRB.

Review Standards. No HHS funds may be awarded for the conduct of research with human subjects unless an approved IRB certifies that the following conditions are satisified: 
(a) The risks to subjects are minimized by using procedures consistent with sound research design and which do not unecessarily expose subjects to risk and whenever appropriate, by using procedures already being performed on the subjects for diagnostic or treatment purposes;

(b) the risks to subjects are reasonable in relation to anticipated benefits, if any, to subjects and to the importance of the knowledge that may reasonably be expected to result;

(c) the selection of subjects is equitable;

(d) informed consent will be sought from each prospective subject or the subject's legally authorized representative in accordance with, and to the extent required by, the regulations;

(e) consent will be appropriately documented;

(f) where appropriate, the research plan makes adequate provision for monitoring the data collected to insure the safety of subjects;

(g) where appropriate, there are adequate provisions to protect the privacy of subjects and to maintain the confidentiality of data; and

(h) where some or all of the subjects are likely to be vulnerable to coercion or undue influence, such as persons with acute or severe physical or mental illness, or persons who are economically or educationally disadvantaged, appropriate additional safeguards have been included in the study to protect the rights and welfare of these subjects.

Consent Provisions. The information provided to prospective subjects or their representatives must be in language they can understand. Consent should be sought only under circumstances that provide the prospective subject or the subject's representative with sufficient opportunity to consider whether or not to participate and that minimize the possibility of coercion or undue influence. No informed consent, whether oral or written, may include any exculpatory language "through which the subject is made to waive or appear to waive any legal rights or release the investigator, the sponsor, the institution or its agents from liability for negligence."15 A copy of the information provided, as well as the signed consent form (if any), must be given to the subject or the subject's representative.

The following elements must be disclosed to subjects for valid informed consent:

(a) an explanation of the purpose of the research and the expected duration of the subject's participation, a description of the procedures to be followed, and identification of any procedures which are experimental;

1545 CFR 46.116. 
(b) a description of any reasonably foreseeable risks or discomforts to the subject;

(c) a description of any benefits to the subject or to others which may reasonably be expected from the research;

(d) a disclosure of appropriate alternative procedures or courses of treatment, if any, that might be advantageous to the subject;

(e) a statement describing the extent, if any, to which confidentiality of records identifying the subject will be maintained;

(f) for research involving more than minimal risk, an explanation as to whether any compensation will be made and any medical treatments are available if injury occurs and, if so, what they consist of, or where further information may be obtained;

(g) an explanation of whom to contact for answers to pertinent questions about the research and research subjects' rights, and whom to contact in the event of a researchrelated injury to the subject; and

(h) a statement that participation is voluntary, refusal to participate will involve no penalty or loss of benefits to which the subject is otherwise entitled, and the subject may. discontinue participation at any time without penalty or loss of benefits to which the subject is otherwise entitled.

Additional information must be provided, when appropriate:

(a) A statement that the particular treatment or procedure may involve risks to the subject (or to an embryo or fetus, if the subject is or may become pregnant) which are currently unforeseeable;

(b) Anticipated circumstances under which the subject's participation may be terminated by the investigator without regard to the subject's consent;

(c) Any additional costs to the subject that may result from participation in the research;

(d) The consequences of a subject's decision to withdraw from the research and procedures for orderly termination of participation by the subject;

(e) A statement that significant new findings developed during the course of the research which may relate to the subject's willingness to continue participation will be provided to the subject; and

(f) The approximate number of subjects involved in the study.

The regulations include additional protections and special procedures for research involving prisoners and for re- 
search involving pregnant women, the human fetus, and human in vitro fertilization. (See Appendix A.)

Sanctions. If an institution or principal investigator is found to have "failed materially" to protect human subjects, the Secretary may terminate or suspend current funds or withhold further HHS research funding (whether or not HHS funds were involved in the research in which the failure to protect subjects occurred).

\section{Summary and Analysis of the Regulations of Other Federal Agencies}

The HHS regulations summarized above provide the gauge against which to measure the regulations and policies of the other Federal agencies.

The Degree of Uniformity: Minor Variations. Seventeen of the twenty-two Federal entities other than HHS that conduct or support biomedical or behavioral research involving human subjects have regulations or policies that substantially conform with HHS regulations (see Table 4). That is, they require review and approval of proposed research by an IRB or similar committee, using standards for review and consent provisions that mirror, or are similar to, those in the HHS regulations.

The regulations of two of these seventeen Federal entities, however, apply to some but not all of the research conducted or supported by those agencies. The Department of Education's regulations for the protection of human subjects apply to contracts, but not to grants. NASA requires IRB review for intramural research but not for extramural research.

Among the agencies that generally conform to 45 CFR 46 , however, there are minor differences that complicate the work of IRBs. For example, the Army, Navy and Air Force require that IRBs determine that prior animal studies have been conducted, where possible, prior to approving human studies. They also require IRBs to determine that facilities where the research will be conducted are adequate to handle foreseeable injuries. The Consumer Product Safety Commission has the same requirement. The National Highway Traffic Safety Administration requires IRBs to review research involving cadavers; HHS and all agencies that follow 45 CFR 46 limit review requirements to research involving living human subjects.

Agencies also have a variety of rules regarding special classes of subjects. The Army has adopted special protections (similar to recommendations of the National Commission) for the participation of children, prisoners, and the mentally disabled in Army research activities. The Navy and the Air Force simply exclude prisoners and the mental- 
TABLE 4.

Agency Conformity with HHS Regulations (45 CFR 46)

\begin{tabular}{|c|c|c|c|c|}
\hline Department or Agency & & & & Notes \\
\hline American National Red Cross & - & - & $\bullet$ & \\
\hline Central Intelligence Agency & - & • & - & \\
\hline $\begin{array}{l}\text { Consumer Product } \\
\text { Safety Commission }\end{array}$ & - & - & $\bullet$ & \\
\hline Department of Agriculture & - & - & - & \\
\hline Department of Commerce & - & - & $\bullet$ & \\
\hline $\begin{array}{l}\text { Department of Defense: } \\
\text { Army }\end{array}$ & $\bullet$ & - & - & \\
\hline Navy & - & $\bullet$ & - & \\
\hline Air Force & - & - & - & \\
\hline Department of Education & - & $\bullet$ & $\bullet$ & $\begin{array}{l}\text { IRBs are required for } \\
\text { contracts but not grants }\end{array}$ \\
\hline Department of Energy & - & - & - & \\
\hline $\begin{array}{l}\text { Department of Housing and } \\
\text { Urban Development }\end{array}$ & $\begin{array}{l}\text { see } \\
\text { notes }\end{array}$ & & & $\begin{array}{l}\text { Independent review when more } \\
\text { than limited potential of harm }\end{array}$ \\
\hline $\begin{array}{l}\text { Denartment of Justice: } \\
\text { Bureau of Prisons }\end{array}$ & - & - & $\bullet$ & \\
\hline $\begin{array}{l}\text { Office of Justice Assist., } \\
\text { Research, and Statistics }\end{array}$ & \begin{tabular}{l|} 
see \\
notes
\end{tabular} & \begin{tabular}{l|} 
see \\
notes
\end{tabular} & \begin{tabular}{|l|} 
see \\
notes
\end{tabular} & $\begin{array}{l}\text { Emplovs advisory boards; } \\
\text { protects confidentiality }\end{array}$ \\
\hline \multicolumn{5}{|l|}{$\begin{array}{l}\text { Dept, of Transportation: } \\
\text { Coast Guard }\end{array}$} \\
\hline \multicolumn{5}{|l|}{ Federal Aviation Admin. } \\
\hline \multicolumn{5}{|l|}{ Federal Highway Admin. } \\
\hline $\begin{array}{l}\text { Natl. Highway Traffic } \\
\text { Safety Administration }\end{array}$ & - & - & - & \\
\hline $\begin{array}{l}\text { Environmental Protection } \\
\text { Agency }\end{array}$ & - & - & - & \\
\hline $\begin{array}{l}\text { National Aeronautics and } \\
\text { Space Administration }\end{array}$ & - & - & $\bullet$ & $\begin{array}{l}\text { IRBs required only for } \\
\text { intramural research }\end{array}$ \\
\hline National Science Foundation & - & - & - & \\
\hline $\begin{array}{l}\text { U.S. Intl. Development } \\
\text { Cooperation Agency }\end{array}$ & - & \begin{tabular}{|l|} 
see \\
notes \\
\end{tabular} & $\begin{array}{l}\text { see } \\
\text { notes }\end{array}$ & $\begin{array}{l}\text { (45 CFR 46) provides } \\
\text { guidance }\end{array}$ \\
\hline Veterans Administration & - & - & - & \\
\hline
\end{tabular}


ly disabled; the Air Force also excludes children. The Army (but not the Navy or the Air Force) specifically prohibits the participation of prisoners of war. The Department of Agriculture excludes pregnant or lactating women from certain kinds of studies; the Air Force excludes females "unless there is reasonable assurance of no concomitant pregnancy that would place the fetus at risk and if methods adopted for contraception do not place the female subject at increased risk without complete disclosure to the female subject."

There are also minor variations regarding what must be disclosed to subjects in the consent process. A number of agencies require information regarding the Privacy Act and the extent to which research data will (or can) be kept confidential; others have no such requirement. The Office of Justice Assistance, Research, and Statistics (OJARS) of the Department of Justice supports research involving surveys, questionnaires and observational data which may deal with sensitive topics such as drug or alcohol use and illegal conduct. With research of this kind, the significant risk to subjects is the possibility of a breach of confidentiality. Therefore, OJARS has extensive regulations that protect the confidentiality of data even from subpoena. In place of IRBs, advisory boards meet several times a year with project staff to review the progress of the research.

The Bureau of Standards provides a completely different description of informed consent. The Bureau's definition (which, among other features, equates "informed consent" with the document that records the agreement reached by investigator and subject) includes:

(a) information on all features of the research that are likely to influence the subject's willingness to participate, such as risk of injury or possibility of embarrassment, discomfort, or emotional stress;

(b) explanation of other aspects of the research about which the subject inquires which is consistent with maintaining the validity of the research; and

(c) an agreement, to be signed by the subject and the principal investigator, which states the responsibilities of each and the relevant features of the research and which makes explicit the right of the subject or the principal investigator to terminate the subject's participation at any time without incurring any legal liability.

The Bureau of Standards also adds that subjects must be free from undue coercion and undue pressure as well as from the inducement of excessively high rewards (monetary or otherwise). The Bureau of Prisons limits incentives for participation to soft drinks and snacks given at testing time. The Navy requires that the sponsor of the research be 
identified and NASA requires that subjects be informed if, for any reason, withdrawal during the conduct of the research is not an option (e.g., because it would be unwise, dangerous, or impossible).

Administrative details also vary among agencies. The Consumer Product Safety Commission and the Navy both require that all consent forms be submitted to the agency along with the research proposal; most agencies apparently do not. The Navy requires that documentation of IRB approval be signed by every member of the IRB; most agencies (including HHS) accept the signature of the chairman. Most agencies require that IRB records pertaining to research activities be retained for a period of $3-5$ years following completion of the research. The Navy requires that such records be retained permanently, and the Air Force requires that copies of all such records be forwarded to the Air Force upon completion of the research.

Clearly, IRBs that review hundreds of research proposals per year, many of which may be submitted to (and even funded by) more than one agency, need to have copies of the regulations of each agency at hand in order to assure compliance with these varied provisions. Furthermore, the regulations are constantly changing. Several Federal departments or entities are now in the process of developing new regulations for the protection of human subjects, including the Departments of Defense and of Transportation, which are formulating department-wide standards, the Department of Agriculture, which is bringing its policies into conformity with the most recent HHS revisions, and the Bureau of Prisons, within the Department of Justice, which is currently drafting new regulations for the protection of inmates as research subjects that generally conform to the HHS regulations.

Agencies Without Formal Regulations. Four Federal entities have no formal regulations specifically for the protection of human subjects involved in research. Three of these four are components of the Department of Transportation (DOT). The Department reports that it is in the process of developing department-wide regulations for the protection of human subjects; however, in 1977 DOT reported to the National Commission that it was then engaged in such an effort. Until the new regulations, which are to conform with HHS regulations, are implemented, three of the four components of the Department lack rules specifying their means of protecting human subjects, while the remaining DOT agency (the National Highway Traffic Safety Administration) has rules that parallel the HHS regulations.

The Department of Housing and Urban Development (HUD) is the only other Federal agency conducting research with human subjects that does not have formal regulations 
for the protection of human subjects. In HUD's initial response to the Commission's inquiry, Donna Shalala (Assistant Secretary for Policy Development and Research) stated that except for a study co-sponsored with HEW, involving the testing of an aversive additive in paint to deter children from eating paint chips, HUD "has never sponsored any human subject or biomedical studies." ${ }^{16}$ Moreover, Dr. Shalala challenged the statement in the National Commission's report that HUD's "housing allowance experiment" constituted research with human subjects. ${ }^{17}$

The definition of "research with human subjects" and the possible inclusion of HUD's activities within such a definition was explored more fully with Dr. Shalala and her staff at hearings before the Commission in July 1980 and in subsequent correspondence. The result was HUD's acknowledgement that some of its research may present risk to human subjects. The Department has now developed a departmental memorandum that requires internally generated projects as well as "unsolicited research proposals" involving risk to human subjects to be approved by an independent review board. ${ }^{18}$ Certification of the board's approval of the research design, as well as a description of the review board's procedures and membership, must be forwarded with the proposal (see Appendix B). The memorandum does not set forth the standards of review nor require IRB approval at the home institutions of those carrying out human research with HUD funds. Moreover, the memorandum does not supply the fundamental analysis needed to establish the differences and similarities between the concerns that motivate regulation of biomedical and behavioral research and those that are appropriate in the case of "social policy experiments" of the type supported by HUD. ${ }^{19}$

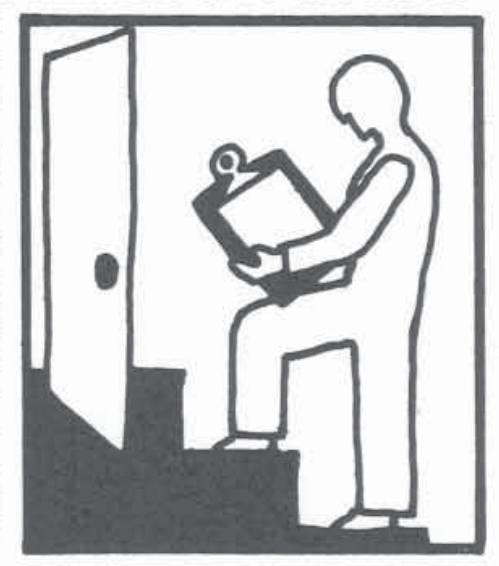

${ }^{16}$ Letter (March 28, 1980) from Donna E. Shalala, Assistant Secretary for Policy Development and Research, Department of Housing and Urban Development.

${ }^{17}$ IRB Report, supra note 2, at 96, 100-101.

${ }^{18}$ HUD Policy Memorandum (February 21, 1981) from Arthur S. Newburg, Director, Office of Management and Program Control, to "All PD\&R Staff" attached to letter (February 24, 1981) from Mr. Newburg to Alexander M. Capron.

${ }^{19}$ See, e.g., Alice M. Rivlin and P. Michael Timpane, eds., Ethi- 


\section{Conclusions}

Concern for the adequacy and uniformity of the rules for the protection of human subjects is raised most immediately by the Federal entities that currently lack procedures and standards that conform with HHS regulations. A lack of internal consistency occurs in two agencies that apply HHS policies and standards to some, but not all, research conducted under their auspices: the Department of Education and NASA. The Commission believes that such regulatory anomalies should be corrected. Further, the policy statements of several agencies that merely refer to HHS regulations "for guidance" should provide more explicit directives.

The Commission believes that achieving uniform regulations throughout the Federal government is an important goal. The high costs of nonuniform rules were forecefully articulated in the findings of the Commission on Federal Paperwork:

If other agencies are permitted to deviate from or even to paraphrase the NIH/HEW regulations [ 45 CFR 46], the result will be unnecessary duplication of reporting, recordkeeping, and other activities on the part of the Government as well as the organization involved. Some agencies, including the National Science Foundation and the Department of Agriculture, have accepted the NIH/HEW regulations by reference, without finding it necessary to paraphrase, interpret, or expatiate. Others, even while recognizing HEW's precedence, phrase their regulations so as to require conformity to their own policies. This creates conflict if future changes in their policies and in HEW's are not identical and simultaneous. In addition, it requires multiple submission of general assurances, which are frequently intricate and lengthy documents and which must be updated periodically. ${ }^{20}$

The achievement of uniform Federal regulations on the protection of human subjects appears to be an achievable objective, since the present HHS regulations provide common ground which most of the affected agencies can apparently accept. Moreover, HHS regulations permit sufficient flexibility for agencies whose involvement with research is limited. For example, the HHS requirements on IRB review and consent for the collection of personally identifiable in-

cal and Legal Issues of Social Experimentation, The Brookings Institution, Washington (1975); Advisory Committee on Experimentation in the Law, Federal Judicial Center, Experimentation in the Law, U.S. Government Printing Office, Washington (1981).

${ }^{20}$ A Report of the Commission on Federal Paperwork: Education, U.S. Government Printing Office, Washington (1977) at 40. 
formation might be supplemented by the Justice Department if it believes that more extensive safeguards are needed to protect the confidentiality of the sensitive data that are often involved in its research projects. Similarly, the activities of the Department of Housing and Urban Development would not be impeded by inappropriate requirements since it supports primarily social science research, much of which is now exempt from HHS regulatory requirements. If any of the research funded by HUD is of the sort to which HHS regulations apply, however, it should be subjected to IRB review using the standards set forth in those regulations. The three remaining Federal entities that appear to have less than fully adequate policies for the protection of human subjects are part of the Department of Transportation which after four years continues to report that it is in the process of developing department-wide regulations to conform with those of HHS.

In summary, the President's Commission has identified the following problems with respect to adequacy and uniformity of Federal rules governing research with human subjects: (1) lack of uniformity among component parts of a department or agency (the Department of Defense, the Department of Justice, and the Department of Transportation); (2) inconsistency with respect to applicability of regulations to all categories of research within a single Federal entity (the Department of Education and NASA); and (3) lack of complete uniformity among all Federal departments and agencies.

The Commission believes that all research involving human subjects that is supported by public monies should conform to a uniform "core" of regulations. The provisions announced by the Department of Health and Human Services earlier this year and codified in 45 CFR 46 provide an acceptable starting point for any attempt to achieve uniformity. The Commission notes, however, that many of the variations adopted by other agencies appear sensible and should be reviewed for possible incorporation in the regulations of HHS which, thereafter, should become the standard for all research regulated, conducted or supported by Federal agencies or by direct appropriations from Congress. Specific recommendations for improving the adequacy and uniformity of Federal regulations governing research with human subjects appear in Chapter Five. 


\section{The Adequacy and Uniformity of the Regulations' Implementation}

In evaluating the implementation of regulations governing research with human subjects, the Commission determined that its most appropriate focus would be not on the IRBs themselves but on the procedures of Federal agencies and on the knowledge these agencies have about the implementation of their rules for protecting human subjects. The Commission reached this conclusion for several reasons. First, it had neither the statutory life nor the budget to undertake an empirical examination of IRBs comparable to the two million dollar study supported by the National Commission for the Protection of Human Subjects from 1975 to 1977 . More important, that study is recent enough so that its findings continue to have a great deal of cogency. One of those findings was that IRBs were not consistently implementing Federal policy particularly with respect to the adequacy of consent documents and IRB involvement after initial review of research proposals. Consequently, in making its recommendations on IRBs, the National Commission stressed the need for the Department of Health, Education, and Welfare (as it was then known) to engage in vigorous "compliance activities" to determine how well its regulations were being implemented and to supply necessary education, encouragement or punishment. ${ }^{1}$

By focusing on implementation from the Federal side, the Commission intends also to encourage an examination of some basic issues about the regulation of human research. The ambiguous nature of the IRB system for regulating human research has never been resolved; indeed,

${ }^{1}$ See, National Commission for the Protection of Human Subjects, Report and Recommendations: Institutional Review Boards (hereinafter, IRB Report) U.S. Government Printing Office, Washington (1978) at 9-12 (Recommendation 2 and comment). 
it has seldom been addressed. To answer the simple question, "What is an IRB," one must confront the tension that is so often found with organizational hybrids. Or, to borrow from the fable, the IRB is like an elephant being described by blind men each of whom perceives it differently. The central difference in perception is between a research institution's vantage point and that of the Federal government. In the view of the former, its IRB is a local body; moreover, it is a outgrowth of the traditional informal mode of "peer review" that characterizes collegial, academic settings. Yet from the Federal viewpoint-and as a matter of historical fact ${ }^{2}$ - the IRB today is a local body established under, and responsive to, Federal rules; in effect, it performs delegated functions under the supervision of Federal officials. ${ }^{3}$

Thus, while past descriptions have emphasized the institutional aspects of the IRB system it seemed appropriate for the Commission to begin its examination of the "adequacy and uniformity of the implementation of the regulations" by focusing on the Federal aspects. In taking up this specific statutory mandate, the Commission does not want to be understood as denying the importance of trust in the IRB system nor as pointing inevitably toward the displacement of such trust by formal review mechanisms. Rather, the Commission began its study of "the implementation of the regulations" by asking responsible officials to report on their means for knowing that the authority delegated to local institutions was being exercised so as adequately to protect human subjects. The result of this initial inquiry was the finding that most agencies, including the grant and contact wings of HHS, have only limited first-hand knowledge of the actual performance of IRBs. The paucity of systematic data was acknowledged by responsible officials, who described for the Commission efforts that have recently been made or that are planned to provide a better ongoing picture of the regulations' actual application. A richer and more detailed understanding of "the implementation of the

${ }^{2}$ Bernard Barber, John J. Lally, Julia L. Makarushka and Daniel Sullivan, Research on Human Subjects-Problems of Social Control in Medical Experimentation, Russell Sage Foundation, New York (1973) at 145-48.

${ }^{3}$ Although many IRB members may feel uncomfortable with such a description of their role, the reality of their Federal responsibilities cannot be denied. Nonetheless, an IRB is not confined to the functions required by the Federal rules nor need it allow such responsibilities to prevent it from playing a role of internal leadership within its institution. Robert Levine has written tellingly of the cost to an IRB's "local credibility" if it identifies the source of its authority and responsibility as resting outside the institution. Robert J. Levine, Ethics and Regulation of Clinical Research, Urban and Schwarzenberg, Baltimore (1981) at 227. 
regulations" came from a second source, namely the Commission's examination of the response of Federal agencies to several reports of regulatory violations or of other serious misconduct by grantees and contractors. While the few instances of alleged misconduct and institutional or Federal failings are not regarded by the Commission as representative of contemporary research or of the functioning of the system to protect human subjects, the Commission is acutely aware of the vulnerability of the present system to (probably unjustified) adverse judgements in the absence of systematic data that would allow the "problem cases" to be viewed in proper perspective.

The Commission sought information not only from the relevant Federal agencies but also through testimony from IRB members and institutional administrators, papers prepared under contract, conferences attended by members of its staff, and recent articles that have appeared in the literature. (In this discussion, as in the previous chapter, the primary focus will be on the policies and procedures of HHS with which other Federal agencies will be compared and contrasted.)

\section{Do Federal Agencies Know How IRBs are Performing?}

Within HHS, two methods are used for obtaining information about IRBs. One approach was developed in NIH for grantee institutions; the other was developed by FDA for research in support of new drug applications. The former approach relies largely on a promise of faithful execution of certain regulatory responsibilities by those at local institutions who have agreed to undertake those responsibilities; the FDA system relies primarily on a system of routine inspections performed during or after the conduct of the research.

The Negotiation of "Assurances" by HHS. The procedures set forth in 45 CFR 46 require all grantee institutions to provide written assurance that they will comply with the HHS regulations to protect human subjects. An institution's assurance of compliance must be approved by the Office for Protection from Research Risks (OPRR) within the Office of the Director, NIH. The information contained in an assurance provides the basis on which a determination is made that the composition and operating procedures of the institution's IRB meet regulatory requirements and that the institution is, therefore, eligible to receive HHS grants and contracts for the conduct of research involving human subjects. In the wake of the revisions to the regulations that took effect in July 1981 , new assurances of compliance must be negotiated by all institutions. This process will take a year or more. Indeed, the Director of OPRR reports that ne- 
gotiations for new assurances implementing the regulations issued May 30, 1974, began in mid-1975 and took more than two years to complete. ${ }^{4}$

Although the process of providing an assurance of compliance with the regulations might ideally provide an occasion for careful consideration by institutions of how they will meet their responsibilities toward human subjects, some aspects of the manner in whieh new assurances are being negotiated decrease the likelihood that grantee institutions will take advantage of the opportunity to review their responsibilities.

A sample assurance (dated July 3, 1981, rev. August 11, 1981) has been distributed by HHS to each institution having a general assurance on file with HHS under the old regulations. OPRR had described plans to offer institutions a variety of model formats for re-negotiating their general assurances; ${ }^{5}$ instead, one sample was provided. In order to affirm its intent to comply with 45 CFR 46 an institution following this 22 page document would have to recite each individual section and subsection of the regulations almost in their entirety. ${ }^{6}$ This recitation has the effect of a litany,

${ }^{4}$ Letter from Charles R. McCarthy to Morris B. Abram (May 7, $1980)$ at 2.

${ }^{5}$ See, e.g., Statement of Charles R. McCarthy at the PRIM\&R Conference on "The New Federal Regulations: What They Do and Do Not Regulate," Boston (March 26-27, 1981) at 38.

"To the extent that the "sample assurance" does go beyond the regulations, questions of a different sort are raised. The sample is not formulated as a series of issues of administration and structure that OPRR believes ought to be addressed. Rather, it sets forth a structure which-by its very conjunction with many requirements of the regulations-HHS seems to expect of an institution. In effect, by including a number of items not covered by the regulations (e.g., the whole concept of an "appeals IRB"; 7 of the 15 elements of "institutional policy" in Sec. I.C. of the "sample" assurances; etc.), the Department appears to adopt policies, principles or rules that have not been subject to the usual process of scrutiny and comment that is necessary in promulgating federal regulations under the Administrative Procedure Act. The "sample" assurance notes at several points that facets which have been made up out of whole cloth (e.g., the creation of an "Office of Research Administration" to exercise administrative responsibilities, including some which, under 45 CFR 46 , appear to rest with the IRB) "will not be appropriate for some institutions and are not required by the HHS regulations." Yet this disclaimer is not provided about many of the amendations to the regulations and, in any event is dissipated by the overall impression created that the model assurance represents the Department's expections. For example, the cover letter informs each institution that "In preparing this sample assurance we have attempted to include all of the elements necessary for compliance with the new regulations." 
rather than focusing an institution's thinking on the specific administrative and structural arrangements through which it will carry out the commitment to abide by 45 CFR 46. Not only is such reiteration unnecessary-a one sentence promise to comply with all regulatory requirements would serve the same function-but it may discourage thoughtful self-scrutiny and actual compliance.

OPRR has explained its choice of format for negotiating assurances by stating that when such a detailed assurance is distributed within an institution "the relevant parts of the regulations would [thereby] be in the hands of the individuals with responsibility for complying with them." Yet this laudable objective is defeated by the chosen format. The sample assurance makes oblique cross references to the regulations; this would make it necessary for anyone expecting to undertand the assurance to have a copy of the regulations in hand as well. ${ }^{7}$

The Commission realizes that while another approach might have been preferable, the single sample assurance is already in use. Moreover, the Department has told the Commission that it shares the Commission's concern that the negotiation of new assurances by all research institutions be

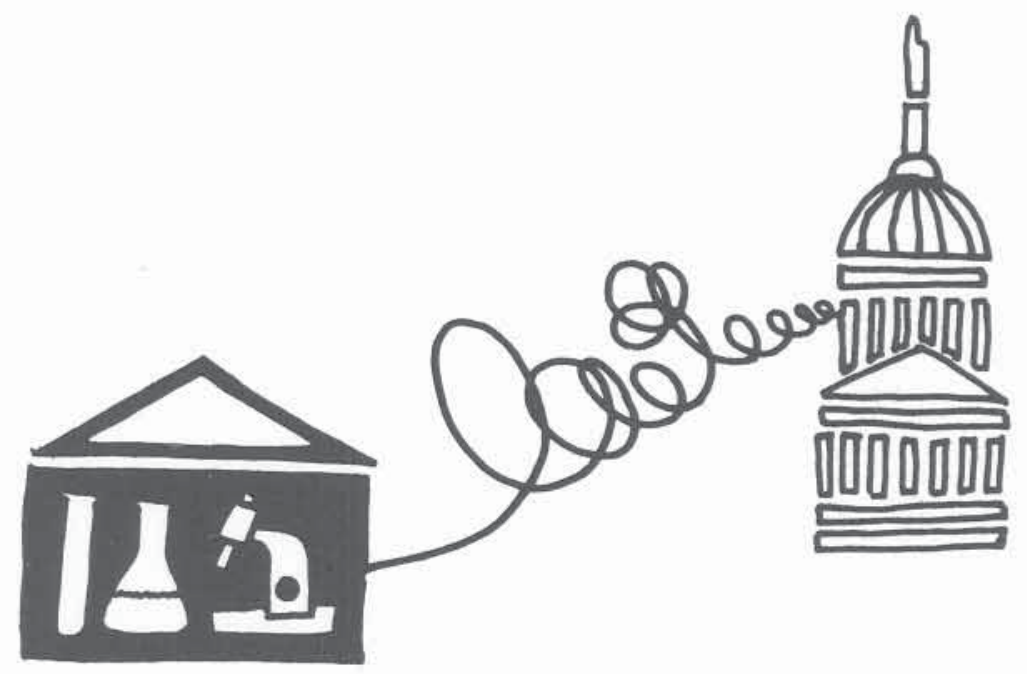

${ }^{7}$ For example, there are many statements of the sort that the institution will act "in accordance with 45 CFR 46.116" or "will comply with the policies set forth in 45 CFR 46 Subpart C." The baldest example of the need for an accompanying set of regulations occurs on the very first page (Sec. I.A.2) of OPRR's model assurance: "Only provisions II.A.16; II.B.1.a,b,d,e,f; and III. of this assurance are applicable to the activities listed above if the only involvement of human subjects will be in one or more of the categories exempted or waived under 45 CFR 46.101(b)(15) or 46.101(e)." 
regarded as an important opportunity for self-examination and appropriate ingenuity on the part of research institutions as they develop administrative mechanisms responsive to their particular needs. The effort devoted to this can yield great dividends in institutional sensitivity to, and readiness to provide effective protection for, the subjects of research.

The Steps Taken by OPRR to Improve Implementation. A more serious limitation of the assurance procedure as it presently exists is its emphasis on providing only a prospective picture of the process of research review that an institution will follow. Recognizing that this provides very little information about the actual performance of the IRB, OPRR has taken several steps. The first, which has been in existence for some time, is to respond to any serious problems that come to the office's attention. Mechanisms exist to bring to OPRR's attention some problems in IRB operations, though they are far from complete or systematic. In any case, most of the "problems" uncovered have not proven to be serious; most are disposed of through a phone call to the institution or through an exchange of correspondence.

To increase its awareness of the adequacy of IRB functioning, OPRR has instructed each "study section" (initial review groups which advise the Institutes on the scientific merit of applications for grants and contracts) to evaluate the investigators' descriptions of six factors bearing on the protection of human subjects (see Appendix B). The "Summary Statement" for each research application, prepared by the executive secretary of the study section, provides a means for the section members to express any concerns about the description of risks, the adequacy of protection against risks, and the balance between risks and benefits. If problems relating to the protection of human subjects are identified by a study section, they are called to the attention of the Institute's advisory council or board when the project is under consideration for funding. OPRR plays a coordinating role in resolving any such problems before HHS funds are permitted to be expended.

OPRR reports that it is planning to systematize the information available from the "Summary Statements" into a data base which could be used to evaluate the IRB system in general and the performance of each IRB in particular. The Commission hopes to learn more about these efforts as part of its work on its next Biennial Report. The sensitivity of such a system is a matter of special concern; for example, will it be able to differentiate serious problems from clerical errors on the part of an investigator or IRB, or to separate 
those instances in which concerns raised by study sections that are found to be "justified" from those which are merely "differences of opinion" between a study section and a conscientious IRB?

Study section review does not provide OPRR either with general information about IRB functioning (since each study section looks only at the "end product" of IRB action in the cases it is reviewing and not at overall IRB activities) or with particular information about the manner in which an IRB follows up on research once approved. Some firsthand information is available to OPRR, however, through various site visit mechanisms. Although OPRR itself has conducted only a few such on-site inspections, the routine institutional site visits conducted by scientific review groups in the General Clinical Research Centers Program (which is operated by the Division of Research Resources at $\mathrm{NIH}$ ) include meetings with IRB members and review of IRB practices. Summary reports of those site visits are reviewed by OPRR; none has triggered further review of an IRB by that Office. ${ }^{8}$

In responding to the National Commission's recommendation of "compliance activities," such as IRB audits and site visits, the Department in August 1979 said that Congressional action would be unnecessary on this point, since such practices were already part of HHS procedures. As already described, systematic efforts in the direction of "compliance" (as opposed to "assurance") mechanisms are still far from complete. Indeed, representatives of the Department have explained that steps toward auditing IRB performance which were described to the Commission in May 1980 remain in the planning stages because OPRR's limited resources are largely devoted to the regular process of reviewing all NIH research proposals for compliance with the regulatory requirements and to the negotiation of new assurances under the regulations promulgated in January 1981.

Although OPRR has not yet instituted regular site visits, it reports that some site visits have been conducted. Yet, since well-defined procedures for auditing IRBs are lacking, OPRR had difficulty in giving a complete picture of the site visits it has conducted. In a letter to the Chairman of the Commission in May 1980, the Director of OPRR defined site visits to include "examination of IRB minutes and interviews with the chairmen and members of the IRB, administrative staff, and research investigators" and reported that OPRR carried out two such site visits in Fiscal Year 1979

${ }^{8}$ Letter from Dr. McCarthy to Morris B. Abram (May 7, 1980) at 3; see also testimony of Dr. McCarthy, transcript of 2 nd meeting of the President's Commission (May 16, 1980) at 81-82. 
and three in Fiscal $1980 .{ }^{9}$ The Deputy Director of OPRR testified in November 1981, however, that his office had conducted a total of 80 site visits between 1975 and 1981, although many of these were "of a routine nature to assist institutions in complying with the regulations in circumstances of special complexity (cooperative research projects of a large scale) or to provide guidance and information on HHS policy and to discuss general problems of IRB operation." 10 Clearly, the November 1981 statement reflects a very different (i.e., more expansive) notion of what constitutes a "site visit." Indeed, the OPRR officials agree that the number of such visits that could properly be termed "audits" of IRB operations was probably "very small," and that few if any of those conducted were in response to allegations of serious problems or to reports from FDA inspection teams, or from the reports of NIH study sections' concerns. ${ }^{11}$ The additional contacts with research institutions do, however, provide OPRR with "extensive general information about IRB functioning even though the information lacks the precision that might come from formal IRB audits and site visits (in the narrow sense)." 12

In order to mount effective "compliance activities," OPRR will need a schedule of, and defined procedures for conducting, either routine or "spot" audits of IRBs. Such steps would permit genuine "site visits" to be readily distinguished from visits to provide guidance or information, on the one hand, and from extraordinary investigations of alleged misconduct, on the other. In order to help HHS obtain more than sporadic glimpses of the performance of IRBs, the Commission is working with OPRR (and the FDA) to develop means of obtaining information about IRBs that are both economical and likely to promote the system's highest aspirations. (Further information on this point is contained in Chapter Four.)

Food and Drug Administration. An approach that is very different from that of NIH is followed by the Food and Drug Administration (FDA), even though it is also a compo-

${ }^{9}$ Testimony of Charles MacKay, Deputy Director, OPRR, transcript of 14th meeting of the President's Commission (November 14, 1981) at 320. See also, "Response to Request for Comments and Corrections of Biennial Report" (undated, distributed by Dr. McCarthy to members of the Commission and Staff on November $14,1981)$ part II at 7.

${ }^{10}$ Testimony of Charles McCarthy, transcript of 14 th meeting of the President's Commission (November 14, 1981) at 321.

${ }^{11}$ Testimony of Dr. McCarthy and Dr. MacKay, 14th meeting of the President's Commission (November 14, 1981) at 333-4.

${ }^{12}$ Letter to Commissioners from Dr. Charles McCarthy (December 28,1981 ). 
nent of the Public Health Service within HHS. The FDA regulates research, regardless of the source of funding, that is performed in support of applictions for approval of new drugs, biologicals, and medical devices to be sold in interstate commerce. Research of this type often presents the greatest need for protection of human subjects.

With the 1981 revisions, the FDA regulations on research involving human subjects have become almost identical to those of 45 CFR 46 , with one important exception (and several minor ones). The FDA does not require prior agency approval of the composition and procedures of IRBs. Instead, FDA makes site visits ("inspections") to approximately 400 IRBs annually to monitor compliance with the requirements of its regulations. Routine inspections include initial inspections and subsequent inspections every 2-3 years for those IRBs found to be in full compliance, or within two years for IRBs found to have only minor deficiencies. Directed inspections are conducted within six months after a routine inspection reveals serious noncompliance with the regulations or when FDA receives information that calls into question the practices of a particular IRB. These site visits are built around the "paper trail" of studies of particular drugs and devices selected by the FDA inspectors. In other words, the performance of the institutions and its IRB are judged on the basis of its documentation of compliance with the regulatory requirements as applied to one or more investigational drugs or devices. (See Appendix B for further description.)

Thus, the FDA does not necessarily know whether an IRB is properly constituted (or even that it exists) unless or until a routine inspection is conducted or some problem arises that triggers an investigation "for cause." 13 The site visits do provide FDA with a means of evaluating the performance of IRBs although, as described in Appendix F, both the quality of the inspections and the communications of findings to OPRR deserve further attention.

Other Federal Agencies. Outside HHS, of the 17 Federal agencies that have adopted the IRB (or similar committee) as a mechanism for assuring the protection of human subjects, 12 report that they rely entirely on an agency review of IRB membership and an assurance of compliance

${ }^{13}$ In a case in which a criminal indictment was recently handed down in Pennsylvania, a scientist allegedly conducted drug research over a period of years without benefit of IRB review. It was only when an FDA reviewer questioned some of the data submitted that an investigation was initiated and it was discovered that the IRB which had purportedly reviewed the protocols had never existed. (United States V. Levine, No. 81-203, E.D.Pa., Indictment, July 9, 1981, Count 18(e) at 8). 
similar to that required by HHS in its approval of institutional assurances (see Table 5). Indeed, six of these agencies require grantees and contractors to have an assurance approved by HHS: the CIA, Department of Commerce, Department of Education, National Highway Traffic Safety Administration (a component of the Department of Transportation), the Environmental Protection Agency, and the National Science Foundation. Eleven accept either an assurance approved by HHS or their own review of IRB composition and procedures. Of these, the Red Cross relies on a system of general assurances, but reports that many of its IRBs have been inspected by the FDA.

Six agencies monitor extramural IRBs via procedures that go beyond a review of IRB membership and acceptance of an institution's promises to comply with regulations. The CIA reports that it conducts site visits "where applicable" and that CIA program managers provide continuing review of the conduct of research projects. Within the Department of Justice, the Federal Bureau of Prisons conducts site visits at least once every two years to inspect both IRBs and ongoing research programs; and both the Law Enforcement Assistance Administration (LEAA) and the National Institute of Justice monitor research via weekly phone calls and periodic site visits. The Veterans Administration has a system of regular site visits through which the Research Advisory Committee in Washington monitors both IRB performance and the conduct of research at VA facilities, and through which IRBs (regional "Human Rights Committees") monitor the conduct of research in the cooperative study programs.

Finally, within the three components of the Department of Defense, intramural IRBs are responsive to a commander who approves all IRB proceedings, and IRBs at institutions receiving Defense Department contracts are subject to review by contracting headquarters. There is no mechanism, however, for systematic monitoring of either the conduct of extramural research or the performance of grantee or contractor IRBs except in the Army, whose Medical Research and Development Command conducts site visits to each contractor prior to approval of the contract. One of the site visitors must be qualified to perform technical review; the other must be qualified "to evaluate the contract as an advocate of the human subjects."

A modest check on IRB performance is provided in some agencies through review of consent forms. At the Consumer Product Safety Commission, consent forms must be approved by the agency prior to initiating research and all signed consent forms are reviewed-and retained-by the agency. Within the Public Health Service, by contrast, routine submission of consent forms to be used in proposed re- 
TABLE 5.

Agency Procedures for Monitoring Performance of Extramural IRBs

\begin{tabular}{|c|c|c|c|c|c|}
\hline Department or Agency & & & & & Notes \\
\hline American National Red Cross & \begin{tabular}{|l|} 
see \\
notes
\end{tabular} & & & & $\begin{array}{l}\text { Supports no extramural } \\
\text { research }\end{array}$ \\
\hline Central Intelligence Agency & - & - & $\begin{array}{l}\text { see } \\
\text { notes }\end{array}$ & & $\begin{array}{l}\text { Site visits are made } \\
\text { "where applicable" }\end{array}$ \\
\hline $\begin{array}{l}\text { Consumer Product Safety } \\
\text { Commission }\end{array}$ & • & - & & & $\begin{array}{l}\text { Agency must approve } \\
\text { all consent forms }\end{array}$ \\
\hline Department of Agriculture & - & - & & & \\
\hline $\begin{array}{l}\text { Department of Commerce } \\
\text { (Bureau of Standards) }\end{array}$ & \begin{tabular}{|l|} 
see \\
notes
\end{tabular} & & & & $\begin{array}{l}\text { Supports no extramural } \\
\text { research }\end{array}$ \\
\hline $\begin{array}{l}\text { Department of Defense } \\
\text { Army }\end{array}$ & - & - & $\begin{array}{l}\text { see } \\
\text { notes }\end{array}$ & & $\begin{array}{l}\text { Site visits prior to } \\
\text { approving each contract }\end{array}$ \\
\hline Navy & - & - & & & \\
\hline Air Force & - & - & & & \\
\hline Department of Education & - & - & & & $\begin{array}{l}\text { TRBs are required for } \\
\text { contracts but not grants }\end{array}$ \\
\hline Department of Energy & - & - & & - & \\
\hline $\begin{array}{l}\text { Department of HHS: } \\
\text { NIH Grants and Contracts }\end{array}$ & - & - & & - & \\
\hline FDA-Regulated tests & - & & - & $\bullet$ & $\begin{array}{l}400 \text { site visits are } \\
\text { conducted each year }\end{array}$ \\
\hline \multicolumn{6}{|l|}{$\begin{array}{l}\text { Department of Housing and } \\
\text { Urban Development }\end{array}$} \\
\hline $\begin{array}{l}\text { Department of Justice: } \\
\text { Bureau of Prisons } \\
\end{array}$ & - & - & - & & $\begin{array}{l}\text { Site visits are made at } \\
\text { least once every } 2 \text { years }\end{array}$ \\
\hline \multicolumn{6}{|l|}{$\begin{array}{l}\text { Office of Justice Assist., } \\
\text { Resear ch, and Statistics }\end{array}$} \\
\hline \multicolumn{6}{|l|}{$\begin{array}{l}\text { Dept. of Transportation: } \\
\text { Coast Guard }\end{array}$} \\
\hline Federal Aviation Admin. & & & & & $\begin{array}{l}\text { Fed. Air Surg. must } \\
\text { approve all research }\end{array}$ \\
\hline \multicolumn{6}{|l|}{ Federal Highway Admin. } \\
\hline $\begin{array}{l}\text { Natl. Highway Traffic } \\
\text { Safety Administration }\end{array}$ & - & - & & & \\
\hline $\begin{array}{l}\text { Environmental Protection } \\
\text { Agency }\end{array}$ & $\bullet$ & - & & & \\
\hline $\begin{array}{l}\text { National Aeronautics and } \\
\text { Space Administration }\end{array}$ & \begin{tabular}{|l|} 
see \\
notes
\end{tabular} & & & & $\begin{array}{l}\text { RBs are required only } \\
\text { for intramural research }\end{array}$ \\
\hline National Science Foundation & - & - & & & \\
\hline $\begin{array}{l}\text { U.S. Intl. Development } \\
\text { Cooperation Agency }\end{array}$ & - & - & & & \\
\hline Veterans Administration & - & - & - & - & \\
\hline
\end{tabular}


search activities is generally not required. The study sections do not routinely examine consent forms, and OPRR reports that, given the volume of research projects flowing through that Office, it cannot undertake this added function. At one time ADAMHA reviewed all consent forms for research it supported, but this practice has now been curtailed. The lone present exception in HHS arises when the government (most usually, the National Cancer Institute) is acting as a "sponsor" of a drug or device being tested, since the FDA requires all sponsors to review consent forms.

\section{Are IRBs Able to Understand and Fulfill Their Obligations?}

This is plainly a time of transition for the IRE system. The National Commission for the Protection of Human Subjects gave careful consideration to the institutional review system and issued recommendations supportive of the basic elements of that system while at the same time seeking to strengthen certain of its important facets. The new regulations, issued by HHS early in 1981, are based substantially on the National Commission's recommendations, and institutions are now at various stages in revising their procedures and negotiating with HHS to accept their assurances of compliance with the regulations. Moreover, HHS is in the process of developing educational materials and conferences to assist IRBs in understanding their responsibilities under the new regulations. Thus, while a new general assessment of the basic institutional review system would be premature, it is appropriate to examine particular problem areas which arose prior to 1981 and appear to be incompletely resolved by the new regulations. Two requirements that seem to pose the greatest difficulty are: (1) continuing review by an IRB of projects it has approved and (2) IRB reporting of adverse affects of serious and continuing noncompliance.

Initial Review. The IRB study undertaken by the National Commission for the Protection of Human Subjects suggested that IRBs had a fairly good understanding of most of their responsibilities for initial review of research involving human subjects, although $25 \%$ of IRB members felt that they, and researchers, needed more information (i.e., better definitions and clearer guidelines) from the Department. ${ }^{14}$ The recent revisions in the HHS regulations provide more explicit guidance than previously offered as to what constitutes research with human subjects and what categories of such research must be reviewed or, alternatively, need not be reviewed. It remains to be seen how well the new regulations and the planned educational

${ }^{14}$ IRB Report, supra note 1, Appendix at I-263 (Table XVII-10). 
programs will meet the IRBs' needs for further guidance. Many of the most important decisions made by IRBs are matters of interpretation and judgment. These are best left to the IRB, as they are not likely to be improved by ever more detailed regulations.

Continuing Review. In contrast to the IRB's role in initial review, available information strongly suggests that many IRBs do not understand what is expected in the way of "continuing review" of projects that the IRB has approved. Although continuing review has been required since $1971,^{15}$ the survey conducted for the National Commission between July 1,1974 , and June 30,1975 , found that only $20 \%$ of IRBs routinely designated members or other representatives to observe the manner in which a research project was being conducted; $63 \%$ reported that they never did, and $17 \%$ said that they did under certain circumstances. Moreover, $38 \%$ of the IRBs reported that in few or none of the proposals they reviewed was there even an understanding that the project would be reviewed again after a specified period of time and $47 \%$ seldom or never received copies of interim reports. ${ }^{16}$

The problems manifested in these statistics clearly need attention. Some improvement might even occur as part of the current process of negotiating assurances with research institutions, if certain definitional difficulties were overcome. For example, "continuing review" and "annual review" appear in the HHS regulations to refer to separate functions (with distinct purposes and justifications). Yet the regulations do not make clear the meaning of the two terms nor the resulting expectations for institutional behavior. ${ }^{17}$

Moreover, anecdotal information received by Commission staff at IRB conferences, and testimony presented to the Commission at hearings in Boston and Los Angeles, indicate the need for better guidance as to the Department's expectations. It appears that few IRBs perform ongoing re-

${ }^{15}$ Department of Health, Education and Welfare, Public Health Service, NIH, The Institutional Guide to DHEW Policy on Protection of Human Subjects, U.S. Government Printing Office, Washington (December 1,1971 ) at 8 .

${ }^{16}$ IRB Report, supra note 1, Appendix at I-207 and at I-44. In fact, $60 \%$ of IRBs never received a copy of final reports.

${ }^{17} 45$ CFR $\$ 46.103(b)(4)$ sets forth in separate subsections that an institution's assurance must contain the "written procedures which the IRB will follow" for "conducting its ... continuing review of research. .." and for "determining which projects require review more often than annually..." 45 CFR $\$ 46.109(\mathrm{e})$ states that an IRB "shall conduct continuing review of research covered by these regulations at intervals appropriate to the degree of risk, but not less than once per year..." 
view of the actual conduct of research; and those that do sometimes meet with resistance. ${ }^{18}$

In addition, there is evidence that at least some IRB members disagree among themselves as to the nature of their responsibility to provide continuing review. ${ }^{19}$ Indeed, some IRBs may even be unaware whether their conclusions and directives are being carried out. For example, in testimony before the Commission a member of one IRB told of her surprise, when her group was called upon to provide an annual re-approval of an ongoing project, to discover that the investigator had been using the consent form found inadequate a year earlier by the IRB rather than the one that they had approved as modified. ${ }^{20}$ Two Commissioners with extensive IRB experience agreed that this is not uncommon. ${ }^{21}$

What is known is that, since HHS funding agencies require certification of IRB approval at least annually, such certification is provided for continued HHS funding. This reapproval by the IRB is clearly intended by the Department to be as serious a matter as a project's initial approval; it is to be based on reports from principal investigators as to the progress of their research and its effects on subjects. The Department lacks data on whether or not this responsibility is generally carried out in the intended manner.

Furthermore, beyond this annual review, HHS has not shown that the amount or nature of "continuing review" performed by IRBs has improved since 1975 . At the very least, it is apparent that whatever the procedures followed by IRBs they were not sufficient to identify even those cases of alleged misconduct reviewed by the Commission which involved research reviewed and approved by an IRB (with the possible exception of the incidents at UCLA), all of which came to light outside these channels. Thus, the Commission has no basis for judging whether or not the requirement of continuing review is being implemented, although

${ }^{18}$ See, e.g., Erica J. Heath, "The IRB's Monitoring Function: Four Concepts of Monitoring," 1 IRB(5) (Aug/Sept. 1979); Testimony of Leonard Glantz and Judith Watkins, Tenth Meeting of the President's Commission, Boston (June 5, 1981); papers prepared for the Workshop on Whistleblowing in Biomedical Research, sponsored by the President's Commission, the AAAS Committee on Scientific Freedom and Responsibility, and Medicine in the Public Interest, Washington (September 21-22, 1981).

${ }^{19}$ Testimony of Leonard Glantz and Judith Watkins, supra note 18.

${ }^{20}$ Testimony of Judith Watkins, supra note 18.

${ }^{21}$ Comments of Commissioners Jonsen and Medearis, 15th meeting of the Commission, Washington (December 12,1981), at $137 \mathrm{~A}$. 
it does not doubt that many IRBs are attempting to, and succeeding in, executing this responsibility in a conscientious and even creative fashion.

Within the other Federal agencies, the situation is essentially the same because they follow the HHS regulations and therefore provide no clearer or more detailed direction to their IRBs than is provided by HHS. In highly structured departments, however, some oversight is possible. Thus, the CIA reports that program managers provide continuing review of ongoing research actually being conducted under the Agency's auspices. Similarly, in the Veterans Administration, the IRBs ("Human Rights Committees") of each of four regional Cooperative Study Coordinating Centers make at least three site visits per year to the various medical centers participating in the cooperative studies. The visits are designed to determine the degree of compliance with, and implementation of, requirements for informed consent and adherence to both the letter and the spirit of guidelines for protecting the rights and welfare of human subjects. During the site visits, IRB members hold discussions with principal investigators and other members of the research team as well as with some of the research subjects. In addition, when deemed appropriate, they review individual medical records. Members or representatives of the VA's Research Advisory Committee (under the direction of the Assistant Chief Medical Director for Research and Development, in Washington) visit the larger VA medical centers (those with annual research budgets in excess of $\$ 500,000$ ). These site visits look primarily at the administration of the medical center's research and development program, through the operation of their IRBs ("Human Studies Subcommittees"), the Research and Development Committee, and the Office of the Assistant Chief of Staff for Research and Development.

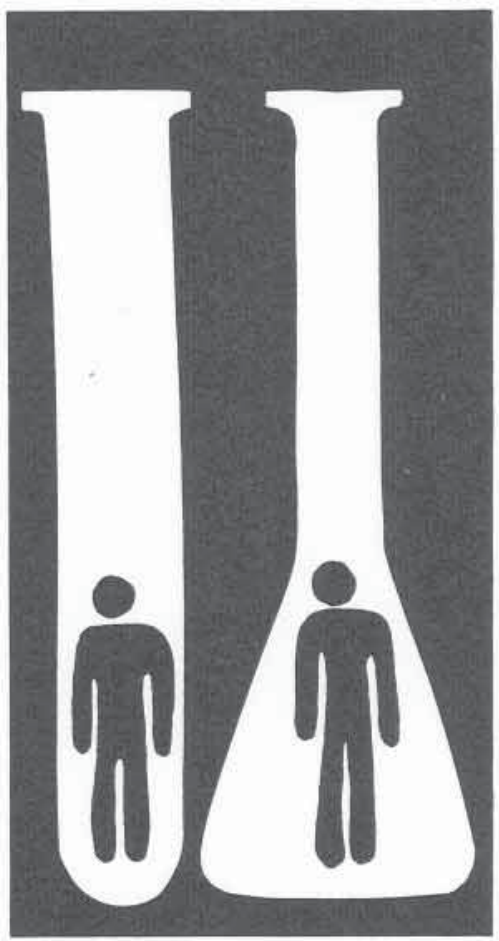

Reporting Requirements. The requirement that IRBs report any unanticipated problems involving risk to subjects or to others that arise during the conduct of research was 
introduced in HHS regulations in $1974 .{ }^{22}$ The Director of OPRR testified to the Commission that this is interpreted to require reporting only of adverse effects not anticipated by the investigator and thus not reflected in the research proposal and consent documents at the time of initial review. ${ }^{23}$ The result is that theoretically, at least, one could expand the catalogue of "risks" in advance, and thus reduce the obligation to report harm to subjects, even when some of the risks are so improbable that their manifestation would, in common sense terms, be "unanticipated."

In the review of IRB practices conducted for the National Commission by the Survey Research Center at the University of Michigan during the first year the 1974 regulations were in effect, fewer than half of the IRBs had either a formal or an informal policy with regard to investigators' reporting research-related injuries or harm to subjects to the IRB. ${ }^{24}$ From data developed during its study of compensation for research injuries, the Commission is aware that present procedures do not lead all events reasonably regarded as adverse effects to be reported. Indeed, only two adverse effects associated with HHS-supported research were apparently reported to OPRR by either IRBs or investigators from 1975-1980. OPRR staff testified that "a small number" of additional reports have been received, through telephone complaints from individuals, most of which "have proved to be unfounded or unverifiable." 25 In 1981, a third serious injury was reported in research supported by the Department: "cardiac arrest with successful resuscitation and no permanent damage." 26 Thus, both in its interpretation of its regulations and its guidance to IRBs on this point, the Department should encourage more active implementation of the requirement that injuries be reported. The Commission is pleased to note, however, that the regulations issued in 1981 now specify a particular HHS office and address to which reports should be addressed rather than simply "to the Secretary."

Besides specifying the office to which reports ought to be sent, the 1981 revision of the HHS regulations added a new reporting requirement: IRBs must report not only

2245 CFR §46.6(d), 39 Federal Register 18914, 18918 (May 30, 1974).

${ }^{23}$ Testimony of Charles R. McCarthy, Second Meeting of the President's Commission, Washington (May 16, 1980) at 93-96.

${ }^{24}$ IRB Report, supra note 1, Appendix at I-35, I-205.

${ }^{25}$ Letter from Charles R. McCarthy to Morris B. Abram (May 7, 1980).

26 "Response to Request for Comments and Corrections of Biennial Report" (November 10,1980); see also chart submitted by Charles R. McCarthy (November 25, 1981). 
unanticipated problems involving risks to subjects but also any serious or continuing noncompliance with the regulations or with the IRB's determinations. ${ }^{27}$ The regulations as written, however, appear to contemplate that the responsibility for investigating and reporting rests with the IRB, and the sample assurance promulgated by OPRR, in describing this provision, states:

For reporting purposes, the IRB will follow the procedures described below:

(1) Any serious or continuing noncompliance by research investigators with the requirements of the IRB-This information shall be reported promptly to the ORA [an administrative office within the research institution to be specified in the new assurances] and OPRR. ${ }^{28}$

As encouragement to implement this provision, local institutions require guidance on the meaning of the terms, i.e., whether or not certain behavior is sufficiently serious or continual as to warrant reporting to OPRR and institutional officials. Although no definition of "serious and continuing noncompliance" has yet been provided OPRR's plan to issue an official commentary to the regulations may meet the IRBs' need for guidance. A review of a random selection of general assurances now on file at HHS suggests, however, that not all IRBs currently have the authority within their institutions to fulfill this obligation. It is also not clear whether all IRBs would have sufficient autonomy to report to HHS any conduct that the institution's administration attempted to conceal if disagreement were to arise on the matter between an IRB and the institution's administration.

The role the IRBs currently have in investigating or resolving reports of misconduct is far from consistent. Indeed, the notion that IRBs should have any role in such activities has been strongly challenged. In testimony received in Boston and Los Angeles from IRB members as well as from hospital and university administrators, and in papers prepared for and discussions held at a 2-day workshop on the role of the IRB in responding to reports of misconduct, the consistent recommendation was that IRBs not be required to perform monitoring, investigative or adjudicative functions. Some people stressed that in most institutions IRBs have neither the time, the resources, nor the expertise

2745 CFR $\S 46.108$ (c), 46 Federal Register 8366, 8388 (Jan. 26, 1981). Such reports may become the basis for a determination by the Secretary to suspend, terminate or withhold research grants or contracts as provided in 45 CFR $\S 46.123$.

${ }^{28}$ Sample Assurance issued by OPRR (July 3, 1981 as revised August 11,1981 ) at 17 . 
to discharge such responsibilities. Others added that adoption of such a role would interfere with the primary function of IRBs: to educate and advise research scientists and to resolve problems in a constructive way. Finally, it was pointed out that most hospitals already have quality assurance mechanisms and other investigative and disputeresolution bodies in place, as do many universities.

Many witnesses and consultants strongly urged that, through a reversal of the chain-of-command-andinformation now specified in the regulations, IRBs be kept informed of all reports and investigations conducted by other responsible institutional bodies relating to misconduct in research involving human subjects, and that IRBs retain the authority to call for such an investigation when reports of misconduct come to their attention. To make such an arrangement effective, an IRB would, of course, need a defined relationship to the quality assurance committee and its activities. The prevailing view was that the primary responsibility for investigating and resolving complaints not be assigned to the IRB.

Among the other Federal agencies that conduct or support research with human subjects, only four indicated that there had been any adverse effects arising in the course of such research: the Bureau of Standards (reporting two injuries), the Federal Bureau of Prisons (citing one lawsuit in which injury was alleged), the Environmental Protection Agency (reporting one adverse reaction) and the Veterans Administration. Within both HHS and the Department of Defense, it is possible that adverse reactions are sometimes reported to project officers or others within the Department. However, there is no central office to which all such reports are referred or any other coordinated system for obtaining and recording such information.

Although not themselves free of all problems, the methods and standards of the FDA indicate that more complete and informative reporting is feasible. Regulations governing research subject to FDA regulation require that clinical investigators report unanticipated problems involving risk to subjects to the IRB and also report "any adverse effect which may reasonably be regarded as caused by, or is probably caused by, the new drug" to the sponsor of the research (e.g., the drug company, the National Cancer Institute, etc.). The sponsor, in turn, must investigate promptly and report to the FDA and to all investigators "any findings associated with (the use of the drug that may suggest significant hazards, contraindications, side-effects, and precautions pertinent to the safety of the drug." The FDA Acting 
Associate Commissioner for Health Affairs estimates that such reports number in the hundreds. ${ }^{29}$

How Do Federal Agencies Respond to Reported or Documented Violations of the Regulations or Other Serious Misconduct of Grantees or Contractors?

The uncertain resonse at the institutional level to reports of alleged misconduct in Federally funded biomedical research is mirrored by a similarly uneven response at the agency level. The Commission's review of agency policies and procedures in this regard is based upon a study of several widely reported incidents of alleged misconduct and upon a series of questions posed to the heads of departments and agencies that conduct or support research with human subjects.

Case Studies. A series of allegations of misconduct on the part of principal investigators and/or junior researchers has been widely reported in the press over the last several years. The cases are summarized in Table 6 and described in Appendix F. Having investigated the procedures followed in each instance, including the Federal response to these incidents, the Commission concludes that policies and procedures for a coordinated, timely, and consistent federal response still need to be developed.

Specifically, taken together these cases indicate a need for: (a) identification of a particular office within each research institution to which reports of alleged misconduct should be directed; (b) clarification of the role of IRBs in responding to allegations of misconduct; (c) clarity about the responsibility of institutional officials to report formal findings of misconduct to the cognizant federal agencies; (d) better guidelines for the timing and mode of the Federal agencies' response; and (e) better coordination and communication among Federal agencies with respect to investigations of reports of serious misconduct, formal findings of facts, and imposition of sanctions based upon such findings.

Questions Posed to the Secretary, HHS. On September 18 , 1980, after reviewing materials relating to the allegations concerning the University of Kansas and Boston University, the Commission through its Chairman, Morris B. Abram, wrote to Patricia Roberts Harris (then Secretary of HHS) that "if correct, these reports raise serious concerns particularly with respect to implementation of the Department's rules." Mr. Abram asked for copies of any and all re-

${ }^{29}$ Memorandum from Acting Associate Commissioner for Health Affairs (FDA) to Director, OPRR (NIH) (November 10, 1981) commenting on a preliminary draft of this report on the Protection of Human Subjects. 


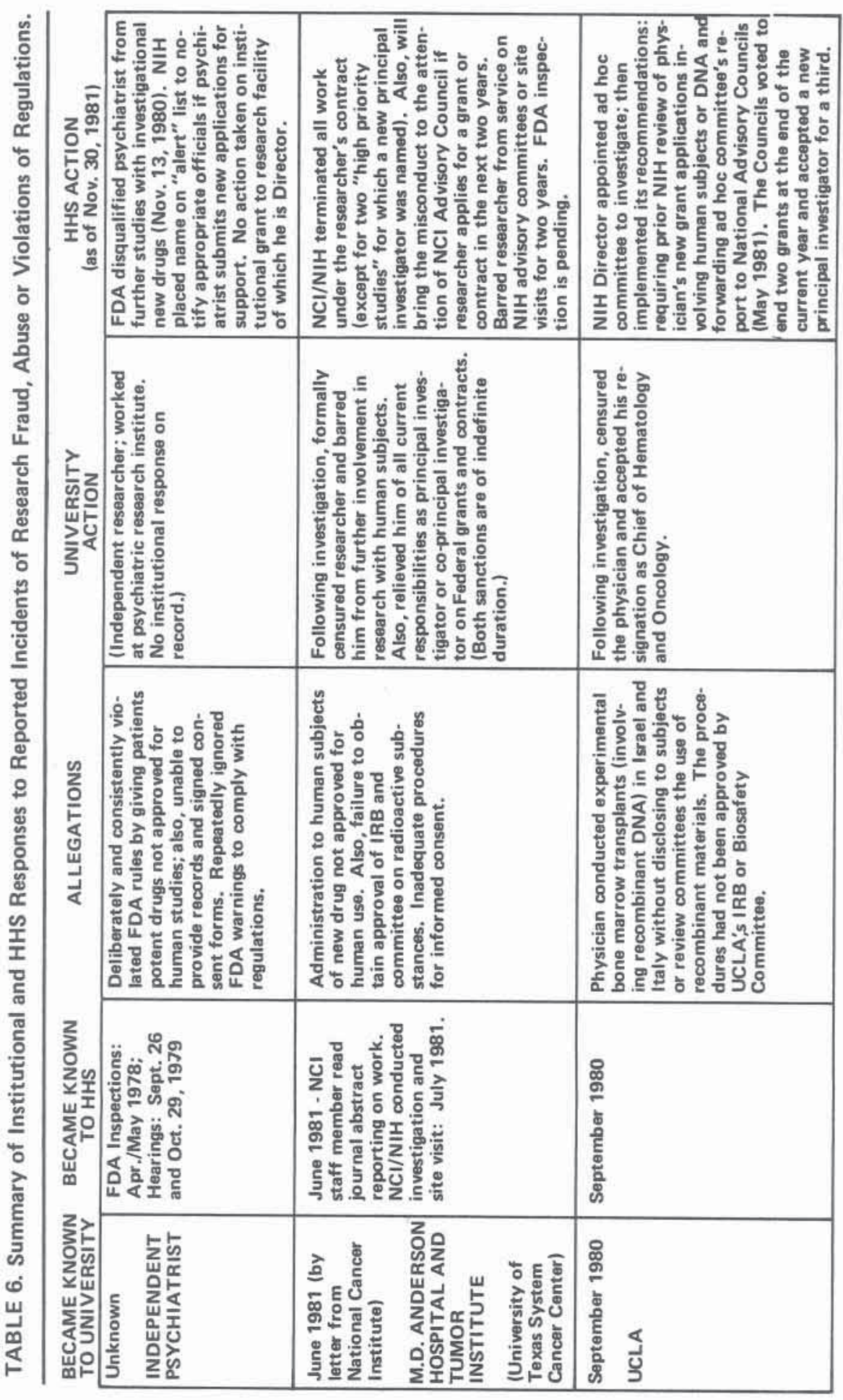




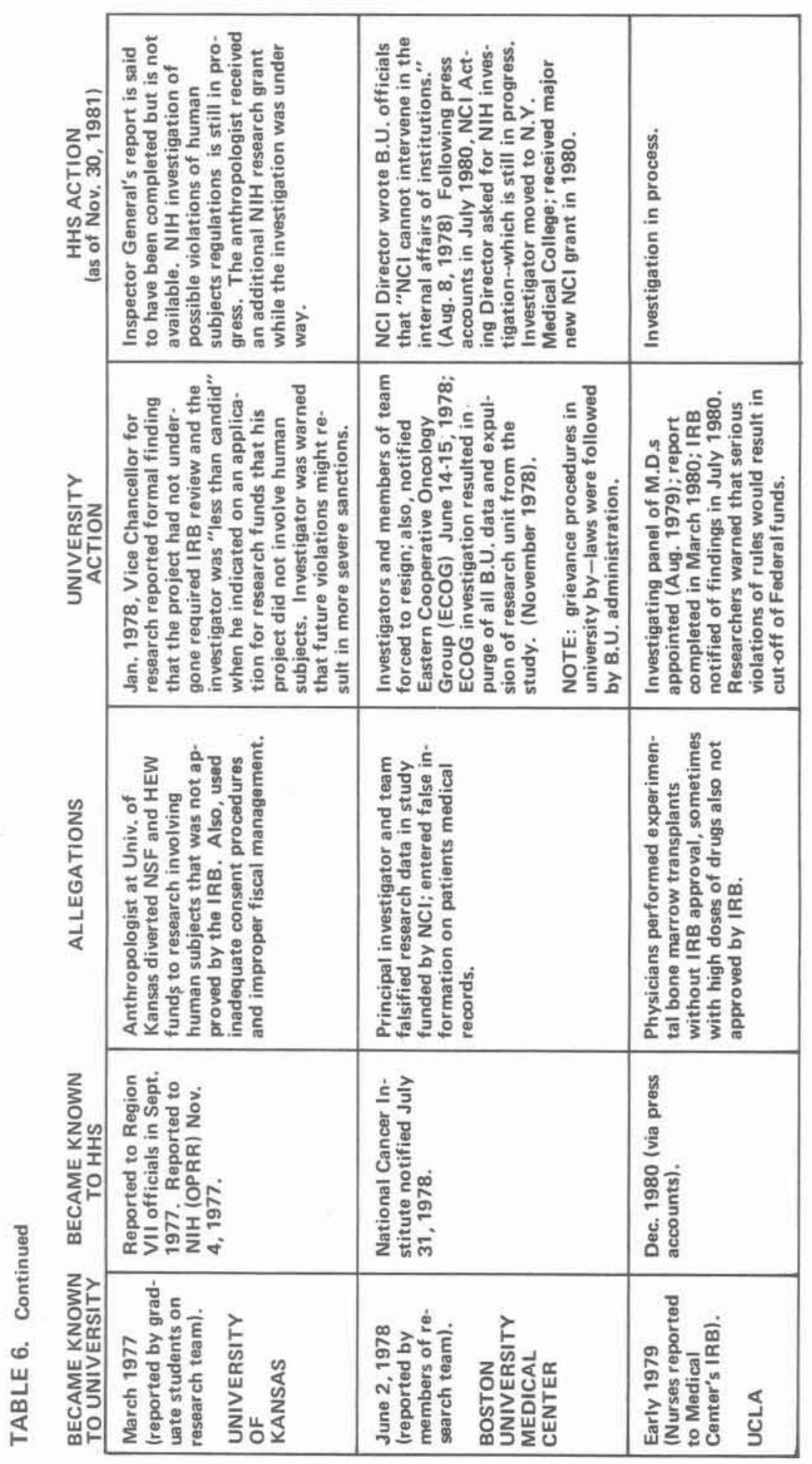


ports related to the two incidents. The heart of the Commission's interest lay, however, with several matters of general policy: (a) whether (or when) it was expected that IRBs and review groups within HHS would be told of serious allegations or findings of misconduct on the part of a scientist whose application for funding is under consideration; (b) the extent of a principal investigator's accountability for research performed under his direction; (c) the Department's interpretation and application of its regulatory provisions that research funds may be withheld from researchers who "fail materially" to protect human subjects; (d) the procedures designed to protect the rights of those who make allegations and those against whom allegations are made; and (e) the effects on human subjects of falsification of research data.

In April 1981, HHS Secretary Richard Schweiker replied that the answers to most of the questions about policy and standards posed by the Commission would depend upon the particulars of a given case. For further guidance, the Secretary referred to the Department's debarment regulatons (45 CFR 76) issued on October 8, 1980. ${ }^{30}$ Yet, as earlier noted by Donald Fredrickson (then Director of NIH), those regulations were designed to preclude persons guilty of fiscal mismanagement or fraud from receiving further HHS grants or contracts. As written, the regulations do not specifically refer to violations of the regulations governing research with human subjects or to scientific fraud. ${ }^{31}$ The debarment regulations do provide for notice, formal hearings, and other "due process" protections for individuals accused of fraud and abuse or serious violation of applicable regulations or conditions governing an HHS grant or contract. The procedures set forth in those regulations have yet to be invoked by $\mathrm{NIH}$, however, although at least two scientists accused of violating the human subjects regulations have had their research funds curtailed in the year since those regulations took effect (see Appendix E).

On several subsequent occasions, the Commission inquired of HHS officals about the Department's interpretation of its rules and how one determines what course of action to take in response to allegations of misconduct or formal findings that misconduct has occurred. Following Secretary Schweiker's letter referring to the debarment regulations, the Commission's chairman wrote the Secretary asking for a meeting to explain the Commission's contin-

${ }^{30} 45$ CFR 76; 45 Federal Register 67262 (October 8, 1980).

${ }^{31}$ Memorandum entitled "Rogues in Science" from the Director, NIH to the Secretary, HHS (August 7, 1980). 
uing concerns more fully. ${ }^{32}$ The Secretary declined to have such a meeting at that time but indicated that Charles McCarthy, the official HHS liaison to the Commisson would continue to provide assistance. ${ }^{33}$ The Commission staff, therefore, arranged for Dr. McCarthy to testify at the September 1981 meeting of the Commission in order to fill in certain points that remained unresolved. In a memorandum confirming that agreement, written in order to provide advance notice of the questions to be asked and to focus discussion at the meeting on policy rather than on individual cases, the issues relating to the Department's debarment procedures were set forth as follows:

Implementation of the Debarment Regulations (45 CFR 76):

a. What are the roles and responsibilities of the various offices at NIH (e.g., OPRR, General Counsel, Associate Director for Extramural Research and Training, etc.) with respect to decisions to initiate debarment proceedings?

b. Who has final authority with respect to such decisions?

c. May suspension of funds or similar sanctions be imposed without invoking the debarment process?

d. If alternative procedures are available, by whom, and according to what standards, are choices made as to which procedure to follow in a particular case?

e. At what point in consideration of debarment will a subject of investigation be formally notified so that he or she may request a hearing under section 76.14 (b)?

f. What factors will be considered in deciding when that point has been reached? Who will make the determination?

g. May a grantee institution or principal investigator, who is the subject of an investigation regarding alleged misconduct, request that debarment proceedings be initiated in order to invoke the hearing provisions ? $^{34}$

Although he had originally agreed to discuss these matters, Dr. McCarthy notified the Commission on September 1 that he now felt it inappropriate to do so because some investi-

${ }^{32}$ Letter from Morris B. Abram to Richard S. Schweiker (May 11, 1981); see Appendix F.

${ }^{33}$ Letter from Richard S. Schweiker to Morris B. Abram (Aug. 24, 1981); see Appendix F.

${ }^{34}$ Memorandum from Deputy Director, President's Commission to NIH Legal Advisor and Director, OPRR (August 17, 1981); see Appendix F. 
gations were still in process. ${ }^{35} \mathrm{He}$ then agreed to meet with Commission staff to discuss the possibility of a written response. When the written response was delivered to the Commission in mid-November, Dr. McCarthy stated that it woụld be premature to answer the series of questions about debarment procedures because Secretary Schweiker had by then agreed to a meeting to discuss those issues, among others. ${ }^{36}$

On December 3, 1981, Secretary Schweiker, together with the Assistant Secretary for Health, the Assistant Secretary for Planning and Evaluation, and two members of the Executive Secretariat, met with Commission Chairman Abram, and the Executive and Deputy Directors of the Commission. As a result of a full exploration of the issues, the Secretary proposed that the Assistant Secretary for Planning and Evaluation work with senior Commission staff to spell out standards under existing regulations for the Department's response to reports of misconduct that would meet the concerns of the Commission as well as those of HHS and the research community. The Commission welcomes this collaborative effort and fully expects that its next Biennial Report will describe the articulation-and implementation-of the relevant policies and procedures.

The FDA's Disqualification Procedures. The FDA has had disqualification procedures in place for a number of years, and since 1964 has invoked those procedures to disqualify 42 scientists from further research under that agency's jurisdiction for varying periods of time. Twenty-six of those disqualifications occurred within the last five years. ${ }^{37}$ Serious deficiencies in the conduct of research, including fraudulent reporting of data or noncompliance with regulations for the protection of human subjects, can form the basis of a disqualification proceeding at FDA.

As explained more fully in Appendix E, however, the process of systematic sharing between NIH and FDA of information about scientists who are the subject of an investigation or who have been subject to agency sanctions is not yet fully developed. Active sharing of information regarding formal findings of misconduct with other Federal

${ }^{35}$ Letter to Barbara Mishkin from Charles R. McCarthy (September 1, 1981); see Appendix F.

${ }^{36}$ "These questions overlap with many of the questions answered in Secretary Schweiker's letter of April 15. Since the Secretary has agreed to meet with the Chairman and Commission staff, it would be premature to amplify what was said in the April 15 letter." Letter to Barbara Mishkin from Charles R. McCarthy (November 10, 1981); see Appendix $F$.

${ }^{37} \mathrm{FDA}$ list entitled "Investigators Found Ineligible to Receive Investigational New Drugs" (December 7, 1980). 
agencies or with appropriate state licensing bodies or professional societies is limited to a "need to know" basis (i.e., if the investigator was employed by a state or is known to have received NIH support). Thus, although the formal findings following an investigation are publicly available on request, only limited efforts are made to alert other organizations that a physician or scientist has been found guilty of serious misconduct in research involving human subjects.

Questions Posed to Other Federal Agencies. On June 11,1981 , the heads of each of the 18 agencies known to conduct or support research with human subjects were asked to provide a description of:

1. Policies or procedures (formal or informal) by which their agency evaluates or monitors the actual performance of agency or extramural Institutional Review Boards (e.g., reporting requirements, site visits, record reviews);

2. Standards and procedures to guide the investigation of complaints regarding the review or conduct of research involving human subjects;

3. The number and character of any such reports or complaints received in the last 5 years (FY 19761980); and

4. The manner in which these complaints were disposed of, the findings that were made, and the sanctions, if any, that were imposed.

As a result of that inquiry, the Commission finds that the situation in the other Federal agencies that conduct or support research with human subjects is virtually identical to that existing at the NIH, insofar as most of those agencies follow the policies and procedures set forth in the HHS regulations (45 CFR 46).

Outside of HHS, only five agencies report having received complaints. The Bureau of Standards, within the Department of Commerce, reported two injuries to subjects, the Bureau of Prisons reported one tort action (arising from research supported by the CIA and conducted between 1955 and 1961); the CIA reported the same complaint and one other also arising out of research conducted in the 1950s; the Environmental Protection Agency reported an incident of accidental exposure of subjects to a throat and eye irritant; and the Veterans Administration reported 5 incidents. (See Appendix B for further details.) Of the five complaints noted by the VA, two proved to be unfounded, two are under investigation, and one resulted in an official reprimand of the principal investigator and his exclusion from further research with human subjects. 
Most of the agencies reported that they have no formal procedures for investigating or responding to complaints. The exceptions were the Bureau of Prisons, NASA, the Department of Defense and the VA. At the first two, complaints are referred to the Office of General Counsel for investigation. Within the Department of Defense and the Veterans Administration, complaints are dealt with first at the local level and, if necessary, are referred up through normal channels. Within the VA, complaints made directly to the Office of the Medical Inspector in Washington may be investigated either by a local team or by a team designated for that purpose operating out of the Washington Central Office. 


\section{Activities of the Commission Extending Into 1982}

\section{Site Visits to IRBs: An Exploratory Study}

The Commission decided against conducting another study along the lines of the survey of IRB procedures and performance that was conducted under the auspices of the National Commission for the Protection of Human Subjects. The present Commission's resources of time and money made such a study infeasible. Also, since the system is in some flux after the issuance of new regulations in 1981, the value of such a study would be problematic. Most importantly, however, the Commission concluded that a study of IRBs themselves would fall outside its proper focus: the procedures of Federal agencies and their awareness of the implementation of their own rules. Instead, the Commission has begun an empirical exploration of a new approach that Federal agencies might employ to develop information about the implementation of rules for the protection of human subjects. The approach involves site visits to IRBs by teams of experienced IRB members and administrators from other institutions, with the support of the Commission staff.

The Commission's interest in site visits grew from several considerations. First, as has been said, little information currently exists as to how requirements for the protection of human subjects are actually carried out at institutions that receive support for human research from HHS, the largest sponsor of such research. This limitation on existing knowledge has been previously recognized and, indeed, was a factor leading to the National Commission's IRB study. Second, most Federal agencies, including HHS, have no procedures for routinely obtaining such information about IRBs. Third, a new approach for developing such information was proposed by the National Commission, but has not yet been implemented by HHS. Specifically, the National Commission recommended that the then Department 
of Health, Education, and Welfare carry out "compliance activities, including site visits and audits of Institutional Review Board records, to examine the performance of the Boards and their fulfillment of institutional assurances and regulatory requirements." 1 These site visits, said the Commission, should be conducted "routinely" and, in addition to assuring "quality control," should be aimed at "educating, improving performance of IRBs, and providing needed advice."2

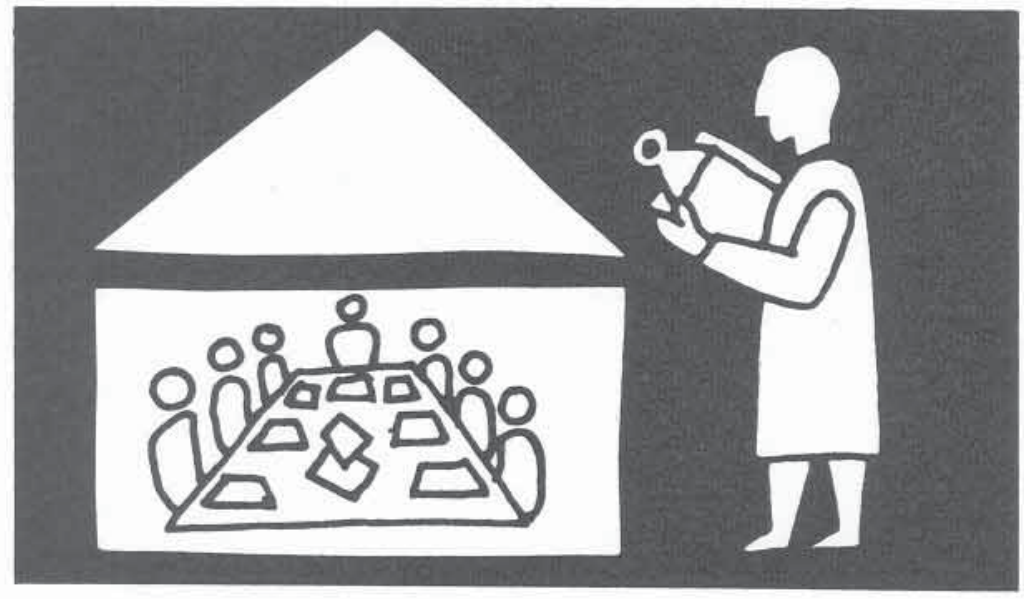

In the Commission's view, this recommendation merits serious consideration. The President's Commission determined that it could play a useful role by specifying the meaning of this recommendation in detailed, operational terms and by exploring on a pilot basis the strengths and weaknesses of this appraoch. Thus, in late 1981 and early 1982, site visit teams formed by the Commission will visit 10-12 institutions. The sites will be selected for their diversity, and will not be "representative" in any statistical sense. The purpose of these exploratory site visits will be to learn whether visits of this type would offer a useful way to develop and share information about IRB functioning. Various methods will be explored, including meetings with IRB members, reviewing records, meeting with investigators, and attending IRB meetings. Each site visit team will be made up of three persons who are experienced IRB members or administrators, in addition to a Commission staff member.

\footnotetext{
${ }^{1}$ National Commission for the Protection of Human Subjects, Report and Recommendations: Institutional Review Boards, U.S. Government Printing Office, Washington (1978) at 10.
}

${ }^{2}$ Id. at 11. 
The site visits will provide material for a report focusing on the possible processes through which information could regularly be developed by the Federal agencies that sponsor human research about the implementation of their regulations. The report is not envisioned as a critique of IRBs in general or of the specific IRBs visited in particular. Rather, the project is intended to illuminate what can be learned through a process of peer-based site visits and what problems exist with this approach. If the method is successful it might also replace the multiplicitous inspections now performed by Federal entities other than HHS which support research and by the FDA. ${ }^{3}$

\section{Guidebook for IRBs}

In 1974, in enacting the National Research Act, Congress directed (then) HEW to provide "a program .... for clarification and guidance with respect to ethical issues raised in connection with biomedical and behavioral research involving human subjects." 4 Very little has been developed thus far, yet is is clear that researchers and IRB members desire help both in understanding the policies and principles that underlie the regulations governing research with human subjects, and in identifying the issues to which one should be sensitive in designing or reviewing research proposals. The Commission has embarked on a project, in collaboration with NIH and FDA, to develop a guidebook for IRBs. A contract was negotiated with a Boston-based organization well-known for sponsoring educational conferences for IRBs throughout the country, to prepare portions of the guidebook under the direction of senior staff of the Commission. Other portions of the book are being developed by NIH/FDA staff.

A draft of the guidebook is under preparation and will be distributed to the Commissioners for review early in 1982. Comments and suggestions from the Commissioners will be incorporated in a final version which should be completed by April 1982.

${ }^{3}$ Some hope for success with the peer site visit approach can be derived from the observation of Robert Levine, the long-time chair of the Yale Medical School IRB, on a related phenomenon:

Members of IRBs with credibility seem to be invited into the realities of the institution by colleagues who want their advice and assistance in fostering mutual goals. Inspectors without credibility, on the other hand, are shown records (appearances of reality) and then only those to which their access is authorized by regulations.

Robet J. Levine, Ethics and Regulation of Clinical Research, Urban and Schwarzenberg, Baltimore (1981) at 226 (citations omitted).

${ }^{4}$ Section 474(b) of Part I, title IV, Public Health Service Act. 


\section{Consideration of the Extension of Federal Regulations and Review Requirements to Research Not Federally Funded}

In September 1980, the Commission concluded that "extension of HHS regulations to research that is not conducted or supported by the Department should be based upon clearer congressional and statutory authority than now exists in the ambiguous language of Section 474 of the Public Health Service Act." 5 In communicating this conclusion to HHS Secretary Patricia Roberts Harris (by whom it was adopted), the Commission indicated, however, that it would consider, at some later date, whether to recommend statutorily-mandated IRB review of research with human subjects regardless of source of funding and, should it conclude that such a requirement is advisable, to recommend appropriate Congressional action. Consideration of this topic, along with other issues about the role of the Federal government, through IRBs, in the protection of human subjects, will be taken up in the Second Biennial Report.

\section{Possible Consideration of the Definition of "Phase 1" Drug Testing in Cancer Chemotherapy}

The recent attention of Congressional committees and the press to informed consent in cancer research has spotlighted a problem regarding early "Phase 1" testing of new anti-cancer drugs. The FDA defines the first two stages of drug research as follows:

Phase 1 starts when the new drug is first introduced into man-only animal and in vitro data are available-with the purpose of determining human toxicity, metabolism, absorbtion, elimination, and other pharmacological action, preferred route of administration, and safe dosage range; Phase 2 covers the initial trials on a limited number of patients for specific disease control or prophylaxis purposes. ${ }^{6}$

In non-cancer studies, Phase 1 drug tests are usually conducted with healthy volunteers, so that the subjects' pathological condition will not interfere with the measurements of the drug's activity in the human body. In such cases, there is no suggestion that the subjects should expect any health benefit from their participation in the research. With cancer drugs, however, toxicity is such that even Phase 1 tests are usually conducted on persons with cancer, often

${ }^{5}$ Letter from Morris B. Abram to Patricia R. Harris (September 18, 1981).

${ }^{6} 21$ CFR \$321.1(a), see para. 10(a) of Form FS-1571 described therein. 
desperate patients for whom all other possible treatments have proven unavailing.

There is considerable confusion as to whether Phase 1 tests of new cancer drugs can be described as "therapeutic" for the patients who will be asked to participate as subjects. IRB members disagree, at times, on this question, ${ }^{7}$ but cancer researchers have testified that they always have therapeutic intent in Phase 1 tests of cancer chemotherapy. ${ }^{8}$ Further, in a recent letter to Representative Henry Waxman (commenting on testimony of the Commission's staff), the Assistant Secretary for Health wrote:

Notwithstanding the fact that some individuals within HHS may not concur, the official position of the Department, including NCI, NIH and FDA, is to regard Phase 1 trials of anti-cancer drugs as potentially therapeutic. The often small, but real possibility of benefit must be weighed against the nearly 100 percent probability of death if experimental therapy is not attempted for the advanced cancer patients who participate in Phase 1 studies. $^{9}$

At a recent meeting of the HHS Secretary's Task Force on NCI/FDA [Regulation of] INDs (Investigational New Drugs), the Commission's Executive Director and Deputy Director urged that this definitional problem be given serious attention. The contrast between the FDA regulations and Dr. Brandt's statement of the Department's "official position" is striking. Perhaps the classifications or nomenclature of Phase 1 and 2 should not be applied to research on cancer chemotherapies. More important, attention should be paid to the ambiguity in the term "therapuetic research" as applied to the initial use of new anti-cancer agents in human beings, in research usually designed to test pharmacokinetic and toxiologic matters. Clarity and candor are

${ }^{7}$ One IRB member reviewing the protocol for Phase 1 tests of MHTTF at M.D. Anderson indicated that it was a therapeutic research project; another, that it was nontherapeutic. See IRB review check lists of Alexander Y.M. Wang, Ph.D., and W.W. Sutow, M.D., reflecting their review of protocol DT 78-31 discussed in Chapter Three.

${ }^{8}$ See testimony of Drs. Emil Freireich, James F. Holland and John E. Ultmann before a joint hearing of the Subcommittee on Health and the Environment of the Committee on Energy and Commerce, and the Subcommittee on Investigations and Oversight of the Committee on Science and Technology, U.S. House of Representatives (October 27, 1981).

${ }^{9}$ Letter from Edward N. Brandt, Jr., M.D., Assistant Secretary for Health, HHS, to the Honorable Henry A. Waxman, Chairman, Subcommittee on Health and the Environment (November 20,1981) at 3-4 (emphasis added). 
needed as much as courage, both in the communication between physician-investigators and patient-subjects and in the unflinching self-appraisal by the cancer research community of the personal (as well as the scientific) meaning of such "heroic" experimentation. The Task Force has indicated a willingness to consider these issues and the Commission awaits its report with great interest.

\section{Report on Problems Identified at IRB Workshops}

Senior staff of the Commission will be attending a number of IRB workshops and conferences during the next year. Some of these are under the sponsorship of NIH and FDA; others are being planned by Commission staff to the extent permitted by reduced fiscal resources. If the workshops indicate that IRB members and research administrators have continuing problems understanding or implementing HHS regulations (or those of other Federal agencies), the Commission will consider what remedies might be appropriate.

\section{Informed Consent and Problems of Privacy in the Research Setting}

The Commission will consider, as part of its next Biennial Report, whether more needs to be said regarding (a) informed consent and (b) privacy in the research setting. The former will depend largely upon whether HHS (and other Federal agencies) adopt the recommendations of the National Commission regarding research involving children and persons institutionalized as mentally disabled; the special principles and procedures set forth in those reports may prove helpful in resolving some difficult issues that have arisen concerning research with patients suffering from senile dementia of the Alzheimer's type. The second topic (privacy) turns on possible enactment of Federal laws that would add statutory guarantees of confidentiality for individuals' medical records. 


\section{Recommendations}

\section{Recommendations for Improving the Adequacy and Uniformity of Federal Laws and Regulations for the Protection of Human Subjects}

Analysis of the Federal regulations surveyed in Chapter Two reveals that rules governing research with human subjects are now largely uniform among, and within, the agencies. The Commission regards this uniformity as a salutary development for several reasons. First, it facilitates administration, resulting in an easing of the regulatory burden on research institutions. Second, uniformity makes oversight simpler and more efficient; deficiencies are more readily identified and improvements have a more pervasive effect.

The survey of the present Federal rules and regulations also reveals, however, small variations among the requirements of the different agencies. Varied regulations for the review of research protocols impose upon local institutions unnecessary complexity and uncertainty in assuring appropriate review. Moreover, since IRBs review protocols prior to submission for funding, at the time of IRB review it is not always clear which agency will ultimately support the proposed research. Also, some research activities are supported by more than one agency. Accordingly, the Commission recommends that several steps be taken to standardize the "core" elements of all governmental regulations that specify basic process and standards for the protection of human subjects. Adoption of these recommendations should provide more simplicity, economy and certainty in the Federal regulation of research with human beings.

1. The President should, through appropriate action, require that all federal departments or agencies adopt as a common core the regulations governing research with hu- 
man subjects issued by the Department of Health and Human Services (codified at 45 CFR 46), as periodically amended or revised, while permitting additions needed by any department or agency that are not inconsistent with these core provisions.

Comment: This recommendation is intended to eliminate unnecessary and confusing regulations and lighten the burden imposed on institutions that conduct human research with Federal funds or subject to Federal supervision.

The regulations of the Department of Health and Human Services already serve as the model for most other Federal agencies and departments that conduct or support research with human subjects. Some Federal entities make explicit reference to 45 CFR 46 in their own rules and rely on HHS accreditation of institutions receiving funds from them, while others set out procedural and substantive requirements (i.e., risk/benefit ratio, informed consent) for review and approval of research projects that are similar to the HHS rules.

The Commission on Federal Paperwork acknowledged the preeminent position that HEW (the predecessor to HHS) has held in the protection of human subjects, and it recommended that the Federal government "speak with one voice" through the Department. ${ }^{1}$ The present recommendation by the President's Commission is consistent with the findings and conclusions of the Paperwork Commission and with a similar recommendation made three years ago by the National Commission for the Protection of Human Subjects. That Commission recommended that:

Federal law should be enacted or amended to provide that each institution which sponsors or conducts research involving human subjects that is supported by any Federal department or agency or otherwise subject to Federal regulation, and each Federal department or agency which itself conducts research involving human subjects, shall give assurances satisfactory to the Secretary of Health, Education, and Welfare that all research involving human subjects sponsored or conducted by such institutions, or conducted by such department or agency, will be reviewed by and conducted in accordance with the determinations of a review board established and operated in accordance with the regulations promulgated by the Secretary... ${ }^{2}$

${ }^{1}$ Commission on Federal Paperwork Education, U.S. Government Printing Office, Washington (1977), Recommendation 9 at 41.

${ }^{2}$ National Commission for the Protection of Human Subjects of Biomedical and Behavioral Research, Report and Recommenda- 
The President's Commission is satisfied that the preeminent role of HHS is deserved. Its leadership rests not only on its role as the major source of Federal funds for health research (as described in Chapter One) but, more importantly, on the attention it has paid to the regulatory issues in this field and to the thoughtful analysis and recommendations concerning its policies and procedures made by the National Commision for the Protection of Human Subjects between 1975 and 1978 .

The HHS regulations provide a sensible "core" stating the essential elements for protecting human subjects, specifically: (1) the characteristics of IRBs (including the minimum requisites for their membership), (2) the role of IRBs in providing prior review of research protocols, including their duties and authority in relation to investigators, to their institutions, and to the sponsors of research, and (3) the standards and procedures that should govern IRB decision-making and investigators' behavior. Standardization of these core regulations for research conducted, supported or regulated by all Federal entities would not merely eliminate the need for more than 200 pages of duplicative provisions in the Code of Federal Regulations and departmental directives but would also remove the uncertainty and confusion created for research institutions and their IRBs by minor variations now buried in the regulations of the various Federal entities.

These small differences in rules (about the composition of IRBs, for instance) do not seem intended to lead to different outcomes in the process of reviewing and approving research protocols. The Commission does not believe, for example, that the regulations of any other agency or department on IRB composition promise better protection for the rights of research subjects than that offered by the HHS regulations. Nevertheless, the pursuit of uniformity around a common set of regulations should be a two-way street: those provisions in other agencies' regulations that vary from the present HHS regulations in wording or in substance should be considered with an open mind. It may be that certain of these variations in procedures or concepts would improve the HHS formulation and ought to be incorporated as part of the "common core" applicable to all agencies. Once this process is completed, not only would the substance of the regulations be improved, but institutions conducting Federally supported research could be certain that in following the HHS regulations, they will be in compliance with the basic requirements of any and all Federal entities that sponsor research.

tions: Institutional Review Boards, U.S. Government Printing Of. fice, Washington (1978), Recommendation (1)(B) at 3. 
In addition to the core requirements there may be a few special restrictions that one or another governmental department or agency may need to impose on research to serve a special objective beyond the basic protection of human subjects' rights and well-being. For example, some government entities may have a policy against the use of certain categories of people in research they sponsor. Or their regulatory obligations may necessitate additional information being disclosed to subjects; for example, since the FDA needs to be able to inspect patient records to assure the accuracy or authenticity of data submitted in support of a New Drug Application, the possibility of FDA inspection of those records is an added element in the informed consent requirements for FDA-regulated clinical trials. Additional requirements such as these are acceptable so long as they do not conflict with or confuse the core requirements of the uniform regulations. Moreover, by consolidating all agencies' regulations at 45 CFR 46 (by means of cross references from those titles of the Code of Federal Regulations germane to the activities of the other agencies), any remaining additions to the core requirements will be highlighted rather than being hidden amongst a mass of repetitious requirements.

The Commission believes that the President has authority to bring about the necessary coordination and simplification of the rules recommended here. Indeed, the President has just issued an Executive Order which requires seven different agencies (or groups of agencies) that constitute the Intelligence Community to comply with HHS regulations governing research with human subjects. ${ }^{3}$ Drawing upon this authority, the President could order the initiation of a government-wide process of consolidating the rules that would further the Administration's goal of regulatory reform. The task could be undertaken by an interagency group under the direction of the Office of Management and Budget, with participation by the President's Commission. The support of many of the affected agencies and departments can be anticipated; indeed, the Commission's official liaisons from several agencies have acknowledged the lead-

${ }^{3}$ Executive Order 12333 (December 4, 1981) applies to all members of the Intelligence Community, which is defined (in \$3.4(f)) as including: (1) the Central Intelligence Agency; (2) the National Security Agency; (3) the Defense Intelligence Agency; (4) the Offices within the Department of Defense for the collection of specialized national foreign intelligence through reconnaissance programs; (5) the Bureau of Intelligence and Research of the Department of State; (6) the intelligence elements of the Army, Navy, Air Force, and Marine Corps, the Federal Bureau of Investigation, the Department of the Treasury, and the Department of Energy; and (7) the staff elements of the Director of Central Intelligence. 
ership role that they already assign to HHS and that they believe should be encouraged.

A timetable of 180 days should be established by the President to provide an incentive for the interagency group to resolve any remaining questions about the HHS core regulations and identify an initial set of special rules beyond the core that are needed by various departments and agencies. If action is not prompt, the Commission suggests that Congress enact legislation directing the Executive branch to establish by a specified date a uniform set of regulations under a lead agency.

2. The President should authorize and direct the Secretary of Health and Human Services to designate an office with government-wide jurisdiction to coordinate, monitor and evaluate the implementation of all regulations governing research with human subjects of Federal departments that conduct, support or regulate such research.

Comment: The central reasons for the first recommendation-a desire to eliminate needless complexity and duplication, and a recognition of the leading role already played by HHS-underlie this recommendation as well. At the moment, the President's Commission has such responsibility on a study basis, but the Commission's statutory life is a limited one and it does not have the supervisory duties and powers of a line agency. Further, once the core regulations have been consolidated, a substantial economy for the Federal government would be realized by assigning responsibility for the review and implementation of the regulations to a single office. For example, it not only wastes Federal funds and personnel but creates needless trouble and expense for a research institution to have the functioning of its IRB monitored separately by each Federal entity that has a funding or regulatory role in research conducted at the institution. Thus, systematic responsibility for the adequacy of the rules and their implementation ought to be lodged in a single Federal office, and that office ought to be located within the Department of Health and Human Services. Should the Secretary choose to designate an already existing office within NIH or FDA to fulfill this function, the office so designated should be elevated to the level of the Office of the Secretary to emphasize its governmentwide supervisory authority.

The existence of a lead office within HHS with coordinating and monitoring responsibilities for the system of regulation will relieve the other Federal entities of some of the substantial burdens of oversight and monitoring. Each Federal entity will still have to make its own administrative arrangements for the review of individual research projects. Some may have need for an office to ascertain that 
attention has been paid in each case to the regulatory requirements and to propose to the Director of the agency and to the designated lead office within HHS any special regulations that are particularly appropriate for that entity's activities. Other Federal agencies may find that this function can be adequately executed by existing subunits within the agency that pass upon the scientific or fiscal aspects of grants and contracts. Still others may be involved in so few research projects involving human subjects that their internal arrangements for review and approval will involve the establishment of an ad hoc committee as needed for each project. All such administrative arrangements should be acceptable under the revised rules and procedures.

3. Each Federal department or agency should have a comprehensive set of rules and procedures governing research with human subjects that applies consistently to all subunits within the department or agency.

Comment: If Recommendations 1 and 2 are adopted, this recommendation will not need separate attention, since essential uniformity within each Federal entity would be a necessary consequence of uniformity among all entities. Unless or until the steps recommended above have been taken, the reasons that led to those recommendationsnamely, the pursuit of simplicity, economy and certaintysupport the present recommendation even more strongly. Bureaucratic explanations for repetitious regulations peppered with minor variations are if not justifiable at least understandable between agencies, but not within subunits of a single agency.

Yet as described in Chapter Two, separate component parts within the Departments of Defense, Justice, and Transportation do each have different policies governing research with human subjects. The Defense Department reports that it is in the process of developing a departmentwide set of regulations; the Department of Transportation reports likewise, but it gave the same report to the National Commission in 1977.

In addition, two departments have regulations that cover research supported through one administrative mechanism but not through another. The Department of Education requires IRB review for research supported by contracts, but not for grants. NASA requires IRB review for intramural research, but not for extramural research. No reason is offered-or apparent-for the different treatments afforded the different categories of research by these two departments.

The Commission believes that each Federal department or agency should have one set of rules and procedures applicable to all research with human subjects supported by 
the department. If the rules are sufficiently flexible, they can be applied to all modalities of research (e.g., biomedical, behavioral, surveys, questionnaires, record reviews, and so forth). Therefore, the Commission sees no justification for differentiating among funding mechanisms or individual departmental components. This recommendation is made, as a formal matter, under $\$ 1802$ (b) of the Commission's enabling statute (42 USC $\$ 300 v-1(b)$ ) to the Secretaries of Defense, Education, Health and Human Services, Justice and Transportation, and to the Administrator of NASA, for action within the specified time periods.

4. All Federal departments and agencies that conduct or support research with human subjects should require principal investigators to submit, as part of their annual reports to the IRB and the funding agency, information regarding the number of subjects who participated in each research project as well as the nature and frequency of adverse effects.

Comment: This recommendation, like the preceeding one, is intended for implementation whether or not the full uniformity and centralization of Recommendations 1 and 2 are achieved. In any event, the Commission suggests the reporting requirements recommended here be uniform so that comparable data are available on a government-wide basis. (The timetable established by $\$ 1802$ (b) of the Commission's authorizing statute applies to this recommendation unless the government-wide task force proposed under Recommendation 1 is at work within 60 days on a uniform set of rules and has published such rules within 180 days thereafter.)

In preparing its report on Compensating for Research Injuries, the Commission was disappointed to discover that data on the number of human subjects who participate in Federally funded research are not routinely and systematically compiled. Data regarding the incidence and severity of injuries that occur in such research are also not collected. The inability to obtain such information was one of the most frustrating aspects of the Commission's attempt to determine whether a program to compensate individuals for injuries resulting from their participation in research is needed. Federally funded investigators are already required (under the terms of their grants and contracts) to report on their projects at least once a year. A requirement that they note in such reports the numbers of subjects and of injuries during the period in question would add only a trivial burden while yielding a large benefit.

The Commission recommends that copies of such reports be collected and reviewed by the IRB at the institution in which the research is conducted and then forwarded to a 
specified office within the funding agency to be collated. Those with oversight responsibility for human research-at Congressional, Presidential or Departmental level-will then be able to obtain information about the number of human subjects and the number of injuries from each Federal agency supporting research with human subjects as well as from each institution conducting such research with Federal funds. This information seems the minimum necessary for public accountability regarding such an important and sensitive enterprise as collectively supported research with human beings.

The Commission is aware of the difficulty of defining injuries or adverse effects in a way that will avoid massive reporting of trivia but at the same time encourage the reporting of significant problems. The Commission notes, however, that several institutions with insurance programs have found means of categorizing harmful effects and that the Veterans Administration has recently implemented a reporting requirement along the lines recommended here. Its initial experience points to some administrative difficulties needing further attention, both by the VA and by other Federal entities implementing this recommendation. Concurrent with such implementation, the Commission suggests that the agencies (ideally, with coordination by the designated "lead office") work together to resolve any remaining definitional problems (e.g., determining whether under- or over-reporting occurs if transient effects such as mild to moderate headache, nausea, and the like are not reported unless they persist so long as to interfere with the subject's normal activities; determining the extent to which injuries caused by the research process can be distinguished from those caused by the treatment being tested or by the subject's disease or condition; etc.). A certain amount of trial and error may be necessary before the optimal definition is developed; nevertheless, refinements and adjustments can be made over time. It is important to make a beginning.

5. The Department of Health and Human Services and all other relevant Federal departments and agencies should proceed promptly to take action on the National Commission's recommendations concerning research involving children and research involving those institutionalized as mentally disabled, and other Federal agencies should also act on the final regulations of HHS governing such research.

Comment: It is now four years since the National Commission for the Protection of Human Subjects transmitted to the Secretary, HEW, its recommendations concerning research involving children and research involving those 
institutionalized as mentally disabled. ${ }^{4}$ Those recommendations address a very complex and sensitive topic: research with subjects who are unable to give legally valid consent to their own participation. The subject is complicated because state law on "proxy consent" is not well developed or clear. The procedures and standards recommended by the National Commission were intended to provide greater protection for children and the mentally disabled than exists under the basic HHS rules. Under current regulations, children and the mentally disabled may be enrolled in research even over their express objections on the basis of parental or guardian consent. Ironically, since the National Commission's recommendations would erect special protections, their adoption might actually facilitate research, since scrupulous compliance with their terms might lay to rest concerns over the status of "proxy consent" in research under the common law.

The legislation that created that Commission required the Secretary to publish those recommendations within 60 days of receipt, and to publish the Department's response (in the form of proposed rulemaking) within the next 180 days. ${ }^{5}$ Although no deadline for implementation of final

${ }^{4}$ National Commission for the Protection of Human Subjects of Biomedical and Behavioral Research, Report and Recommendations: Research Involving Children, U.S. Government Printing Office, Washington (1977); National Commission for the Protection of Human Subjects of Biomedical and Behavioral Research, Report and Recommendations: Research Involving Those Institutionalized as Mentally Infirm, U.S. Government Printing Office, Washington (1978).

Specifically, both children (age 7 and over) and the mentally disabled would be given an explanation of the proposed procedures geared to their level of understanding and, if the research presented no likelihood of benefit to them, would have an opportunity to assent or refuse to participate. In addition, research presenting more than minimal risk and no likelihood of benefit to the subjects would be permitted to involve children or the mentally disabled if: (a) the risk is no more than a minor increase over minimal; (b) the research is relevant to the subjects' condition; and (c) the research holds out the promise of significant benefit in the future to either the subject or others with similar disorders or conditions. Finally, the National Commission recommended review at a national level (with opportunity for public participation) of proposed research that would present more than a minor increment of risk and no anticipated benefit to children or the mentally disabled but may be of major significance to the solution of a serious health problem affecting persons similarly situated. As noted earlier, action on these recommendations might clear the way for important research on severely disabling conditions such as senile dementia of the Alzheimer's type.

${ }^{5}$ National Research Act, Pub. Law 93348, §205 (1974). 
regulations was set forth in the National Commission's enabling legislation, the President's Commission is certain that Congress anticipated an orderly and expenditious proceeding. Surely, it did not contemplate that the Department would prolong its rulemaking over a period of years.

The President's Commission agrees with the National Commission about the importance of pediatric research and of research to prevent or alleviate serious cognitive and emotional disorders. This Commission also shares the concerns of the National Commission that the subjects of such research be properly protected. The Commission concludes, therefore, that the time is long past for action, either by adoption, rejection or modification of the National Commission's recommendations. This recommendation, like Recommendations 3 and 4 , is made pursuant to $\$ 1802$ (b) of the President's Commission's authorizing legislation, to the Secretary of Health and Human Services, and to the heads of all other Federal entities that conduct or support research with children or institutionalized mental patients. Within 60 days, this recommendation shall be published by each agency, and each agency is then obliged within 180 days to act upon the recommendation, favorably or unfavorably, and to announce its disposition and reasons. The President's Commission would regard this requirement to be met by a single publication in the Federal Register if the government-wide task force proposed under Recommendation 1 is at work on establishing a uniform set of rules and regulations by 60 days from the date of this Report and has published proposed uniform regulations within 180 days thereafter. Plainly, such unified action would avoid adding to the needless duplication that already characterizes regulations in this field.

6. Congress should attach the following condition to any direct appropriations for "private" research entities: "No funds appropriated under this Act may be used, directly or indirectly, to support research involving human subjects unless such research is reviewed and conducted in compliance with either (1) appropriate regulations of [the disbursing agency] or (2) the regulations of the Department of Health and Human Services (45 CFR 46)."

Comment: It has come to the Commission's attention that Federal monies are appropriated to organizations that are established as private, non-profit corporations. In the case of the Gorgas Memorial Institute of Tropical and Preventive Medicine, Inc., which conducts research on tropical and other diseases in Panama, the funds are disbursed through the Fogarty International Center at the NIH, but the Fogarty Center lacks authority to require the Gorgas Institute to follow the rules on the protection of human subjects that attach to other research that receives funds from NIH. 
In the absence of specific legislation, such recipients of direct appropriations are not required to comply with any regulations governing research with human subjects.

The Commission recommends that Congress attach conditions to its appropriations that would require compliance with regulations for the protection of human subjects participating in research supported by those funds. As noted above, the Commission would prefer to see a uniform standard applied to all research supported by Federal monies; if this is to be accomplished, private organizations receiving "line item" appropriations should have to comply with the designated standard. Even if uniformity of regulations among agencies is not achieved, however, the Commission recommends as an alternative that Congress require such entities to comply with the regulations of either HHS or of the disbursing agency, if other than HHS.

\section{Recommendations for Improving Institutional and Federal Oversight of Research and the Response to Reports of Misconduct.}

As discussed in Chapters One and Three of this Biennial Report, the Commission has concentrated its efforts regarding Federal regulations for the protection of human subjects on scrutinizing the adequacy of Federal oversight and the implementation of the regulations. Several recommendations on implementation and Federal compliance activities are made in this Report pursuant to $\$ 1802$ (b) of the Commission's statute; the process of review is ongoing and further recommendations may be forthcoming in the next Biennial Report.

Examining the implementation of the present regulations has, moreover, revealed certain problems with those regulations themselves. These problems emerged through the Commission's hearings on, and studies of, instances of alleged fraud or abuse in research involving human subjects. The few cases of alleged misconduct examined by the Commission should not be regarded as grounds for indicting the research enterprise in general or the IRB system in particular. Rather, the cases demonstrate the need for an oversight process that would provide the systematic data necessary to place the "problem cases" in context and to justify the confidence generally expressed regarding the present system. Furthermore, the cases bring to the fore basic questions about the role and functions of IRBs, questions that will be the subject of further study by the President's Commission during the preparation of its next Biennial Report.

For the moment, the Commission has identified several aspects of institutional responsibility in need of clarifica- 
tion in the HHS regulations (which, it is assumed, will soon have even broader applicability as the formal basis for government-wide standards). These matters are addressed in Recommendations 7 and 8.

7. 45 CFR Section 46.103, which specifies the minimum requirements for an institutional assurance, should be amended by inserting two new clauses under (b):

(5) The designation of a specific office within the institution that will be responsible for: (i) receiving reports of alleged misconduct in research involving human subjects; (ii) investigating promptly and fairly; and (iii) reporting formal findings of misconduct both to the institution's IRB which approved the research and to the Secretary.1 The institutional office so designated need not be created specifically for this purpose but may be the relevant IRB itself or another existing office already having responsibility for quality assurance within the institution. Such office shall report all ongoing investigations of alleged research misconduct involving human subjects as well as formal findings to the IRB, and shall consult with the IRB on all matters relating to the conduct of research with human subjects.

(6) Written procedures for insuring prompt reporting to designated institutional officials, and by them to the Secretary, 1 of the results of any investigations or inquiries carried out under the preceding subsection or under $\S 46.108$ (c) that reveal research misconduct or serious or continuing noncompliance with Federal or institutional requirements for the protection of human subjects.

[Note: Footnote 1 in the existing 45 CFR 46 specifies the Office for Protection from Research Risks as the place where reports should be filed within the Department.]

Comment: Recommendation 7 is closely related to Recommendation 8. Taken together, the two recommendations seek to clarify the roles and responsibility of IRBs and other offices within research institutions in assuring compliance with Federal regulations. Detailed commentary follows Recommendation 8 .

8. 45 CFR Section 46.108 (c) should be revised to read as follows:

[In order to fulfill the requirement of these regulations, each IRB shall]...

(c) Be responsible for reporting to the appropriate institutional officials any serious or continuing noncompliance by investigators with the requirements and determinations of the IRB, or with the provisions of these regulations, or with good research practices, that is revealed during the IRB's continuing or annual review of research or through reports made directly to a member of the IRB or its staff. 
(d) Establish procedures for receiving and acting upon findings of misconduct in research involving human subjects, made by the office designated pursuant to $\$ 46.103(\mathrm{~b})(5)$.

Comment: These two recommendations will add language to the HHS regulations, but they will actually simplify those regulations by making clear that institutions may employ a variety of internal arrangements to deal with alleged misconduct by researchers. These proposals result from the Commission's reexamination of the HHS rules with an eye toward the great diversity of institutional structures and administrative procedures to be found in universities, hospitals and other research institutions.

As written, the HHS regulations appear to place on the IRB responsibility for investigation and adjudication of all questions or allegations that arise about research with human beings. The regulations also appear to require that IRBs communicate their findings directly to the Department rather than through normal internal channels at their institutions. In some (perhaps most) institutions, however, the IRB may not be the body best suited, by tradition, knowledge or institutional role, to perform these functions. The Commission received forceful testimony from IRB members at several research centers as well as from institutional officials and invited consultants that IRBs should not perform monitoring, investigative, or adjudicative functions. ${ }^{6}$ In their view, such responsibilities would interfere with the primary role of IRBs: to educate and advise research scientists regarding their obligations toward human subjects and to resolve problems in a constructive manner. The Commission notes that most research institutions already have estalished appropriate quality assurance mechanisms and that efficient management would be impaired by splitting such duties between two offices.

Yet, as part of their responsibility to maintain "continuing review" of research projects they have approved $(\S 46.109(\mathrm{e}))$, IRB members do need to know of any

${ }^{6}$ Erica Heath has suggested several types of "monitoring" activities carried out by IRBs: (1) periodic reappraisal of an on-going project based upon review of documents prepared by the investigator; (2) review of the actual consent process; (3) review to ascertain that the investigator is adhering to the protocol; and (4) oversight in an institution to identify unapproved research. Erica J. Heath, "The IRBs Monitoring Function: Four Concepts of Monitoring," 1 IRB 1-3 (Aug./Sept. 1979). Dr. Levine raises provocative questions about the "field work" by IRB members entailed in the last three classes of activities. Robert J. Levine, Ethics and Regulation of Clinical Research, Urban \& Schwarzenberg, Baltimore (1981) at 231-33. 
findings of misconduct. Therefore, rather than being "responsible for reporting to appropriate institutional officials" about violations of relevant rules ( $\$ 46.108$ (c), emphasis added), at most institutions the IRB should be one body to which others (who are responsible for investigating and adjudicating) communicate the results of their investigations.

Relatively few incidents serious enough to warrant fullscale investigation and adjudication are expected to occur in human research that has undergone advance review and approval. To resolve such matters, it is expected that most institutions will choose to rely on an already existing body. Only under exceptional circumstances will a special office or committee need to be created within an institution's research administration to handle these functions. Flexibility in format may be retained by designating a particular official (such as "the Vice-President for Research"), who can fulfill his or her responsibilities by calling upon any standing or ad hoc committee that would be appropriate in light of a specific problem. In any case, the duty ought to be that of the institution itself (under \$46.103), but need not necessarily be lodged with the IRB (under $\$ 46.108$ ), although an IRB is not precluded from this role under the Commission's recommended amendment to $\$ 46.103$.

The Commission therefore recommends that HHS clarify its regulations to make explicit that the investigation and adjudication of alleged misconduct may be conducted by those offices already charged with such responsibilities. Representatives of the Department have assured the Commission that this is the intent of the regulations and that assurances reflecting such institutional arrangements are acceptable.

The details of process and procedure need not be recited in the institution's assurance with HHS, but they do deserve advance thought and planning by the institution. Experience is a great teacher, but preparation can provide certainty and a better chance for order and fairness. Thus, the assurance should guarantee that whatever mechanism the institution chooses will be able to provide: (i) a prompt investigation; (ii) an impartial adjudicating body; (iii) full opportunity for the complaining parties and the accused to explain their positions, present evidence, call witnesses, etc.; and (iv) protection from institutional reprisals for good faith complainants and witnesses.

Every effort should be made to encourage institutional personnel to report problems through internal channels. The responsible office should not only be identified in the institution's written assurance but should also be announced to all research personnel and subjects (e.g., by a 
statement on the consent form giving the name of a responsible official to contact in the case of problems). The use of internal channels will also be encouraged if institutions protect those who report in good faith, resolve problems informally to the extent possible, and impose appropriate disciplinary measures for serious acts of misconduct. Procedures to protect against institutional reprisals should also be publicized and all staff should be made aware of their obligation to assist the administration in upholding high standards of conduct.

Whenever the body responsible for resolving allegations of misconduct is not the IRB, the institution's assurance ought also to guarantee at least that the IRB will be kept informed and consulted regarding any alleged misconduct that involves or may affect human research subjects. The institution must assure the Department that the latter will be notified of any relevant findings. Serious misconduct should be reported to the cognizant Federal agency, once a formal determination has been made. Administrators and investigators receiving Federal funds should understand that they have a legal obligation to do so and that knowing provision of false information to the Federal government is a felony. If an institution makes a formal finding that false information has been contained in a grant application, annual report, or data submitted to a regulatory agency, the institution may incur criminal liability if officials fail to report such a finding. Although an IRB should not officially be placed, as a body, in the awkward position of being a (toothless) watchdog for laxity on the part of superior officials within an institution, neither the regulations nor institutional rules should preclude the IRB (or individual members) from making reports directly to the Department if required under unususal circumstances.

Education and attitude can play a large part in encouraging adherence to professional norms and standards. Federal administrators can aid this process by giving more precise meaning to phrases such as "material failure to protect human subjects" and by spelling out the standards governing the imposition of sanctions (issues about which the Commission is continuing to hold discussions with HHS officials). Institutional administrators can establish a clear commitment to upholding professional standards and enforcing Federal regulation by taking reports of problems seriously and by acting promptly and fairly to resolve complaints.

Professional societies and state licensing boards can also encourge adherence to scientific norms and compliance with Federal regulations governing research with human subjects. The principle of adhering to legal and 
regulatory requirements, like adherence to basic ethical norms, has been endorsed by many bodies in professions that conduct human research. These principles also deserve to be highlighted in professional codes of ethics and/or in the official commentary on such codes. More attention should be devoted to ethical and regulatory standards for human research as part of post-doctoral training in clinical investigation. Clear actions of this sort would provide a warning to all that misconduct in research may be a basis for disciplinary action by professional societies and specialty boards and even by state licensing boards.

9. Federal departments and agencies should establish government-wide procedures for making determinations on suspension and debarment of grantees and contractors alleged to have engaged in misconduct in Federally supported research with human subjects. Final determinations and sanctions imposed should be entered onto a consolidated list of individuals and made known to all Federal agencies involved with human research, to state licensing boards, and to appropriate professional societies.

Comment: The immediate cause for concern is the apparent need for NIH and FDA to clarify standards and procedures for response to reports of misconduct in research under their jurisdiction. All Federal entities should work together, under the lead of the newly created HHS office, as proposed in Recommendations 1 and 2 above, to formulate and apply a uniform set of standards for the investigation of incidents in which any agency has a regulatory interest. Procedures to protect both those who are accused and those who make good faith reports of misconduct should be developed and made known to all agency staff who might receive such reports or participate in the subsequent investigation. Gradations in penalty-from a temporary suspension of grant support to a lengthy debarment from all Federal research activities - will be needed to reflect differences in the degree of an investigator's culpability. Consideration should also be given to methods for "rehabilitation" of a researcher or institution and for expungement of the record.

Currently, an individual who is debarred or suspended by one Federal agency from receiving further grants and/or contracts remains eligible to receive research funds from other Federal agencies. Indeed, the other agencies may not have any knowledge of the administrative sanctions imposed by the first. The Commission believes that any investigator found to have failed to protect human subjects or otherwise seriously violated the conditions of a research grant from one agency should not be eligible to receive Federal support for the same, or similar, research from other 
agencies for an appropriate period of time. The mechanism recommended would provide an efficient and fair procedure for assuring that scientists cannot go "forum shopping" for more lax or lenient agencies once a final administrative finding of misconduct has been made. It would also provide assurance that such findings would be made only after the accused scientist has been afforded adequate notice of the charges and an opportunity to answer those charges at an administrative hearing, with representation by counsel and an opportunity to present evidence (see Appendix G).

Formal determinations should also be actively shared with appropriate state licensing boards and national organizations such as professional societies and pharmaceutical manufacturing associations. Although such information is currently available on request, no attempt is made to forward reports to other agencies or boards unless a specific request is made. 



\section{Appendices}

Appendix A: HHS Regulations on Protection of Human Subjects (45 CFR 46)

Appendix B: Summaries of Federal Agencies' Rules and Procedures Governing Research with Human Subjects

Appendix C: Agencies Included in Commission's 1980 Survey

Appendix D: Correspondence with HHS Regarding Amendments to the Department's Rules

Appendix E: Case Studies: Five Incidents of Alleged Misconduct in Biomedical Research

Appendix F: Correspondence with HHS Regarding Procedures for Responding to Reports of Misconduct

Appendix G: HHS Debarment Regulations and Related Rules

Appendix H: Correspondence with the Deputy Director, $\mathrm{OMB}$

Appendix I: Witnesses Who Testified at Commission Hearings

Appendix J: Participants in the Workshop on Whistleblowing in Biomedical Research 



\section{HHS Regulations on Protection of Human Subjects (45 CFR 46)}

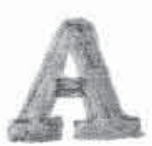

\section{PART 46-PROTECTION OF HUMAN \\ SUBJECTS}

\section{Subpart A-Basic HHS Policy for Protection of Human Research Subjects}

Sec

46.101 To what do these regulations apply?

46.102 Definitions.

46. 103 Assurances.

46.104 Section reserved.

46.105 Section reserved

46.106 Section reserved.

46.107 IRB membership.

46.108 IRB functions and operations.

46. 109 IRB review of research.

46.110 Expedited review procedures for certain kinds of research involving no more than minimal risk, and for minor changes in approved research.

46.111 Criteria for IRB approval of research.

46.112 Review by institution.

46.113 Suspension or termination of IRB approval of research.

46.114 Cooperative research.

46.115 IRB records.

46.116 General requirements for informed consent.

46.117 Documentation of informed consent.
46.118 Applications and proposals lacking definite plans for involvement of human subjects.

46.119 Research undertaken without the intention of involving human subjects.

46.120 Evaluation and disposition of applications and proposals.

46.121 Investigational new drug or device 30-day delay requirement.

46.122 Use of federal funds.

46.123 Early termination of research funding; evaluation of subsequent applications and proposals.

46.124 Conditions.

\section{Subpart B-Additional Protections Pertaining to Research, Development, and Related Activities Involving Fetuses, Pregnant Women, and Human In Vitro Fertilization}

Sec.

46.201 Applicability.

46.202 Purpose

46.203 Definitions.

46.204 Ethical Advisory Boards.

46.205 Additional duties of the Institutional Review Boards in connection with activities involving fetuses, pregnant women, or human in vitro fertilization. 46.206 General limitations.

46.207 Activities directed toward pregnant women as subjects. 


\subsection{Activities directed toward fetuses in utero as subjects. \\ 46.209 Activities directed toward fetuses ex utero, including nonviable fetuses, as subjects. \\ 46.210 Activities involving the dead fetus, fetal material, or the placenta. \\ 46.211 Modification or waiver of specific requirements.}

\section{Subpart C-Additional Protections} Pertaining to Biomedical and Behavioral Research Involving Prisoners as Subjects

Sec.

46.301 Applicability.

46.302 Purpose.

46.303 Definitions

46.304 Composition of Institutional Review Boards where prisoners are involved.

46.305 Additional duties of the Institutional Review Boards where prisoners are involved.

46.306 Permitted activities involving prisoners.

Authority: 5 U.S.C. 301 ; sec. $474($ a), 88 Stat. 352 (42 U.S.C. $289 l-3(a)$ ).

\section{Subpart A-Basic HHS Policy for Protection of Human Research Subjects}

Source: 46 FR 8386, January 26, 1981

\section{46.101 To what do these regulations apply?}

(a) Except as provided in paragraph (b) of this section, this subpart applies to all research involving human subjects conducted by the Department of Health and Human Services or funded in whole or in part by a Department grant, contract, cooperative agreement or fellowship.

(1) This includes research conducted by Department employees, except each Principal Operating Component head may adopt such nonsubstantive, procedural modifications as may be appropriate from an administrative standpoint.
(2) It also includes research conducted or funded by the Department of Health and Human Services outside the United States, but in appropriate circumstances, the Secretary may, under paragraph (e) of this section waive the applicability of some or all of the requirements of these regulations for research of this type.

(b) Research activities in which the only involvement of human subjects will be in one or more of the following categories are exempt from these regulations unless the research is covered by other subparts of this part:

(1) Research conducted in established or commonly accepted educational settings, involving normal educational practices, such as (i) research on regular and special education instructional strategies, or (ii) research on the effectiveness of or the comparison among instructional techniques, curricula, or classroom management methods.

(2) Research involving the use of educational tests (cognitive, diagnostic, aptitude, achievement), if information taken from these sources is recorded in such a manner that subjects cannot be identified, directly or through identifiers linked to the subjects.

(3) Research involving survey or interview procedures, except where all of the following conditions exist: (i) responses are recorded in such a manner that the human subjects can be identified, directly or through identifiers linked to the subjects, (ii) the subject's responses, if they became known outside the research, could reasonably place the subject at risk of criminal or civil liability or be 
damaging to the subject's financial standing or employability, and (iii) the research deals with sensitive aspects of the subject's own behavior, such as illegal conduct, drug use, sexual behavior, or use of alcohol. All research involving survey or interview procedures is exempt, without exception, when the respondents are elected or appointed public officials or candidates for public office.

(4) Research involving the observation (including observation by participants) of public behavior, except where all of the following conditions exist: (i) observations are recorded in such a manner that the human subjects can be identified, directly or through identifiers linked to the subjects, (ii) the observations recorded about the individual, if they became known outside the research, could reasonably place the subject at risk of criminal or civil liability or be damaging to the subject's financial standing or employability, and (iii) the research deals with sensitive aspects of the subject's own behavior such as illegal conduct, drug use, sexual behavior, or use of alcohol.

(5) Research involving the collection or study of existing data, documents, records, pathological specimens, or diagnostic specimens, if these sources are publicly available or if the information is recorded by the investigator in such a manner that subjects cannot be identified, directly or through identifiers linked to the subjects.

(c) The Secretary has final authority to determine whether a particular activity is covered by these regulations.

(d) The Secretary may require that specific research activities or classes of research activities conducted or funded by the Department, but not otherwise covered by these regulations, comply with some or all of these regulations.

(e) The Secretary may also waive applicability of these regulations to specific research activities or classes of research activities, otherwise covered by these regulations. Notices of these actions will be published in the Federal Register as they occur.

(f) No individual may receive Department funding for research covered by these regulations unless the individual is affliated with or sponsored by an institution which assumes responsibility for the research under an assurance satisfying the requirements of this part, or the individual makes other arrangements with the Department.

(g) Compliance with these regulations will in no way render inapplicable pertinent federal, state, or local laws or regulations.

(h) Each subpart of these regulations contains a separate section describing to what the subpart applies. Research which is covered by more than one subpart shall comply with all applicable subparts.

\section{\$ 46.102 Definitions.}

(a) "Secretary" means the Secretary of Health and Human Services and any other officer or employee of the Department of Health and Human Services to whom authority has been delegated.

(b) "Department" or "HHS" means the Department of Health and Human Services. 
(c) "Institution" means any public or private entity or agency (including federal, state, and other agencies).

(d) "Legally authorized representative" means an individual or judicial or other body authorized under applicable law to consent on behalf of a prospective subject to the subject's participation in the procedure(s) involved in the research.

(e) "Research" means a systematic investigation designed to develop or contribute to generalizable knowledge. Activities which meet this definition constitute "research" for purposes of these regulations, whether or not they are supported or funded under a program which is considered research for other purposes. For example, some "demonstration" and "service", programs may include research activities.

(f) "Human subject" means a living indıvidual about whom an investigator (whether professional or student) conducting research obtains (1) data through intervention or interaction with the individual, or (2) identifiable private information. "Intervention" includes both physical procedures by which data are gathered (for example, venipuncture) and manipulations of the subject or the subject's environment that are performed for research purposes.

"Interaction"' includes communication or interpersonal contact between investigator and subject. "Private information", includes information about behavior that occurs in a context in which an individual can reasonably expect that no observation or recording is taking place, and information which has been provided for specific purposes by an individual and which the individual can reasonably expect will not be made public (for example, a medical record). Private information must be individually identifiable (i.e., the identity of the subject is or may readily be ascertained by the investigator or associated with the information) in order for obtaining the information to constitute research involving human subjects.

(g) "Minimal risk" means that the risks of harm anticipated in the proposed research are not greater, considering probability and magnitude, than those ordinarily encountered in daily life or during the performance of routine physical or psychological examinations or tests.

(h) "Certification"' means the official notification by the institution to the Department in accordance with the requirements of this part that a research project or activity involving human subjects has been reviewed and approved by the Institutional Review Board (IRB) in accordance with the approved assurance on file at HHS. (Certification is required when the research is funded by the Department and not otherwise exempt in accordance with $\S 46.101(b))$.

\section{$\$ 46.103$ Assurances.}

(a) Each institution engaged in research covered by these regulations shall provide written assurance satisfactory to the Secretary that it will comply with the requirements set forth in these regulations.

(b) The Department will conduct or fund research covered by these regulations only if the institution has an assurance approved as provided in this section, and only if the institution 
has certified to the Secretary that the research has been reviewed and approved by an IRB provided for in the assurance, and will be subject to continuing review by the IRB. This assurance shall at a minimum include:

(1) A statement of principles governing the institution in the discharge of its responsibilities for protecting the rights and welfare of human subjects of research conducted at or sponsored by the institution, regardless of source of funding. This may include an appropriate existing code, declaration, or statement of ethical principles, or a statement formulated by the institution itself. This requirement does not preempt provisions of these regulations applicable to Department-funded research and is not applicable to any research in an exempt category listed in $\S 46.101$.

(2) Designation of one or more IRBs established in accordance with the requirements of this subpart, and for which provisions are made for meeting space and sufficient staff to support the IRB's review and recordkeeping duties.

(3) A list of the IRB members identified by name; earned degrees; representative capacity; indications of experience such as board certifications, licenses, etc., sufficient to describe each member's chief anticipated contributions to IRB deliberations; and any employment or other relationship between each member and the institution; for example: full-time employee, parttime employee, member of governing panel or board, stockholder, paid or unpaid consultant. Changes in IRB membership shall be reported to the Secretary. ${ }^{1}$

(4) Written procedures which the IRB will follow (i) for conducting its initial and continuing review of research and for reporting its findings and actions to the investigator and the institution; (ii) for determining which projects require review more often than annually and which projects need verification from sources other than the investigators that no material changes have occurred since previous IRB review; (iii) for insuring prompt reporting to the IRB of proposed changes in a research activity, and for insuring that changes in approved research, during the period for which IRB approval has already been given, may not be initiated without IRB review and approval except where necessary to eliminate apparent immediate hazards to the subject; and (iv) for insuring prompt reporting to the IRB and to the Secretary ${ }^{1}$ of unanticipated problems involving risks to subjects or others.

(c) The assurance shall be executed by an individual authorized to act for the institution and to assume on behalf of the institution the obligations imposed by these regulations, and shall be filed in such form and manner as the Secretary may prescribe.

(d) The Secretary will evaluate all assurances submitted in accordance with these regulations through such officers and employees of the Department and such experts or consultants engaged for this purpose

\footnotetext{
' Reports should be filed with the Office for Protection from Research Risks, National Institutes of Health, Department of Health and Human Services, Bethesda, Maryland 20205.
} 
as the Secretary determines to be appropriate. The Secretary's evaluation will take into consideration the adequacy of the proposed IRB in light of the anticipated scope of the institution's research activities and the types of subject populations likely to be involved, the appropriateness of the proposed initial and continuing review procedures in light of the probable risks, and the size and complexity of the institution.

(e) On the basis of this evaluation, the Secretary may approve or disapprove the assurance, or enter into negotiations to develop an approvable one. The Secretary may limit the period during which any particular approved assurance or class of approved assurances shall remain effective or otherwise condition or restrict approval.

(f) Within 60 days after the date of submission to HHS of an application or proposal, an institution with an approved assurance covering the proposed research shall certify that the application or proposal has been reviewed and approved by the IRB . Other institutions shall certify that the application or proposal has been approved by the IRB within 30 days after receipt of a request for such a certification from the Department. If the certification is not submitted within these time limits, the application or proposal may be returned to the institution.

\section{\$ 46.104 [Reserved]}

\section{46.105 [Reserved]}

\section{\$ 46.106 [Reserved]}

\section{46.107 IRB membership.}

(a) Each IRB shall have at least five members, with varying backgrounds to promote complete and adequate review of research activities commonly conducted by the institution. The IRB shall be sufficiently qualified through the experience and expertise of its members, and the diversity of the members' backgrounds including consideration of the racial and cultural backgrounds of members and sensitivity to such issues as community attitudes, to promote respect for its advice and counsel in safeguarding the rights and welfare of human subjects. In addition to possessing the professional competence necessary to review specific research activities, the IRB shall be able to ascertain the acceptability of proposed research in terms of institutional commitments and regulations, applicable law, and standards of professional conduct and practice. The IRB shall therefore include persons knowledgeable in these areas. If an IRB regularly reviews research that involves a vulnerable category of subjects, including but not limited to subjects covered by other subparts of this part, the IRB shall include one or more individuals who are primarily concerned with the welfare of these subjects.

(b) No IRB may consist entirely of men or entirely of women, or entirely of members of one profession.

(c) Each IRB shall include at least one member whose primary concerns are in nonscientific areas; for example: lawyers, ethicists, members of the clergy.

(d) Each IRB shall include at least 
one member who is not otherwise affiliated with the institution and who is not part of the immediate family of a person who is affiliated with the institution.

(e) No IRB may have a member participating in the IRB's initial or continuing review of any project in which the member has a conflicting interest, except to provide information requested by the IRB.

(f) An IRB may, in its discretion, invite individuals with competence in special areas to assist in the review of complex issues which require expertise beyond or in addition to that available on the IRB. These individuals may not vote with the IRB.

\section{46.108 IRB functions and operations.}

In order to fulfill the requirements of these regulations each IRB shall:

(a) Follow written procedures as provided in $\$ 46.103$ (b)(4).

(b) Except when an expedited review procedure is used (see $\$ 46.110$ ), review proposed research at convened meetings at which a majority of the members of the IRB are present, including at least one member whose primary concerns are in nonscientific areas. In order for the research to be approved, it shall receive the approval of a majority of those members present at the meeting.

(c) Be responsible for reporting to the appropriate institutional officials and the Secretary ${ }^{1}$ any serious or

\footnotetext{
' Reports should be filed with the Office for Protection from Research Risks, National Institutes of Health, Department of Health and Human Services, Bethesda, Maryland 20205 .
}

continuing noncompliance by investigators with the requirements and determinations of the IRB.

\$ 46.109 IRB review of research.

(a) An IRB shall review and have authority to approve, require modifications in (to secure approval), or disapprove all research activities covered by these regulations.

(b) An IRB shall require that information given to subjects as part of informed consent is in accordance with $\S 46.116$. The IRB may require that information, in addition to that specifically mentioned in $\$ 46.116$, be given to the subjects when in the IRB's judgment the information would meaningfully add to the protection of the rights and welfare of subjects.

(c) An IRB shall require documentation of informed consent or may waive documentation in accordance with $\$ 46.117$.

(d) An IRB shall notify investigators and the institution in writing of its decision to approve or disapprove the proposed research activity, or of modifications required to secure IRB approval of the research activity. If the IRB decides to disapprove a research activity, it shall include in its written notification a statement of the reasons for its decision and give the investigator an opportunity to respond in person or in writing.

(e) An IRB shall conduct continuing review of research covered by these regulations at intervals appropriate to the degree of risk, but not less than once per year, and shall have authority to observe or have a third party observe the consent process and the research. 


\section{\$46.110 Expedited review procedures for certain kinds of research involving no more than minimal risk, and for minor changes in approved research.}

(a) The Secretary has established, and published in the Federal Register, a list of categories of research that may be reviewed by the IRB through an expedited review procedure. The list will be amended, as appropriate, through periodic republication in the Federal Register.

(b) An IRB may review some or all of the research appearing on the list through an expedited review procedure, if the research involves no more than minimal risk. The IRB may also use the expedited review procedure to review minor changes in previously approved research during the period for which approval is authorized. Under an expedited review procedure, the review may be carried out by the IRB chairperson or by one or more experienced reviewers designated by the chairperson from among members of the IRB. In reviewing the research, the reviewers may exercise all of the authorities of the IRB except that the reviewers may not disapprove the research. A research activity may be disapproved only after review in accordance with the non-expedited procedure set forth in $\S 46.108$ (b).

(c) Each IRB which uses an expedited review procedure shall adopt a method for keeping all members advised of research proposals which have been approved under the procedure.

(d) The Secretary may restrict, suspend, or terminate an institution's or IRB's use of the expedited review procedure when necessary to protect the rights or welfare of subjects.

\subsection{Criteria for IRB} approval of research.

(a) In order to approve research covered by these regulations the IRB shall determine that all of the following requirements are satisfied:

(1) Risks to subjects are minimized: (i) By using procedures which are consistent with sound research design and which do not unnecessarily expose subjects to risk, and (ii) whenever appropriate, by using procedures already being performed on the subjects for diagnostic or treatment purposes.

(2) Risks to subjects are reasonable in relation to anticipated benefits, if any, to subjects, and the importance of the knowledge that may reasonably be expected to result. In evaluating risks and benefits, the IRB should consider only those risks and benefits that may result from the research (as distinguished from risks and benefits of therapies subjects would receive even if not participating in the research). The IRB should not consider possible long-range effects of applying knowledge gained in the research (for example, the possible effects of the research on public policy) as among those research risks that fall within the purview of its responsibility.

(3) Selection of subjects is equitable. In making this assessment the IRB should take into account the purposes of the research and the setting in which the research will be conducted.

(4) Informed consent will be sought from each prospective subject or the subject's legally authorized 
representative, in accordance with, and to the extent required by \& 46.116.

(5) Informed consent will be appropriately documented, in accordance with, and to the extent required by $\S 46.117$.

(6) Where appropriate, the research plan makes adequate provision for monitoring the data collected to insure the safety of subjects.

(7) Where appropriate, there are adequate provisions to protect the privacy of subjects and to maintain the confidentiality of data.

(b) Where some or all of the subjects are likely to be vulnerable to coercion or undue influence, such as persons with acute or severe physical or mental illness, or persons who are economically or educationally disadvantaged, appropriate additional safeguards have been included in the study to protect the rights and welfare of these subjects.

\section{46.112 Review by institution.}

Research covered by these regulations that has been approved by an IRB may be subject to further appropriate review and approval or disapproval by officials of the institution. However, those officials may not approve the research if it has not been approved by an IRB .

\section{\$ 46.113 Suspension or termination of IRB approval of research.}

An IRB shall have authority to suspend or terminate approval of research that is not being conducted in accordance with the IRB's requirements or that has been associated with unexpected serious harm to subjects. Any suspension or termination of approval shall include a statement of the reasons for the IRB's action and shall be reported promptly to the investigator, appropriate institutional officials, and the Secretary. ${ }^{1}$

\section{\$ 46.114 Cooperative research.}

Cooperative research projects are those projects, normally supported through grants, contracts, or similar arrangements, which involve institutions in addition to the grantee or prime contractor (such as a contractor with the grantee, or a subcontractor with the prime contractor). In such instances, the grantee or prime contractor remains responsible to the Department for safeguarding the rights and welfare of human subjects. Also, when cooperating institutions conduct some or all of the research involving some or all of these subjects, each cooperating institution shall comply with these regulations as though it received funds for its participation in the project directly from the Department, except that in complying with these regulations institutions may use joint review, reliance upon the review of another qualified IRB, or similar arrangements aimed at avoidance of duplication of effort.

\section{46.115 IRB records.}

(a) An institution, or where appropriate an IRB, shall prepare and maintain adequate documentation of IRB activities, including the following:

(1) Copies of all research proposals reviewed, scientific evaluations, if

\footnotetext{
1 Reports should be filed with the Office for Protection from Research Risks, National Institutes of Health, Department of Health and Human Services, Bethesda, Maryland 20205.
} 
any, that accompany the proposals, approved sample consent documents, progress reports submitted by investigators, and reports of injuries to subjects.

(2) Minutes of IRB meetings which shall be in sufficient detail to show attendance at the meetings; actions taken by the IRB; the vote on these actions including the number of members voting for, against, and abstaining; the basis for requiring changes in or disapproving research; and a written summary of the discussion of controverted issues and their resolution.

(3) Records of continuing review activities.

(4) Copies of all correspondence between the IRB and the investigators.

(5) A list of IRB members as required by $\S 46.103$ (b)(3).

(6) Written procedures for the IRB as required by $\S 46.103$ (b)(4).

(7) Statements of significant new findings provided to subjects, as required by $\$ 46.116$ (b)(5).

(b) The records required by this regulation shall be retained for at least 3 years after completion of the research, and the records shall be accessible for inspection and copying by authorized representatives of the Department at reasonable times and in a reasonable manner.

\section{\& 46.116 General requirements for informed consent.}

Except as provided elsewhere in this or other subparts, no investigator may involve a human being as a subject in research covered by these regulations unless the investigator has obtained the legally effective informed consent of the subject or the subject's legally authorized representative. An investigator shall seek such consent only under circumstances that provide the prospective subject or the representative sufficient opportunity to consider whether or not to participate and that minimize the possibility of coercion or undue influence. The information that is given to the subject or the representative shall be in language understandable to the subject or the representative. No informed consent, whether oral or written, may include any exculpatory language through which the subject or the representative is made to waive or appear to waive any of the subject's legal rights, or releases or appears to release the investigator, the sponsor, the institution or its agents from liability for negligence.

(a) Basic elements of informed consent. Except as provided in paragraph (c) or (d) of this section, in seeking informed consent the following information shall be provided to each subject:

(1) A statement that the study involves research, an explanation of the purposes of the research and the expected duration of the subject's participation, a description of the procedures to be followed, and identification of any procedures which are experimental;

(2) A description of any reasonably foreseeable risks or discomforts to the subject;

(3) A description of any benefits to the subject or to others which may reasonably be expected from the research;

(4) A disclosure of appropriate alternative procedures or courses of 
treatment, if any, that might be advantageous to the subject;

(5) A statement describing the extent, if any, to which confidentiality of records identifying the subject will be maintained;

(6) For research involving more than minimal risk, an explanation as to whether any compensation and an explanation as to whether any medical treatments are available if injury occurs and, if so, what they consist of, or where further information niay be obtained;

(7) An explanation of whom to contact for answers to pertinent questions about the research and research subjects' rights, and whom to contact in the event of a researchrelated injury to the subject; and

(8) A statement that participation is voluntary, refusal to participate will involve no penalty or loss of benefits to which the subject is otherwise entitled, and the subject may discontinue participation at any time without penalty or loss of benefits to which the subject is otherwise entitled.

(b) Additional elements of informed consent. When appropriate, one or more of the following elements of information shall also be provided to each subject:

(1) A statement that the particular treatment or procedure may involve risks to the subject (or to the embryo or fetus, if the subject is or may become pregnant) which are currently unforeseeable;

(2) Anticipated circumstances under which the subject's participation may be terminated by the investigator without regard to the subject's consent;

(3) Any additional costs to the subject that may result from participation in the research;

(4) The consequences of a subject's decision to withdraw from the research and procedures for orderly termination of participation by the subject;

(5) A statement that significant new findings developed during the course of the research which may relate to the subject's willingness to continue participation will be provided to the subject; and

(6) The approximate number of subjects involved in the study.

(c) An IRB may approve a consent procedure which does not include, or which alters, some or all of the elements of informed consent set forth above, or waive the requirement to obtain informed consent provided the IRB finds and documents that:

(1) The research is to be conducted for the purpose of demonstrating or evaluating: (i) Federal, state, or local benefit or service programs which are not themselves research programs, (ii) procedures for obtaining benefits or services under these programs, or

- (iii) possible changes in or alternatives to these programs or procedures; and

(2) The research could not practicably be carried out without the waiver or alteration.

(d) An IRB may approve a consent procedure which does not include, or which alters, some or all of the elements of informed consent set forth above, or waive the requirements to obtain informed consent provided the IRB finds and documents that:

(1) The research involves no more than minimal risk to the subjects; 
(2) The waiver or alteration will not adversely affect the rights and welfare of the subjects;

(3) The research could not practicably be carried out without the waiver or alteration; and

(4) Whenever appropriate, the subjects will be provided with additional pertinent information after participation.

(e) The informed consent requirements in these regulations are not intended to preempt any applicable federal, state, or local laws which require additional information to be disclosed in order for informed consent to be legally effective.

(f) Nothing in these regulations is intended to limit the authority of a physician to provide emergency medical care, to the extent the physician is permitted to do so under applicable federal, state, or local law.

\section{46.117 Documentation of informed consent.}

(a) Except as provided in paragraph (c) of this section, informed consent shall be documented by the use of a written consent form approved by the IRB and signed by the subject or the subject's legally authorized representative. A copy shall be given to the person signing the form.

(b) Except as provided in paragraph (c) of this section, the consent form may be either of the following:

(1) A written consent document that embodies the elements of informed consent required by $\$ 46.116$. This form may be read to the subject or the subject's legally authorized representative, but in any event, the investigator shall give either the subject or the representative adequate opportunity to read it before it is signed; or

(2) A "short form" written consent document stating that the elements of informed consent required by $\S 46.116$ have been presented orally to the subject or the subject's legally authorized representative. When this method is used, there shall be a witness to the oral presentation. Also, the IRB shall approve a written summary of what is to be said to the subject or the representative. Only the short form itself is to be signed by the subject or the representative. However, the witness shall sign both the short form and a copy of the summary, and the person actually obtaining consent shall sign a copy of the summary. A copy of the summary shall be given to the subject or the representative, in addition to a copy of the "short form."

(c) An IRB may waive the requirement for the investigator to obtain a signed consent form for some or all subjects if it finds either:

(1) That the only record linking the subject and the research would be the consent document and the principal risk would be potential harm resulting from a breach of confidentiality. Each subject will be asked whether the subject wants documentation linking the subject with the research, and the subject's wishes will govern; or

(2) That the research presents no more than minimal risk of harm to subjects and involves no procedures for which written consent is normally required outside of the research context.

In cases where the documentation requirement is waived, the IRB may 
require the investigator to provide subjects with a written statement regarding the research.

8 46.118 Applications and proposals lacking definite plans for involvement of human subjects.

Certain types of applications for grants, cooperative agreements, or contracts are submitted to the Department with the knowledge that subjects may be involved within the period of funding, but definite plans would not normally be set forth in the application or proposal. These include activities such as institutional type grants (including bloc grants) where selection of specific projects is the institution's responsibility; research training grants where the activities involving subjects remain to be selected; and projects in which human subjects' involvement will depend upon completion of instruments, prior animal studies, or purification of compounds. These applications need not be reviewed by an IRB before an award may be made. However, except for research described in $\S 46.101$ (b), no human subjects may be involved in any project supported by these awards until the project has been reviewed and approved by the IRB, as provided in these regulations, and certification submitted to the Department.

8 46.119 Research undertaken without the intention of involving human subjects.

In the event research (conducted or funded by the Department) is undertaken without the intention of involving human subjects, but it is later proposed to use human subjects in the research, the research shall first be reviewed and approved by an IRB, as provided in these regulations, a certification submitted to the Department, and final approval given to the proposed change by the Department.

\section{46.120 Evaluation and disposition of applications and proposals.}

(a) The Secretary will evaluate all applications and proposals involving human subjects submitted to the Department through such officers and employees of the Department and such experts and consultants as the Secretary determines to be appropriate. This evaluation will take into consideration the risks to the subjects, the adequacy of protection against these risks, the potential benefits of the proposed research to the subjects and others, and the importance of the knowledge to be gained.

(b) On the basis of this evaluation, the Secretary may approve or disapprove the application or proposal, or enter into negotiations to develop an approvable one.

\section{\$ 46.121 Investigational new drug} or device 30-day delay requirement.

When an institution is required to prepare or to submit a certification with an application or proposal under these regulations, and the application or proposal involves an investigational new drug (within the meaning of 21 U.S.C. 355(i) or 357 (d)) or a significant risk device (as defined in 21 CFR $812.3(\mathrm{~m})$ ), the institution shall identify the drug or device in the certification. The 
institution shall also state whether the 30-day interval required for investigational new drugs by 21 CFR 312.1(a) and for significant risk devices by 21 CFR 812.30 has elapsed, or whether the Food and Drug Administration has waived that requirement. If the 30-day interval has expired, the institution shall state whether the Food and Drug Administration has requested that the sponsor continue to withhold or restrict the use of the drug or device in human subjects. If the 30-day interval has not expired, and a waiver has not been received, the institution shall send a statement to the Department upon expiration of the interval. The Department will not consider a certification acceptable until the institution has submitted a statement that the 30-day interval has elapsed, and the Food and Drug Administration has not requested it to limit the use of the drug or device, or that the Food and Drug Administration has waived the 30-day interval.

\section{\$ 46.122 Use of Federal funds.} Federal funds administered by the Department may not be expended for research involving human subjects unless the requirement of these regulations, including all subparts of these regulations, have been satisfied.

\section{\& 46.123 Early termination of research funding; evaluation of subsequent applications and proposals.}

(a) The Secretary may require that Department funding for any project be terminated or suspended in the manner prescribed in applicable program requirements, when the Secretary finds an institution has materially failed to comply with the terms of these regulations.

(b) In making decisions about funding applications or proposals covered by these regulations the Secretary may take into account, in addition to all other eligibility requirements and program criteria, factors such as whether the applicant has been subject to a termination or suspension under paragraph (a) of this section and whether the applicant or the person who would direct the scientific and technical aspects of an activity has in the judgment of the Secretary materially failed to discharge responsibility for the protection of the rights and welfare of human subjects (whether or not Department funds were involved).

\section{\$ 46.124 Conditions.}

With respect to any research project or any class of research projects the Secretary may impose additional conditions prior to or at the time of funding when in the Secretary's judgment additional conditions are necessary for the protection of human subjects.

\author{
Subpart B-Additional Protections \\ Pertaining to Research \\ Development, and Related \\ Activities Involving Fetuses, \\ Pregnant Women, and Human in \\ Vitro Fertilization \\ SourCe: 40 FR 33528, Aug. 8, 1975, 43 FR \\ 1758, January 11, 1978, 43 FR \\ 51559, November 3, 1978
}




\section{\$ 46.201 Applicability.}

(a) The regulations in this subpart are applicable to all Department of Health, Education, and Welfare grants and contract supporting research, development, and related activities involving: (1) The fetus, (2) pregnant women, and (3) human in vitro fertilization.

(b) Nothing in this subpart shall be construed as indicating that compliance with the procedures set forth herein will in any way render inapplicable pertinent State or local laws bearing upon activities covered by this subpart.

(c) The requirements of this subpart are in addition to those imposed under the other subparts of this part.

\subsection{Purpose.}

It is the purpose of this subpart to provide additional safeguards in reviewing activities to which this subpart is applicable to assure that they conform to appropriate ethical standards and relate to important societal needs.

\section{$\$ 46.203$ Definitions.}

As used in this subpart:

(a) "Secretary" means the Secretary of Health, Education, and Welfare and any other officer or employee of the Department of Health, Education, and Welfare to whom authority has been delegated.

(b) "Pregnancy" encompasses the period of time from confirmation of implantation (through any of the presumptive signs of pregnancy, such as missed menses, or by a medically acceptable pregnancy test), until expulsion or extraction of the fetus. (c) "Fetus" means the product of conception from the time of implantation (as evidenced by any of the presumptive signs of pregnancy, such as missed menses, or a medically acceptable pregnancy test), until a determination is made, following explusion or extraction of the fetus, that it is viable.

(d) "Viable" as it pertains to the fetus means being able, after either spontaneous or induced delivery, to survive (given the benefit of available medical therapy) to the point of independently maintaining heart beat and respiration. The Secretary may from time to time, taking into account medical advances, publish in the FEDERAL R EGISTER guidelines to assist in determining whether a fetus is viable for purposes of this subpart. If a fetus is viable after delivery, it is a premature infant.

(e) "Nonviable fetus" means a fetus ex utero which, although living, is not viable.

(f) "Dead fetus" means a fetus $e x$ utero which exhibits neither heartbeat, spontaneous respiratory activity, spontaneous movement of voluntary muscles, nor pulsation of the umbilical cord (if still attached).

(g) "In vitro fertilization" means any fertilization of human ova which occurs outside the body of a female, either through admixture of donor human sperm and ova or by any other means.

\section{46.204 Ethical Advisory Boards.}

(a) One or more Ethical Advisory Boards shall be established by the Secretary. Members of these board(s) shall be so selected that the board(s) will be competent to deal with medical, legal, social, ethical, and 
related issues and may include, for example, research scientists, physicians, psychologists, sociologists, educators, lawyers, and ethicists, as well as representatives of the general public. No board member may be a regular, full-time employee of the Department of Health, Education, and Welfare.

(b) At the request of the Secretary, the Ethical Advisory Board shall render advice consistent with the policies and requirements of this Part as to ethical issues, involving activities covered by this subpart, raised by individual applications or proposals. In addition, upon request by the Secretary, the Board shall render advice as to classes of applications or proposals and general policies, guidelines, and procedures.

(c) A Board may establish, with the approval of the Secretary, classes of applications or proposals which:

(1) Must be submitted to the Board, or (2) need not be submitted to the Board. Where the Board so establishes a class of applications or proposals which must be submitted, no application or proposal within the class may be funded by the Department or any component thereof until the application or proposal has been reviewed by the Board and the Board has rendered advice as to its acceptability from an ethical standpoint.

(d) No application or proposal involving human in vitro fertilization may be funded by the Department or any component thereof until the application or proposal has been reviewed by the Ethical Advisory Board and the Board has rendered advice as to its acceptability from an ethical standpoint.

\section{46.205 Additional duties of the Institutional Review Boards in connection with activities involving fetuses, pregnant women, or human in vitro fertilization.}

(a) In addition to the responsibilities prescribed for Institutional Review - Boards under Subpart A of this part, the applicant's or offeror's Board shall, with respect to activities covered by this subpart, carry out the following additional duties:

(1) Determine that all aspects of the activity meet the requirements of this subpart;

(2) Determine that adequate consideration has been given to the manner in which potential subjects will be selected, and adequate provision has been made by the applicant or offeror for monitoring the actual informed consent process (e.g., through such mechanisms, when appropriate, as participation by the Institutional Review Board or subject advocates in: (i) Overseeing the actual process by which individual consents required by this subpart are secured either by approving induction of each individual into the activity or verifying, perhaps through sampling, that approved procedures for induction of individuals into the activity are being followed, and (ii) monitoring the progress of the activity and intervening as necessary through such steps as visits to the activity site and continuing evaluation to determine if any unanticipated risks have arisen);

(3) Carry out such other responsibilities as may be assigned by the Secretary. 
(b) No award may be issued until the applicant or offeror has certified to the Secretary that the Institutional Review Board has made the determinations required under paragraph (a) of this section and the Secretary has approved these determinations, as provided in $\S 46.120$ of Subpart A of this part.

(c) Applicants or offerors seeking support for activities covered by this subpart must provide for the designation of an Institutional Review Board, subject to approval by the Secretary, where no such Board has been established under Subpart A of this part.

\subsection{General limitations.}

(a) No activity to which this subpart is applicable may be undertaken unless:

(1) Appropriate studies on animals and nonpregnant individuals have been completed;

(2) Except where the purpose of the activity is to meet the health needs of the mother or the particular fetus, the risk to the fetus is minimal and, in all cases, is the least possible risk for achieving the objectives of the activity.

(3) Individuals engaged in the activity will have no part in: (i) Any decisions as to the timing, method, and procedures used to terminate the pregnancy, and (ii) determining the viability of the fetus at the termination of the pregnancy; and

(4) No procedural changes which may cause greater than minimal risk to the fetus or the pregnant woman will be introduced into the procedure for terminating the pregnancy solely in the interest of the activity. (b) No inducements, monetary or otherwise, may be offered to terminate pregnancy for purposes of the activity.

[40 FR 33528, Aug. 8, 1975, as amended at 40 FR 51638. Nov. 6, 1975]

\section{\$ 46.207 Activities directed toward pregnant women as subjects.}

(a) No pregnant woman may be involved as a subject in an activity covered by this subpart unless: (1) The purpose of the activity is to meet the health needs of the mother and the fetus will be placed at risk only to the minimum extent necessary to meet such needs, or (2) the risk to the fetus is minimal.

(b) An activity permitted under paragraph (a) of this section may be conducted only if the mother and father are legally competent and have given their informed consent after having been fully informed regarding possible impact on the fetus, except that the father's informed consent need not be secured if: (1) The purpose of the activity is to meet the health needs of the mother; (2) his identity or whereabouts cannot reasonably be ascertained; ( 3 ) he is not reasonably available; or (4) the pregnancy resulted from rape.

\section{\$ 46.208 Activities directed toward fetuses in utero as subjects.}

(a) No fetus in utero may be involved as a subject in any activity covered by this subpart unless: (1) The purpose of the activity is to meet the health needs of the particular fetus and the fetus will be placed at risk only to the minimum extent necessary 
to meet such needs, or (2) the risk to the fetus imposed by the research is minimal and the purpose of the activity is the development of important biomedical knowledge which cannot be obtained by other means.

(b) An activity permitted under paragraph (a) of this section may be conducted only if the mother and father are legally competent and have given their informed consent, except that the father's consent need not be secured if: (1) His identity or whereabouts cannot reasonably be ascertained, (2) he is not reasonably available, or (3) the pregnancy resulted from rape.

\section{46.209 Activities directed toward fetuses ex utero, including nonviable fetuses, as subjects.}

(a) Until it has been ascertained whether or not a fetus ex utero is viable, a fetus ex utero may not be involved as a subject in an activity covered by this subpart unless:

(1) There will be no added risk to the fetus resulting from the activity, and the purpose of the activity is the development of important biomedical knowledge which cannot be obtained by other means, or

(2) The purpose of the activity is to enhance the possibility of survival of the particular fetus to the point of viability.

(b) No nonviable fetus may be involved as a subject in an activity covered by this subpart unless:

(1) Vital functions of the fetus will not be artificially maintained,

(2) Experimental activities which of themselves would terminate the heartbeat or respiration of the fetus will not be employed, and
(3) The purpose of the activity is the development of important biomedical knowledge which cannot be obtained by other means.

(c) In the event the fetus ex utero is found to be viable, it may be included as a subject in the activity only to the extent permitted by and in accordance with the requirements of other subparts of this part.

(d) An activity permitted under paragraph (a) or (b) of this section may be conducted only if the mother and father are legally competent and have given their informed consent, except that the father's informed consent need not be secured if: (1) his identity or whereabouts cannot reasonably be ascertained, (2) he is not reasonably available, or (3) the pregnancy resulted from rape.

\section{46.210 Activities involving the dead fetus, fetal material, or the placenta. \\ Activities involving the dead fetus,} mascerated fetal material, or cells, tissue, or organs excised from a dead fetus shall be conducted only in accordance with any applicable State or local laws regarding such activities.

\section{46.211 Modification or waiver of specific requirements.}

Upon the request of an applicant or offeror (with the approval of its Institutional Review Board), the Secretary may modify or waive specific requirements of this suipart, with the approval of the Ethical Advisory Board after such opportunity for public comment as the Ethical Advisory Board considers appropriate in the particular instance. In making such decisions, the 
Secretary will consider whether the risks to the subject are so outweighed by the sum of the benefit to the subject and the importance of the knowledge to be gained as to warrant such modification or waiver and that such benefits cannot be gained except through a modification or waiver. Any such modifications or waivers will be published as notices in the FEDERAL R EGISTER

\section{Subpart C-Additional Protections Pertaining to Biomedical and Behavioral Research Involving Prisoners as Subjects}

Source: 43 FR 53655, Nov 16, 1978 $\$ 46.301$ Applicability.

(a) The regulations in this subpart are applicable to all biomedical and behavioral research conducted or supported by the Department of Health, Education, and Welfare involving prisoners as subjects.

(b) Nothing in this subpart shall be construed as indicating that compliance with the procedures set forth herein will authorize research involving prisoners as subjects, to the extent such research is limited or barred by applicable State or local law.

(c) The requirements of this subpart are in addition to those imposed under the other subparts of this part.

\section{$\$ 46.302$ Purpose.}

Inasmuch as prisoners may be under constraints because of their incarceration which could affect their ability to make a truly voluntary and uncoerced decision whether or not to participate as subjects in research, it is the purpose of this subpart to provide additional safeguards for the protection of prisoners involved in activities to which this subpart is applicable.

\section{46.303 Definitions.}

As used in this subpart:

(a) "Secretary" means the Secretary of Health, Education, and Welfare and any other officer or employee of the Department of Health, Education, and Welfare to whom authority has been delegated.

(b) 'DHEW" means the Department of Health, Education, and Welfare.

(c) "Prisoner" means any individual involuntarily confined or detained in a penal institution. The term is intended to encompass individuals sentenced to such an institution under a criminal or civil statute, individuals detained in other facilities by virtue of statutes or commitment procedures which provide alternatives to criminal prosecution or incarceration in a penal institution, and individuals detained pending arraignment, trial, or sentencing.

(d) "Minimal risk"' is the probability and magnitude of physical or psychological harm that is normally encountered in the daily lives, or in the routine medical, dental, or psychological examination of healthy persons.

\section{\$ 46.304 Composition of Institutional Review Boards where prisoners are involved. In addition to satisfying the requirements in $\S 46.107$ of this part, an Institutional Review Board, carrying out responsibilities under}


this part with respect to research covered by this subpart, shall also meet the following specific requirements:

(a) A majority of the Board (exclusive of prisoner members) shall have no association with the prison(s) involved, apart from their membership on the Board.

(b) At least one member of the Board shall be a prisoner, or a prisoner representative with appropriate background and experience to serve in that capacity, except that where a particular research project is reviewed by more than one Board only one Board need satisfy this requirement.

\section{\$ 46.305 Additional duties of the Institutional Review Boards where prisoners are involved.}

(a) In addition to all other responsibilities prescribed for Institutional Review Boards under this part, the Board shall review research covered by this subpart and approve such research only if it finds that:

(1) The research under review represents one of the categories of research permissible under \& 46.306(a)(2);

(2) Any possible advantages accruing to the prisoner through his or her participation in the research, when compared to the general living conditions, medical care, quality of food, amenities and opportunity for earnings in the prison, are not of such a magnitude that his or her ability to weigh the risks of the research against the value of such advantages in the limited choice environment of the prison is impaired;
(3) The risks involved in the research are commensurate with risks that would be accepted by nonprisoner volunteers;

(4) Procedures for the selection of subjects within the prison are fair to all prisoners and immune from arbitrary intervention by prison authorities or prisoners. Unless the principal investigator provides to the Board justification in writing for following some other procedures, control subjects must be selected randomly from the group of available prisoners who meet the characteristics needed for that particular research project;

(5) The information is presented in language which is understandable to the subject population;

(6) Adequate assurance exists that parole boards will not take into account a prisoner's participation in the research in making decisions regarding parole, and each prisoner is clearly informed in advance that participation in the research will have no effect on his or her parole; and

(7) Where the Board finds there may be a need for follow-up examination or care of participants after the end of their participation, adequate provision has been made for such examination or care, taking into account the varying lengths of individual prisoners' sentences, and for informing participants of this fact.

(b) The Board shall carry out such other duties as may be assigned by the Secretary.

(c) The institution shall certify to the Secretary, in such form and manner as the Secretary may require, that the duties of the Board under this section have been fulfilled. 


\section{\$ 46.306 Permitted research} involving prisoners.

(a) Biomedical or behavioral research conducted or supported by DHEW may involve prisoners as subjects only if:

(1) The institution responsible for the conduct of the research has certified to the Secretary that the Institutional Review Board has approved the research under $\$ 46.305$ of this subpart; and

(2) In the judgment of the Secretary the proposed research involves solely the following:

(A) Study of the possible causes, effects, and processes of incarceration, and of criminal behavior, provided that the study presents no more than minimal risk and no more than inconvenience to the subjects;

(B) Study of prisons as institutional structures or of prisoners as incarcerated persons, provided that the study presents no more than minimal risk and no more than inconvenience to the subjects;

(C) Research on conditions particularly affecting prisoners as a class (for example, vaccine trials and other research on hepatitis which is much more prevalent in prisons than elsewhere; and research on social and psychological problems such as alcoholism, drug addiction and sexual assaults) provided that the study may proceed only after the Secretary has consulted with appropriate experts including experts in penology medicine and ethics, and published notice, in the Federal R egister, of his intent to approve such research; or

(D) Research on practices, both innovative and accepted, which have the intent and reasonable probability of improving the health or wellbeing of the subject. In cases in which those studies require the assignment of prisoners in a manner consistent with protocols approved by the IRB to control groups which may not benefit from the research, the study may proceed only after the Secretary has consulted with appropriate experts, including experts in penology medicine and ethics, and published notice, in the FEDERAL R EGISTER, of his intent to approve such research.

(b) Except as provided in paragraph (a) of this section, biomedical or behavioral research conducted or supported by DHEW shall not involve prisoners as subjects.

\section{NOTICES}

\section{HUMAN SUBJECTS \\ Minimum Criteria Identifying the Viable Fetus}

On March 13, 1975, regulations were published in the FEDERAL R EGISTER (40 FR 11854) relating to the protection of human subjects in research, development, and related activities supported by Department of Health, Education, and Welfare grants and contracts. These regulations are codified at $45 \mathrm{CFR}$ Part 46. 
Elsewhere in this issue of the FEDERAL R EGISTER, the Secretary is amending 45 CFR Part 46 by, among other things, adding a new Subpart B to provide additional protections pertaining to research, development, and related activities involving fetuses, pregnant women, and in vitro fertilization.

Section 46.203(e) of Subpart B provides inter alia as follows:

The Secretary may from time to time. taking into account medical advances, publish in the FEDERAL R EgISTER guidelines to assist in determining whether a fetus is viable for purposes of this subpart.
This notice is published in accordance with $\S 46.203$ (e). For purposes of Subpart B, the guidelines indicating that a fetus other than a dead fetus within the meaning of $\S 46.203(\mathrm{~g})$ is viable include the following:

an estimated gestational age of 20 weeks or more and a body weight of 500 grams or more.

FEDERAL REGISTER, VOL 40 , AUGUST 8, 1975 


\section{Summaries of Federal Agencies' Rules and Procedures Governing Research with Human Subjects}

Policies and Procedures of Other Federal Agencies 121

American National Red Cross 121

Central Intelligence Agency 122

Consumer Product Safety Commission $\quad 124$

Department of Agriculture $\quad 125$

Department of Commerce 127

Department of Defense: $\quad 129$

Army 129

Navy $\quad 133$

Air Force $\quad 137$

Department of Education $\quad 142$

Department of Energy 143

Department of Housing and Urban Development 144

Department of Justice: $\quad 145$

Bureau of Prisons 145

Office of Justice Assistance, Research,
and Statistics

Department of Transportation: $\quad 149$

Coast Guard 149

Federal Aviation Administration $\quad 149$

Federal Highway Administration $\quad 150$

National Highway Safety Administration $\quad 151$

Environmental Protection Agency 153

National Aeronautics and Space Administration $\quad 154$

National Science Foundation 158

U.S. International Development Cooperation Agency 159

Veterans Administration 160 


\section{DEPARTMENT OF HEALTH AND HUMAN SERVICES (HHS)}

(See Appendix A for the full text of the HHS regulations)

\section{Research Conducted or Supported by HHS.}

HHS conducts and supports extensive biomedical and behavioral research.

Source: P.L. 93-348 (1974); 45 CFR 46 (revised January 26, 1981); DHEW Grants Administration Manual, Chap. 1-40; Public Health Service Instruction Booklet for Grant Application Form PHS 398 (rev. 5/80); NIH Handbook for Executive Secretaries (May 1980); NIH Orientation Handbook for Members of Scientific Review Groups (August 1981); 45 CFR 76 (October 9, 1980); letter (May 7, 1980) and chart (November 25, 1981) from Charles R. McCarthy, Director, Office for Protection from Research Risks.

Applicability: 45 CFR 46 applies to all research involving human subjects conducted or supported in whole or in part by HHS with the exception of categories of research specifically exempt (see below). "Human subject" is defined as a living individual about whom an investigator conducting research obtains (1) data through intervention or interaction with the individual, or (2) individually identifiable private information. Categories of research exempt from HHS regulations ( 45 CFR 46) include:

(A) Research conducted in established or commonly accepted educational settings, involving normal educational practices, such as (1) research on regular and special education instructional strategies, or (2) research on the effectiveness of or the comparison among instructional techniques, curricula, or classroom management methods.

(B) Research involving the use of educational tests (cognitive, diagnostic, aptitude, achievement), if information taken from these sources is recorded in such a manner that subjects cannot be identified, directly or through identifiers linked to the subjects.

(C) Research involving survey or interview procedures, except where all of the following conditions exist: (1) Responses are recorded in such a manner that the human subjects can be identified, directly or through identifiers linked to the subjects, (2) the subject's responses, if they became known outside the research, could reasonably place the subject at risk of criminal or civil liability or be damaging to the subject's financial standing or employability, and (3) the research deals with sensitive aspects of the subject's own behavior, such as illegal conduct, drug use, sexual be- 
havior, or use of alcohol. All research involving survey or interview procedures is exempt, without exception, when the respondents are elected or appointed public officials or candidates for public office.

(D) Research involving the observation (including observation by participants) of public behavior, except where all of the following conditions exist: (1) Observations are recorded in such a maner that the human subjects can be identifed, directly or through identifiers linked to the subjects, (2) the observations recorded about the individual, if they became known outside the research, could reasonably place the subject at risk of criminal or civil liability or be damaging to the subject's financial standing or employability, and (3) the research deals with sensitive aspects of the subject's own behavior such as illegal conduct, drug use, sexual behavior, or use of alcohol.

(E) Research involving the collection or study of existing data, documents, records, pathological specimens, or diagnostic specimens, if these sources are publicly available or if the information is recorded by the investigator in such a manner that subjects cannot be identified, directly or through identifiers linked to the subjects.

45 CFR 76 are the regulations concerning debarment and suspension from eligiblity for financial assistance.

\section{Review Procedures:}

(A) Local Review. Each institution engaged in research covered by 45 CFR 46 must provide written assurance satisfactory to the Secretary, HHS, assurance must at a minimum include (a) a statement of principles governing the institution in the fulfillment of its responsibilities for protecting the rights and welfare of human subjects, (b) designation of one or more Institutional Review Boards (IRBs) established in accordance with the regulations, and for which provisions are made for meeting space and sufficient staff to support the IRB's review and record keeping duties, (c) a list of IRB members by name, earned degrees, indications of experience, representative capacity, and relationship to the institution, and (d) written procedures for: (1) conducting initial and continuing review of research proposals and activities, and for reporting its findings and actions to the investigator and the institution, (2) determining which projects require review more often than annually and which projects need verification from sources other than the investigators that no material changes have occurred since previous IRB review, (3) reporting any proposed changes in a research activity to the IRB, and insuring that such changes are reviewed when necessary, and (4) the reporting of unanticipated problems involving risks to subjects or others, to the IRB and to HHS. 
The IRB must be competent to review the research proposals for conformity with institutional commitments and regulations, applicable law, and standards of professional conduct and practice. The IRB must be composed of no less than five persons of varying backgrounds sufficiently capable and qualified to review research proposals and activities commonly conducted by the institution. No IRB may consist entirely of men or of women; of officers, employees or agents of the institution; or of members of a single professional group. Each IRB must include at least one member whose primary concerns are in nonscientific areas.

Institutions submitting an application for research funds from HHS must certify that the proposal has been reviewed and approved by the appropriate IRB in conformity with the requirements set forth in 45 CFR 46 . IRB decisions must be made at convened meetings with a majority of members present, one of which must be a member whose primary concerns are in nonscientific areas. In order for the research to be approved, it must be approved by a majority of those IRB members present at the meeting.

An IRB may use an expedited review procedure in the case of specified categories of research when it finds that there is no more than minimal risk. Expedited review procedures may also be followed in the case of minor changes in previously approved research during the period for which approval is authorized. The Secretary has published in the Federal Register a list of categories of research activities that are eligible for expedited review if the IRB determines that they involve no more than minimal risk. Under an expedited review procedure, the review may be carried out by the IRB chairperson or by one or more experienced IRB members designated by the chairperson. The reviewers may exercise all the authorities of the IRB except that reviewers may not disapprove the research. Disapproval requires IRB review in accordance with non-expedited review procedures. Each IRB which uses an expedited review procedure shall adopt a method for keeping all members advised of research proposals that have been approved by expedited review.

(B) Agency Review. After the research institution certifies that the IRB has reviewed and approved a research proposal, the entire research plan is reviewed at the agency level by initial review groups ("study sections"). In addition to reviewing the scientific merit and soundness of each application, these review groups also consider aspects of the research related to the protection of human subjects.

Each application for research involving human subjects must include a description of: 
(1) criteria for subject selection or the sources of specimens or data from human subjects

(2) recruitment and consent procedures;

(3) potential risks to subjects;

(4) proposed procedures for protecting against or minimizing those risks;

(5) potential benefits to be gained by the subjects, as well as society in general; and

(6) the relation between the risks to subjects and the anticipated benefits.

Study Sections are directed to review the applicant's descriptions of those factors and to include in the "Summary Statement" of their review any concerns that members wish to express regarding the assessment of risks and benefits, the acceptability of the risks, the adequacy of measures to minimize or protect against risks, and the procedures for selection of subjects, recruitment, and consent.

Any problems identified by the scientific review bodies are brought to the attention of the appropriate National Advisory Council or Board (often after consultation with OPRR staff). Following scientific review, OPRR reviews each summary statement to determine whether problems relating to human subjects have been properly identified. Where problems exist, OPRR coordinates resolution of the problems by the appropriate funding institute or agency. No HHSfunded research with human subjects may be initiated before such problems are resolved.

HHS officials make the final decision as to whether or not the research will be funded, taking into account recommendations of the initial review groups and the advisory councils.

Review Standards: In order to approve research the IRB must determine that the following requirements are satisfied:

(1) the risks to subjects are minimized by using procedures consistent with sound research design and which do not unnecessarily expose subjects to risk, and whenever appropriate, by using procedures already performed on the subjects for diagnostic or treatment purposes;

(2) the risks to subjects are reasonable in relation to anticipated benefits, if any, to subjects, and the importance of the knowledge that may reasonably be expected to result;

(3) selection of subjects is equitable;

(4) informed consent will be sought from each prospective subject or the subject's legally authorized repre- 
sentative in accordance with, and to the extent required by the regulations;

(5) consent will be appropriately documented;

(6) where appropriate, the research plan makes adequate provision for monitoring the data collected to insure the safety of subjects;

(7) where appropriate, there are adequate provisions to protect the privacy of subjects and to maintain the confidentiality of data; and

(8) where some or all of the subjects are likely to be vulnerable to coercion or undue influence, such as persons with acute or severe physical or mental illness, or persons who are economically or educationally disadvantaged, appropriate additional safeguards have been included in the study to protect the rights and welfare of these subjects.

Research that has been approved by an IRB may be subject to further appropriate review and approval or disapproval by officials of the institution. However, those officials may not approve the research if it has not been approved by an IRB.

The IRB must have authority to suspend or terminate approval of research that is not being conducted in accordance with the IRB's requirements or that has been associated with unexpected serious harm to subjects. Any suspension or termination of approval must include a statement of the reasons for the IRB's action and be reported promptly to the investigator, appropriate institutional officials, and the Secretary.

Consent Provisions: Investigators are required to obtain the legally effective informed consent of the subject or the subject's legally authorized representative, before involving them in any research project covered by the regulations. Prospective subjects, in circumstances free from coercion or undue influence, must be given sufficient opportunity to consider whether or not to participate. Information must be provided in language that is understandable to the subject or to the subject's representative and a copy of the information provided and the signed consent form must be given to the subject or the subject's representative. No exculpatory language may be included.

(A) The Basic Elements of Information Necessary for Informed Consent.

(1) A statement that the study involves research, an explanation of the purposes of the research and the expected duration of the subject's participation, a description of the procedures to be followed, and 
identification of any procedures which are experimental;

(2) A description of any reasonably foreseeable risks or discomforts to the subject;

(3) A description of any benefits to the subject or to others which may reasonably be expected from the research;

(4) A disclosure of appropriate alternative procedures or courses of treatment, if any, that might be advantageous to the subject;

(5) A statement describing the extent, if any, to which confidentiality of records identifying the subject will be maintained;

(6) For research involving more than minimal risk, an explanation as to whether any compensation and an explanation as to whether any medical treatments are available if injury occurs and, if so, what they consist of, or where further information may be obtained;

(7) An explanation of whom to contact for answers to pertinent questions about the research and research subjects' rights, and whom to contact in the event of a research-related injury to the subject; and

(8) A statement that participation is voluntary, refusal to participate will involve no penalty or loss of benefits to which the subject is otherwise entitled, and the subject may discontinue participation at any time without penalty or loss of benefits to which the subject is otherwise entitled.

(B) Additional Elements of Informed Consent. When appropriate, one or more of the following elements of information must also be provided to each subject:

(1) A statement that the particular treatment or procedure may involve risks to the subject (or to the embryo or fetus, if the subject is or may become pregnant) which are currently unforeseeable;

(2) Anticipated circumstances under which the subject's participation may be terminated by the investigator without regard to the subject's consent;

(3) Any additional costs to the subject that may result from participation in the research;

(4) The consequences of a subject's decision to withdraw from the research and procedures for orderly termination of participation by the subject;

(5) A statement that significant new findings developed during the course of the research which may relate to the subject's willingness to continue participation will be provided to the subject; and 
(6) The approximate number of subjects involved in the study.

(C) Modification or Waiver of Consent Requirements. An IRB may approve a consent procedure which does not include, or which alters, some or all of the elements of informed consent set forth above, or waive the requirement to obtain informed consent provided the IRB finds and documents that:

(1) The research is to be conducted for the purpose of demonstrating or evaluating: (a) Federal, state, or local benefit or service programs which are not themselves research programs, (b) procedures for obtaining benefits or services under these programs, or (c) possible changes in or alternatives to these programs or procedures; and

(2) The research could not practicably be carried out without the waiver or alteration.

An IRB may also approve a consent procedure which omits or which alters some or all of the elements of informed consent, or waive the requirements to obtain informed consent provided the IRB finds and documents that:

(1) The research involves no more than minimal risk to the subjects;

(2) The waiver or alteration will not adversely affect the rights and welfare of the subjects;

(3) The research could not practicably be carried out without the waiver of alteration; and

(4) Whenever appropriate, the subjects will be provided with additional pertinent information after participation.

(D) Documentation of Informed Consent. Informed consent must be documented by the use of a written consent form approved by the IRB and signed by the subject or the subject's legally authorized representative. The documentation of consent may take one of two forms. The consent document must either contain all the basic elements of informed consent or else state that the elements of informed consent have been presented orally. In the latter case the IRB must approve a written summary of what is to be presented orally and there must be a witness to the oral presentation who must sign both the short form and a copy of the summary. The subject or the subject's representative must always be given adequate opportunity to read the consent form before signing it and must be provided with a copy of the document. When a short form is used, a copy of the summary must be provided as well.

An IRB may waive the requirement for the investigator to obtain a signed consent form if it finds: (1) that the only 
record linking the subject and the research would be the consent document and the principal risk would be potential harm resulting from a breach of confidentiality or (2) that the research presents no more than minimal risk and involves no procedures for which written consent is normally required outside of the research context. In cases where the requirement for documentation of consent is waived, the IRB may require the investigator to provide subjects with a written statement regarding the research.

Special Subjects: Additional protections and special procedures are required for research involving prisoners and for research involving fetuses, pregnant women, and human in vitro fertilization. The sorts of research that these subjects may be involved in is restricted and the IRB is required to make additional determinations before approving any research that involves such subjects. See 45 CFR 46 Subpart B for the additional protections pertaining to research, development, and related activities involving fetuses, pregnant women, and human in vitro fertilization. See 45 CFR 46 Subpart $C$ for the additional protections pertaining to biomedical and behavioral research involving prisoners as subjects.

Sanctions: The Secretary may terminate or suspend funding if an institution has materially failed to comply with the terms of HHS regulations (45 CFR 46). Debarment regulations (45 CFR 46) set forth procedures for temporary suspension of institutions or individuals from eligibility under HHS discretionary programs for financial assistance. Causes for debarment include fiscal mismanagement, conviction for any criminal offense related to obtaining a contract or performing under a contract, and serious violation of any applicable statute, regulations, or other terms or conditions of a previous award of financial assistance. The final decision to debar rests with the Secretary of HHS and "shall be rendered solely in the best interest of the Government." The HHS debarment provisions do not refer specifically to noncompliance with regulations for the protection of the rights and welfare of human subjects.

Reporting of Injuries and Complaints: Prior to July 1981, HHS regulations required that unanticipated problems involving risks to subjects be reported to IRBs; the regulations which became effective July 27, 1981 specifically require institutions to have procedures for reporting unanticipated problems involving risks to subjects or others to the Office for Protection from Research Risks (OPRR). Furthermore, IRBs now are required to report to appropriate institutional officials as well as to OPRR any cases of serious or continuing noncompliance. If the problems involve drugs or medical devices they are also to be reported to the FDA. 
In 1979-81 OPRR received nineteen reports of alleged noncompliance with the regulations. In three cases no action was necessary because the incident proved to be unfounded or unverifiable. In two cases the institution's response to the problem was considered adequate and no further action was required. In two cases an institution has been required to correct its review procedures and in one case an institution has been suspended from participation in a cooperative oncology study. OPRR has twice taken action against an investigator; one investigator has been cautioned, another researcher has had special restrictions and conditions attached to research funds. Nine cases are still under investigation or awaiting a decision regarding Departmental action. In one of these cases, however, the research contract has been partially terminated and the investigators reprimanded and restrictions imposed.

In addition, OPRR received four reports in 1979-81 of alleged research injuries. In two cases where the injury was either minor or left no permanent ill effects, further investigation was not required. A case in which death was allegedly connected with the use of an FDA approved drug for an unapproved purpose was investigated by the State mental health department. It was determined that the activity was not research and the physician was cautioned that, in the future, review by an appropriate committee in the State mental health department is required. In another case, clearly involving the death of a research subject, an NIH investigation established that death was caused by an underlying condition (not disclosed by the subject) which contraindicated participation in the research.

\section{The Food and Drug Administration (FDA)}

Source: 21 CFR 50, 56, 812, 813 [Intraocular lenses] 312.1, 16 (January 27, 1981); FDA Compliance Program Guidance Manual: Institutional Review Board Program 7348.809, transmittal 80-30, (April 14, 1980).

Applicability: The FDA regulations (21 CFR 56) apply to clinical investigations involving human subjects conducted (1) pursuant to requirements for prior submission to FDA or (2) in support of applications for permission to conduct further research or to market regulated products (e.g., drugs, biologicals, medical devices). These regulations, with a few exceptions, conform with HHS regulations (45 CFR 46).

21 CFR 50 sets forth requirements for informed consent.

21 CFR 312 governs investigational use of new drugs. 
21 CFR 812 governs investigational medical devices.

21 CFR 16 provides procedures for regulatory hearings before the FDA.

21 CFR 56 governs the organization, composition, and function of IRBs.

Under most circumstances investigations that commenced before July 27,1981 are exempt from the IRB review requirements of 21 CFR 56. The emergency use of a test article is also exempt from the IRB review requirements provided that such emergency use is reported to the IRB within five working days. Any subsequent use of the test article at the institution is subject to IRB review.

Review Procedures: The composition and review procedures of the IRB conform with HHS regulations (45 CFR 46). Although IRB certification of review is required in the case of intraocular lens investigations, certification is not required in the case of drugs and biologics. FDA neither negotiates assurances with institutions nor conducts agency review of individual research proposals of the sort conducted by HHS.

Review Standards: The review standards conform with those of HHS regulations (45 CFR 46).

Consent Provisions: In addition to the basic elements of informed consent that are required by HHS regulations ( 45 CFR 46), FDA requires that subjects be informed of the possibility that their records will be inspected by FDA. The obligation to obtain informed consent is exempt from the general informed consent requirements if both the investigator and a physician who is not otherwise participating in the clinical investigation certify in writing all of the following:

(1) The human subject is confronted by a lifethreatening situation necessitating the use of the test article;

(2) Informed consent cannot be obtained from the subject because of an inability to communicate with, or obtain legally effective consent from, the subject;

(3) Time is not sufficient to obtain consent from the subject's legal representative; and

(4) There is available no alternate method of approved or generally recognized therapy that provides an equal or greater likelihood of saving the life of the subject.

If immediate use of the test article is, in the investigator's opinion, required to preserve the life of the subject, and time is not sufficient to obtain the independent determinations described above, in advance of using the test article, the clinical investigator may make the necessary determinations to be reviewed and evaluated in writing within 
five days by a physician who is not participating in the clinical investigation.

The documentation required must, in all instances, be submitted to the IRB within five working days after the use of the test article.

Sanctions: Administrative sanctions for apparent noncompliance with FDA regulations in the operation of an IRB include:

(1) withholding approval of new studies at an institution;

(2) directing that no new subjects be added to studies underway;

(3) termination of studies underway when doing so would not endanger the subjects; and

(4) when the apparent noncompliance creates a significant threat to the rights and welfare of human subjects, notify relevant state and federal regulatory agencies and other parties with a direct interest in the agency's action of the deficiencies in the operation of the IRB.

The Commissioner of FDA may disqualify an IRB or an institution if, following a regulatory hearing, the Commissioner determines that: (1) the IRB has refused or repeatedly failed to comply with any of the regulations, and (2) the noncompliance adversely affects the rights or welfare of the human subjects in a clinical investigation.

If an institution or its IRB that reviewed the investigation refuses to allow an inspection, the FDA may refuse to consider a clinical investigation in support of an application for a research or marketing permit.

Principal investigators may also be disqualified for noncompliance with FDA regulations. FDA has disqualified 42 investigators since $1964 ; 26$ of these within the last five years.

Reporting of Injuries and Complaints: Investigators are required to report "any adverse effect which may reasonably be regarded as caused by, or is probably caused by, the new drug" to the sponsor. The sponsor of the research is required to promptly investigate and report to the FDA and to all investigators " $\ldots$ any findings associated with (the) use of the drug that may suggest significant hazards, contraindictions, side-effects, and precautions pertinent to the safety of the drug." These reports, when received by the FDA, are reviewed by the appropriate Reviewing Division to determine the appropriate course of action. Although an accurate count of the number of the reports received annually by the FDA is not available, a conservative estimate is in the hundreds. 


\section{POLICIES AND PROCEDURES OF OTHER FEDERAL AGENCIES}

\section{The American National Red Cross}

The Red Cross conducts clinical research related to its blood program. This may include studies of the motivation of blood donors or clinical trials related to HHS grants or studies necessary for the licensure of new products by FDA.

Source: Blood Services Directive 4.38 (revised December 1981); letter to the National Commission (November 17, 1977) from George M. Elsey, President; letter (April 15, 1980) from Jerome H. Holland, Ph.D., Office of the Chairman; letters (July 28, 1981, and December 15, 1981) from George M. Elsey.

Applicability: Blood Services Directive 4.38 is applicable to all Red Cross research studies involving human subjects or materials of human origin. Exception: Certain procedures found by the Red Cross Headquarters Committee for the Protection of Human Subjects not to involve risk may be exempt from local review requirements, provided HHS funds or FDA regulations are not involved. Procedures specifically exempted include the nonclinical use of blood components derived from units of blood collected from Red Cross donors in the normal course of blood center activities; removal for nonclinical studies of up to forty-five milliliters of additional whole blood subsequent to the donation of a unit of blood, through the same venipuncture; and the nonclinical use of commercial blood or blood components or blood collected previously in the course of routine clinical procedures, or another approved research project.

Review Procedures: The Red Cross requires that local review boards be established in conformity with procedures set forth in the HHS regulations (45 CFR 46) but permits either the regional blood center or the collaborating institution to fulfill these requirements. Either institutions or Red Cross regional centers may submit proposals for local review to an Institutional Review Board (IRB) with an approved assurance on file at HHS. Alternatively, research proposals from the Washington, D.C., metropolitan region blood center may be submitted directly to the National Red Cross Committee for the Protection of Human Subjects for review. This committee has an approved general assurance on file at HHS and therefore complies with HHS regulations (45 CFR 46). 
In the case of research that is neither funded by HHS nor regulated by FDA, the Red Cross requires that the research be approved by a local IRB that is in conformity with HHS regulations ( 45 CFR 46). The IRB is not required to have an approved general assurance on file with HHS; however, the FDA and the Red Cross conduct periodic inspections of the implementation of all Red Cross directives at regional centers.

Review Standards: The Red Cross requires compliance with the IRB review standards of HHS regulations (45 CFR 46).

Consent Provisions: The Red Cross requires compliance with HHS informed consent regulations ( 45 CFR 46). In addition, it is Red Cross policy that when abnormalities are found in the course of conducting studies on blood obtained from donors, the principal investigator is obliged to inform the donor of such abnormalities and to keep the information confidential "unless specifically released in writing by the donor or a legally appointed representative of the donor."

Sanctions: No specific provisions are made for sanctions in the case of noncompliance.

Reporting of Injuries and Complaints: The Red Cross reports no injuries or complaints during FY 1976-1981.

\section{Central Intelligence Agency (CIA)}

The CIA conducts and supports biomedical and behavioral research.

Source: Executive Order 12333 (December 4, 1981); Regulation $7-1 \mathrm{c}(1)(\mathrm{k})$ (revised January 16, 1981); letter (June 16, 1980) from Frank C. Carlucci, Acting Director; letter (July 23, 1981) from William J. Casey, Director; letter (November 24, 1981) from Bernard M. Malloy, M.D., Liaison Officer to the Commission.

Applicability: The Executive Order requires that all research conducted or sponsored by the Intelligence Community comply with the HHS regulations (45 CFR 46). * Regulation $7-1 \mathrm{c}(1)(\mathrm{k})$ incorporates the requirements of the

\footnotetext{
* Executive Order 12333, Part 3.4(f), defines the Intelligence Community as consisting of:
}

(1) The Central Intelligence Agency;

(2) The National Security Agency; .

(3) The Defense Intelligence Agency; 
Executive Order into the operating regulations of the CIA. The provisions concerning research with human subjects that appear in.Executive Order 12333 are unchanged from those of Executive Order 12036 of January 24, 1978.

Review Procedures: The CIA adheres to the provisions of HHS regulations ( 45 CFR 46). Contractors are required to provide a formal institutional assurance of compliance with HHS regulations (45 CFR 46), certification of IRB approval of the proposed research, the identity and qualifications of IRB members, and a copy of the IRB approved consent release. These items are subject to review and approval by the Director through an Agency Human Subject Research Panel (HSRP). The HSRP disseminates procedural instructions and information necessary for the establishment and operation of IRBs; it promotes compliance with Regulation 7-1 by standardizing the information required for documentation and certification; and it evaluates all documentation and certification pertaining to human research sponsored or conducted by the CIA. The monitoring of compliance includes evaluation of initial and ongoing reviews conducted by the IRB.

Continuing review is conducted at least annually by the research program managers. Site visits are undertaken where applicable.

Review Standards: The CIA requires that those conducting the research adhere to HHS regulations (45 CFR 46).

Reporting of Injuries and Complaints: The CIA reports that although there have been no complaints arising from research conducted during FY 1976-1981, two complaints regarding research conducted during the late 1950's have recently been filed: Don Roderick Scott, et al. v. William Casey, et al., Civil Action Number C-81-29A [N.D. Ga]; and Mrs. David Orlikow, et al. v United States, Civil Action Number 80-3163 [D.D.C.].

(4) The offices within the Department of Defense for the collection of specialized national foreign intelligence through reconnaissance programs;

(5) The Bureau of Intelligence and Research of the Department of State;

(6) The intelligence elements of the Army, Navy, Air Force, and Marine Corps, the Federal Bureau of Investigation, the Department of Treasury, and the Department of Energy; and

(7) The staff elements of the Director of Central Intelligence. 


\section{Consumer Product Safety Commission (CPSC)}

The Consumer Product Safety Commission supports research to determine safety standards for consumer products.

Source: 16 CFR 1028 (42 Federal Register 36819, July 18, 1977); letter (June 12, 1980) from Susan B. King, Chairman; letter (July 30, 1981) from Margaret A. Freeston, Acting General Counsel.

Applicability: The regulations apply to all grants or contracts or other agreements supporting research or related activities in which human subjects are involved. Exception: The regulations are not applicable to opinion surveys, questionnaires, or solicitation of information about past events.

Review Procedures: CPSC adopts the HHS provisions (45 CFR 46) for establishment of Institutional Review Boards (IRBs). Grantees or contractors may utilize an IRB having an approved general assurance on file at HHS or, alternatively, may submit an assurance directly to CPSC for approval, following the same procedures and requirements as those required by the HHS regulations.

CPSC reviews applications to determine either that the applicant institution has an approved general assurance on file at HHS or, alternatively, to ascertain compliance with requirements for an assurance negotiated directly with CPSC. In addition, CPSC submits proposals for further evaluation to such consultants and staff as it deems appropriate. Such evaluation may take into account, among other pertinent factors, the apparent risk to subjects, the adequacy of protection against risks, the potential benefits of the research to the subjects and to others, and the importance of the knowledge to be gained. CPSC may impose additional safeguards for the protection of human subjects (such as restrictions on the use of certain subjects or groups of subjects or the use of additional procedures for informed consent). Consent forms developed by the contractor are reviewed and approved by staff.

Review Standards: CPSC applies the review standards of the HHS regulations, with the following addition: the IRB must determine that "a qualified psychologist, doctor of medicine, or other appropriate professional, having established emergency medical procedures, will oversee each test."

Consent Provisions: CPSC generally follows the consent provisions of the HHS regulations. All signed consent forms are returned to the Commission.

Sanctions: CPSC may withhold or withdraw grant or contract funds if an investigator or institution fails materi- 
ally to discharge its responsibility for the protection of the rights and welfare of human subjects.

Reporting of Injuries and Complaints: The CPSC reports no injuries or complaints during FY 1976-1981.

\section{Department of Agriculture}

The Department of Agriculture conducts and supports biomedical and behavioral research related to human nutrition and health and safety.

Source: Administrative Memorandum No. 130-2 (November 26, 1976); Administrative Memorandum 730 (November 26, 1976); Administrative Memorandum 130-3 (July 11, 1977); letter (April 7, 1980) from Bob Bergland, Secretary; letter (July 8, 1981) from John R. Block, Secretary. The policies of the Department of Agriculture are currently under revision to bring them into conformity with HHS regulations (45 CFR 46).

Applicablity: Administrative Memorandum No. 130-2 applies to research involving human subjects conducted or supported by the Agricultural Research Service and the Cooperative State Research Service of the Department of Agriculture. It is specifically applicable to "economic, social and behavioral research that may involve varying degrees of discomfort, irritation, or harrassment of persons or groups and to research in which rights of privacy of persons must be safeguarded" in addition to "biological science research." Administrative Memorandum No. 130-2 is applicable to all such research conducted or supported by the Department of Agriculture, and sets forth departmental review procedures and responsibilities. Administrative Memorandum 730 sets forth additional requirements for certain taste test and quality evaluation studies. Administrative Memorandum 130-3 applies to research conducted at a facility for metabolic studies in human nutrition.

Review Procedures: The Department of Agriculture requires that IRBs be established in conformity with procedures set forth in the Institutional Guide to DHEW Policy on Protection of Human Subjects, but requires IRB review of all studies involving human subjects, thus bringing its policy in conformance with HHS regulations (45 CFR 46). * This requirement may be fulfilled by an IRB having an approved general assurance on file with HHS or, alternatively, by an IRB with similar composition and duties whose compliance with HHS regulations is "ascertained" by the De-

* The major substantive difference between the Guide and the present regulations ( 45 CFR 46 ) is that the former applied only to research projects determined by the investigator to involve subjects at risk, whereas the latter applies to all research involving human subjects except certain categories specifically exempted by the Secretary, HHS. 
partment of Agriculture. (No procedures for doing so are provided.)

Documentation of IRB review and approval must be forwarded to the Human Studies Review Committee in the Agriculture Research Service which reviews all research proposals involving human subjects conducted or supported by the Department of Agriculture. No medical or biological research involving human subjects may be initiated without written approval of this committee. Written progress reports must be submitted by the investigator. Where appropriate, a study may also require review by the Human Metabolic Unit Oversight Committee. Either committee (Human Studies or Metabolic Unit) may require termination of a study if deemed necessary for the safety and protection of human volunteers. Approval of the Human Studies Committee is also required for taste tests and quality evaluation studies involving food additives or chemicals not "generally recognized as safe" by the FDA and for studies involving pesticides or other chemical residues for which the acceptable level has not yet been established. Exempt from review. by the committee are consumer acceptance tests that require prior approval by the FDA.

Review Standards: Review standards are those stated in the 1971 Guide to DHEW Policy on Protection of Human Subjects, with the following addition. Selections of persons or groups for study must be made "without regard to sex, race, color, religion, or national origin unless these characteristics are factors to be studied." Any investigation that includes such characteristics as factors for classification must be approved in writing by the director of the responsible agency.

Consent Provisions: The Agriculture Research Service adopts the consent provisions set forth in the Guide to DHEW Policy on Protection of Human Subjects.

Special Subjects: No pregnant or lactating women may be included in studies to evaluate the safety or nutritional qualities of foods or in taste tests involving food additives or chemcials that are not listed by FDA as "generally recognized as safe" or that involve residues of pesticides or other chemcials for which an acceptable level has not been established by FDA, the Environmental Protection Agency or the Animal and Plant Health Inspection Service. Children may participate in taste tests and quality evaluation studies only with the written approval of their parents.

Sanctions: No provisions are made for sanctions in the case of noncompliance.

Reporting of Injuries and Complaints: The Department of Agriculture reports no injuries or complaints during FY 1976-1981. 


\section{Department of Commerce}

\section{National Bureau of Standards}

The Bureau of Standards conducts research related to product safety; environmental measurements and standards for air, water and noise pollution, and radiation safety; prosthetic devices; materials for dental research; mine safety; and lead paint poisoning control. Much of the research conducted by the Bureau of Standards is at the request of various regulatory agencies.

Source: NBS Administrative Manual 3.01 Appendix A (as amended May 25, 1979); NBS Policy Bulletin No. 12 (February 14, 1975); letter (April 22, 1980) from Clifford J. Parker, Acting Director of Personnel, Department of Commerce.

Applicability: The policy applies to research conducted or supported by the Bureau of Standards where human subjects are used or humans are involved in any role other than that of investigator.

Review Procedures: A Human Research Ethics Committee, appointed by the Director of the Bureau of Standards, reviews all research proposals involving human subjects. Members include federal employees both from within the Bureau and from outside, with a broad range of expertise. Among the five members, there must be at least one medical doctor, one behavioral scientist, and one engineer or physical scientist. Two alternate members are appointed to serve in the absence of a regular member or in cases when a regular member cannot vote because of conflict of interest. "Line managers" in the organizations performing human research may serve as members, but they are excluded from deliberations concerning such research performed within their organizations. No individual may serve as a committee member where he or she is a principal investigator or is directly associated with the proposed research. The chairperson of the committee may request advice or information from the Office of the Legal Advisor or other organizations within the Bureau of Standards as well as anyone outside the Bureau. Recommendations for approval require unanimous concurrence of the five committee members (or alternates serving in their place).

The Bureau of Standards' Human Research Ethics Committee is responsible for initial review and ongoing monitoring of all research. The committee serves in an advisory capacity to the Director of NBS. The committee may discuss proposed research with the principal investigator, negotiate modifications with the investigator, and recommend approval or disapproval of the research to the Director of the Bureau of Standards or his designee. The authority of the 
Director or his designee to approve or disapprove research may not be delegated to a member of the committee.

Review Standards: Review by the Human Research Ethics Committee is limited to concerns of an ethical nature; review for technical soundness is performed through other supervisory channels. The ethics review is designed to protect the physical and psychological well-being of subjects, to assure that Bureau of Standards' policies are observed, and to protect the Bureau against errors in ethical judgment that might result in harm to subjects, lawsuits and/or adverse publicity. Subjects must be protected against an unreasonable degree of physical danger or psychological distress. As required by the Privacy Act, provisions are made to protect the confidentiality of records pertaining to individual research subjects. Adequate preparations must be made for treatment of injuries that may occur.

Consent Provisions: Subjects must be provided with all the information that is likely to influence their willingness to participate, as well as with explanations of any other aspects about which they inquire. They must sign a form which explains the responsibilities of both subjects and investigators and which makes explicit the subjects' right to withdraw at any time "without incurring legal liability." Prospective subjects must be free from undue pressure, coercion or temptation by excessively high rewards of a monetary or any other nature. Data may not be used for any purpose other than that described to the subjects without their written consent.

If the "control of the expectations of subjects with respect to the purpose of the research, the design of the research, or the specific events which will occur during the course of the research" is necessary in order to obtain useful data and reach valid conclusions, such "control" is permissible provided the review committee determines that: (a) it is absolutely necessary to the success of the research; (b) the personal safety and dignity of the subjects are not compromised; (c) there is good reason to believe that it would be irrelevant to the subjects' decisions to participate in the research; and (d) the subjects are debriefed in a manner and at a time that is maximally compatible with their well-being and with the success of the research.

Special Subjects: If the proposed subjects are not legally, psychologically or intellectually capable of giving informed consent because of age or any other reason, the committee must ascertain whether it is appropriate to use such subjects and, if so, shall insure that lawful consent is obtained from the parent or legal guardian. In such cases, the committee must consult with the Bureau of Standards' Legal Advisor. 
Sanctions: No provisions are made for sanctions in the case of noncompliance.

Reporting of Injuries and Complaints: The principal investigator is required to inform the Director of NBS and the chairperson of the committee immediately of any accident involving injury to any human subject participating in NBS research; within 10 days the committee must review the protocols in effect and recommend any changes that may be deemed appropriate to the Director and the principal investigator. The Director will then approve or disapprove the recommended changes and communicate such approval or disapproval to the chairperson of the committee and to the principal investigator.

Two injuries have been reported since the guidelines were first implemented in 1975. One was an alleged back injury during research developing portability guidelines for the FTC; similar experiments were reviewed closely to prevent similar injuries. The other injury involved a fall by a participant in a study of "Emergency Egress from Mobile Homes." As injuries of this type had been anticipated, the study was not changed; however, the participant agreement was modified to explain the risks more clearly.

\section{Department of Defense (DOD)}

Source: Letter (May 12, 1980) from William S. Augerson, Major General, MC, USA, Deputy Assistant Secretary of Defense (Health Resources and Programs); memorandum (July 23, 1981) for Captain Flynn from Phillip E. Winter, Colonel, MC, USA, Military Assistant for Medical and Life Sciences. A Department of Defense directive concerning the conduct of biomedical or behavioral research involving human subjects is currently in draft form; release is expected early in 1982 . The proposed directive will, in principle, conform with HHS regulations ( 45 CFR 46). Until the departmental policy goes into effect until the individual branches of the DOD will follow the guidelines set forth below.

Review Procedures: Review of research is the responsibility of the commander of the facility at which the research is being conducted.

Reporting of Injuries and Complaints: Dealing with complaints is a command responsibility. There are no central records of injuries or complaints.

\section{Army}

The Army conducts and supports extensive biomedical and behavioral research involving human subjects, including basic research and clinical investigations. 
Source: U.S. Army Regulation 70-25 (July 31, 1974); Army Regulation 40-7 (April 4, 1975); Army Regulation 40-38 (amended September 1, 1975); Office of the Surgeon General Regulation 15-2 (September 28, 1981); U.S. Army Medical Research and Development Command Regulation 70-25 (April 27, 1981); Memorandum of Understanding Between the Food and Drug Administration (FDA) and the Department of Defense (39 Federal Register 41570, November 27, 1974); Armed Services Procurement Regulation, DAR 1-604 (May 15, 1980); letter (October 15, 1981) from Roger A. Bennett, LTC, MSC, Chief, Human Use Review Office.

Applicability: Army Regulation $70-25$ is applicable world-wide to intramural research wherever human volunteers are used as subjects. Army Medical Research and Development Command Regulation $70-25$ is applicable world-wide to all intramural research and to research supported by Army grants and contracts, regardless of Army appropriation source. Regulation $40-7$ applies to the investigational use of drugs and the use of Schedule I controlled drug substances whether such use occurs intramurally or by grant or contract. Army Regulation 40-38 applies to the clinical investigation program. Office of The Surgeon General Regulation 15-2 describes the standards and procedures for review and approval of research and clinical investigation protocols involving human subjects by the Surgeon General's Human Subjects Research Review Board. The Memorandum of Understanding Between the Food and Drug Administration and the Department of Defense applies to clinical investigations involving drugs that are classified for reasons of national security, and waives the requirement to file a formal "Claim for Exemption" otherwise imposed by FDA. * Research conducted or supported by Army Intelligence is governed by the directives of the Intelligence Community (see p. 122). The Armed Services Procurement Regulation, DAR 1-604 concerns the conditions for debarment and suspension.

The Army adopts the exemptions of the HHS regulations ( 45 CFR 46 ) as revised January 26,1981 . In addition, the following activities are not covered by the Army regulations concerning research with human subjects: flight training, jump training, marksmanship training, ranger training, fire drills, gas drills, handling of explosives, normal training or other military duties as part of an experiment wherein disclosure of experimental conditions to participating personnel would reveal the artificial nature of such conditions and defeat the purpose of the investigation, and epidemiological studies.

*The Department of Defense reaffirmed on May 12, 1980, that it has never invoked this special exemption. 
Review Procedures: The Army adopts the review procedures set forth in the HHS regulations ( 45 CFR 46). Medical centers, grantees or contractors may utilize an Institutional Review Board with an approved assurance on file at HHS, or they may establish an IRB that complies with the provisions of HHS regulations and submit assurance of such compliance to the Army. Prior to approval of any new contract involving risk to human subjects, a site visit shall be conducted by at least two representatives of the command, to determine whether or not the technical provisions as well as the provisions for the protection of human subjects can be met. Committees established to review intramural research must include, whenever possible, at least one lawyer and one clergyman. Intramural research is reviewed by local committees prior to submisssion to the Human Use Review Office in Washington, just as extramural research is reviewed by IRBs.

A Human Use Review Office, under the direction of the Assistant Surgeon General for Research Development, is the central Army processing point for all extramural and intramural research involving human subjects. The staff includes two pharmacists and a biostatistician. Additional outside review and advice may be sought, including supervision of the review by a physician.

Local commanders and the Inspector General are responsible for determining compliance of medical hospitals with directives from the Surgeon General; yearly site visits by Headquarters personnel ensure compliance of research laboratories. Annual reports must be submitted to the Human Use Review Office.

All protocols (except those deemed to be of low risk by the Human Use Review Office) * are reviewed by a Human Subject Review Board. This board is composed of the Assistant Surgeon General for Research and Development, or his designee; seven consultants (expert in medicine, surgery, pharmacy, behavioral science, preventive medicine, allied medical sciences, and infectious disease); a chaplain; an attorney; and two community representatives. The board's recommendations for approval or disapproval (including any dissenting opinions) are forwarded to the Surgeon General who makes the final decision regarding each protocol.

* Studies deemed to be of low risk include analysis of hair, nail clippings, or deciduous teeth; collection of external excretions; recording of data by physical sensors applied superficially (EEG, EKG); and collection of no more than $450 \mathrm{ml}$. of blood within a six week period from subjects who are over 18 years of age and not anemic. 
Although most of the intramural research involving human subjects is conducted either in Army hospitals or in Army research laboratories, the regulations are applicable to all components of the Army. The Surgeon General has encouraged all agencies to construe the language of the regulations broadly, to include, for example, soldier test of uniforms, artillery pieces, vehicles and other equipment, when such tests put participants at more than minimal or at unusual risk. Tests from any Army component that may expose human subjects to risk are reviewed by the Human Use Review Office in the same manner as research conducted under the auspices of the Medical Research and Development Command. High risk exposure tests are acted upon by the Surgeon General's Human Subjects Research Review Board.

Review Standards: The Army adopts the review standards of the HHS regulations. In addition to meeting such standards, all studies conducted or supported by the Army must meet scientific standards including: (1) use of the minimum number of human subjects necessary to achieve the required results; (2) performance of appropriate laboratory and animal studies prior to involving human subjects; (3) avoidance of all unnecessary physical and mental discomfort; (4) proper preparations and adequate facilities to handle any foreseeable injuries; and (5) appropriate qualifications of principal investigators and those assisting in the research.

Consent Provisions: Provisions governing informed consent are those of the HHS regulations, supplemented as follows. All consent forms must contain the appropriate data required by the Privacy Act of 1974 . Provisions must normally be made for debriefing subjects following their participation in research; this is mandatory for research involving deception. Additional provisions are made for consent to research involving special subjects, as described below.

Special Subjects: Special protections and restrictions apply to research involving children, pregnant women, prisoners, ${ }^{*}$ the institutionalized mentally infirm and mentally disabled subjects, including:

(1) limitation of research to projects that either will benefit the subjects directly or cannot be conducted on any other subject population;

(2) requirement for consent of children and mentally incompetent subjects, in addition to the consent of a legal

*The Assistant Surgeon General for Research and Development has written the National Commission (November 28, 1977) that by current policy, prisoners and others with restricted civil liberties are not regarded as acceptable subjects of research. 
guardian, when such subjects are able to express an opinion regarding their participation in research;

(3) adequate living conditions, employment opportunities and medical care in any prison proposed as a research site; and

(4) a site visit by a senior medical officer and a member of the Army's legal staff to any prison or mental institution proposed as a research site. Prisoners of war may not be used as research subjects under any circumstances.

Compensation: The regulations provide that civilian or military volunteers may be treated for research-related injuries in Army medical facilities and that military personnel are eligible for workers' compensation.

Additional Provisions: Research involving nuclear, biological, or chemical threat agents must be approved by the Secretary of the Army after review by the Surgeon General's Human Subjects Research Review Board.

Research conducted abroad must comply with Army regulations as well as with all laws and customs of the country in which the research will be conducted. If, in exceptional circumstances, the laws or customs of the country involved would render a particular provision of Army regulations unacceptable, a waiver may be granted by Army Medical Research and Development Command Headquarters following a site visit by a senior medical officer and a member of the legal staff.

Sanctions: In cases of noncompliance, civilian contractors are subject to debarment from Armed Services contracting under DAR 1-604 et seq. Military members are subject to administrative, non-judicial, and in flagrant cases judicial sanctions.

Reporting of Injuries and Complaints: The principal investigator is responsible for immediately reporting to the Surgeon General any alarming adverse effects. Changes and unanticipated problems in a research activity, as well as any change of investigators must also be reported.

\section{Navy}

The Navy conducts and supports biomedical and behavioral research related to basic factors underlying health and disease, effects of environmental stress, methods for studying biological systems and for diagnosing, treating and preventing disease or injury, basic psychological functions, psychological response to stress, and group behavior.

Source: Secretary of the Navy Instruction 3900.39A (March 20, 1978); Bureau of Medicine and Surgery Instructions 6000.4C (September 20, 1976) and 3900.6 (April 2, 1976); Memorandum of Understanding Between the Food 
and Drug Administration and the Department of Defense (39 Federal Register 41570, November 29, 1974); Office of Naval Research Instruction 3900.34A (February 28, 1979); Office of Naval Research Guide for Protection of Human Subjects (October 1978); letter (October 16, 1981) from J.R. Schmidt, Director of Programs and Scientific Advisor.

Applicability: Secretary of Navy Instruction 3900.39A applies to the utilization of human subjects in Navysupported studies conducted either by other government activities or by contractors and in experiments conducted in Navy activities regardless of the source of funding. The use of personnel as operators in the test and evaluation of vehicles, equipment and materials, e.g., test pilots and parachute test jumpers, is exempt from the provisions of this instruction unless the primary purpose of a particular experiment is the effect of the experimental item on a human subject. Bureau of Medicine and Surgery Instruction 3900.6 applies to medical research "performed at BUMEDmanaged activities irrespective of the source of funding support" if such research entails risk to subjects as a result of their participation. Bureau of Medicine and Surgery Instruction $6000.4 \mathrm{C}$ applies to the intramural Clinical Investigation Program conducted at Navy regional medical centers, with the exception of "those research proposals that are unique to the operational mission of the Navy and Marine Corps (militarily relevant), which may be approved and supported through the Director of Defense Research and Engineering." The Memorandum of Understanding Between the Food and Drug Administration and the Department of Defense applies to clinical investigations involving drugs that are classified for reasons of national security, and exempts such research from the filing of a formal "Claim for Exemption" with FDA. * The Office of Naval Research Guide and Instruction 3900.34A implements those provisions of the Secretary of the Navy Instruction 3900.39A that concern the utilization of human subjects in Navysupported contracts other than those involving use of Navy or Marine Corps personnel or employees of the Department of the Navy.

Review Procedures: The Navy adopts the review procedures of HHS regulations ( 45 CFR 46) as they existed prior to the January 1981 revisions of those regulations. Although Navy regulations refer to the 1971 Institutional Guide to DHEW Policy on Protection of Human Subjects the review procedures required by the Navy are those of the HHS regulations. (The only substantive difference between the Guide and the regulations, on the matter of review procedures, is

*The Department of Defense reaffirmed on May 12, 1980, that it has never invoked this special exemption. 
whether IRB review is required for all research involving human subjects, or only for research involving risk to human subjects. By requiring that all research involving human subjects be reviewed by an IRB, the Navy has adopted the standard of the HHS regulations.)

Clinical investigation proposals are submitted from local medical departments, through the Regional Clinical Investigation Center, to the Director of Clinical Investigation, who serves under the Commanding Officer of the Naval Health Sciences Education and Training Command. Proposals must be reviewed for compliance with all applicable directives and approved by the Regional Clinical Investigation Center prior to submission (with a priority score) to the Health Sciences Education and Training Command for review, approval and funding. Annual progress reports are required, and changes in research personnel, objectives or funding requirements must be reported within a reasonable amount of time. Reports are also required when a project is terminated (explaining the reasons for termination) or when a project is completed.

Each contractor which engages or intends to engage in research projects involving human subjects must establish an IRB whose composition and review procedures conform with HHS regulations ( 45 CFR 46). Prior to the award of a contract by the Office of Naval Research, (1) the proposed protocol and the contractor's IRB must be approved by the Office of Naval Research, and (2) the organization applying for a contract or sponsoring an individual applying for such a contract must provide, as part of the protocol, written assurances that it will abide by Department of the Navy policy for the protection of human subjects as set forth in the ONR Guide. A proposal involving the use of human volunteer subjects will not be approved by the Office of Naval Research unless it has been reviewed and approved by the contractor's IRB. IRB approval of a research proposal is indicated by the proposal being signed by all members of the IRB.

Review Standards: The Navy adopts the review standards of the HHS regulations. In addition to meeting such standards, all studies conducted or supported by the Navy must meet the following study standards: (1) use of the minimum number of human subjects necessary to achieve the required results; (2) performance of appropriate laboratory and animal studies prior to involving human subjects; (3) avoidance of all unnecessary physical and mental discomfort, suffering, or injury; (4) the degree of risk to be taken must not exceed that required by the urgency or importance of the program to which the study is related; (5) proper preparations and adequate facilities to handle 
any foreseeable injuries; (6) appropriate qualifications of principal investigators and those assisting in the research; and (7) no greater intrusion into the privacy of subjects than is absolutely necessary for the conduct of the study involved.

Consent Provisions: Provisions governing informed consent are those of the HHS regulations, supplemented as follows. The subject must be made aware of the provisions of the Privacy Act of 1974 and an appropriate Privacy Act statement must be included in the consent form. In addition, consent forms must be signed by a witness who is not directly involved with the research. Third party consent may be used "only when the prospective human subject is factually capable of giving informed consent but is legally incapable of giving informed consent. Persons who are not factually capable of giving informed consent shall not be used as subjects." The consent forms used in extramural research must identify the Navy as the sponsor of the study.

Special Subjects: Subjects who are unconscious or in great pain, prisoners, institutionalized mentally disabled persons, and those not factually capable of giving informed consent may not participate in research.

Compensation: Medical or dental treatment, including hospitalization if necessary, must be provided to any subject who requires such treatment or hospitalization as a result of participation as soon as such need is recognized. Where appropriate, provisions shall be made in advance for rapid medical evacuation of subjects to an adequate hospital facility, military or otherwise, in case of emergency.

Additional Provisions: Approval of the Assistant Secretary of the Navy (Research, Engineering and Systems) is required for studies in the following special categories:

(1) research projects involving nuclear, chemical or biological warfare agents;

(2) research projects involving severe and unusual intrusions either physical or psychological, on the person of the human subject (e.g. consciousness-altering drugs, mind-control techniques, abnormal environments involving extreme risk);

(3) research projects and clinical investigations involving potential political or public embarrassment to the Department of the Navy.

All records associated with the use of human subjects in research projects or clinical investigations shall be retained permanently. In addition, a copy of the signed consent statement shall be filed in the subject's health record, together with sufficient documentation to clearly identify by name or code any drugs administered, whether 
investigational or not, investigational procedures performed, and significant observations, including any adverse effects. The maintenance of such records shall be a matter of primary concern during laboratory and program review or inspection.

Sanctions: There are no provisions for sanctions in the case of noncompliance.

\section{Air Force}

The Air Force conducts biomedical and behavioral research in Medical Service treatment and clinical investigation programs; it also conducts and supports research in the aerospace research and development program.

\section{Clinical and Investigation Program}

Source: Air Force Regulation 169-6 (November 4, 1977); and Memorandum of Understanding Between the Department of Defense and the Food and Drug Administration (39 Federal Register 41570, November 29, 1974).

Applicability: These regulations apply to research involving the biological, behavioral or psychological study of persons, their bodies or their surroundings conducted by or in collaboration with Air Force Medical Service personnel. Applicability thus appears to be limited to intramural research. Such research is generally conducted in Air Force medical facilities and Air Force clinical research laboratories. Exceptions: (1) Studies involving nonidentifiable data collected from medical records, passive observation, analysis of excreta, diagnostic, surgical, or autopsy specimens; (2) treatment administered with the consent of the Director of Base Medical Services as a life-sustaining measure; and (3) the use of human volunteers in the Air Force Biotechnology Research, Development, Test and Evaluation Program (see below) provided the diagnostic and treatment procedures employed conform to accepted professional practice and all medications used are administered in a manner approved by the Food and Drug Administration. The Memorandum of Understanding Between the Food and Drug Administration and the Department of Defense applies to clinical investigations involving drugs that are classified for reasons of national security, and exempts such research from the filing of a formal "Claim for Exemption" to the FDA. *

Review Procedures: Review procedures are similar to those of HHS regulations (45 CFR 46) with the following additions: (1) Institutional Review Boards, chaired by a physician, must include at least three lay members, including at least one lawyer and one clergyman; (2) medi-

*The Department of Defense reaffirmed on May 12, 1980, that it has never invoked this special exemption. 
cal or dental officer (as appropriate) other than the investigator must be assigned responsibility for assuring proper conduct of the experiments and the professional care of volunteers; and (3) the physician or dental officer may terminate the study at any time.

The medical facility commander is responsible for establishing an Institutional Review Board (IRB), for approving or disapproving each proposal following the IRB's review, and for assuring compliance with applicable Air Force regulations. $\mathrm{He}$ is also responsible for submitting approved proposals to the Surgeon General's Clinical Investigation Committee, and assuring that Committee approval is received before an investigation is initiated. He must submit progress reports to the Office of the Surgeon General every six months, and a final report of findings and conclusions upon completion or termination of each investigation.

A Clinical Investigation Committee, appointed by the Surgeon General, reviews and approves or disapproves all clinical research not involving the investigational use of drugs, serves as the Review Board for proposals that do involve the investigational use of drugs, and generally monitors the overall clinical investigation program of the Air Force. The Surgeon General must approve any study involving investigational drugs.

Review Standards: Studies must meet the following standards: (1) the rights and welfare of human subjects must be safeguarded; (2) any risks to subjects must be outweighted by potential benefits in terms of medical advances; (3) the design should use the minimum number of volunteers consistent with the study objectives; (4) the nature of the investigation must require participation of human subjects; (5) preliminary tests with laboratory animals and human simulators, should be performed, as far as possible; and (6) unnecessary physical or mental discomfort should be avoided.

Consent Provisions: Consent provisions generally follow the HHS regulations ( 45 CFR 46) with the following additions: (1) consent forms must be signed by at least one witness as well as by the officer who advises the volunteer of possible consequences of participation in the research; and (2) the completed consent form must be filed in the volunteer's medical record.

Special Subjects: Minors and mentally disabled or institutionalized mentally infirm individuals may participate as subjects only if the nature of the research is such that no other subjects are suitable. Legally effective informed consent must be given by parents or a guardian, and the consent of a mentally disabled subject must also be ob- 
tained, when the subject is capable of comprehending what is proposed. Children should be given the right to refuse to participate "depending upon the circumstances" and, as they approach maturity, should be given an opportunity to consent, as well. It is recommended that the local Staff Judge Advocate be consulted regarding consent for the participation of children in research, since no hard and fast rules can be laid down. Prisoners may participate in research only if it concerns the diagnosis, treatment, prevention or etiology of the particular impairment with which the prisoner is afflicted, and there is a direct potential benefit to the prisoner.

Sanctions: The Air Force reports that facility commanders have the authority to terminate a study for noncompliance with AFR $169-6$ and that studies may be terminated for cause by higher headquarters command authority.

Reporting of Injuries and Complaints: Misadventures must be reported by the Director of Base Services directly to the Surgeon General. If the misadventure is serious, this must be reported by "electrical means" as quickly as possible, followed by a complete written narrative within 15 days.

Aerospace Research, Development, Test and Evaluation Studies Program

Source: Air Force Regulation 169-3 (February 12, 1979); letter (October 14, 1981) from Paul F. Fallon, Colonel, USAR, BSC, Assistant for Medical Research and Standardization.

Applicability: This regulation applies to all research, development, test, and evaluation involving risk to human subjects, conducted or supported by the Air Force. It does not apply to research conducted under the clinical investigation program. A human subject is considered at risk "if the subject is exposed to the possibility of harm-physical, biological, psychological, sociological, or other-as a consequence of any act or omission which increases ordinary risks of daily life, excluding the recognized risks inherent in a chosen occupation or field of service." Persons involved in hazardous occupational duties such as flight testing, pressure chamber training, and handling explosives, etc., are not considered "at risk" for the purposes of this regulation.

Review Procedures: Review procedures are similar to those of HHS regulations (45 CFR 46). Each organization within the Air Force that intends to conduct research involving human subjects must establish a local Human Use Committee to review such research proposals. Each local committee must be composed of not less that five per- 
sons, preferably consisting of at least one lawyer, one clergyman, and two physicians. The chairman must be a physician. The local committee reviews all projects that involve human subjects to determine whether or not they are at risk. When human subjects are found to be at risk and the committee recommends approval, the project is submitted to the Air Force Human Use Committee for review and final approval by the Surgeon General. If human subjects are not at risk, the project need not be submitted to the Air Force Committee. The Air Force Human Use Committee consists of representatives from the following offices: two representatives from the clinical consultants division, two representatives from the aeromedical consultants division, two representatives from the research and development office of the aero-medical division, one lawyer, and one chaplain. The Director of Professional Services, Office of the Surgeon General, serves as Chairman. He reviews all proposals submitted by local Human Use Committees, determines whether review by the Air Force Human Use Committee is required, and notifies the major command and the organization submitting the proposal of its approval or disapproval.

In addition to reviewing all research in which human subjects are at risk, the Air Force Human Use Committee reviews reports of misadventure involving human subjects, and requests for waivers from any of the provisions of this regulation. A separate review board established by the Surgeon General reviews all projects involving the use of investigational drugs on human subjects.

No contract involving human subjects will be awarded to an individual unless he or she is affiliated with, or sponsored by, an organization that can and does, assume responsibility for those subjects. All institutions must have either a general or special assurance on file with HHS before the contract is awarded. The IRB must provide written assurance to the Air Force that it will abide by the policy for the protection of human subjects as stated in AFR 169-3. Certification of IRB review and approval is required. Contracts involving the use of investigational drugs must be approved by the Air Force Surgeon General through the Director of Professional Services before the project may begin.

Review Standards: The Air Force adopts the review standards of HHS regulations. In addition to meeting such standards, all studies conducted or supported by the Air Force must meet scientific standards including: (1) use of the minimum number of human subjects necessary to achieve the required results; (2) performance of appropriate laboratory, animal, and "nonliving analog" (e.g., dummies) studies prior to involving human subjects; (3) avoidance of all unnecessary physical and mental discomfort; (4) the de- 
gree of risk to be taken does not exceed that required by the urgency or importance of the research program to which the study is related; (5) proper preparations and adequate facilities to handle any foreseeable injuries; and (6) appropriate qualifications of principal investigators and those assisting in the research. There must be no greater intrusion into the privacy of subjects than is absolutely necessary for the conduct of the study involved.

Consent Provisions: Generally, to give legally valid consent, subjects must be 21 years of age except in jurisdictions in which a lesser age is specified. * The Air Force adopts the consent provisions of HHS regulations (45 CFR 46) with the following addition. Consent must be documented in writing by each volunteer in the presence of at least one witness who must also sign the consent form.

Special Subjects: "Participation of females as volunteer subjects is permitted only when there is reasonable assurance of no concomitant pregnancy which would place the fetus at risk and if methods adopted for contraception do not place the female subject at increased risk without complete disclosure to the female subject. Children, prisoners, mentally disabled persons, and institutionalized mentally infirm persons must not participate as human subjects in Air Force research projects."

Additional Provisions: Projects conducted outside the United States must comply with all laws and customs of the country in which the research will be conducted. In exceptional circumstances, when the laws or customs of the country indicate that certain provisions of the regulations would not be acceptable, special permission may be granted by the Surgeon General for a waiver. Only the Surgeon General may grant such a waiver.

Sanctions: The Air Force reports that the facility commanders have the authority to terminate a study for noncompliance with AFR 169-3 and that studies may be terminated for cause by higher headquarters command authority.

Reporting of Injuries and Complaints: "Any misadventure that is coincident with, or possibly results from using human subjects [in USAF conducted or supported] research" must be reported to the Surgeon General's office. Intramural "misadventures" must be reported within 24 hours. Reports should include the following information:

(1) a description of the extent and severity of the injuries;

(2) the identity of the injured individuals;

* For active duty personnel participating in intramural studies, there is no minimum age requirement. 
(3) explanation of how the injuries occurred;

(4) a summary of the research protocol;

(5) time, date, and place of incident; and

(6) name of person to contact for additional information.

If the misadventure is serious the commander will submit a complete narrative report within 15 days.

\section{Department of Education (USED)}

The Department of Education supports research in areas such as systems for rehabilitating and assisting handicapped persons; vocational education programs and support services; postsecondary libraries, collection, analysis, and dissemination of education statistics; and teaching and learning, education policy and organization, and dissemination and improvement of education practice.

Source: DHEW Procurement Regulation, Title 41 Subpart 3-4.55 (36 Federal Register 200, October 15, 1971); Education Division General Administrative Regulations (EDGAR) 100a. 681 (45 Federal Register 22494, April 3, 1980); letter (October 31, 1980) from Shirley M. Hufstedler.

Applicability: The DHEW Procurement Regulations guide the Department of Education in the area of protection of human subjects under contracts. EDGAR applies to direct and state-administered grant programs.

Review Procedures: It is the responsibility of Department of Education professional staff and program consultants to identify contracts that involve risk to human subjects. No contract identified as involving risk to human subjects may be awarded until acceptable assurance has been given that the project or activity will be subject to initial and continuing review by an appropriate institutional committee. The contractor must be affiliated with or sponsored by an institution with either a general or an appropriate special assurance on file with HHS.

Education Division General Administrative Regulations (EDGAR) require grantees to protect human subjects from physical, psychological, or social injury. The regulations contain a cross reference to HHS regulations (45 CFR 46) which according to Education Department officials is intended to offer grantees guidance in complying with the requirement. A substantial portion of the Department's grantees follow the HHS regulations (45 CFR 46) in any event either because of a funding relationship with HHS or because of general institutioanl policy. In the past, the Office of Education required the sponsor agency to identify possible cases of risk, whether or not awardees had done so, and 
to include appropriate measures to reduce risk either in award negotiations or award documents. For the most part these practices are continued by custom in former HEW Education Division units.

Review Standards: In the case of contracts review by the local IRB in accordance with HHS regulations (45 CFR $46)$ is required. Grantees are referred to the HHS regulations (45 CFR 46) for guidance concerning standards.

Reporting of Injuries and Complaints: Awardees who have filed certifications of Institutional Review Board review and approval follow the reporting procedures provided in their written assurances required by regulation. Other awardees are responsible for reporting changes in the protocol or untoward events in program reports generally filed on a quarterly basis. The Department of Education reports no injuries or complaints since it was established in 1979.

\section{Department of Energy (DOE)}

The Department of Energy supports biomedical research involving human subjects. Most research supported by DOE consists of epidemiological studies.

Source: 10 CFR 745 (41 Federal Register 52434, November 30, 1976, as amended in 42 Federal Register 30492, June 15, 1977)-(These regulations were issued by the Energy Research and Development Administration and continue in effect pursuant to Section 705(a) of the Department of Energy Organization Act. Authority: letter to the National Commission (December 1, 1977) from James L. Liverman, Acting Assistant Secretary for Environment, DOE); letter (June 25, 1980) from Ruth C. Clusen, Assistant Secretary for Environment; letter (no date) from Charles W. Edington, Acting Associate Director, Office of Health and Environmental Research; 10 CFR 745. (45 Federal Register 78600, November 25, 1980, proposed rule).

Applicability: DOE regulatons and guidelines are "applicable to all DOE agreements supporting research, development and related activities in which human subjects are involved, either by (a) collecting data through intervention or interaction with the person, or (b) obtaining identifiable private information." The requirements are applicable to research conducted outside the United States and its territories "to the maximum extent practicable as determined by the Administrator on a case-by-case basis, taking into account the relevant laws and practices of the foreign nation in which the activity will be conducted."

Review Procedures: DOE regulations and guidelines for the protection of human subjects conform with HHS regulations (45 CFR 46). The institution conducting bio- 
medical research is responsible for conforming to HHS regulations on protection of human subjects. The DOE accepts an assurance approved by HHS as documentation of such compliance, or alternatively, will negotiate an assurance directly with an institution receiving DOE support. DOE staff reviews assurances for general acceptability taking into account, among other pertinent factors, the adequacy of the proposed Institutional Review Board in light of the anticipated scope of the applicant institution's activities and the types of subject populations likely to be involved, the appropriateness of the proposed initial and continuing review procedures in light of the probable risks, and the size and complexity of the institution. No provision is made for agency review of individual research proposals.

Review Standards: DOE requires compliance with the review standards set forth in HHS regulations (45 CFR 46).

Consent Provisions: DOE adopts and enforces the consent provisions of HHS regulations (45 CFR 46).

Sanctions: DOE adopts the sanctions of HHS, namely, withholding or withdrawal of grant or contract funds if an investigator or institution fails materially to fulfill responsibilities for protection of human subjects.

Reporting of Injuries and Complaints: The DOE reports no injuries or complaints during FY 1976-1981. If a complaint were received DOE would conduct an on-site visit and investigation.

\section{Department of Housing and Urban Development (HUD)}

The Department of Housing and Urban Development supports research involving human subjects in projects such as the Experimental Housing Allowance Program and programs related to the reduction of risk from lead-based paints.

Source: Staff Guidance Memorandum, Office of Management and Program Control (February 24, 1981); Guidelines for Unsolicitied Proposals enclosed with letter (February 24,1981 ) from Arthur S. Newburg, Director, Office of Management and Program Control.

Applicability: The Memorandum provides guidance for the design and implementation of research and demonstrations that may involve human subjects.

Review Procedures: Each project is examined for the possibility of potential harm to its human participants. When such a potential is found, "the project decision package should include a written statement containing a review of that potential and the steps taken to remove it or mini- 
mize it." Where more than a limited potential for harm is found, outside persons knowledgeable in accepted practices to diminish that potential are to be consulted, and a record of their qualifications and recommendations, as well as the actions taken, included in the materials forwarded for decision. Where the potential for harm is clear, no action should be taken on proposed research unless knowledgeable colleagues participate in the project design and implementation and the finished design is submitted to prior independent review (external to the Office of Policy Development and Research). Each person in the concurrence process should assess the adequacy of the provisions to protect the human participants in proposed research.

Unsolicited research proposals that involve human subjects in which there is any potential for physical, social, psychological, or financial harm to the subjects must be approved by an independent review board. The review board's approval of the research design, as well as a description of the review board's procedures and membership, must be forwarded to HUD with the unsolicited proposal.

Review Standards: The Office of Policy Development and Research requires that care be exercised in the design and implementation of all research and demonstration projects conducted by that Office "to assure that no harm whether physical, social, psychological, or financial, occur to any person participating in such projects." Projects which might involve risk of harm to human subjects include: "(a) experiments or demonstrations in which there is a control group treated differently from an experimental group; (b) projects involving questions of privacy or disclosure of private information; and (c) work in codes, standards, or testing that requires human responses or must be measured against human characteristics in the development of those standards."

Consent Provisions: It is necessary to obtain the informed consent of participants before undertaking any project in which participants are at risk of harm.

Reporting of Injuries and Complaints: HUD reports no injuries or complaints during FY 1976-1981.

\section{Department of Justice}

\section{Bureau of Prisons}

The Bureau of Prisons conducts and supports research related to correctional programs.

Source: Policy Statement 2211.1A (May 29, 1975); Policy Statement 2211.12 (October 31, 1975); Policy Statement 37000.3 (June 10, 1977); Policy Statement 6110.1A (April 3, 1978); Proposed Rules 28 CFR Part 512 (January 12, 1979); 
Draft Program Statement (April 1, 1980) which would rescind 6110.1A; letters (April 21, 1980 and July 23, 1981) from Norman A. Carlson, Director, Federal Prison System.

The Bureau of Prisons is currently drafting regulations (Draft Program Statement on Research) for the protection of human subjects involved in research conducted within the Bureau. The Draft Program Statement is in general agreement with current HHS regulations (45 CFR 46). Until the Draft Program Statement is implemented, the guidelines set forth below remain in effect.

Applicability: Policy Statement 2211.1A establishes procedures for processing requests for records of the Federal Prison System. Policy Statement 2211.12 establishes procedures for implementation of the Privacy Act of 1974. Policy Statement 37000.3 prohibits the conduct of medical experimentation and pharmaceutical testing on inmates. Policy Statement 6110.1A contains the requirements and procedures for review of research involving human subjects conducted within the Bureau of Prisons.

Review Procedures: Research proposals made at the institutional or regional level must be reviewed by a Research Committee prior to submission to the Bureau of Prisons' Chief of Research. Suggested membership includes the warden or associate warden, research analyst, chief psychologist, a unit manager or department head, an inmate, a representative of the employees union and a representative of the community.

The Director of the Bureau of Prisons must approve all research projects. This authority may not be delegated. The Chief of Research sets the number and frequency of progress reports that will be required for each project, depending upon the nature of the research. At a minimum, reports must be submitted to the prison warden and forwarded to the Chief of Research of the Bureau of Prisons once each year.

Review Standards: Research proposals are reviewed for relevance to the misssion of the Bureau of Prisons, for potential benefits to mankind or advancement of knowledge, for professional standing of the investigator, for amount of risk to subjects, for assurance of confidentiality and for assurance that the conduct of the research will not adversely affect Bureau of Prisons' programs or operations. Priority is given to projects holding promise for advancing knowledge and capability for treatment of offenders.

Consent Provisions: The Bureau of Prisons generally follows the consent provisions of HHS regulations (45 CFR 46). 
Additional Provisions: Incentives for participation must be limited to soft drinks and snacks given at the test setting.

Investigators must adhere to all requirements of the Privacy Act of 1974 and implementing regulations. They may not report information which can be used to identify an individual to any party other than to Bureau of Prisons research personnel without written consent of the subject. Further, no individual other than an employee of the Bureau of Prisons may have access to personally identifiable information without the written consent of the individual from whom the information was obtained, unless the information is already accessible to the general publiç.

Reporting of Injuries and Complaints: Research Committtees must report research violations to the Director of Research of the Federal Prison System. Suspected violations of law are referred to the Office of General Counsel.

The Bureau of Prisons reports that one tort claim was filed in 1981 for an injury allegedly resulting from CIAfunded drug research conducted from 1955 to 1961. The Bureau of Prisons has denied the claim as time-barred, and has filed a motion to dismiss the case.

\section{Office of Justice Assistance, Research, and Statistics}

The Office of Justice, Assistance, Research, and Statistics supports research in crime prevention and treatment of offenders through the Law Enforcement Assistance Administration (LEAA) and the National Institute of Justice (NIJ) to study the effectiveness of different approaches to civil and criminal justice, including: preventing and reducing crimes, improving efforts to detect, combat and prevent white-collar crimes, and improving the overall functioning of the criminal justice system. Studies generally involve the use of survey instruments and observational data and may deal with sensitive topics such as drug or alcohol use and illegal conduct.

Source: LEAA Guideline G6060.1 (1974); 28 CFR 22 (41 Federal Register 54816, December 15, 1976); LEAA Guidelines on Confidentiality of Research and Statistical Data (1978); Justice System Improvement Act of 1979 (84 Stat. 197; 42 U.S.C. 3701 et seq.); letter (April 29, 1980) from Henry S. Dogin, Acting Director, Office of Justice Assistance, Research, and Statistics.

Applicability: The regulations and implementing guidelines apply to all research conducted or supported under authority of the Justice System Improvement Act of 
1979, including categorical grants funded by LEAA and research supported by the National Institute of Justice. *

Review Procedures: Recipient organizations conducting research funded by the National Institute of Justice are not required to use IRBs. However, a system of advisory boards and team monitoring is built into most grants. Such boards generally are composed of five to ten persons, jointly selected by the grantee and the NIJ monitor. They meet several times a year with project staff to review the progress of the research.

Research Standards: A privacy certificate must be submitted as part of any application for funding in which research or statistical data identifiable to a private person are to be collected. The certificate must assure compliance with the privacy provisions described below. In addition, no funds may be used to support psychosurgery, medical procedures which seek to modify behavior by aversion therapy, chemotherapy (except as part of routine clinical care) or physical therapy. A very limited number of projects involving medical research (using programs generally accepted as not involving physical or psychological risk to the patient) may be supported.

Consent and Confidentiality Provisions: The regulations governing confidentiality of data provide:

(1) That identifiable research and statistical data may only be used (without consent of the individual) for research or statistical purposes;

(2) That data may only be transferred in identifiable form pursuant to a transfer agreement ensuring recipient compliance with confidentiality limitations;

(3) That, except in noted circumstances, subjects must be advised that data will only be used for research or statistical purposes;

(4) That upon completion of a project identifiers must be destroyed or otherwise separated from data and permanently secured; and

(5) That copies of identifiable data are immune from administrative or judicial process (i.e., subpoena).

*The regulations also apply to the activities of the Bureau of Justice Statistics, which provides for the collection and analysis of statistical information concerning crime and the operation of the criminal justice system. Since the Bureau deals only with nonpersonally identifiable data collected by the Bureau of the Census, however, none of its activities constitute research with human subjects under the definition now in place in 45 CFR 46. Therefore, the Bureau of Justice Statistics is not included in this survey. 


\section{Department of Transportation (DOT)}

Source: Letter (May 27, 1980) from Martin Convisser, Director, Office of Environment and Safety; letter (August 11,1981 ) from Donald R. Trilling, Director, Office of Industry Policy.

The Department of Transportation is currently drafting departmental regulations (DRAFT Department Order 7000) for the protection of human subjects involved in DOT sponsored research. The Draft Order generally conforms to HHS regulations (45 CFR 46) in force prior to 1981 revisions. Until the Draft Order is implemented, however, individual components of DOT will continue to follow the guidelines set forth below.

\section{U.S. Coast Guard}

The Coast Guard supports and conducts research relating to safety in both recreational and maritime vessels, including research into the efficacy of personal flotation devices for both average and physically handicapped individuals.

Source: Memo from Chief, Office of Research and Development, included in the letter (May 27, 1980) from Martin Convisser, Director, Office of Environment and Safety; Memorandum from U.S. Coast Guard commenting on proposed changes to HHS regulations (45 CFR 46) for the protection of human subjects, forwarded (June 19, 1980) by Martin Convisser.

Review Procedures: There are no formal regulations or policies for the protection of human subjects in research conducted or supported by the Coast Guard; however, the Coast Guard uses the provisions of HHS regulations ( 45 CFR 46) as guidelines. Major Coast Guard research projects involving biomedical or behavioral research (specifically hypothermia and personal floatation devices for the physically handicapped) have been conducted under contract with institutions having an Institutional Review Board with a general assurance on file at HHS. These IRBs have reviewed the Coast Guard projects, though not specifically required to do so.

Reporting of Injuries and Complaints: The Coast Guard reports no injuries or complaints in FY 1976-1981.

\section{Federal Aviation Administration (FAA)}

The FAA conducts and supports aeromedical research to study factors contributing to injury or accidents, to establish aeromedical standards for airmen, to maintain fitness and performance of aviation personnel, and to improve the working procedures and environment of air traffic control personnel. 
Source: Order 9950.3A (December 6, 1974)-Medical Research Program Guides; letter to the National Commission (July 25, 1975) from Stanley R. Mohler, then Chief, Aeromedical Applications Division, Office of Aviation Medicine.

Applicability: Order 9950.3A applies to aeromedical research activities conducted intramurally under the auspices of the Civil Aeromedical Institute (CAMI) or supported by contract or other government agency sponsorship agreement.

Review Procedures: The Office of Aviation Medicine reviews all research proposals for scientific merit and to establish research priorities. All research must be approved by the Federal Air Surgeon following technical review by the Research Task Review Panel composed of agency physicians, psychologists, engineers and other scientists. Review by outside specialists is occasionally performed in special circumstances.

Review Standards: There are no formal standards concerning protection of human subjects. In all research in which human subjects are employed consideration is given to any possible hazard. Special provisions are made for incidents. For example, in pressure chamber experiments, a pressurized chartered airplane stands by for evacuation of any subject to the Brooks Air Force Base pressure facility in the unlikely event that repressurization of a subject is required. No experiment is ever undertaken in which the likely outcome would be injury or death to a subject. During the conduct of any potentially hazardous research, a physician is in the building on call in case of a mishap. Informed consent procedures are rigorously followed. Subjects are completely briefed on their role in experiments, and are told they may voluntarily cease participation in the project at any time they choose.

Reporting of Injuries and Complaints: The FAA reports no injuries or complaints during FY 1976-1981.

\section{Federal Highway Administration}

The Federal Highway Administration conducts and supports research designed to study motorist behavior, skill, and ability as it relates to the driving process. The tests involved do not impose any risk to subjects over that involved in the normal operation of an automobile.

Source: There are no formal regulations or policies for the protection of human subjects in research conducted or supported by the Federal Highway Administration. (No biomedical research is conducted or supported.)

Staff investigations are performed principally by re- 
search psychologists "who are bound by the American Psychological Association's code of ethics for the conduct of experiments with human subjects," and work plans for contractor studies "are carefully reviewed to assure minimum risk to subjects of both traffic engineering studies and controlled experiments."

Reporting of Injuries and Complaints: The Federal Highway Administration reports no injuries or complaints during FY 1976-1981.

\section{National Highway Traffic Safety Administration (NHTSA)}

Source: NHTSA Order 700-1 (revised April 24, 1979); NHTSA Order 700-2 (revised April 24, 1979); NHTSA Order 700-3 (revised June 30, 1980); NHTSA Order 700-4 (April 24, 1979); Memorandum from R. Rhoads Stephenson, Associate Administrator for Research and Development, included in letter (May 27, 1980) from Martin Convisser, Director, Office of Environmental Safety.

Applicability: NHTSA Orders $700-1,700-2$, and $700-3$ are applicable to all NHTSA intramural research and all NHTSA contracts supporting research involving human subjects. NHTSA Order 700-4 applies to the use of cadavers in NHTSA-sponsored experiments.

Review Procedures: DOT Order 700-1 adopts by reference the general assurance and review procedures of the HHS regulations ( 45 CFR 46). No grant or contract involving human subjects will be made to an individual unless he or she is affiliated with or sponsored by an institution which can and does assume responsibility for the subjects involved. The institution's Institutional Review Board must review and approve such activity, and the institution must submit to NHTSA a certification of such review and approval.

Review by the NHTSA's Human Use Review Panel and approval of both the responsible Associate Administrator and the Chief Counsel are required for any project involving human subjects. The Human Use Review Panel recommends approval, disapproval, or approval with modifications; the Associate Administrator and the Chief Counsel are responsible for approving or disapproving the research. Requests for Proposals are reviewed by the Human Use Panel and must be approved by the Associate Administrator and the Chief Counsel before proposals are accepted. A bidder responding to a Request for Proposals must describe methods and procedures proposed for the protection of the rights and welfare of human test subjects. The proposer must indicate availability of an IRB, but this initial proposal does not require IRB approval. When a contract has been 
signed, the contractor will develop a detailed protocol. No work can be initiated, however, until the experimental protocol has been approved by NHTSA and by the contractor's IRB.

Review Standards: NHTSA requires full compliance with HHS regulations ( 45 CFR 46). In addition, review for the protection of human subjects includes consideration of whether subjects are given adequate physical and psychological evaluations or monitoring prior to their selection, during the experiments, and after completion of the research; whether there are trained medical personnel and adequate equipment for emergency treatment; whether risks are reduced as much as possible; whether there are alternate ways of obtaining the desired information; what the criteria are for selection of human subjects; whether remuneration will be commensurate with the risk involved, but not so excessive as to constitute undue inducement; and whether there are adequate plans to ensure privacy and confidentiality according to the provisions of the Privacy Act of 1974.

Consent Provisions: NHTSA follows the consent provisions of HHS regulations (45 CFR 46) including provisions that subjects be given information regarding (1) medical compensation and/or liability insurance in force (together with any limits involved); (2) nature and extent of medical supervision and emergency procedures; and (3) review by the contractor's IRB.

Compensation: Facilities and professional attention required for subjects who may suffer physical, psychological, or other injury as a result of participation in an activity will be provided.

Special Provisions: NHTSA Order 700-4 establishes policy and procedures to ensure proper procurement, treatment, and disposition of human cadavers utilized in NHTSA-sponsored research. IRB approval is required. The contractor should make a reasonable effort to obtain the approval of the next-of-kin whenever the IRB determines that the proposed project goes beyond the normal scope of teaching and research, within the context of the appropriate local statutes.

Reporting of Injuries and Complaints: The Contract Technical Manager monitors the contractor's compliance with the HHS regulations. He or she is responsible for assuring that the contractor reports any unexpected results or real or claimed injuries, and for informing the Human Use Review Panel of any untoward or unexpected event which could affect the safety of the subjects. In addition, the contractor's IRB has the responsibility for the continuing surveillance of the contractor's performance. 
Although NHTSA reports no injuries or complaints during FY 1976-1981, the need and the procedures for research involving cadavers has been questioned. Representative John E. Moss, Chairman of the Investigations Subcommittee of the House Committee on Interstate and Foreign Commerce expressed his concern in a letter (October 25, 1977) to Secretary Brock Adams. All testing involving cadavers was suspended in November 1977 until the need and the review procedures for such research could be thoroughly assessed. The need for this sort of research was affirmed and strict guidelines for the protection of the dignity and privacy of the human body were recommended. NHTSA now has uniform policies and procedures for the conduct of research involving cadavers, including a requirement for review and approval by an IRB.

\section{Environmental Protection Agency (EPA)}

The Environmental Protection Agency conducts and supports research related to the effects of pollutants on human beings.

Source: EPA Order 1000.17 (October 25, 1977); letter to the National Commission (December 19, 1977) from Stephen J. Gage, Acting Administrator for Research and Development; letter (February 24, 1981) from Hugh W. McKinnan, Medical Officer, Office of Health Research; letter (August 5, 1981) from Andrew P. Jovanorich, Acting Assistant Administrator for Research and Development.

Applicability: Order 1000.17 applies to all intramural studies, grants, contracts, Public Law 480 projects, and other research with human subjects supported in whole or in part by EPA. Exceptions: Order 1000.17 does not apply to (1) opinion polls, questionnaires or the solicitation of information about past events; (2) the taking of blood, urine, mothers' milk, "nonviable fetus tissue" or human tissue samples; or (3) the conduct of any medical observations where such testing is not preceded or followed by purposeful exposure to chemicals, physical conditions or other environmental conditions being tested. EPA is developing orders to address (1) the acquisition of information and the collection of tissue or fluid samples (blood, urine and human milk) for use in epidemiologic studies, and (2) the conduct of research by industrial laboratories for the purpose of acquiring data required by EPA for product approval.

Review Procedures: EPA requires compliance with HHS regulations (45 CFR 46) for the establishment of Institutional Review Boards, and further requires that grantees, contractors or other parties responsible for the conduct of 
research with human subjects have an approved general or special assurance on file at HHS. Applications for an assurance may be made to HHS through the EPA Deputy Administrator for Health Research.

Certification of IRB review and approval, and a description of the procedures to be used in obtaining informed consent (along with a copy of the consent form to be used) must be submitted to the EPA Deputy Assistant Administrator for Health Research for review and approval.

Review Standards: EPA requires compliance with the review standards of HHS regulations ( 45 CFR 46). In addition, EPA will not support any research involving (1) risk of substantial or irreversible injury to a human subject, or (2) determining whether or not a substance is a carcinogen by testing on human subjects.

Consent Provisions: EPA requires compliance with the consent provisions of HHS regulations (45 CFR 46) and with any subsequent modifications thereto.

Sanctions: The Deputy Assistant Administrator for Health Research may terminate a grant, contract or other agreement in the case of noncompliance with approved human testing procedures or if the Secretary, HHS, withdraws his approval of the general or special assurance.

Reporting of Injuries and Complaints: The EPA reports one incident in which three subjects suffered throat and eye irritations. The study was interrupted, and an on-site investigation was conducted by intramural personnel as well as the quality assurance contractor. Laboratory officials, the chairman of the Human Subjects Rights Committee, and the legal staff were notified immediately. All subjects were briefed and examined.

\section{National Aeronautics and Space Administration (NASA)}

NASA conducts and supports biomedical and behavioral research in biotechnology, environmental biology, spacecraft simulation and medicine.

Source: NASA Management Instruction 7100.8 (February 2, 1972); NASA Management Delegation AD 7100.9 (February 2, 1972); Ames Management Manual 7170-1 (as revised March 19, 1969); Ames Memorandum 74/200 (December 11, 1974); and Lyndon B. Johnson Space Center Management Instruction 7100.8C (October 5, 1979); letter (May 2, 1980) from Thomas A. Mutch, Associate Administrator for Space Science; letter (July 28, 1981) from Andrew J. Stofan, Acting Associate Administrator for Space Science. 
Applicability: NASA Management Instruction 7100.8 applies to "all human research conducted by NASA, by or under the direct supervision of a NASA officer or employee or an officer or employee detailed to NASA from another Government agency." It specifically does not apply to human research conducted under grant or contract or conducted "under a cooperative arrangement or agreement entered into by NASA and another Government agency, private entity, or non-Federal public entity." NASA officials report, however, that intramural review boards "usually review and approve all human research proposals and protocols." The Management Delegation empowers the Directors of each NASA field installation and, for NASA Headquarters, the NASA Director of Life Sciences, to authorize human research and to grant such waivers as are permitted under the NASA instructions. The Ames Management Manual applies ONASA policy both to all humaan research conducted at the Ames Research Center, Moffet Field, California, and to all human research conducted for or on behalf of Ames by NASA contractors, subcontractors or grantees "to the extent that [AMM 7170-1] is incorporated by reference or otherwise in the relevant contract, subcontract, or grant." The Lyndon B. Johnson Management Instruction applies to all human research conducted by, or under the direct supervision of officers or employees of the Johnson Space Center. The NASA employee at Johnson Space Center initiating a grant or contract "should ensure that guidelines consistent with those contained in NMI 7100.8 are included or that the policies and procedures of NMI 7100.8 are incorporated by reference on any such agreement.

Exceptions: Although neither of the two space centers make such exceptions, the NASA Management Instruction 7100.8 does not apply to research "as determined by the principal investigator, ${ }^{\star}$ that is: (a) performed by or under the supervision of a physician (who may be the principal investigator) for the purpose of diagnosing, preventing, curing or alleviating disease in a particular human subject; (b) performed primarily for the human subject's benefit; and (c) recognized generally by the medical profession as proper." Nor does it apply to research involving no risk (as determined by the principal investigator) or to (1) evaluative procedures authorized by the Civil Service Commission or by other government agencies to determine the state of an employee's health; (2) research involving as subjects individuals who are specially trained for that occupation (e.g.,

* The investigator's determinations must be approved by "line management:" letter (November 16, 1977) from Robert A. Frosch, Administrator, NASA. 
using test pilots to evaluate air or space flight equipment); or (3) research involving NASA employees whose regular position description includes such tests or evaluative procedures.

Review Procedures: The NASA Office of Life Sciences neither conducts nor directly supports research involving human subjects. All such research is conducted under the auspices of the NASA field centers (primarily Ames and Johnson). Both Ames Research Center and the Johnson Space Center require (in their own management directives) that their intramural research be reviewed by a review board. NASA officials report that, "at least at the Ames Research Center, an attempt is made to obtain reports of the results of the extramural IRB's findings prior to the funding of research proposals." IRB review of extramural research, however, does not appear to be required.

The IRB at the Johnson Center is chaired by the Senior Medical Officer of the Space Life Sciences Directorate and includes three Space and Life Sciences Directorate representatives, a representative of both the Chief Counsel and the Director of Safety, Reliability, and Quality Assurance. Three ad hoc members may also be appointed by the Chairman. The composition of the review board at the Ames Center as set forth in Ames Memorandum 74/200 includes three staff physicians, a life scientist, and three additional individuals not connected with the organization conducting the research. The Chairperson is the Division Chief, Simulation Sciences.

Research proposals must be approved by the installation's counsel's office, safety office and medical officer before being approved by the appropriate authorized NASA official (i.e., the Director of the Ames Research Center, the Senior Medical Officer of the Space and Life Sciences Directorate at the Johnson Center, and the Director of Life Sciences at NASA Headquarters, respectively). At the Ames Center, the Director also signs each test participant's certification of medical acceptability forwarded by the physician conducting the medical examination.

Review Standards: Research involving human subjects is reviewed to determine that: (1) the importance of the research objective outweighs the risk to the subjects; (2) subjects will not be exposed unnecessarily to risk of injury, discomfort or inconvenience; and (3) the subject or his or her representative will be compensated in the event the subject suffers loss, injury, illness, disease or death as a result of participating in the research. The review at the two research centers also assesses the scientific merit of the research, the competence of the investigators, and the ade- 
quacy of the facilities for the safe conduct of the research, and for treatment of injuries.

Consent Provisions: NASA consent provisions generally follow those of HHS regulations (45 CFR 46) with the following modification. Subjects must be informed if, for any reason, withdrawal during the conduct of the research is not an option (because it would be "unwise, dangerous, or impossible"'). In exceptional cases, waivers of the consent requirements may be granted by "the cognizant authorized NASA official" if such requirements are deemed "not to be necessary, for various reasons, to protect the subjects."

Special Subjects: The Ames Manual provides that no person who is a minor or who is without legal capacity to give his voluntary informed consent may be a subject of human research without the specific authorization, in writing, of the NASA Administrator. (No such provision appears in the other manuals.)

Additional Provisions: The Ames Research Center requires that all human subjects be examined by a physician, who has been informed of the nature of the proposed research, for a determination of fitness. Subjects must be reexamined at the conclusion of the research, and reports of the results of both the examinations must be forwarded to the Director of the Research Center.

Sanctions: There are no provisions for sanctions in the case of noncompliance.

Reporting of Injuries and Complaints: The authorized official at the Center conducting the research must be informed in the event of any injury, illness or disease that occurs to subjects, any change in the environment or in a subject's response that could lead to some medical disturbances and any change in the research as described in the approved protocol. The authorized NASA official is required to consider whether or not the prospective subject is eligible for worker's compensation or other insurance in the case of injury, loss, or death as a result of participating in the research. "No human subject shall be asked to waive any rights that may arise against the United States in connection with any injury, loss, illness, disease or death suffered by the subject as a result of human research."

A sample consent form used at the Johnson Space Center contains the following information: "I understand that in the event of physical injury resulting from the experiment and calling for immediate action or attention that NASA will provide the necessary emergency treatment. I also understand that NASA will pay for any claims of injury, loss of life or property damage to the extent required by the Federal Employees Compensation Act, the Federal Tort 
Claims Act, and the National Aeronautics and Space Act, as amended. Any consent to participate as a test subject shall not be construed as a release of NASA from any future liability which may arise from, or in connection with, the above tests or experiments."

NASA reports no injuries or complaints during FY 1976-1981.

\section{National Science Foundation (NSF)}

The National Science Foundation supports research involving human subjects primarily in the behavioral and social sciences. The NSF normally does not support clinical research (i.e., on diagnosis or treatment of disease, abnormality, or malfunction in people or the testing of drugs).

Source: Section 711 NSF Grant Policy Manual (revised March 1981); letter to the National Commission (November 9, 1977) from Richard T. Louttit, Director, Division of Behavioral and Neural Sciences; letters (March 21, 1980 and July 16, 1981) from Eloise E. Clark, Assistant Director, Biological, Behavioral, and Social Sciences.

Applicability: The policy applies to research, and related activities supported by NSF grants.

Review Procedures: NSF adopts HHS requirements ( 45 CFR 46) for review by an Institutional Review Board (IRB). The grantee is required to provide NSF with certification that the appropriate IRB has reviewed and approved the proposed research. If the grantee is not affiliated with an institution that has a general assurance on file at HHS, NSF will contact HHS and request that a special assurance be negotiated.

Review Standards: NSF grantees must comply with review standards of HHS regulations (45 CFR 46).

Consent Provisions: NSF grantess must comply with the consent provisions set forth in HHS regulations ( 45 CFR 46).

Special Subjects: NSF specifically applies its policy to research, and related activities in which students are involved as subjects.

Sanctions: No provisions are made for sanctions in the case of noncompliance.

Reporting of Injuries and Complaints: "There are no special procedures for monitoring the research, nor for being informed of 'untoward or unexpected events.' Grantees provide annual progress reports on continuing grants, which are reviewed by appropriate program officers before continuing funding is provided." The NSF reports no injuries or complaints during FY 1976-1981. 


\section{United States International Develop- ment Cooperation Agency}

\section{Agency for International Development (A.I.D.)}

The Agency for International Development supports research in a variety of fields including agriculture, rural and urban development, health, population, nutrition, education, economics, institutional and social development, natural resources and environment, energy, and science and technology.

Source: Manual entitled Contract Program in Centrally Funded Research, issued by the Agency for International Development, January 1977 (reprinted 1981); letter (April 24, 1980) from Sander Levin, Assistant Administrator for Development Support; letter (July 13, 1981) from Curtis Farrar, Acting Senior Assistant Administrator for Science and Technology.

Applicability: A.I.D. policy for the protection of human subjects applies to all grants, contracts or other awards for the support of research involving human subjects conducted both within and outside the United States.

Review Procedures: A.I.D. requires initial and continuing review and approval of each research project by "an appropriate committee of the applicant institution." A.I.D. reviews each institution's assurance for: (1) compliance with requirements for initial and continuing review, (2) adequacy of the institution's review committee structure, (3) its review procedures, and (4) the facilities and personnel available to protect the health and safety of human subjects. In addition, each institution must certify to A.I.D. for each proposal that its committee has reviewed and approved the proposed research. Where applicable, A.I.D. also requires evidence of compliance with regulations of the Food and Drug Administration. The Agency may submit research protocols involving human subjects to independent review by staff, consultants and advisory groups. The Agency's central research program is reviewed by the A.I.D. Research Advisory Committee (RAC), an external advisory group of experts from educational and other institutions. The RAC gives close attention to provisions for the safeguarding of human subjects in its reviews.

Review Standards: Review must assure that (a) the rights and welfare of the individuals involved are adequately protected, (b) the methods used to obtain informed consent are adequate and appropriate, and (c) the risks and the potential benefits of the investigation are assessed. 
Consent Provisions: The consent procedures must be adequate and appropriate. For guidance A.I.D. refers to HHS regulations (45 CFR 46).

Additional Provisions: Research conducted outside the United States must comply with all the above provisions and, in addition, conform to legal and other requirements governing human research in the country in which the research will be conducted. For guidance A.I.D. refers to HHS regulations (45 CFR 46).

For A.I.D. supported multinational research projects, such as clinical trials of new drugs and diagnostic substances for tropical diseases in developing countries, A.I.D. follows the consent procedures of the Human Volunteer Committees of the World Health Organization.

Sanctions: There are no specific provisions for sanctions in the case of noncompliance. However, noncompliance may provide the basis for termination.

Reporting of Injuries or Complaints: A.I.D. reports no injuries or complaitns during FY 1976-1981.

\section{Veterans Administration (VA)}

The Veterans Administration conducts and supports biomedical and behavioral research in its hospitals, clinics and centers, and permits outside investigators to collaborate in such research at those facilities.

Source: Veterans Administration Issue $\mathrm{M}-3$, Chapter 1, Part 1, as modified by interim issue 10-75-8 (March 10, 1975), 10-77-46 (November 18, 1977) and 10-78-17 (June 13, 1978); Circular 10-75-121 (June 19, 1975); Circular 10-79-232 (September 25, 1979); guidelines for VA Cooperative Studies (September 1979); Circular 10-81-162 (August 11, 1981); letter (April 17, 1980) from Donald L. Custis, M.D., Chief Medical Director; letter (April 23, 1980) from Dorothy Rasinski, M.D., J.D., FCLM, VA Liaison; letter (July 2, 1981) from Turner Camp, M.D., Associate Deputy Chief Medical Director. VA manual M-3, Part 1 has been revised and is in the final stages of approval.

Applicability: The guidelines apply to all VA research whether it is being performed under the auspices of the Medical, Health Services, or Rehabilitative Engineering Research and Development Office.

Review Procedures: Each local Research and Development Committee appoints subcommittees on human studies (IRBs) as required. The composition of the subcommittee on human studies must conform with HHS regulations. The subcommittee reports its recommendations to the Research and Development Committee who must review and approve 
the recommendations of the subcommittee but cannot alter or reject a report that recommends disapproval for either ethical or legal reasons.

Review Standards: The VA generally follows the review standards set forth in HHS regulation (45 CFR 46).

Consent Provisions: The VA adopts the consent requirements of HHS regulations ( 45 CFR 46). Subjects must sign each of the pages of information provided them concerning the purpose, procedures, risks, etc. of the proposed research project. In addition all subjects must sign a standardized consent form (VA Form 10-1086) informing them of existing compensation and treatment provisions in the event of injury, assuring them of the privacy and confidentiality of their medical records, providing them with the opportunity to indicate any limitation they may wish to place on their consent to participate in the research project at hand, and reminding them of their right to withdraw from the study at any time.

The VA permits several or all of the subjects to sign the same information sheets when the procedure is simple and the experiment is brief. The signed consent forms are kept separate from the information sheets. The investigator may give subjects their own copies of the information sheets; but one copy of each sheet must be signed by the subject and retained by the investigator. In addition, investigators "must assure that the consent is given freely without threats even by implcation, without promises of unrealistic results, and without excessive material reward for participation."

Additional Provisions: "Experimental procedures must not be added surreptitiously to accepted clinical ones; socalled 'bootleg' or 'piggy-back' research is forbidden."

Reporting of Injuries: "Adverse results" may be handled locally with no report to Central Office. However, the IRB (Human Studies Subcommittee) must consider and recommend action in any instance of "research abuse" in which it is claimed that a subject's rights were violated or the subject's safety unduly jeopardized during research. In such cases, the IRB forwards its report and recommendations to the local Research and Development Committee, which then advises Central Office.

Beginning with FY 1982, each principal investigator is required to report at the close of each fiscal year the following information:

(1) the total number of research projects in his/her program;

(2) the number of those projects which included human subjects; 
(3) the total number of human subjects involved in those programs;

(4) the number of those subjects participating in research who were physically injured or who experienced any unanticipated physical complications as a result of their participation;

(5) of those "injured" subjects, the number requiring outpatient medical care, with the total number of outpatient visits; and

(6) of those "injured" subjects the number who required hospitalization, with the total number of hospital days.

"Adverse result/injury in the course of research" is defined as follows: "Any anticipated or unanticipated physical effect (either the effect itself or the frequency of the effect if its occurrence had been anticipated or predicted) which required additional follow-up treatment, or hospitalization. Minor physical effects, e.g., transient vertigo, nausea, headache, should not be included."

The VA reports that there were five alleged injuries or complaints during FY 1976-1981. After thorough investigations, two of the alleged injuries or complaints were determined to be unfounded or could not be established. Two complaints are still under investigation, and one complaint resulted in a finding that the research investigator had deviated from the patient selection criteria described in the protocol. The investigator has been withdrawn from all research activities, and an official reprimand has been placed in his personnel record. 


\title{
Agencies Included in Commission's 1980 Survey
}

\author{
Agencies Reported by National Commission \\ to be Conducting or Supporting Research with Human \\ Subjects \\ American National Red \\ Cross \\ Central Intelligence Agency \\ Commission on Civil Rights \\ Consumer Product Safety \\ Commission \\ Department of Agriculture \\ Department of Commerce \\ Department of Defense \\ Department of Education * \\ Department of Energy \\ Department of Health and \\ Human Services * \\ Department of Housing and \\ Urban Development \\ Department of Justice \\ Department of State \\ Department of \\ Transportation \\ Department of the Treasury \\ Environmental Protection \\ Agency \\ International \\ Communication Agency \\ National Academy of \\ Sciences \\ National Aeronautics and \\ Space Administration \\ National Science \\ Foundation \\ Veterans Administration
} *Formerly part of the Department of Health, Education and
Welfare 
Agencies Not Previously Reported as Conducting or Supporting Research with Human Subjects

ACTION

Administrative Conference of the U.S.

Advisory Commission on Intergovernmental Relations

Advisory Council on Historic Preservation American Battle Monuments Commission

Appalachian Regional Commission

Arms Control \& Disarmament Agency Civil Aeronautics Board Commission of Fine Arts Committee for Purchase from the Blind and Other Severely Handicapped

Commodity Futures Trading Commission

Community Services Administration

Copyright Royalty Tribunal

Delaware River Basin Commission

Equal Employment Opportunity Commission

Export-Import Bank of the U.S.

Farm Credit Administration

Federal Communications Commission

Federal Council on the Aging

Federal Deposit Insurance Corporation

Federal Home Loan Bank Board

Federal Labor Relations Authority

Federal Maritime Commission

Federal Mediation \& Conciliation Service
Federal Mine Safety and Health Review Commission

Federal Trade Commission Foreign Claims Settlement Commission of the United States

General Services Administration Gorgas Memorial Institute of Tropical and Preventive Medicine, Inc.

Harry S Truman Scholarship Foundation

Inter-American Foundation

International Trade Commission

Interstate Commerce Commission

National Capital Planning Commission

National Credit Union Administration

National Endowment for the Arts

National Transportation Safety Board

Nuclear Regulatory Commission

Occupational Safety and Health Review

Panama Canal Commission

Postal Service

President's Committee on Employment of the Handicapped

President's Council on Physical Fitness and Sport Selective Service System. Small Business Administration Smithsonian Institute Tennessee Valley Authority 
Correspondence with HHS Regarding Amendments to the Department's Rules

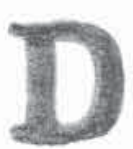


President's Commission for the Study of Ethical Problems in Medicine and Biomedical and Behavioral Research

2000 K Street, N.W.. Suite 555. Washington, DC 20006 (202) 653-8051

September 18,1980

Honorable Patricia Roberts Harris

Secretary

Department of Health and Human

Resources

Washington, D.C. 20201

Dear Secretary Harris:

I am writing on behalf of the President's Commission to transmit comments on proposed HHS regulations governing research with human subjects ( 45 CFR 46). Because the proposed regulations were published more than a year ago and have already received extensive public comment, the Commission has decided not to prolong the rulemaking process by exercising its authority under section $1802(\mathrm{~b})$ of the Public Health Service Act to make formal recommendations which would have to be published for public comment and notice of your official decision. Rather, we hope that you will adopt our recommendations substantially as offered or advise us of your reasons if you find that it would be unwise or infeasible to do so.

Although the Commission will be submitting its biennial report on the regulations of all federal agencies for the protection of human subjects in 1981, we would like to make substantive recommendations on two aspects of the proposed HHS final regulations at this time in order to avoid proposing modifications shortly after their issuance, which we understand will occur shortly. The recommendations that are attached address the applicability of HHS regulations to: (a) research not conducted or supported by the Department; and (b) social science research involving no discernible risk. The more difficult problems of research involving either deception or participant observation in "private" settings will be addressed in our biennial report.

Briefly, we have concluded that extension of HHS regulations to research that is not conducted or supported by the Department should be based upon clearer congressional and statutory authority than now exists In the ambiguous language of Section 474 of the Public Health Service Act. We recommend, therefore, that 45 CFR 46 be made applicable on its face, and in implementation through the process of negotiating "assurances" with research institutions, only to research with human subjects that is conducted or supported by HHS. At the same time, we would like to emphasize our support for the IRB process and our hope that research institutions can be encouraged voluntarily to apply IRB review procedures to all research with human subjects for which such revicw is appropriate. 
For the time being, however, this should be done through institutional mechanisms and through appropriate professional organizations. The Commission will consider, as part of 1 ts biennial report to Congress, whether to recommend statutorily-mandated IRB review of research with human subjects regardless of source of funding. If we determine that such a requirement would be advisable, we shall recommend appropriate Congressional action.

Although we believe that for research not funded by the Department explicit authority is lacking to require institutions to follow the procedures established by HHS, we conclude nonetheless that the Department may (and in some instances should) decline to support institutions or investigators who have violated subjects' rights in the past. Therefore, we recommend that the final regulations retain the provision now embodied in 45 CFR $\$ 46.121$ (b) that permits the Secretary to withhold research funds from an institution or principal investigator that has failed materially to protect human subjects in research (whether or not HHS funds were involved). This provision should be noted in a preamble setting forth the policy underlying 45 CFR 46 . If necessary to effectuate this recommendation, additional provisions should be added to the regulations to require institutions or investigators applying for HHS research funding to submit information, and to permit Department officials to develop any further facts, needed to resolve substantial allegations of serious wrongdoing in previous unfunded research.

Second, we believe that efforts to protect human subjects are ultimately disserved by the extension of regulatory procedures to ever broader areas. In a word, the full panoply of prior review ought not apply to activities in which there is no discernible risk to human subjects. We know that you are sensitive to these concerns as well. To mark the restriction of the regulations' sweep more plainly, we recommend several modifications in the proposed rules published in August 1979. We would establish three categories of research that may be exempt from IRB review: (a) research involving questionnaires, interviews, or standard educational or psychological tests, in which the agreement of subjects to participate is already an implicit or explicit part of a research process which itself will involve little or no risk; (b) research in which consent is not typically obtained because the gathering of lifformation involves merely observation of behavior in public places (for which there is no reasonable expection of privacy), review of publicly available information, or analysis of data containing no personally Identifiable information; and (c) soctal, economic, or health service research conducted under governmental aegis (such as the HEW Medicare copayment experiments or the OEO negative income tax experiment) in which consent of "subjects" may or may not be warranted by statute.

The exemption of the first two categories arises from a recognition that they involve procedures, commonly employed by social and behavioral scientists, which in most instances are wholly innocuous. We believe it is, however, useful ti differentiate the categories because the first emphasizes the subjects having an opportunity to decline to participate, while the second depends on common acceptance that the information being sought is not regarded as private. 
The third category is quite distinct, as it may involve greater risks and may touch on private matters, and consent may not always be appropriate. Here the basis for the exemption is that the research is initiated and sponsored, not merely funded, by the government and involves variations in existing or proposed federal policies and programs. Nevertheless, it is the judgment of the Commission that Federal agencies should take seriously their responsibility to assure that the integrity of subjects participating in such research is respected and that the research is conducted in a way that will provide valid answers to important questions about the cost and effectiveness of federally sponsored programs. Thus, although the precise requirements of 45 CFR 46 would not apply, we believe it is important for the Department to develop review procedures, appropriate to the individual research program, to protect the rights and welfare of people who are involved as "subjects."

We hope that our comments will assist your Department in resolving controversies which have arisen over these important issues.

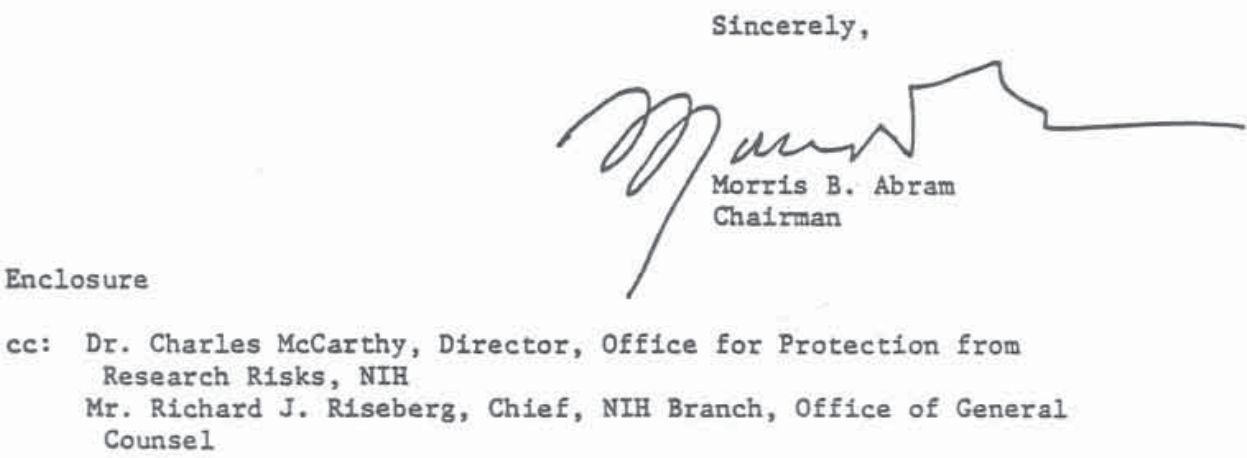


RECONMENDATIONS REGARDING PROPOSED AMENDMENTS TO HHS

REGULATIONS GOVERNING RESEARCH WITH HUMAN SUBJECTS (45 CFR 46)

The President's Commission for the Study of Ethical Problems in Medicine and Biomedical and Behavioral Research makes the following recormendations to the Secretary, HHS, regarding proposed regulations governing research with human subjects ( 45 CFR 46 ).

I. Preamble

There should be a preamble to the regulations which is an integral part of 45 CFR 46 (not simply introductory language in the Federal Register publication thereof). Such preamble should emphasize the following:

A. That the Department encourages all institutions to review and require prior approval of all research with human subjects according to procedures set forth in the regulations;

B. That the Department may withhold research grants or contracts from any institution or investigator that has failed materially to protect the human subjects of research for which he, she or it has been responsible, whether funded by the Department or not (\$46.121); and

c. That although certain categories of research may be exempt from revicw requirements, respect for subjects must always be observed and may of ten warrant procedures for obtaining informed consent. For example, students who are asked to be subjects of research involving standard educational tests should be informed that: (1) the test is not part of their required school curriculum; (2) it will have no bearing on their grade; and (3) they may choose not to participate in the test without 
fear of adverse responses on the part of their teacher or other staff of the school. Similarly, subjects of research involving the gathering of private information in return for participation in a pilot social program should be informed that their participation is voluntary (if it is) and that they may decline to participate without loss of any benefits to which they are entitled. Provisions for protecting confidentiality of data (and the extent to which data are vulnerable to subpoena or release to other government agencies) should also be explained.

II. Section 46.101

A. Paragraph (b) should be deleted and conforming changes made throughout the regulations. The Commission believes that clearer Congressional direction and statutory language than that contained in section 474 of the Public Health Service Act is necessary before federal regulatory powers can be extended to non-federally funded research activities.

B. Paragraph (c) should be revised as follows:

(b) These regulations do not apply to the following categories of research provided that the subjects are non-institutionalized, competent adults from whom informed consent will be received:

1. Research conducted in established or commonly accepted educational settings, involving normal educational practices, such as (A) research on regular and special education instructional strategies; or (B) research on the effectiveness of, or the comparison among, instructional techniques, curriculum, or classroom management. 
2. Research involving solely the use of standard educational or psychological tests and testing procedures, including diagnostic, cognitive, aptitude, or achievement tests, if the information obtained through such tests is recorded in such a manner that subjects cannot reasonably be identified, directly or indirectly.

3. Research involving solely interview or survey procedures if (A) results are recorded in such a manner that subjects cannot reasonably be identified directly or through identifiers linked to the subjects, or (B) the research does not deal with information which, if confidentiality were breached, could place the subjects at risk of criminal prosecution, civil liability, loss of employment, or other serious adverse consequences, except in settings in which subjects may feel coerced to participate (e.g., when the manner or place in which participation is solicited could imply or lead subjects to fear that noncooperation may cause treatment or services to be withheld).

4. Interviews or survey research on any topic, if the respondents are elected or appointed public officials or persons running for public office.

5. Research involving solely a combination of any of the activities described above. 
(c) These regulations do not apply to the following categories of research provided that the research presents no risk of harming subjects or of invading their privacy:

1. Survey activities involving solely product and marketing research, journalistic research, historical research, studies of organizations, public opinion polls, or management processes.

2. Research involving solely the collection of, or the study of previously collected, information that is publicly available.

3. Research involving solely observation of behavior in public places, except (A) in settings where the subjects to be observed have a reasonable expectation of privacy (e.g., rest rooms, hospitals, university dormitories, "store-front" legal offices, cashiers' stations in banks, etc.), or'(B) when events are to be staged by the investigators to test individual responses to particular situations involving potential emotional stress, embarrassment, or illegal conduct. 4. Research involving the study of documents, records, data sets, or human materials, when: (A) the sources or materials do not contain identifiers or cannot reasonably be linked to Individuals; or (B) the sources or materials were originally given in a setting in which the subjects had no reasonable expectation that they would be kept confidential.

5. Research involving solely a combination of any of the activities described above. 
(d) These regulations do not apply to research designed to evaluate federally sponsored social, economic, or health service programs, or proposed changes in such programs, where: (1) the appropriate Departmental official has been given explicit Congressional authority to modify a program for research purposes, (2) the programs or changes to be evaluated are themselves within the statutory authority of the agency to adopt, and (3) the research involves no limitation or withholding of a benefit to which the subjects are legally entitled or which other individuals, similarly situated, continue to receive under the program being evaluated. 


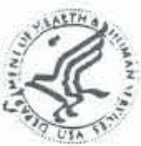

\author{
THE SECRETARY OF HEALTH AND HUMAN SERVICES
}

WASHINGTON, O.C. 20201

\title{
J4A 191981
}

Mr. Morris B. Abram

Chairman

President's Commission for the Study of

Ethical Problems in Medicine and Biomedical

and Behavioral Research

2000 K Street, N.W.

Washington, D.C. 20006

Dear Mr Abram:

I am responding further to your letter regarding Health and Human Services regulations governing research involving human subjects.

I have carefully considered your recommendations regarding coverage of human subjects research not funded by this Department and exemption from coverage for certain kinds of behavioral and social science research.

I have approved final regulations that, for the most part, adopt your recommendations and similar recommendations made by the Office of Management and:Budget and the White House Office of Science and Technology Policy.

Specifically, those regulations cover only human subjects research funded by the Department. The regulations also require institutions receiving Department human research funding to assure that they are protecting all of their human research subjects, and empower the Department to withhold research fundinc in the absence of such assurances. In addition, the regulations exempt the following kinds of research from coverage:

- Research in commonly accepted educational settings involving normal practices;

- Research involving educational tests where subjects cannot be identified by third parties;

- Research involving surveys, interviews or observation of public behavior except where subjects can be identified by third parties and could reasonably be subject to criminal prosecution or financial harm if illegal or otherwise sensitive behavior were disclosed to any third party.

- Research involving existing records which are publicly available or where subjects cannot be identified by third parties. 
Mr. Morris B. Abram - Page 2

The Secretary may also grant ad hoc waivers from coverage provided that he or she publishes a notice of this waiver in the Federal Register.

I expect these final regulations to be published in the Federal Register next week. Because they are voluminous, I am not enclosing a copy. Please contact Dr. Charles McCarthy at 496-7005 if you would like a copy of the regulations or any additional information.

Thank you for your valuable comments on these important regulations which, I am confident, will serve to enhance protection of human research subjects.

Sincerely yours,

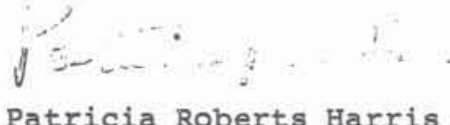

Patricia Roberts Harris 



\section{Case Studies: Five Incidents of Alleged Misconduct in Biomedical Research}

During 1980 and 1981, a number of incidents of alleged misconduct in the performance of Federally regulated research received national attention in the press. Using the press accounts as a point of departure, Commission staff assembled copies of original documents from which to piece together a description of five such incidents. (Copies of all documents cited in the footnotes, are retained in the Commission's files.) In one or two instances, where the absence of a specific procedure seemed important and the documents (although suggestive) lacked precision, the matter was confirmed by telephone conversation both with the pertinent Federal officials and with other persons involved in the matter. As the material makes clear, some of the cases have been through the entire process of HHS investigation and imposition of sanctions; other cases are still under investigation. They are recounted here for the light they may shed on local and Federal oversight processes (as discussed in Chapters Three and Five) and not as a basis for drawing any adverse conclusions about research or the IRB as a means for its regulation.

1. Boston University. In June 1978 , junior members of a research team in the oncology unit of Boston University Medical Center reported to hospital administrators that data had been falsified both in research reports and on individual patients' medical records. They also alleged that there had been violations of HEW rules on IRB review and informed consent. Within two weeks hospital administrators had convened an ad hoc investigative committee, received its reports, and initiated procedures to remove the principal investigator from its staff. They also alerted the funding agency (the National Cancer Institute) and the collaborative oncology group to which data from the research unit were submitted. In July, officials from the B.U. Medical Center 
met with high level staff at the Cancer Institute to provide further information on the incident, but were told that NCI "cannot intervene in the internal affairs of institutions, or pass judgment on individuals, in situations in which we are not directly involved." 1

Approximately six months later, in January 1979 , the Cancer Institute approved and encumbered research funds in the amount of $\$ 1$ million for the principal investigator of the B.U. Medical Center Project who by then had taken a position at a medical center in New York. None of the review groups at NIH that approved the subsequent research grant were told of the charges against the principal investigator. Two years later, after a five-day series of articles on the incident was published in the Boston Globe, ${ }^{2}$ the Cancer Institute requested an investigation of the matter by the NIH Division of Management Survey and Review. ${ }^{3}$ That investigation is still in progress, as is a parallel investigation initiated the same month by OPRR.

2. University of Kansas. In March 1977, two graduate students in the anthropology department at the University of Kansas lodged a series of complaints against a professor with whom they had worked, alleging that venepuncture and genetic counseling had been performed in a project in Central America by anthropologists and graduate students who lacked proper training for such activities. They further alleged that consent procedures were inadequate and that federal funds had been misappropriated. The Vice Chancellor for Research and Graduate Studies at Kansas found many of the charges to be unsubstantiated, but also found that the principal investigator had embarked on the research without the necessary IRB review and approval, in violation of university rules as well as applicable federal regulations. A formal letter of warning was issued to the principal investigator, but no sanctions were imposed and

${ }^{1}$ Letter to John I. Sandson, M.D., and John H. Betjemann from Arthur Upton, M.D., Director, NCI (August 8, 1978) agreeing with the position taken by his senior staff in July. A complete documentary account of the sequence of events at Boston University Hospital and NCI is contained in a chronology of events prepared by Commission staff and submitted with the testimony of the Executive and Deputy Directors at hearings held by Rep. Albert Gore, Jr., April, 1981. See, Fraud in Biomedical Research, Hearings Before the Subcommittee on Investigations and Oversight of the Committee on Science and Technology, U.S. House of Representatives (March 31, April 1, 1981) at 136-139.

2 "Spotlight" series, Boston Globe, Sunday, June 29 through Thursday, July 3, 1980.

${ }^{3}$ Memorandum from Dr. Vincent T. DeVita, Jr., Acting Director, $\mathrm{NCI}$ to Acting Director, Division of Management Survey and Review, NIH (July 3,1980 ). 
no reports were made to the cognizant federal agencies.

The graduate students, dissatisfied with the university's disposition of the matter, formally complained to the then Department of Health, Education and Welfare in September 1977 , as well as to several professional societies, including the American Anthropological Association. The Executive Board of that Association considered a report of a special ad hoc Committee of Inquiry in April 1980 and concluded "that there are no grounds for action under the Principles of Professional Responsibility." ${ }^{4}$ Here, as in the Boston University case, the principal investigator subsequently received additional HHS research funds. The Department's investigation into the matter is still in progress.

In both incidents, those who reported the alleged misconduct have fared badly. At Boston University, the junior members of the research team were dismissed along with the principal investigators when the project was halted and a multi-million dollar suit has been filed by the principal investigator against some of them for tortious interference with contractual relations. At the University of Kansas, adverse actions were taken with respect to the graduate students' academic standing. (The students and the administration differ as to the basis of those actions.) A million dollar suit for slander and libel was also filed in Kansas against the graduate students, their lawyers, and others who assisted them in pursuing their complaints. It is not clear whether the investigations under way at HHS will be completed in time for the findings to be introduced as evidence in any of the pending litigation.

3. FDA Disqualification of Dr. Nathan Kline. On November 13, 1980, the Food and Drug Administration (FDA) disqualified New York psychiatrist Nathan Kline from further drug testing on human subjects. ${ }^{5}$ This action followed hearings in September and October 1979, which were held as a result of an inspection of Dr. Kline's activities in April and May 1978. The disqualification was based upon Kline's persistent and deliberate violations of FDA rules by giving patients potent drugs not approved for human studies. There were also serious breaches of rules on informed consent and on record keeping. The FDA Commissioner concluded that Dr. Kline's action adversely affected the safety of his subjects and therefore formally disqualified Dr. Kline from further investigational drug studies over which

${ }^{4}$ Letter from Edward J. Lehman, Executive Officer, American Anthropological Association, to Anta Montet-White, Chair, Department of Anthropology, University of Kansas (April 28, 1980).

${ }^{5}$ Food and Drug Administration, Department of Health and Human Services, In the Matter of Nathan S. Kline, M.D., Commissioner's Decision (November 13, 1980). 
FDA has regulatory authority.

The Commission subsequently inquired of OPRR about the effect Dr. Kline's FDA disqualification would have on his eligibility to receive NIH grants or contracts. Specifically, Section 76.10 of the HHS debarment regulations promulgated in 1980 applies only to "serious violation of the applicable statutes, regulations, or other terms and conditions of a previous award of financial assistance" or to "disbarment from Government contracting, subcontracting or financial assistance by a Government agency (including an agency within HHS)." Therefore, it is not apparent whether debarment from activities under federal regulation (e.g., by FDA) would necessarily be interpreted as cause for debarment under Section 76.10.6

In reply, Dr. McCarthy, OPRR's director, reported that his office had been alerted by FDA about Dr. Kline's formal disqualification (some four or more moths after the determination had been reached) and had placed his name on an "alert" system so that appropriate NIH officials would be notified if any applications for research grants or contracts are received from Dr. Kline in the future. ${ }^{7}$ (It does not appear that the "alert" system is specified in any HHS regulations, so that the Commission is unable to evaluate the appropriateness of the criteria employed for a person's inclusion nor for the sanctions, if any, that are imposed on those included.)

Dr. McCarthy further reported that Dr. Kline currently had no research support from either NIH or ADAMHA (the Alcohol, Drug Abuse, and Mental Health Administration) and that the FDA disqualification would not automatically result in NIH debarment or even in the initiation of debarment proceedings. Instead, NIH would take the reasons for the FDA disqualification into account "along with all other pertinent information" in considering whether to initiate debarment proceedings. ${ }^{8}$ Although it is technically correct that there are no NIH or ADAMHA research grants to Dr. Kline as principal investigator, there is-apparently unbeknownst to OPRR-an NIH Biomedical Research Support Grant to Rockland Research Institute which lists Dr. Kline as the Program Director. ${ }^{9}$ The most recent award under that grant (now in its 15 th year) was in the amount of $\$ 36,174$

${ }^{6}$ Memorandum from Deputy Director, President's Commission, to Director, OPRR (Feb. 19, 1981).

${ }^{7}$ Letter from Charles R. McCarthy (Director, OPRR) to Barbara Mishkin (Deputy Director, President's Commission) (May 19, 1981).

${ }^{8}$ Id.

${ }^{9} \mathrm{Grant}$ \#2S07RR05651-15. 
covering a period from April 1, 1981 through March 31, 1982. Dr. Kline is a member of an 8-person committee at Rockland Research Institute that decides how the money will be allocated. ${ }^{10}$ For a person "disqualified" by the FDA, the consequence in terms of research support from HHS may be both more and less than one would gather from the regulations.

4. UCLA Medical Center. Early in 1979, a group of nurses complained to the IRB at the UCLA Medical Center that physicians had been performing experimental bone marrow transplants without IRB approval. Although it is not entirely clear to what extent the transplants and accompanying chemotherapy were innovative, "last-ditch" therapies for seriously ill patients, and to what extent they constituted "research," UCLA rules require review of all such activities by the IRB (known at UCLA as the Human Subjects Protection Committee). In fact, in a letter to the Commission staff, Dr. Sherman Mellinkoff, the Dean of the Medical School, reported that: "the investigators ... made a misjudgment when they altered the protocol for the treatment in vitro of bone marrow obtained for patients in remission prior to its reinfusion into the patient from whom it had been obtained." 11

Dr. Mellinkoff further reported that as a result of an inquiry by a panel of physicians appointed by the administration of the medical center, the researchers "were told that the university's policy was to follow precisely the regulations related to human subjects protection ... [and] that serious violations of these regulations would require us to request that the funding agencies withdraw their support." Dr. Mellinkoff further noted that "since [then-applicable] federal regulations do not require reporting of an inquiry or warning by a university to its researchers and since no patient had been endangered by the change in protocol, the funding sources were not notified." 12

Nevertheless, one of the UCLA physicians working on experimental bone marrow transplantation, subsequently became the first biomedical investigator formally sanctioned by NIH for violations of human subjects regulations in research supported by HHS. These sanctions resulted from another experiment in which patients in Israel and

${ }^{10}$ Letter from Dr. Thomas Bowery, Director, NIH Biomedical Research Support Program, NIH to Barbara Mishkin (December 2, 1981) attaching 14th Year Annual Progress Report of Rockland Research Institute, which lists members of Allocation Committee at p.6.

${ }^{11}$ Letter from Sherman Mellinkoff to Alexander M. Capron, Executive Director, President's Commission (February 5, 1981).

${ }^{12}$ Id. 
Italy were treated with altered bone marrow in violation of applicable rules governing both the use of recombinant DNA techniques and the protection of human subjects. ${ }^{13}$ Specifically, Dr. Martin J. Cline failed to disclose to the IRB at Hadassah Hospital in Israel, or to the patients in Israel and Italy, that the bone marrow transplants would contain recombinant DNA material ${ }^{14}$ despite the fact that the review board at Hadassah went to considerable length to verify that the procedure would not involve recombinant DNA. ${ }^{15}$ (There are no review committees in Italy comparable to IRBs. ${ }^{16}$ ) Moreover, the procedures he used were the same as those submitted to the IRB at UCLA in May 1979 and disapproved on July 16,1980 , after four outside consultants all advised that more animal studies should be conducted prior to human experimentation. ${ }^{17}$

The UCLA general assurance with HHS specifically states that all research performed by UCLA employees (even if performed elsewhere) must be reviewed by an IRB at the collaborating institution; and UCLA must receive a report of that review. ${ }^{18}$ Although no NIH funds were used to perform the studies abroad, or to pay the cost of the trip, the materials used in Israel and Italy were prepared at UCLA as part of research supported by NIH. ${ }^{19}$

The Office for Protection from Research Risks at NIH first became aware of the possibility that Dr. Cline had performed research using recombinant DNA and in violation of $\mathrm{NIH}$ rules in September 1980. Following a letter from the NIH Director to the UCLA Chancellor, and the Chancellor's reply, the Director established an ad hoc committee to consider the report from UCLA, determine whether NIH regulations had been violated, and recommend appropriate action. Meanwhile Dr. Cline's resignation from his position as Chief of Hematology and Oncology was accepted by the UCLA Chancellor and the Medical School Dean as appropriate under the circumstances.

${ }^{13}$ Statement of the Director, NIH, accompanying the release of the Report concerning Martin J. Cline, M.D. (May 26, 1981).

${ }^{14}$ Memorandum from Chairman, NIH Ad Hoc Committee on UCLA Report (transmitting the Committee's report) to Director, NIH (May 21,1981 ) at $7-10,16-21$.

15 Id. at $14-15,21$.

${ }^{16} \mathrm{Id}$. at 10.

${ }^{17}$ Id. at 6 . The IRB voted on July 16,1980 to disapprove the protocol. Dr. Cline was formally notified on July 22; the procedure was performed on the patient in Israel on July 10, 1980 and on the patient in Italy on or about July 15, 1980.

${ }^{18}$ Id. at $11-12$.

${ }^{19} \mathrm{Id}$. at 20. 
The NIH ad hoc committee reported in May 1981 that Dr. Cline's activities violated both the NIH Guidelines on use of recombinant DNA and the Department's regulations for the protection of human subjects. The Committee recommended that four actions be taken and NIH Director Fredrickson accepted them all: (1) prior NIH approval will be required for any new application from Dr. Cline for NIH support of research involving human subjects; (2) prior NIH approval will be required for each project of his involving recombinant DNA; (3) the Director of each NIH Institute currently supporting research grants for which Dr. Cline is principal investigator should forward the report of the Ad Hoc Committee to the Institute's Advisory Council for advice regarding continuation of such grants; and (4) for each application for new or competing renewal of $\mathrm{NIH}$ grants, the study sections and National Advisory Councils shall consider the report of the Ad Hoc Committee in making decisions regarding support of the research. ${ }^{20}$

All four recommendations were implemented. In September and October 1981, National Advisory Councils of the three NIH institutes that had been funding Dr. Cline's research reviewed the ad hoc committee's report and forwarded their recommendations to the Acting Director, NIH, through the Associate Director for Extramural Research and Training who endorsed all but one recommendation. ${ }^{21}$

The National Institute of Arthritis, Diabetes and Digestive and Kidney Diseases has been supporting Dr. Cline's research in "A New Method of Bone Marrow Culture," providing $\$ 33,172$ in direct costs for September 1981-August 1982 , and for the next two years, $\$ 41,232$ and $\$ 44,109$, respectively. This Institute recommended that each annual report be signed by a responsible official of UCLA certifying that the research was carried out "in keeping with the intent and conditions for which the award was made." 22

The National Heart, Lung, and Blood Institute is currently supporting Dr. Cline's research on "Treatment of Hemoglobinopathies by Gene Insertion," providing $\$ 81,647$ in direct costs, the first year, and $\$ 78,647$ and $\$ 83,787$ in two subsequent years. Its Advisory Council, after considering the record and debating the issues, concluded that "the actions of Dr. Cline are reprehensible and ... warrant disciplinary action." The Council supported the NIH actions already taken and further recommended that Dr. Cline provide assurance that he will not engage in human

${ }^{20}$ Statement of the Director, NIH, supra, note 39.

${ }^{21}$ Memorandum from Associate Director for Extramural Research and Training to Acting Director, NIH (Nov. 12, 1981).

${ }^{22}$ Id. 
experimentation involving recombinant DNA for a period of three years. Finally, the Council voted to terminate the Heart, Lung and Blood Institute's support of Dr. Cline at the end of the first year (March 31, 1981.) ${ }^{23}$

The National Cancer Institute has been funding two grants of which Dr. Cline is principal investigator; one, a research grant, was funded through November 1981 but was scheduled to run through May 1982; the other, a project grant covering four program areas in medical oncology, has been revised by UCLA for consideration for renewal with a new principal investigator. The National Cancer Advisory Board recommended that Dr. Cline's research grant be funded through the originally scheduled termination date of May 31, 1982. The Board also recommended that the project grant be supported through February 28,1982 , to provide continuity until the revised application (with the new principal investigator) could be reviewed by the Board at its January meeting. The Board also recommended, however, that Dr. Cline not receive any further support from the extension of the grant. ${ }^{24}$

Although Dr. Cline had been asked to comment on a draft of the NIH ad hoc committee's report and had replied that he had no response to make "at this time," ${ }^{25}$ he was not invited to respond at any other time or in any other manner to the charges against him. ${ }^{26}$ Finally, knowing the ad hoc committee's negative conclusions but not knowing when the advisory councils would act upon them nor how to contact the councils, Dr. Cline sent a letter to the Executive Secretary of the ad hoc committee on September 17, 1981 , to be forwarded to the advisory councils "providing arguments in support of his actions as well as more general comments on review and approval of innovative research." 27 That letter, however, was not received by NIH until September 28 and thus was too late to be taken into consideration by the two National Advisory Councils that reviewed his case on September 24 and 25. Only the National Cancer Advisory Board (which did not meet until October 6) had Dr. Cline's letter at the time of its consideration

${ }^{23} \mathrm{Id}$.

${ }^{24}$ Id.

${ }^{25}$ Report of NIH Ad Hoc Committee, supra note 40, at 19.

${ }^{26}$ Confirmed by personal communications (Nov. 23, 1981) with Dr. Charles McCarthy, Director, OPRRR and Dr. Martin Cline. Dr. Cline expressed frustration at his inability to get his explanatory letter to the Advisory Councils in time for them to take it into consideration, noting that no one told him the dates of the Council meetings or how to address communications to them.

${ }^{27}$ Memorandum from Associate Director for Extramural Research and Training, supra note 47. 
of the matter. ${ }^{28}$

Authorities cited by NIH for imposition of the sanctions included: (1) grants administration regulations for terminating or suspending a grant and related provisions for appeal of such action to the Department's Grants Appeals Board; (2) HHS regulations for attaching conditions to grants as a consequence of poor performance; (3) the regulations governing research with human subjects that state that the Secretary may withhold or withdraw departmental support of research from investigators or institutions that "fail materially" either to comply with the terms of a grant or to protect human subjects; and (4) similar provisions contained in guidelines governing NIH-funded projects involving recombinant DNA. ${ }^{29}$ The regulations setting forth the procedures for debarment and suspension (that provide an accused scientist with notice and an opportunity for a hearing) were not invoked. ${ }^{30}$

5. M.D. Anderson Hospital and Tumor Institute (University of Texas System Cancer Center, Houston). In June 1981, an employee of the National Cancer Institute (NCI) read a brief medical journal report by researchers at M.D. Anderson Hospital on the administration of a new drug, 5-methyltetrahydrohomofolate (referred to as MTHHF), to six cancer patients. The report was noteworthy because MTHHF had not been cleared for use in human subjects by either the Food and Drug Administration or by NCI at the time the research was conducted. Subsequent investigation revealed that the drug had been provided to the principal investigator by NCI under a contract explicitly limiting its use to animal research. NCI officials immediately wrote to administrators at M.D. Anderson and to the principal investigator, suspending further work on MTHHF and announcing a site visit to take place on July $13,1981 .^{31}$

The significance for the President's Commission of the

${ }^{28}$ Id.

${ }^{29}$ See, 45 CFR 74, Subpart M; 45 CFR Part 16; 42 CFR Part 50, Subpart D; 45 CFR 74.7; 45 CFR 46.121-122; 45 Federal Register 77384 (November 21, 1980).

${ }^{30} 45$ CFR 76 (45 Federal Register 67262, October 9, 1980). In the executive summary of the regulations, Secretary Patricia R. Harris stated: "the effect of the regulations will be to establish a procedure, with due process safeguards, to render persons ineligible to receive HHS financial assistance for reasonable periods of time." The regulations became effective on November $10,1980$.

${ }^{31}$ Memorandum from Deputy Director, NCI to Director, NCI (July $24,1981)$ on: Clinical Pharmacology Study of [MTHHF] carried out at M.D. Anderson Hospital and Tumor Institute, University of Texas System Cancer Center, Summary Report of NIH Site Visit Team. 
lengthy site visit report and accompanying documents lies not solely in what was discovered about the MTHHF experiment that was conducted in 1980 , but rather in the evidence that was turned up which reveals serious deficiencies in the review process at M.D. Anderson and in the response to that evidence made by officials at NCI and NIH. Equally notable was the lack of communication between the NIH and FDA (which had inspected the IRB at M.D. Anderson less than half a year earlier). ${ }^{32}$ This suggests that the coordinated oversight of IRBs falls a good deal short in reality of the system that is set forth on paper.

Among the documents reviewed by the site visitors were a protocol by another investigator for "Phase 1 Evaluation of Homofolic Acid" (homofolic acid is another name for MTHHF) and an accompanying consent form, both of which had been approved by the hospital's IRB in August 1978. ${ }^{33}$ The study was never carried out as described in the 1978 protocol, but this was the only documentation available to the NCI site visit team, since the study actually conducted during 1980 was not based on a protocol or set of consent documents approved by the IRB. The information available about the 1978 protocol suggests that the consent form employed there was a general form used for Phase 1 trials (i.e., only the name of the drug had to be filled in), and this surmise is confirmed by a later statement of a hospital administrator, who described the consent form as the standard one in use at the time. ${ }^{34}$

In light of the clear violation of both FDA and HHS rules that had brought the nine member site visit team (including one representative of OPRR) to Houston, the apparent deficiencies in the IRB review procedures and in the standards for informed consent (which are described in greater detail below) might have triggered a broader investigation of the protection of human subjects at M.D. Anderson Hospital. Instead, sanctions were directed primarily at the principal investigator; broader remedies were limited to specific steps to tighten up the procedures of the hospital's pharmacy and a formal directive that the hospital

${ }^{32}$ Report of IRB Inspection of M.D. Anderson Hospital, FDA (March 20, 1981).

${ }^{33}$ Summary Report of NIH Site Visit Team, supra note 57 . The protocol, numbered DT 78-31, the consent form, and the certification of IRB approval are among background documents attached to the site visit report.

${ }^{34}$ Testimony of James Bowen, Associate Vice President for Research, M.D. Anderson, before a joint hearing of the Subcommittee on Health and the Environment, Committee on Energy and Commerce and the Subcommittee on Oversight and Investigations, Committee on Science and Technology, U.S. House of Representatives (October 27, 1981). 
"develop a document that describes in detail the policies and procedures for clinical research using investigational drugs, including protocol review and approval, IRB procedures ..."35 - the absence of which demonstrates failings that ought never to have existed if the institution's "general assurance" with HHS had been adequately implemented in the first place. A follow-up site visit to determine how well the procedures described in the new document are being implemented was deferred for six months; by contrast, a representative of the NCI's Investigational Drug Branch returned to M.D. Anderson on July 28, 1981 (two weeks after the initial site visit), to review records of additional studies. This second visit turned up further problems (both in protocol review and in consent forms) which were characterized by the Deputy Director of NCI as being "general" in nature. ${ }^{36}$

The problems with the MTHHF protocol as approvedwhich might have been shown to be "general" problems had OPRR also chosen to follow up immediately with a broader inquiry - were numerous. Three stand out: the lack of clarity about the type of study subjects were being asked to join, the failure to reveal potential adverse effects, and the misleading impression created that the drug-actually in the earliest phase of testing-was being offered as treatment of a disease.

The objectives of the study, as set forth in the approved protocol, were:

(1) To determine the maximum tolerated dose of MTHHF administered by single dose intermittent intravenous infusion;

(2) To determine the qualitative and quantitative toxicity and reversibility of toxicity of MTHHF administered in this fashion; and

(3) To investigate the clinical pharmacology of MTHHF and rationale for dose and schedule chosen.

These objectives fell into two groups: (1) and (2), which concerned toxic effects, and (3) which was aimed at discovering the drug's metabolism, absorption and the like. Together, these objectives define a "Phase 1 test," as the FDA

${ }^{35}$ Report of NIH Site Visit Team, supra note 57 , at 8 . OPRR recently reported additional "intensive interaction" with M.D. Anderson "to develop revised procedures which explicity bar 'Standard' or 'Master' [consent] forms." (Comments on November draft Biennial Report.) The use of standard forms, however, was already explicitly barred by the hospital's 1975 "Code and Methods of Procedure" for activities involving human subjects.

${ }^{36}$ Memorandum from Deputy Director, DCT, NCI, to Director, NCI, on Follow-up on M.D. Anderson Site Visit (August 6, 1981). 
terms it-namely, research to answer basic questions about pharmacokinetics and safety through initial trials in the first few human beings after laboratory and animal work has been completed.

It is a matter of some importance that these two sets of purposes be made very clear, both in the protocol and (particularly) in the consent form, since the effects of the two aspects of the study are likely to be very different for the subjects. In the second branch of their experiment, it was intended to give a relatively small dose of MTHHF "labeled" with a small amount of radioactivity. This amount would be too small to be expected to have any effect on patient-subjects' tumors. The size of the dosage probably explains why the consent form would put these words into a prospective subject's mouth: "I understand ... that the amount of drug used solely for the pharmacology studies ... will be free of toxic effects." 37

Any subject who understood the term "pharmacology studies" to be synonymous with the experiment itself-an understandable, indeed predictable, mistake, given the way the consent form is written-would have gotten the misleading impression that the study as a whole, to the extent it was not treatment, would be "free of toxic effects." Yet, the other branch of the study design was actually a search for "the highest dose which does not cause the following toxicities," which had been reported from studies on dogs and monkeys: ${ }^{38}$

severe hemolytic anemia, ... congestive heart failure, life-threatening arrhythmias, .... severe diarrhea requiring hospitalization for fluid replacement, ... coma, seizures, nerve paralysis, progressive mental deterioration or weakness.

The standard to be used was that

if three patients develop any of the above toxicities at a similar dose level during Phase 1 evaluation, the dose will be considered to be above the maximum tolerated dose. ${ }^{39}$

The amount of the drug that would produce those effects in humans was unknown; by step-wise increments (or decrements, if the initial guess on tolerable dosage was too high) the researchers intended to find the point where these (or other) toxic side effects would begin.

One would expect such possible consequences to be

${ }^{37}$ The consent form is contained in the Summary Report of the NIH Site Visit Team, supra note 57.

${ }^{38}$ Id., Protocol DT 78-31, paragraph 3.14: Animal Toxicology.

${ }^{39}$ Id., Protocol DT 78-31. Appendix A, Maximum Tolerated Dose. 
spelled out clearly in the consent form. They were not mentioned. Of course, under the HHS rules in effect at the time the protocol was approved, it was also (and still is) permissible to use a "short form" written consent that indicates that "the basic elements of informed consent have been presented orally to the subject." But in that case, "written summaries of what is to be said to the patient are to be approved by the Board." The rules required that the form be signed not only by the subject but also "by an auditor witness to the oral presentation and to the subject's signature. A copy of the approved summary, annotated to show any additions, is to be signed by the persons officially obtaining the consent and by the auditor witness." 40 No such summaries were prepared for, or approved by the IRB (nor do any such forms and procedures appear to have employed in the MTHHF study actually performed 1980), which violated not only the HHS regulations but M.D. Anderson Hospital's own general assurance. ${ }^{41}$

The failure of the consent form to describe the risks of the experiment is more grave because of another, perhaps central, deficiency in the form: it gives the impression that the cancer patient is being asked to consent to treatment, with perhaps some small added studies ("free of toxic effects") on the side. The form does not make clear that MTHHF had never before been administered to humans and therefore that its possible efficacy was wholly unknown. The language of the consent form, as approved by the IRB, is instead replete with references to "therapy" and "my treatment." Indeed, after formal language naming the physician and the "treatment," the body of the consent form be-

${ }^{40}$ Section 46.110 of the 1974 regulations required documentation of the "actual procedure utilized in obtaining legally effective informed consent and the basis for Institutional Review Board determinations that the procedures are adequate and appropriate." The documentation of consent was permitted to take one of two forms in biomedical research. When the "short form" written consent procedures was utilized, the document must indicate "that the basic elements of informed consent have been presented orally to the subject or his legally authorized representative." Sample copies of the consent form and of the summaries as approved by the Board must be retained in its records.

More typically, a subject is provided with "a written document embodying all of the basic elements of informed consent. This may be read to the subject or to his legally authorized representative, but in any event he or his legally authorized representative must be given adequate opportunity to read it." The regulation required that the document be signed by the subject or his legally authorized representative, and that "Sample copies of the consent form as approved by the Board ... be retained in its records."

${ }^{41}$ Report of FDA's Inspection Report, supra note 58, Exhibit \#2. 
gins with the assertion: "I am about to receive a form of chemotherapy recommended by my physician. He has explained the potential benefits and hazards of this treatment to me." 42

Although the NCI site visitors' report did note that the consent procedures in this case failed to conform to the HHS regulations and the hospital's general assurance, most of the attention (and subsequent sanctions) were based upon the principal investigator's having acted on the (incorrect) assumption that in the two years since the IRB approved the protocol, appropriate clearance had been obtained from the FDA and NCI to administer the drug to humans. There was no apparent concern that the deficiencies revealed in the MTHHF consent form might be widespread or that the IRB should have mechanisms to assure that all additional certifications are in place prior to giving its final approval for a research project. ${ }^{43}$ Nor did the site visitors find noteworthy the fact that at least two IRB members had disagreed as to whether the research would be "therapeutic" for the subjects and, moreover, had advised that additional information be provided in the consent forms. ${ }^{44}$

The response of both $\mathrm{NIH}$ and the administrators at M.D. Anderson was to direct strong criticism and sanctions against the principal investigator. NIH terminated all work under the contract in question, except for two studies "of high programmatic priority" for which a new principal investigator was named, and the government sought reimbursement of funds used to support the unauthorized clinical studies. ${ }^{45}$ The hospital, in addition, formally censured the principal investigator and barred him from further participation in studies involving human subjects. He was also relieved of all responsibilities as principal investigator or co-principal investigator on federal contracts or grants. (Both of the latter sanctions are of indefinite duration but

${ }^{42}$ Consent form in Summary Report of NIH Site Visit Team, supra note 57.

${ }^{43}$ The principal investigator had also failed to obtain approval from the hospital's Radioactive Drug Research Committee, which was required for use of radioactive "labels" which facilitate study of the subjects' metabolism of the drug.

${ }^{44}$ Summary Report of NIH Site Visit Team, supra note 57, Reviews of Protocol DT 78-31 by Alexander Y.M. Wang, Ph.D. (81878) and W.W. Sutow, M.D. (August 2, 1978).

${ }^{45}$ Memorandum from Director, NCI to Acting Director, NIH (August 6,1981 ) forwarding Recommendations Regarding Ti Li Loo, Ph.D. and the M.D. Anderson Hospital and Tumor Institute, University of Texas System Cancer Center and attached Site Visit Report. 
are subject to periodic review. $)^{46}$

A joint NIH/NCI panel that reviewed the site visit report added two additional sanctions: that the investigator's infraction be brought to the attention of the appropriate NIH advisory council should he submit a grant or contract proposal during the next two year period and that he not be asked to serve on any NIH advisory committees or as a site visitor during that same period. ${ }^{47}$

The Director of OPRR reported to the Commission that his office engaged in additional correspondence and telephone calls with M.D. Anderson, following the formal imposition of sanctions by $\mathrm{NIH}$, in an effort to improve the hospital's overall review procedures. The only recommendations directed at the institution and formally endorsed by the Acting Director of NIH, however, were that its procedures for handling investigational new drugs be improved with respect to documentation, record keeping and distribution from the pharmacy and that "documents be developed by the University which describe the policies and procedures for the clinical research utilizing investigational drugs, which will ensure compliance in the future with the NCI policy and HHS regulations for the protection of human subjects with follow-up visits by $\mathrm{NCI}$ and the Office of Protection for Research Risk [sic]." 48

Throughout, officials at NIH remained unaware of the routine FDA inspection of M.D. Anderson that had taken place on March 20,1981,49 despite the assurances given to the President's Commission that NIH has developed good communication with FDA and that "when FDA inspectors find any practice which may constitute noncompliance with 45 CFR 46, the HEW regulations, OPRR is immediately notified." ${ }^{50}$ Perhaps OPRR was not notified of the clear deficiencies reported by the FDA inspectors because, although the reviewers noted a failure to conduct annual review of individual protocols (instead, the IRB reviewed and reapproved the "parent project" which might contain any number of individual protocols), the FDA classified the re-

${ }^{46}$ Id.

${ }^{47}$ Id.

${ }^{48}$ Id. The sanctions recommended by NCI were approved by the NIH Acting Director on August 11, 1981. (See concurrence signature on p.4 of the memorandum.)

${ }^{49}$ Testimony of Charles MacKay, Deputy Director, OPRR, at 14th meeting of the President's Commission (Nov. 14, 1981) at 323.

${ }^{50}$ Testimony of the Director, OPRR at the 2nd meeting of the President's Commission (May 16, 1980) at 82. See also, letter from Dr. Charles R. McCarthy to Morris B. Abram (May 7, 1980) at 4. 
sults of its inspection as "No Action [is] Indicated." 51 The failure of the IRB to review each protocol, however, violates regulations governing research supported by HHS as well as FDA's own regulations governing research with investigational new drugs. Moreover, while the FDA investigation showed that, in the case of the drug reviewed, the IRB had required modifications in the consent form, the important changes recommended by the two IRB members with primary review responsibilities in that case were not in fact incorporated in the revised form as approved. ${ }^{52}$ Finally, the form (also for a Phase 1 drug study) is less than clear and candid about the likelihood (or lack thereof) of therapeutic benefit to subjects and contains "boilerplate" language that certain information has been provided, rather than a full description of the information itself. In the absence of any summary of the risks, the consent form and the IRB review process described in the FDA inspection documents appear not to meet the HHS regulations and the hospital's general assurance, just as was true in the IRB's handling of the 1978 MTHHF protocol.

It appears, therefore, that neither the FDA nor the NIH has developed inspection procedures that are sensitive to significant factors; moreover, communication between FDA and NIH regarding their site visits is far from adequate. An additional problem is whether "Phase 1" tests of new cancer drugs can be considered "therapeutic" and, if so, whether they should still be classified as "Phase 1."

${ }^{51}$ FDA Inspection Report, supra note 58 , at 1.

${ }^{52}$ Id. See, Exhibits la-d, 4c, and 4d. 


\section{Correspondence with HHS Regarding Procedures for Responding to Reports of Misconduct}

Date

September 18, 1980 Chairman wrote to Sec'y Harris, summarizing events at Boston Univ. and Kansas, and inquiring about HHS policies and procedures for enforcing its regulations. Questions related to:

1. how grantee institutions are expected to implement and enforce the regulations;

2. definitions of "material failure" to comply;

3. standard of proof for a finding of material failure;

4. "due process" for accused investigators;

5. policies of HHS re current grants/contracts and pending applications of researchers accused of serious misconduct; and

6. policies of HHS re disqualification from future grants/ contracts after a finding of material failure to protect human subjects - and circumstances under which such action has been or would be taken.

October 9, 1980
HHS issued regs "to establish a procedure with due process safeguards" for debarment and suspension of grantees and contractors. 
November 18, 1980 Secretary Harris sent partial response, attaching an Aug. 7 memo from $\mathrm{NIH}$ Director Fredrickson (who indicated that debarment regulations "are designed primarily to handle violations of business management policies ... [but] fradulent research practices present a different set of problems"). Secretary Harris promised a fuller response after Assistant Secretary for Health (Richmond) had studied the problem.

February 19, 1981 Commission staff asked Director, OPRR, about the effect of FDA Disqualification (for violations of regs. governing research with human subjects) on a scientist's eligibility to receive NIH/ADAMHA grants and contracts.

April 15, 1981

Secretary Schweiker responded to Chairman's letter of Sept. 18 by answering most questions with "that depends upon the facts of a particular case" and by referring to the debarment regulations.

May 11, $1981 \quad$ Chairman asked Secretary Schweiker for a meeting to discuss issues not fully resolved by his April 15th response.

May 19, 1981 Director, OPRR, responded to staff inquiry that FDA disqualification would not be grounds per se for NIH debarment but would be taken into account if the scientist submitted an application for NIH/ADAMHA support.

July 10, 1981 Staff asked NIH Legal Advisor and Director, OPRR, to discuss at September meeting of Commission the role of the IRB in responding to reports of misconduct; also, to explain NIH procedures for responding to such reports. They agreed to do so.

August 17, 1981 Staff memo to NIH Legal Advisor and Director, OPRR set forth questions to address at Sept. meeting:

1. the role of the IRB in "continuing review" of research;

2 . the role of the IRB in reporting incidents of non- 
compliance to HHS; and

3 . the role of offices at NIH (general counsel, OPRR, Division of Management Survey and Review, Associate Director for Extramural Programs) in responding to reports of misconduct-and the conditions under which debarment proceedings can or would be triggered.

August 24, 1981 Secretary Schweiker responded to Chairman that since several investigations of fraud and misconduct are in process, it would not be appropriate to meet with him "at this time." However, Dr. McCarthy will continue to assist the Commission.

September 1, 1981 Dr. McCarthy wrote that the Secretary's August 24 letter reminds him. "it is not appropriate to appear before the Commission" until investigations have been completed-and declines to make a presentation at the September meeting.

September 4,1981 Staff writes Dr. McCarthy explaining (again) that our questions have to do with process, not the substance of ongoing investigations.

September 4, 1981 Dr. McCarthy responds that he would be pleased to respond to our questions in writing.

October 28, 1981 The Secretary agrees to a meeting with Commission Chairman.

November 5, 1981 Staff writes Dr. McCarthy, urging that he submit his responses as soon as possible, since the Biennial Report (already in draft form) must be submitted to Congress by the end of the year.

November 14, 1981 Dr. McCarthy delivers a response (dated November 10) in which he again declines to answer the questions posed, since the Secretary has agreed to a meeting with the Commission Chairman and staff. 
President's Commission for the Study of Ethical Problems in Medicine and Biomedical and Behavioral Research 2000 K Street, N.W., Suite 555, Washington, DC 20006 (202) 653-8051

September 18, 1980

\author{
Honorable Patricia Roberts Harris \\ Secretary \\ Department of Health and Human \\ Resources \\ Washington, D.C. 20201 \\ Dear Secretary Harris: \\ I am writing on behalf of the President's Commission to request \\ information pursuant to Title XVII, Sections 1802 (c) and 1803 (d) (1) \\ of the Public Health Service Act, regarding reported incidents in which \\ HHS grantees appear to have violated existing regulations for the \\ protection of human subjects ( 45 CFR 46 ). If correct, these reports \\ raise serious concerns particularly with respect to implementation of \\ the Department's rules.
}

\title{
A. Boston University
}

The first incident involves alleged violations of HHS requirements for IRB review and informed consent, as well as falsification of research data, that occurred in the Boston University research unit (headed by Dr. Marc H. Straus) conducting studies supported by the National Cancer Institute. We understand from Dr. Charles McCarthy, Director of the Office for Protection from Research Risks (NIH), that several investigations into this incident are in process within the Department. We would like to receive copies of any and all reports on this matter that are submitted to you, and be notified of any Departmental action taken.

In addition, we are particularly interested in learning the reasons underlying the decision by officials of the Cancer Institute not to share their information about the allegations with the review groups, both within the Department and at the university, that subsequently approved awards of further research funds to the principal investigator involved. We recognize that no proof of direct complicity in the scheme by the principal investigator has been made; nevertheless, since he is responsible for research performed under his direction, and since published accounts report that the abuses have been acknowledged, the case seems clearly to fall within the situation contemplated by the applicable regulations: 


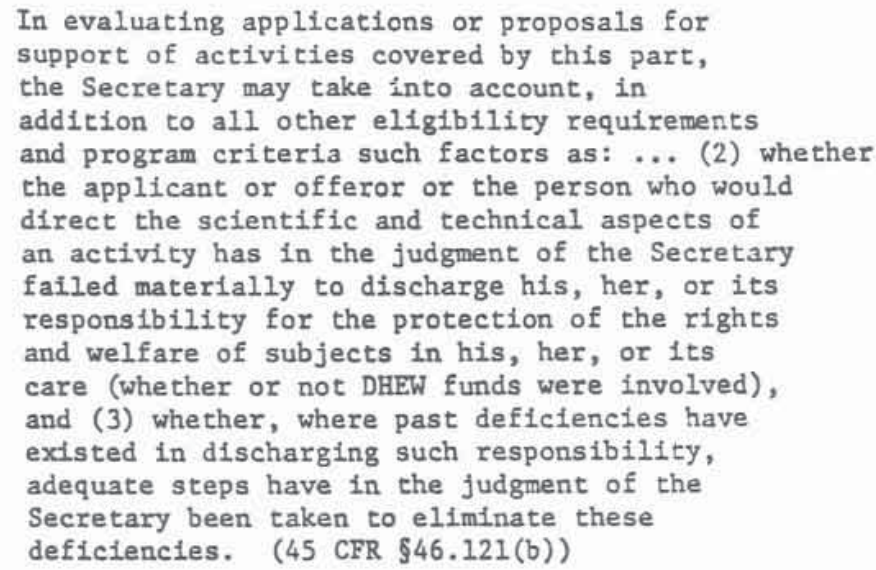

The Commission views falsification of patients' medical records for research purposes as a serious matter. Such falsification has the potential for causing inaccurate evaluations of a patient's condition and consequent errors in treatment. Palse data also put all subjects In a research project at risk to the extent that decisions regarding continuation or cessation of a clinical trail, and subsequent conclusions regarding preferred treatment, will be based upon incorrect data. The Commission is considering whether an institutuion's IRB and the Department's own review groups should have an opportunity to take into account allegations, admissions, or proof of material failures to protect human subjects when these groups are deciding about the continuation of research activities or the awarding of further funds to the principal investigator or the research unit involved.

\section{B. University of Kansas}

The second incident which has come to our attention involves a study at the University of Kansas in which an anthropologist appears to have diverted federal funds from approved projects to support research that was neither reviewed nor approved by the IRB. The research involved performance of venipunctures and genetic counseling by anthropologists and students with no formal training in either activity. Questions have been raised, as well, about the consent procedures that were used. This Incident is also under investigation by your Department. We understand from Dr. McCarthy's office that a report by the Inspector General regarding the principal investigator's funds has been forwarded to you and that OPRR is now in a position to investigate those aspects of the case that Involve possible violations of $45 \mathrm{CFR} 46$. Agaln, please send us copies of any and all reports you receive on this matter and notify us of any action taken.

These two incidents raise questions regarding the relationship between the Department, the grantee institutions, and principal investigators about which the Commission would be interested in learning your current policy: 
1. What does the Department intend by the following statement?

Safeguarding the rights and welfare of subjects at risk in activities supported under grants and contracts from DHEW is primarily the responsibility of the institution which receives or is accountable to DHEW for the funds awarded for the support of the activity. ( 45 CFR $\$ 46.103(e)$ )

2. How are the institutions expected to insure that all research is reviewed as required and conducted in a manner that conforms to the approved protocol? What action is an institution expected to take if an investigator fails to comply with either HHS or institutional rules? by:

3. What constitutes "materfal failure" to protect human subjects
a) the institution?
b) the principal investigator?

4. What standard of proof does the Department require for a finding of such material failure?

5. What is considered "due process" necessary to protect the rights of an investigator alleged to have failed to protect human subjects for whom he or she is responsible?

6. During the period when allegations of wrongdoing are being investigated and resolved, what steps are taken by the Department to Insure the protection of human subjects in ongoing research conducted under the direction of that investigator and in research for which the Investigator has pending or subsequently submitted applicacions?

7. What determines the response of HHS after a finding of material failure to protect human subjects? Is there a policy regarding ineligibility to recelve further research grants or contracts for a certain period of years? May an investigator or institutaion be disqualified, permanently or for a period of years, from receiving further research support from the Department? Under what circumstances, if any, has such action been taken? Under what circumstances, if any, would the Department take such action in the future?

Finally, I should 11ke to note that the Commission appreciates the assistance and cooperation we have received from both Dr. Charles McCarthy and Mr. Richard Riseberg. We look forward to continuing productive relations with these and other members of your staff.

Sincerely yours,

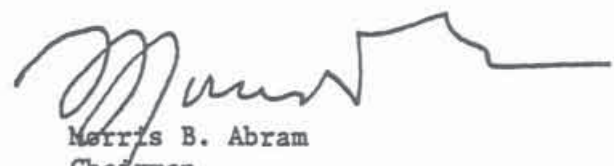

cc: Dr. Charles McCarthy, Director, office/for Protection from Research Risks, NIH

Mr. Richard J. Riseberg, Chief, NIH Branch, Office of General Counse 1 


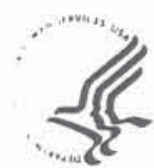

THE SECAETARY OF HEALTH AND HUMAN SERVICES

WASHINGTON, D.C. 20201

NOV 181980

Mr. Morris B. Abram

Chairman

President's Commission for the study of

Ethical Problems in Medicine and Biomedical

and Behavioral Research

2000 K Street, N.W., Suite 555

Washington, D.C. 20006

Dear Mr. Abram:

Thank you for your September 18 letters regarding the proposed regulations governing research with human subjects and requesting information regarding incidents in which HHS grantees appear to have violated existing regulations for the protection of human subjects.

I have asked Dr. Richmond to study these issues and report to me. I will respond to you further after I have reviewed his report.

In response to your request for reports on the incident at Boston University, I am enclosing a memorandum I received from Dr. Fredrickson.

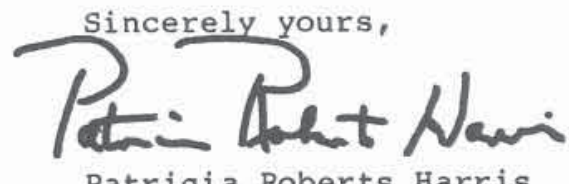

Enclosure 


\section{MEMORANDUM}

To

The Secretary
Through: US

Through: US

FROM : Director, NIH

SUBJECT: Possible Falsification of Clinical Data at Boston University....

INFORMATION (Secretarial Request, 7/31/80)

I am sending you herewith:

1) a memorandum from the Director, NCI, describing NCI's actions with regard to continued funding of Dr. Marc Straus; and

2) a background discussion of the 1 imfts of NIH procedural safeguards in coping with rogues in science.

Should you desire to discuss this important matter further, I would be pleased to do so.

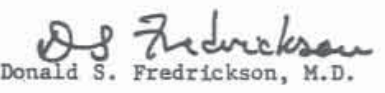

cc: Dr. Julfus B. Richmond 


\section{MEMORANDUM}

DEPARTMENT OF HEALTH, EDUCATION, AND WELFARE

PUBLIC HE.ILTH SERVICE

NATIONAL. INSTITUTES OF HEALTH

ro

The Secretary

Through: US

DATE: AUR \& :S

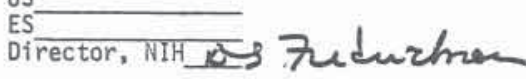

FROM : Director, National Cancer Institute

SUBJECT: Possible Falsification of $\mathrm{Clinical}$ Data at Boston University... INFORMATION (Secretarial Request, 7/31/80)

PURPOSE

To provide background information on the alleged falsification of data, actions taken and subsequent funds obtained by Dr. Marc Straus.

RECOMMENDED USES OF INFORMATION

Background only.

EXECUTIVE SUMMARY

Report of falsification by Boston University led to removal of clinical data from NCI-sponsored trial evaluation and dismissal of Dr. Straus. Dr. Straus was later awarded a grant for studies not involving clinical trials. Recently the NCI also discovered that Dr. Straus also received a smal1 amount of money $(\$ 4,000)$ on the grant of another investigator.

FACTS

A series of articles recently appeared in the Boston Globe alleging that patient records had been altered at Boston University during 1978 and possibly somewhat earlier. The research group, under the direction of Dr. Marc Straus, was a member of one of the large cancer clinical cooperative groups, the Eastern Cooperative Oncology Group (ECOG). The attached chronology of events clearly demonstrates the rapid series of actions taken by Boston University, ECOG, and the National Cancer Institute (NCI) to protect the patients undergoing treatment and the integrity of the clinical data (Attachment 1).

Further official action by the NCI occurred recently when it was brought to our attention by the NIH legal advisor that a possible criminal violation may have occurred if the data falsification was done for the purpose of justifying continued grant support under false pretenses. In view of that possibility, I sent a memorandum on July 3,1980 , to the Division of Management Survey and Review, NIH, requesting an investigation 
The Secretary

of the case (Attachment 2). That organization has consulted the Office of the Inspector General, DHHS, which has decided not to investigate the matter itself, and has, therefore, referred it back to NIH. The investigation by the Division of Management Survey and Review will begin in about a month.

During the period between the 1978 incidents and the Boston Globe articles, Dr. Straus had submitted a large program project grant application to the NCI (1-P01-CA-27719-01). The application, entitled "Application of Cell Kinetics to Cancer Chemotherapy, " included three major components: (1) human cell kinetics, (2) animal cell kinetics, and (3) clinical studies. A site visit by twelve experts was held on November 2, 1979, and the application was then reviewed by a chartered peer review study section, the NCI Clinical Cancer Program Projects Review Cormittee, later in November. This group recommended disapproval of the clinical studies but recommended approval of the other two components with a very good priority score of 174 . The application was approved by the National Cancer Advisory Board (NCAB) in January 1980 and has since been funded.

At the time of NCAB approval, the question of funding this grant was discussed by senior NCI staff. A decision was made to fund the grant based on three primary factors: (1) the grant received not just a fundabie but a very good priority score following a detailed review by a group of experts; (2) the grant, as approved, does not include clinical therapeutic studies which were the subjects of the falsification charges; and (3) Dr. Straus has not been convicted or indicted on any charges related to this incident. In view of the ill-defined status of the various investigations and the resultant uncertainty regarding individual blame, I believe the NCI has acted in a proper manner.

It recently came to our attention that $\mathrm{Dr}$. Straus had also received a small amount of funding (about $\$ 4,000$ ) early this year as a participant on a grant at his current institution, New York Medical College. Dr. Andre

Abitol is the Principal Investigator of this grant (5-R10-CA-18358-05). This was a continuation grant and, therefore, not subjected to peer review. We have discovered that the funds have already been disbursed, and it appears that no action is feasible at this time.

I would be happy to supply any additional information you may desire.

$$
\text { Vineañ t. 20Vico }
$$

Vincent T. DeVita, Jr., M.D.

Attachments 
Chronology of Events Related to Allegations that Research Data

was Falsified at Boston University

1) 1968 - Boston University joined the Eastern Cooperative Oncology Group (ECOG), Principal Investigator - Dr. Robert Schilling.

2) $6 / 17 / 75$ - Dr. Marc Straus became Principal Investigator on the Boston University ECOG grant.

3) 6/78 - Boston University was informed by Dr. Straus' associates that ECOG records had been falsified.

4) $6 / 14 / 78$ - Telephone call and mailgram from Dr. Levinsky of Boston University to Dr. Paul Carbone (Chairman of ECOG) stated that Dr. Straus had been relieved of his duties as Oncology Division Chief.

5) $6 / 15 / 78$ - Dr. Carbone forbade Boston University to accrue patients to ECOG protocols.

6) 6/23/78 - ECOG Executive Committee convened and issued a letter to Dr. Levinsky formally notifiying him that Boston University's participation in ECOG was suspended.

7) $6 / 78$ - Dr. Straus left Boston University.

8) $9 / 78$ - Dr. Straus joined the New York Medical Center division at the Westchester County Medical Center.

9) 10/24/78 - Site visit by ECOG representatives (Drs. Hugh Davis, Janet Wolter Arnold Mittelman) to Boston University. Site visit team confirmed that the allegation of altered records was well documented (altered patient ages and dates of surgery). However, the site visit team could not determine which individual or individuals were responsible for record al terations.

10) $11 / 22 / 78$ - Boston University formally dropped from membership in ECOG. 
Acting Director

JUL 2 บ พจก

Division of Management Survey and Review, NIH

Acting Director, NCI

Possible falsification of data at Boston University

You may be aware of a series of newspaper articles appearing this week in the Boston Globe relating to possible falsification of patient data at Boston University by a research group headed at the time by Dr. Marc Straus. I am attaching a chronology of events relating to that incident.

It should be pointed out that a number of actions were taken rapidiy after initial indications of a problem were made known:

1. Boston University's participation in the Eastern Cooperative Oncology Group (ECOG), one of our large, grant-supported clinical cooperative groups, was cancelled with our concurrence.

2. All of Boston University's data were stricken from ECOG records.

3. The grant to Boston University was cancelled.

4. Dr. Straus and several members of his staff were forced to resign.

The above actions certainly appeared severe. However, several things have recently happened to lead us to re-examine the issue. There is continued uncertainty as to the individual(s) responsible for the falsification, and now the possibility that a violation of criminal statutes may have occurred. Also, Dr. Straus has recently re-entered the grant system.

I should, therefore, like to request an investigation of the case by your Division. For your information, we understand that the Massachusetts Board of Registration and Discipline in Medicine and the Food and Drug Administration are also investigating the case, and you may wish to communicate with those organizations.

If there is further information you and your staff need from us, please let me know. My staff and I will be pleased to cooperate fully with your investigation.

Attachment

Vincent T. DeVita, Jr., M.D. Acting Director National Cancer Institute

cc: Dr. Raub

Mr. Riseberg

SAS/VTD/eb/7/2/80 


\section{MEMORANDUM}

To : The Secretary Through: US
DEPARTMENT OF HEALTH, EDUCATION, AND WELFARE PUBLIC HE.ILTH SERVICE

NATIONAL INSTHTUTES OP HEALTH

FROM : Director, NIH

SUBJECT: Rogues in Science: the Limitations of Procedural Safeguards... INFORMATION

PURPOSE

To provide background on and further discussion of the general issues raised by the alleged falsification of research data by Dr. Marc Straus at Boston University.

RECOMMENDED USES OF INFORMATION

Background for consideration of policy-issues raised by introduction of derogatory information regarding applicants for research funding.

EXECUTIVE SUMMARY

Present and proposed procedures for dealing with known or suspected violations on the part of grantees and contractors do not fully address issues related to solentific performance. NIH is currently developing improved procedures for dealing with these matters and plans to solicit the views of advisory body members regarding the appropriate roles of agency staff and advisors.

FACTS

Present Procedures The recent case involving alleged falsification of research data under an NCI-supported grant at Boston University raises questions about the roles and responsibilities of agency officials, individuals and institutions engaged in Federally-sponsored research. Also at issue is the role of advisory bodies that, in the case of NIH, play an important role in selecting projects for funding. While cases involving fraudulent research practices are extremely rare, they invariably generate considerable interest because of the generally high esteem accorded scientists, especially biomedical scientists. In addition, the nature of the research process and the relationships involved present special problems in handling known or suspected abuses. 


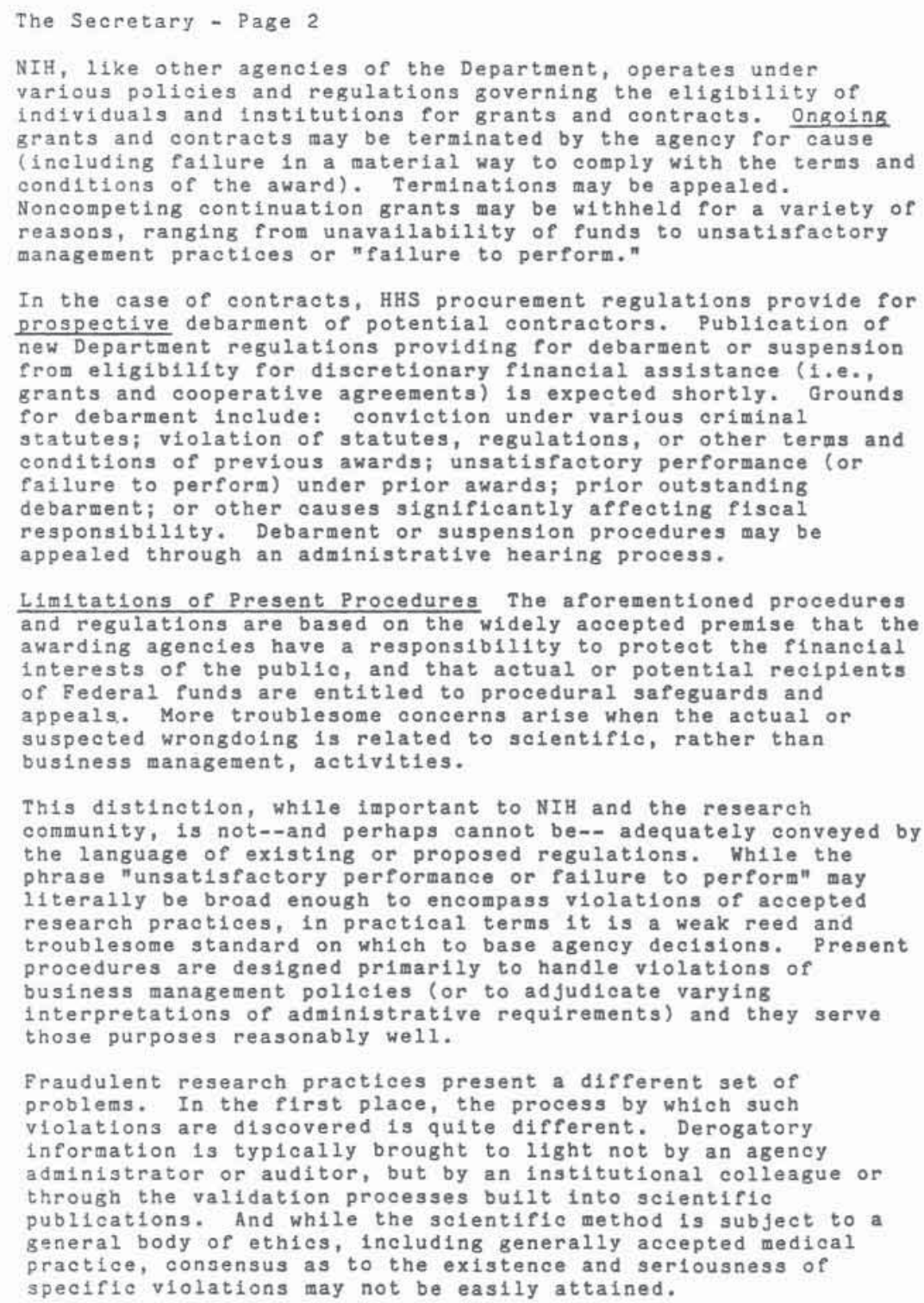




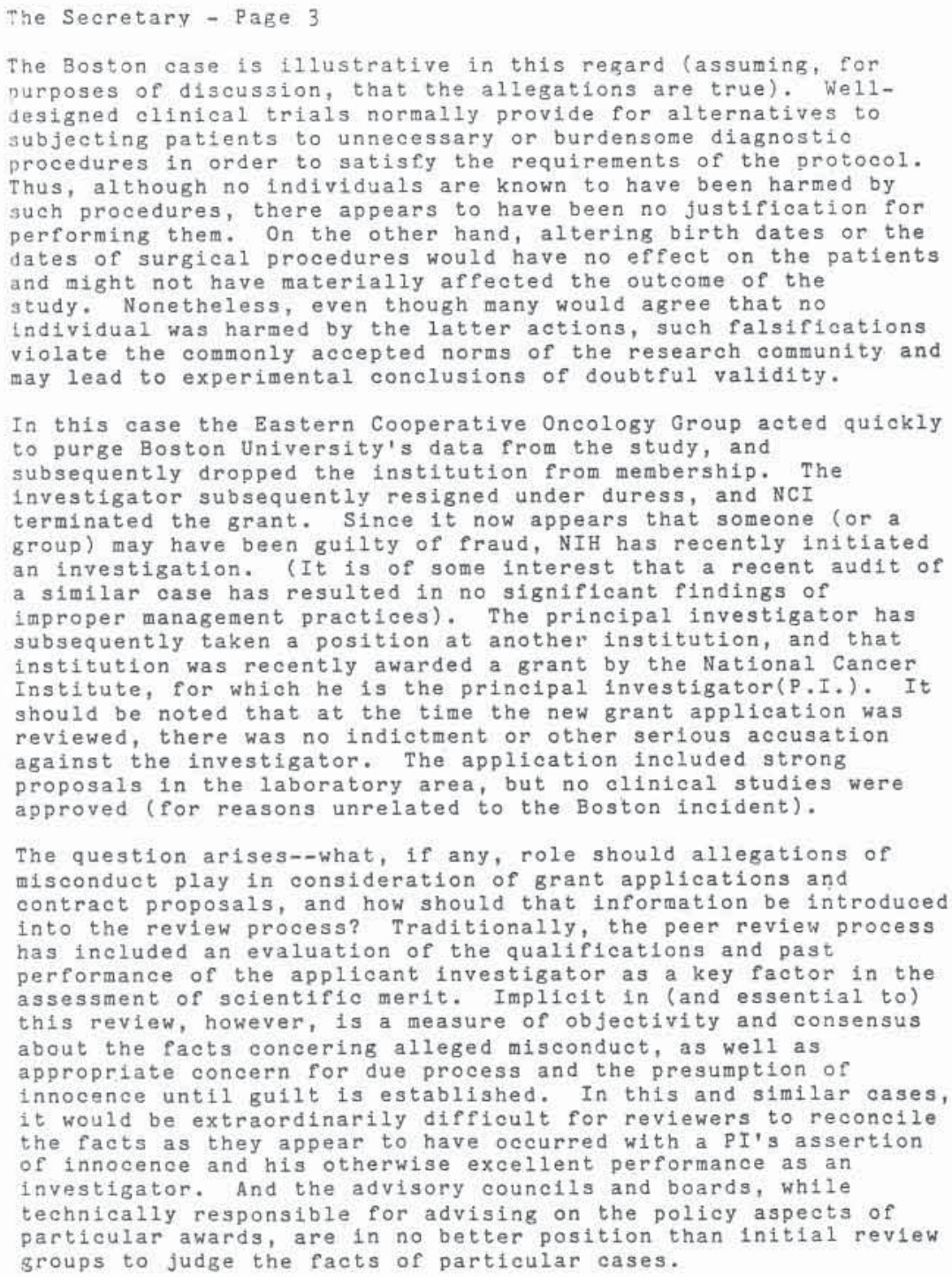




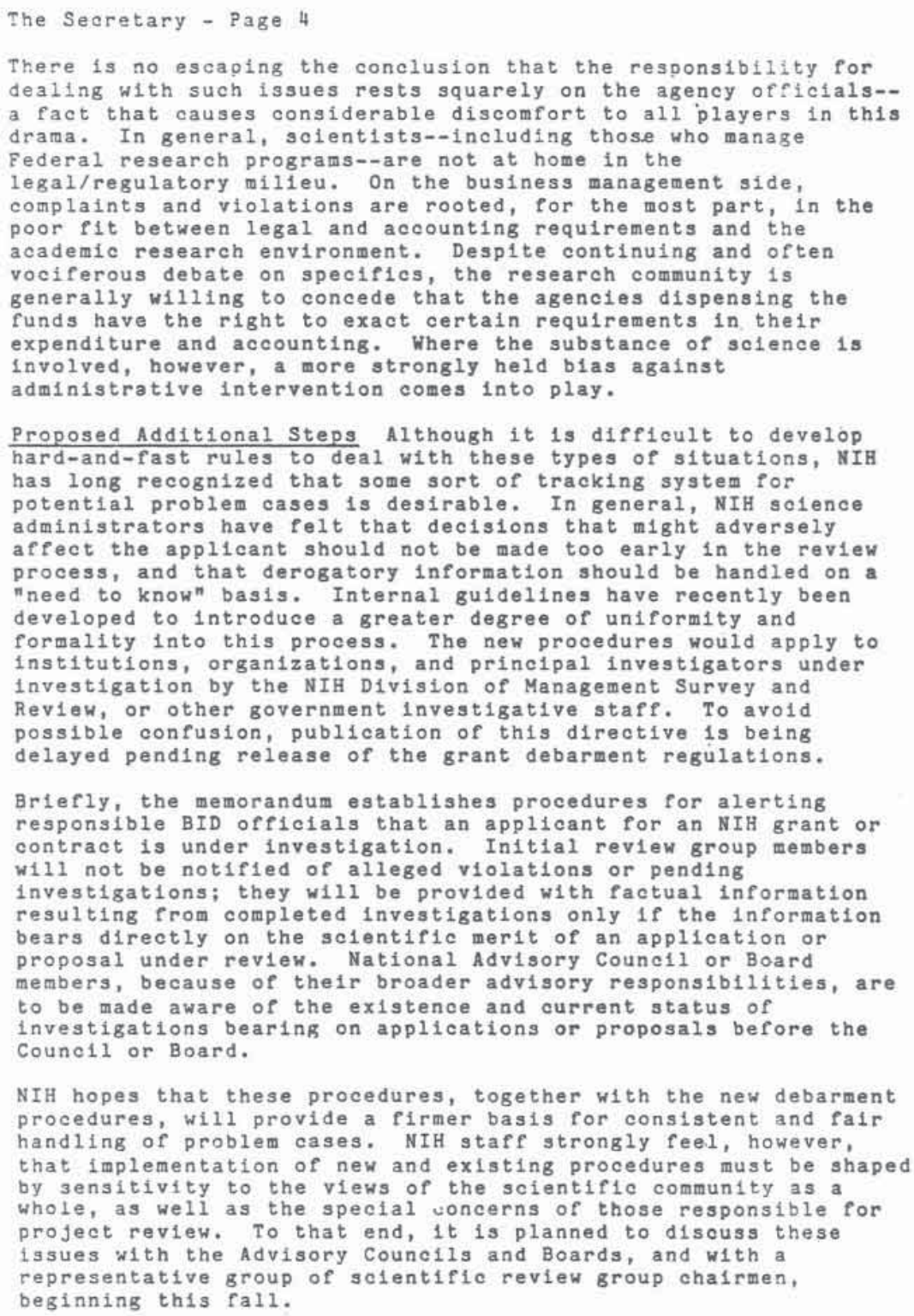

NIH hopes that these procedures, together with the new debarment procedures, will provide a firmer basis for consistent and falr handling of problem cases. NIH staff strongly feel, however, that implementation of new and existing procedures must be shaped by sensitivity to the views of the scientific community as a whole, as well as the speclal voncerns of those responsible for project review. To that end, 1 t is planned to disouss these issues with the Advisory Councils and Boards, and with a representative group of scientific review group chalrmen, beginning this fall.

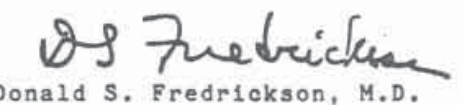


President's Commission for the Study of Ethical Problems

in Medicine and Biomedical and Behavorial Research

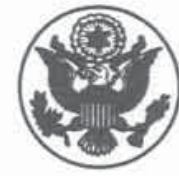

in Medicine and Biomedical and Behavorial Research

\section{MEMORANDUM}

To:

Director, OPRR/NIH

Date: February 19, 1981

From:

Deputy D1rector

Subject

Debarmant of Nathan Kalne

Attached is the article I mentioned to you, the other day, describing FDA's debarment of Nathan KIfne from further drug testing. Since a number of the charges (apparently substantiated) had to do with violation of rules for the protection of human subjects, this would seem to be a case that might result in debarment from NIH grants and contracts under Section 76.10 of your new regulations on that subject.

After you have had a chance to familiarize yourself with the facts of the case, I would appreciate learning whether any action w111 be taken with respect to $\mathrm{Dr}$. Kline's eligibility to receive PHS grants or contracts. (Does he have any current funding from NIH or ADAMBA?) I would also be interested in learning why FDA did not notify your office of the debarment. Does 1ts current policy of alerting your office to problems it uncovers apply only to IRB's and not to Individual 1nvest1gators?

Pinally, I note that the causes for debarment under Section 76.10 apply only to "serious violation of the applicable statutes, regulations, or other terms and conditions of a previous award of financial assistance" [para(a)] or to "Debarment from Government contracting, subcontracting, or financial assistance by a Government agency (Including an agency within iifs)" [para(f)]. Debarment from activities under federal regulation (e.8., by FDA) is not specifically 1dentified as a cause for debarment from HHS grants and contracts. Do you know whether the regulations w111 be interpreted as encompassing debarment by FDA as a cause for debarment under Section 76.10 ?

I am sending a copy of this memorandum to Dick RIseberg under the assumption that your response w111 be prepared after consultation with General Counsel.

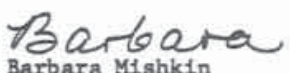

Bnclosure

ce: Mr. Riseberg 


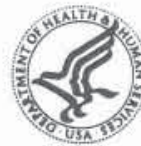

THE SECRETARY OF HEALTH AND HUMAN SERVICES

WASHINGTON, O.C. 20201

APR 151981

Mr. Morris B. Abram

Chairman, President's Commission for the

Study of Ethical Problems in Medicine

and Biomedical and Behavioral Research

2000 K Street, N.W., Suite 555

Washington, D.C. 20006

Dear Mr. Abram:

In a letter dated November 18, 1980, former Secretary Harris acknowledged two letters dated September 18, 1980, which you wrote on behalf of the President's Commission. It is my understanding that staff in the office of the Secretary had contacted the commission on this matter. This letter confirms these contacts.

One of your letters included suggestions regarding the final regulations for the protection of human subjects involved in research. I have enclosed ( $T a b \mathrm{~A}$ ) a copy of final regulations ( 45 CFR 46 ) which were promulgated in the Federal Register on January 26, 1981. We believe these satisfy the major concerns expressed in your letter.

Your other letter requests information concerning reported incidents in which grantees of the Department of Health and Human Services (HHS) appear to have violated existing regulations for the protection of human subjects in two specific cases: (1) by a Boston University research unit headed by Dr. Marc H. Straus; and (2) by an anthropologist at the University of Kansas.

My predecessor directed Dr. Fredrickson, Director, National Institutes of Health (NIH), to carry out rigorous investigations of each of these serious charges. The NIH Division of Management Survey and Review and the office for Protection from Research Risks are working together on these cases. Both investigations are well advanced.

The investigation of the Boston University research requires careful evaluation of hundreds of patient records, laboratory reports, IRB minutes, protocol reviews, and interviews with University administrators, IRB members, Dr. Straus and members of his research unit (who are now located 
in several institutions), National Cancer Institute officials, and other interested parties. A careful. assessment of all of this information will require several months. You will understand that it would be inappropriate to discuss details of this investigation before it has been completed. We will forward a full report to your Commission at the earliest possible date.

The investigation at the University of Kansas involves incidents that occurred both within the University-including University officials, the investigator in question, his assistants, and the IRB chairman and members--and incidents that occurred in Central America. This investigation is nearer completion than the one described above. Nevertheless, the facts in the case must be checked carefully and evaluated before a final report is issued. A full report will be forwarded to you at the earliest possible date.

You raised seven specific questions concerning procedures for implementing the Department's regulations for the protection of human research subjects. Responses to these questions are found at Tab B. Supplementary material related to the questions in your letter is found at Tab $\mathrm{C}$.

In closing, I wish you well in your efforts to carry out the important studies assigned in your mandate.

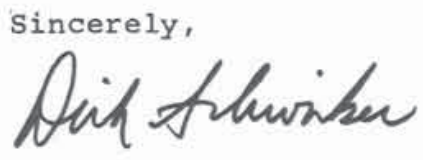

Richard S. Schweiker Secretary

Enclosures

(TAB A CONTAINED THE REVISED REGULATIONS GOVERNING RESEARCH

WITH HUMAN SUBJECTS, PUBLISHED JANUARY 26, 1981. THEY ARE REPRINTED IN FULL AT APPENDIX A OF THIS REPORT.) 
$\underline{T a b} B$

Question 1: "What does the Department intend by the following statement: 'Safeguarding the rights and welfare of subjects at risk in activities supported under grants and contracts from DHEW is primarily the responsibility of the institution which receives or is accountable to DHEW for the funds awarded for the support of the activity (45 CFR $\$ 46.103(3)$ ).' "

Response: As you know, the regulations in which the quoted statement appears have recently been revised. However, the statement was intended generally to encompass at least the following:

(a) Institutions which carry out the described activities must provide. the Department with an assurance of compliance with 45 CFR 46 which commits them to (1) adopting a statement of principles which will govern the institution in the discharge of its responsibilities for protecting the rights and welfare of human research subjects; (2) providing for review and approval of research covered by the regulations by a properly constituted IRB; ( 3 ) setting forth a plan of procedures which the institution and IRB will follow in its initial and continuing review of proposals and activities covered by 45 CFR 46; (4) developing procedures which the IRB will follow in providing advice,and counsel concerning the Board's activities, insuring prompt reporting to the Board of changes in an activity and unanticipated problems involving risk to subjects or to others, and insuring reporting of such problems to HHS; and (5) developing procedures which the institution will follow to maintain an active and effective Board.

(b) Institutions must accept primary responsibility for complying with federal, state and local laws pertaining to research involving human subjects.

(c) Institutions are responsible for the conduct of investigators involving human subjects when such investigators are acting on behalf of the institution.

(d) Institutions are responsible--through the agency of IRBs--for determining that the risk/benefit ratio is favorable in all research carried out under the regulations.

(e) Institutions are responsible for obtaining legally effective informed consent from subjects, or legally authorized representatives in the case of minors or incompetents, whenever required to do so by the regulations.

Question 2: "How are the institutions expected to insure that all research is reviewed as required and conducted in a manner that conforms to the approved protocol? What action is an institution expected to take if an investigator fails to comply with either HHS or institutional rules?"

Response: Institutions are expected to promulgate policy requirements and to insure that all affected personnel are acquainted with them. 
The policy requirements are set down in the plan set forth in the assurance of compliance on file with the Department. The plan must include all of the elements itemized under Question 1. The institution is expected to take whatever action is appropriate if an investigator fails to comply with HHS or institutional rules.

Question 3: "What constitutes 'material failure' to protect human subjects by: (a) the institution? (b) the principal investigator?"

Response: This depends on a multiplicity of factors and must be left to the discretion of the Secretary based upon the facts in each particular case. The Secretary, HHS, shall determine in each instance what constitutes "material failure." Examples of what may constitute material failure are: failure to provide for IRB review of research subject to 45 CFR 46; failure to insure a favorable risk/benefit ratio; failure to obtain legally effective informed consent where required.

NOTE: Questions 4 through 7 deal primarily with the formal procedures for handling violations of Department requirements. Enclosed at Tab $C$ are copies of Department regulations concerning these matters (45 CFR \$\$74.11074.116; 45 CFR 16; 45 CFR 76; and 42 CFR 5OD).

Ouestion 4: "What standard of proof does the Department require for a finding of such material failure?"

Response: This also depends on a variety of factors and is based upon the facts of each case. In reaching a decision, in the human subjects' context, the Secretary would take into consideration the principles described in 45 CFR 46.

Question 5: "What is considered 'due process' necessary to protect the rights of an investigator alleged to have failed to protect human subjects for whom he or she is responsible?"

Response: If an HHS agency decides to terminate a grant for material failure to comply with the terms and conditions of an award, the grantee has the right to appeal that decision through the Department's grant appeals process. In circumstances when the Secretary seeks to debar an institution or individual or believes that grounds for debarment exist, procedures for written notification, request for hearing and review by the Secretary are set forth in 45 CFR $\$ \$ 76.14,76.15$ and 76.22 .

Question 6: "During the period when allegations of wrongdoing are being investigated and resolved, what steps are taken by the Department to insure the protection of human subjects in ongoing research conducted under the direction of that investigator and in research for which the investigator has a pending or subsequently submitted application?" 
Response: In addition to specific restrictions cited at 45 CFR $\$ \$ 76.16$ and 76.23 concerning debarment and suspension, the Secretary may require that Department funding for any project be terminated or suspended based the circumstances of the particular case (45 CFR \$74.115). Where applications for funding are pending, the Secretary may take into account factors such as whether the applicant has been subject to a termination o suspension and whether the applicant has materially failed to discharge responsibility for the protection of the rights and welfare of human subj (45 CFR \$46.123).

Question 7: "What determines the response of HHS after a finding of material failure to protect human subjects? Is there a policy regarding ineligibility to receive further research grants or contracts for a certain period of years? May an investigator or institution be disqualified, permanently or for a Deriod of years, from receiving further research support from the Department? Under what circumstances, if anv, has such action been taken? Under what circumstances, if any, would the Department take such action in the future?"

Response: The determination is left to the discretion of the Secretary based on the findings in the varticular case. Ineligibility to receive further funding is based on all the circumstances (including any mitigatj facts) of the particular case and the restrictions as determined by the Secretary. Final regulations concerning debarment from eligibility for financial assistance were published in the Federal Register on October 9. 1980. There were no instances of debarment prior to that date, although regulations governing debarment from contract eligibility were published in 1972 (41 CFR Subparts 1-1.6, 3-1.6). The bases for contract debarment are largely similar to those set forth in the financial assistance debarment regulations.

(ADDITIONAL ENCLOSURES CONTAINED HHS RULES FOR DEBARMENT AND

SUSPENSION OF GRANTEES AND CONTRACTORS, TERMINATION OF AWARDS,

AND APPEALS OF SUCH ACTIONS. THESE REGULATIONS ARE REPRINTED

AT APPENDIX G OF THIS REPORT.) 
President's Commission for the Study of Ethical Problems in Medicine and Biomedical and Behavioral Research

2000 K Street, N.W., Suite 555, Washington, DC 20006 (202) 653-8051

May 11, 1981

The Honorable Richard S. Schweiker

Secretary

Department of Health and Human Services

Washington, D.C. 20201

Dear Mr. Schweiker:

Thank you for your letter of April 15, 1981, responding to certain inquiries posed by this Commission last September to your predecessor, Patricla Roberts Harris. As you know, questions about your Department's standards and policies for dealing with reports of research fraud and abuse are an important part of the Commission's mandate (P.L. 95-622); we are required to report to the President and the Congress by December of this year on the adequacy of the implementation of all rules governing research with human subjects.

The Commission discussed the Department's response at our May 9 meeting and found that a number of matters of importance were not resolved by the April 15 letter. Rather than engage in further exchange of correspondence, I request on the Commission's behalf that you meet with our Director and staff members in the next several weeks. The Commission will be discussing these matters at its next meeting (June 5, in Boston). At that time we will receive testimony relating to the federal and institutional response to reports of falsification of data in research supported by the National Cancer Institute at Boston University. We wish to have the necessary clarifications of Departmental policy prior to that meeting. Someone from our office will be calling within the next week to arrange an appointment. If your schedule does not permit you to meet personally with our staff, I hope you will arrange for someone in your immediate office to do so.

We appreciate your assistance in assuring prompt attention to this matter.

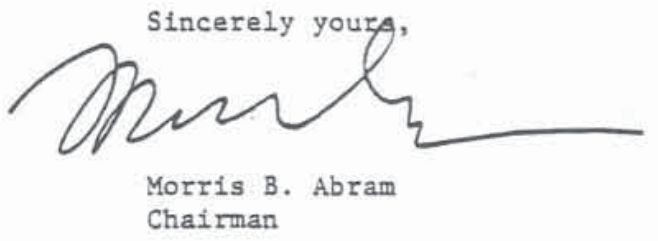




$\begin{array}{ll}\text { May 19, } 1981 & \text { Public Health Service } \\ \begin{array}{l}\text { National Institutes of Health } \\ \text { Bethesda, Maryland 20205 }\end{array}\end{array}$

\author{
Ms. Barbara Mishkin, Deputy Director \\ President's Commission for the Study \\ of Ethical Problems in Medicine and \\ Biomedical and Behavioral Research \\ 2000 K Street, NW - Suite 555 \\ Washington, D.C. 20006 \\ Dear Barbara:
}

This is in response to your letter of February 19 which, as you know, was lost for a period of time. Thank you for sending a duplicate copy.

Your first question deals with notification to the office for Protection from Research Risks (OPRR) by the Food and Drug Administration (FDA) of the disqualification of Dr. Nathan Kline. It is customary for the FDA to notify NIH of the names of persons disqualified by the FDA. When we discussed this matter on the telephone, OPRR had not received official notification of Dr. Kline's disqualification. Shortly thereafter we did receive notification from FDA.

Upon receipt of the information from FDA we checked the Division of Research Grants' grant and contract file (IMPAC) to see whether Dr. Kline is currently receiving, or applying for, any research support from the NIH/Alcohol, Drug Abuse, and Mental Health Administration. Our check indicates that he is not receiving any funds for research, and that he has no pending applications or proposals.

Accordingly we entered Dr. Kline's name in the "Awaiting Receipt of Application" (ARA) alert system. In the event that Dr. Kline should apply for funds from NIH or ADAMHA, the Associate Director for Extramural Research and Training, OPRR, Division of Management Survey and Review, and the appropriate Bureau/Institute/Division Director will be notified.

As part of the implementing procedures following publication of 45 CFR 46 on January 26, 1981, we are negotiating a memorandum of understanding with the FDA to formalize the customary procedures already in place. Finally you ask whether debarment by FDA will be interpreted as a cause for debarment under Sec. 76.10 of the HHS regulations. The answer to that question is that if an individual who has been disqualified by FDA should apply for funding, the reasons for the FDA's action will be taken into consideration, along with all other pertinent information, in deciding whether to initiate debarment proceedings under 45 CFR 76 .

This letter has been reviewed by the NIH legal advisor.

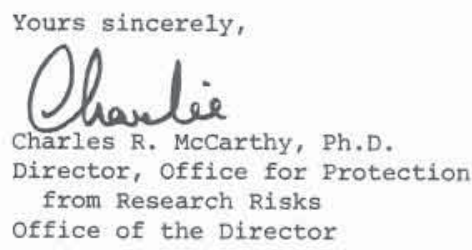




\section{President's Commission for the Study of Ethical Problems in Medicine and Biomedical and Behavioral Research}

Suite 555, 2000 K Street, N.W., Washington, DC 20006 (202) 653-8051

TO:

Chief, NIH Branch

DATE: August 17, 1981

Office of General Counsel

HHS

Director

Office for Protection from

Research Risks

NIH

FROM: Deputy Director

SUBJECT: September Meeting of the

President's Commission

The agenda in the attached meeting book reflects my conversation with you at Airlie House, in July, in which you indicated a willingness to discuss various aspects of implementation of 45 CFR 46 at the September meeting of the Commission. I hope that you will speak briefly (approximately 15 minutes for your combined remarks) on the following topics:

1. The Role of the IRB in "continuing Review" of ongoing research as required by Sections 46.103 (b) (4) and 46.109 (e):

J

a. Are IRBs expected to do more than receive and review periodic reports (usually, annual reports) of ongoing research?

b. If so, what form should their continuing review take?

2. The Role of the IRB in reporting incidents of serious or continuing noncompliance as required by Section $46.108(\mathrm{c})$ :

a. In formulating the reporting requirement, did the Department contemplate that IRBs would act independently of other committees or offices within their institution?

b. What should happen if the IRB and a departmental or administrative office within a grantee institution differ as to whether an incident should be reported?

c. Do directions for negotiating general assurances under the revised regulations offer any guidance on this point? 
3. Implementation of the Debarment Regulations ( 45 CFR 76):

a. What are the roles and responsibilities of the various offices at NIH (e.g., OPRR, General Counsel, Associate Director for Extramural Research and Training, etc.) with respect to decisions to initiate debarment proceedings?

b. Who has final authorfty with respect to such decisions?

c. May suspension of funds or similiar sanctions be imposed without invoking the debarment process?

d. If alternative procedures are avallable, by whom, and according to what standards, are choices made as to which procedure to follow in a particular case?

e. At what point in consideration of debarment will a subject of investigation be formally notified so that he or she may request a hearing under section $76.14(\mathrm{~b})$ ?

f. What factors will be considered in deciding when that point has been reached? Who will make the determination?

8. May a grantee institution or principal investigator, who is the subject of an investigation regarding alleged misconduct, request that debarment proceedings be initiated in order to invoke the hearing provisions?

We hope that you will feel free to discuss any additional factors relevant to our deliberations on the implementation of HHS regulations for the protection of human subjects. Please don't hesitate to call if you have any questions, of either substance or procedure, regarding the September meeting.

In order to enhance your thinking on the organfzation and structure of IRBs, I am enclosing a clipping from Current Contents on that subject. 


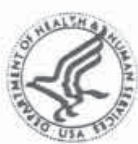

THE SECRETARY OF HEALTH AND HUMAN SERVICES WASHINGTON, D.C. 20201

\section{AUG 241981}

Mr. Morris B. Abram

Chairmàn

President's Commission for the Study

of Ethical Problems in Medicine and

Biomedical and Behavioral Research

$2000 \mathrm{~K}$ Street, N.W.

Suite 555

Washington, D.C. 20006

Dear Mr. Abram:

This is in response to your letter of May 11 concerning the Department of Health and Human Services (HHS) policies and procedures for responding to allegations of research fraud and abuse. As you noted in your letter. I have already answered seven detailed questions put to me by the Commission. My letter dated April 15 cited a variety of regulations and policies that guide the Department in its efforts to respond to allegations of misconduct by institutions or individuals.

In general, the rules are designed to provide safeguards for the rights of the public, the rights of human research subjects, the rights of the accused and the rights of accusers. Sometimes these rights appear to be in conflict. In such cases, room must be left for the exercise of judicious balancing of the competing interest.

Several investigations of alleged fraud or abuse are currently underway within the Department. As we proceed with these investigations, we are not only making efforts to correctly interpret and enforce existing rules and policies, but to evaluate and improve the processes by which unfortunate situations of this kind can be brought to resolution.

Since these investigations are underway, it is not appropriate for me to meet with you at this time. Following completion of the investigations and approval of recommendations emanating therefrom, we will inform you of them. At that time, a meeting would be useful.

In the meantime, Dr. Charles R. McCarthy, HHS liaison to the Commission, will continue to assist you in your assessments and I will follow your progress through his reports to me.

Sincerely,

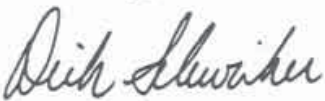

Richard S. Schweiker Secretary 
DEPARTMENT OF HEALTH, EDUCATION, AND WELFARE

PUBLIC HEALTH SERVICE

NATIONAL INSTITUTES OF HEALTH

BETHESDA. MARYLAND 20205

September 1, 1981

Ms. Barbara Mishkin, Deputy Director

President's Cammission for the Study

of Ethical Problems in Medicine and

Biamedical and Behavioral Research

$2000 \mathrm{~K}$ Street, NW Suite 555

Washington, D.C. 20006

Dear Barbara:

This is in response to your memorandum of August 17 concerning your request for cambined remarks by $\mathrm{Mr}$. Riseberg and me at the Camission's September meeting in Los Angeles. We have reviewed the topics that you outlined for our presentation and realize that they are similar to those addressed in letters fram Secretary Schweiker dated April 15 and August 24. We feel that there is very little that we can add to what the Secretary has already presented to the Carmission. Furthermore, the Secretary stated that it is "inappropriate" for him to discuss on-going investigations until they have been completed and recommendations from them have been approved. The Secretary's statement on this matter serves as a reminder for us that it is not appropriate to appear before the Commission in the context of discussion of these investigations. We have discussed this matter with senior officials in the Department who cancur in this judgment.

Accordingly, we respectfully decline your invitation to make a presentation to the Commission in Los Angeles. However, we will be present to take note of all the Commission's deliberations.

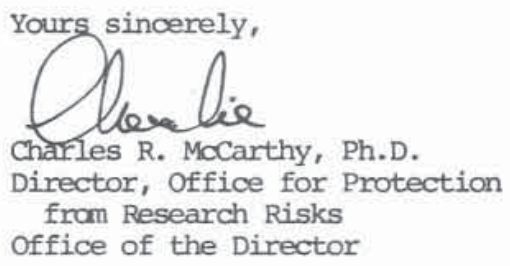

$\infty$ : Mr. Riseberg 


\section{President's Commission for the Study of Ethical Problems} in Medicine and Biomedical and Behavioral Research

Suite 555, 2000 K Street, N.W., Washington, DC 20006 (202) 653-8051

September 4,1981

Dr. Charles R. McCarthy

Director

Office for Protection from

Research Risks

Westwood Building, Room 3A-18

National Institutes of Health

Bethesda, Maryland 20205

Dear Charlie:

Your letcer of September 1 to Barbara Mishkin leaves me somewhat preplexed about how to proceed in preparing our first Biennial Report to Congress on the implementation of the federal regulations for the protection of human subjects. The first lnkling that we had that you would be unable to fulfill the planned appearance which Barbara Mishkin first discussed with you at our meeting in July was when we called you yesterday to discuss the testimony and to suggest that you might wish to focus on a very recently completed investigation as a way of reviewing the procedural steps without compromising an ongoing investigation.

What is troubling is not merely the small disruption in the agenda for our Los Angeles meeting but rather: first, the apparent misunderstanding that exists between yourself, other officials in the Department, and ourselves, and second, the obstacles that now threaten to make difficult the timely completion of the Biennial Report.

Secretary Schweiker's August 24, 1981, letter quite plainly states that 1t was "not appropriate for me [Secretary Schweiker] to meet with you at this time." We understand the basis for his reluctance to meet as arising because he had interpreted our request as focusing on particular Investigations first mentioned in our letter of September 18, 1980, to Secretary Harris. While we belleve there are a number of matters of policy that it would be frultful to discuss with the Secretary, it is mderstandable that he wishes to conserve his time and not risk in any way prefudicing those investigations which are still ongoing. On the other hand, the August 24 letter also declares that Dr. Charles R. McCarthy "will continue to assist you in your assessments." I am therefore baffled by the interpretation in your letter of September 1 that no one in the Department may communicate formally with the Commission on any matter while any investigations are ongoing or incomplete. We are simply asking for your assistance in understanding the intent of the Department's regulations for the protection of human subjects and the Department's interpretation of the applicability of its regulations to certain kinds of situations. We are not asking for any progress reports or preliminary judgments relating to any ongoing or contemplated investigations.

Without your assistance the Commission will be left to report on regulations requiring "ongoing review and reporting" by IRBs, regulations which the IRBs themselves apparently have difficulty in interpreting. If IRBs do not understand what is intended, they will be unable to fulfill their responsibilities. Further, this Commission cannot assess how all the 
regulations are being 1 mplemented until we understand what the Department intends by them. If we are unable to obtain such an understanding, I'm afraid we shall have to report as much to Congress.

Looking specifically at the questions conveyed to you and Mr. R1seberg by Barbara Mishkin's memorandum of August 17, 1981, I do not see any that ought to raise concern for involvement of ongoing investigations. The first set of questions relate to "continuing review" of research projects; the second set concern the responsibillty of an IRB in reporting incidents of noncompliance with federal regulations; and the third set relates to the 1 mplementation of the new HHS debarment regulations. None of these stray beyond questions of process and procedure into a request for details concerning any ongoing investigation. That being so, I do not understand how the Department's investigations might be compromised by your explanations of the process by which such regulations are applied--a process which you can 11lustrate, as required, by reference to already completed investigations such as the one mentioned recently in the Blue Sheet. It is true that the detall with which Barbara put the questions may sound somewhat like a formal interrogatory; however, as we have explained to you, the Intent was to provlde you with ample opportunity to consult widely within the Department in preparing your answers and to obtain whatever clearance might be necessary so that you would not be surprlsed with a series of questions at the time of the meeting which you might justifiably prefer not to answer on the record without time for reflection and consultation.

The second major reason for my concem mentioned at the outset is that the timing of our report, as you know, is such that $1 \mathrm{t}$ will require full Commission discussion no later than November. From your description of the work of the OPRR on the present 1nvestigations, reports will not be completed until sometime in October. Further, you would anticipate that it would be several months before the reports have been finally passed upon by your superiors in the Department. If your Interpretation of Secretary Schweiker's letter is correct-1.e., that we cannot expect any discussion by you or others even concerning process and procedure while these investigations are ongoing-we are effectively precluded from any interaction with the Department on this subject in time to be reflected in our first Blennial Report this fall. Furthermore, there is real danger of infinite delay, since there is always a possibility of some ongoing investigation of research misconduct, which could then stand in the way of communication between the Commission and HAS.

I hope, therefore, that 1 w w1l be possible to clear up this apparent misunderstanding, both as $1 \mathrm{t}$ relates to your testifying at the meeting in Los Angeles, and, more 1mportantly, as 1 t relates to the assistance which you are able to provide the Commission in fulfilling its statutory responsibilities. We appreclate the help you have provided throughout the life of the Commission and look forward to working with you on the same basis for the remainder of our existence.

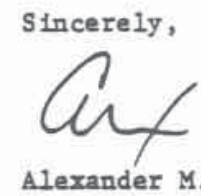

Alexander M. Capron Executive Director

cc: The Honorable RIchard S. Schweiker Richard Riseberg, Esq. 


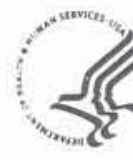

Mr. Alexander M. Capron

Executive Director

President's Camission for the Study

of Ethical Problems in Medicine and

Bicmedical and Behavioral Research

2000 K Street, NW Suite 555

Washington, D.C. 20006

Dear Alex:

Your letter of September 4 was delivered to me this afternoon. Since the time remaining before the Camission's meeting is short, I hasten to respond so that you can make your plans, accordingly.

First, let me reiterate that I did not say and did not intend to convey the understanding that "no one in the Department may communicate formally with the Commission on any matter while any investigations are ongoing or incomplete." However, since I am directly involved in the conduct of ongoing investigations, I did say that it is "not appropriate to appear before the Comission in the context of discussion of these investigations. Since the questions you wished Mr. Riseberg and myself to discuss relate to evolving Departmental policies, I indicated to you in a subsequent telephone call that we would be pleased to respond to the Commission in writing providing we can obtain proper clearances within the Department. We continue to be prepared to do so, if you are willing to have us respond in that way.

We stand ready to cooperate with the Comission in every way that we can. However, if you wish us to make statements concerning developing policies of the Department, we must have an opportunity to clear these statements with all of the necessary authorities.

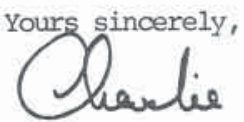

Charles R. MoCarthy, Ph.D.

Director, Office for Protection

from Research Risks

Office of the Director

cc: Mr. Riseberg 


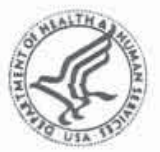

THE SECRETARY OF HEALTH AND HUMAN SERVICES WASMINGTON, D.C. 20201

\section{OCT 281981}

Mr. Morris B. Abram

Chairman

President's Commission for the Study

of Ethical Problems in Medicine and

Biomedical and Behavioral Research

2000 K Street, N.W.

Suite 555

Washington, D.C. 20006

Dear Mr. Abram:

You have written requesting a meeting to discuss our Department's policies and procedures for dealing with reports of research fraud and abuse. As you know, we have several such reports under active investigation at the present time.

I am prepared to meet with you to discuss those matters subject to the condition that no specific case under investigation be discussed.

Please ask your staff to call my office and arrange a mutually satisfactory time.

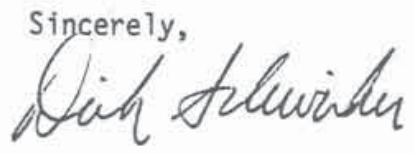

Richard S. Schweiker Secretary 


\section{President's Commission for the Study of Ethical Problems in Medicine and Biomedical and Behavioral Research}

Suite 555, 2000 K Street, N.W., Washington, DC 20006 (202) 653-8051

November 5,1981

Charles R. McCarthy, Ph.D.

Director, office for Protection

from Research Risks

office of the Director

National Institutes of Health

Westwood Building, Room 3A-16

Bethesda, Maryland 20205

Dear Charlie:

Since, as you know, we are in the process of completing our draft report on Protection of Human Subjects, we very much need to have the materials you have promised, at various times, to provide. As I recall, these include the following:

1. Written answers to the questions originally put forth

in my memorandum of August 17, 1981 (which you declined

to answer at a Commission meeting but which, at a meeting

that Brad Gray and I held with you on October 14, you

indicated you would respond to in writing);

2. Any corrections or modifications necessary to assure the accuracy and completeness of our summary of HHS rules and procedures for the protection of human subjects;

3. Information on the number of research projects, IRBs, human subjects and budget for HHS intramural research (as requested in my memorandum to liaison of ficers, dated August 19,1981 , and my request to you on October 14 to try to provide at least some data on your intramural research programs); and

4. Answers to the questions posed by Brad Gray when he and I met with you, Dick Riseberg, and Charles MacKay on September 18, 1981.

I recognize the unusual demands on your time these last few months, but would regret very much having to issue our Biennial Report with so much information still missing. I would appreciate receiving as much of the material as possible by the time of the Commission meeting on November 13th.

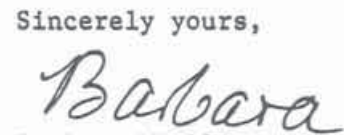

Barbara Mishkin

Deputy Director 


\begin{tabular}{ll} 
DEPARTMENT OF HEALTH \& HUMAN SERVICES & Public Health Service \\
\hline November 10,1981 & $\begin{array}{l}\text { National Institutes of Health } \\
\text { Bethesda, Maryland } 20205\end{array}$
\end{tabular}

Ms. Barbara Mishkin, Deputy Director President's Commission for the Study of Ethical Problems in Medicine and Biamedical and Behavioral Research 2000 K Street, NW - Suite 555 Washington, D.C. 20006

Dear Barbara:

The following information is provided in response to your letter of November 5 .

I. Answers to questions set forth in your memorandum of August 17:

Question 1 - Are IRBS expected to do more than receive and review periodic reports of ongoing research? If so, what form should their continuing review take?

Answer - IRBs are required to carry out continuing review of research covered by 45 CFR 46 at intervals appropriate to the degree of risk, but at least one full review must be conducted each year. Intermediate continuing review may range from review of reports filed by investigators to the establishment of a mechanism (e.g., a committee) for regular data monitoring in order to assure the safety of subjects. In some cases IRBs have required weekly reporting on the progress of each subject involved in research. In other instances IRBs have exercised their authority to observe or have a third party observe the consent process and the research. Protocols for large clinical trials frequently include data and safety monitoring committees which establish "stopping rules" for termination of a trial if the data shows that any subjects may be subjected to inappropriate risks.

In every case the IRB must determine the appropriate mode in which continuing review is to take place.

Question 2 - In formulating the reporting requirement, did the Department contemplate that IRBs would act independently of other committees or offices within their institution? What should happen if the IRB and a departmental or administrative

office within a grantee institution differ as to whether an incident should be reported? Do directions for negotiating general assurances under the revised regulations offer any guidance on this point? 
Answer - The sample assurance prepared by OPRR states that research investigators and department heads are responsible for reporting promptly to the Office of Research Administration (ORA) [or other senior institutional official(s)] and to the IRB any serious or continuing noncompliance with the requirements of the assurance or deteminations of the IRB.

The sample further states that for reporting purposes the IRB will report the following:

(1) Any serious or continuing noncompliance by research investigators with the requirements of the IRB This information shall be reported promptly to the ORA and the OPRR.

(2) Injuries to human subjects - Information received by the IRB concerning injuries to subjects shall be reported promptly to the ORA. (The ORA is responsible for reporting to the OPRR.)

(3) Unanticipated problems - Information received by the IRB concerning unanticipated problems involving risks to subjects or others shall be reported promptly to the ORA. (The ORA is responsible for reporting to the OPRR.)

(4) Suspension or termination of IRB approval - Each IRB suspending or terminating approval of research protocols shall include a statement of the reasons for the IRB's action and shall report the action promptly to the research investigator, the ORA and the OPRR.

Question 3 - Relates to Implementation of Debarment Regulations.

Answer - These questions overlap with many of the questions answered in Secretary Schweiker's letter of April 15. Since the Secretary has agreed to meet with the Chaiman and Commission staff, it would be premature to amplify what was said in the April 15 letter.

II. Corrections or modifications necessary to assure the accuracy and campleteness of our summary of HHS rules and procedures for the protection of human subjects.

Answer - Any summary of the regulations requires amission of critical information. We, therefore, strongly recommend inclusion of the entire set of requlations, since this is the only way we can be certain that distortions will not occur, and we point out that it would take nearly as long to read the sumary as the regulations. Nevertheless, we have tried to edit the draft summary found in Appendix A of the Biennial Report. We found that it contained numerous errors and misleading statements. Consequently, even after editing, we cannot fully guarantee the "accuracy" of the summary. We have made our editorial comments on the attached copy of Appendix A. Also included are two memoranda fram Dr. Nightingale of FDA containing corments on the FDA portion of the summary. 
III. You requested information on the number of research projects, IRBs human subjects and budget for HHS intramural research.

Answer - While we did not have time to compile figures on all HHS intramural research programs, we do have figures relating to intramural program in the NIH Clinical Center which is the largest part of the HHS intramural program.

For FY 1980

- The Clinical Center had 9 IRBs until September 1, 1980, after which a 10th IRB was established. In addition, the National Institute on Aging utilizes the IRB at Baltimore City Hospital.

- The Clinical Center admitted 7,541 inpatients and identified 4,475 first visits of outpatients. (Note: this figure is for calendar year 1980. FY 1980 figures would be at approximately the same level.)

- The Clinical Center IRBs approved 162 new research projects and exercised continuing review over a total of 689 projects in FY 1980.

- The total cost of the Clinical Center program in FY 1980 was $\$ 68,800,000$. This figure includes some expenditures for research with animal subjects, but most of it was expended in support of human subjects research.

IV. Answers to questions proposed by you and Brad Gray on September 18.

Answer - Brad Gray withdrew his questions on that date. Consequently, we cannot answer them until and unless he resubmits them.

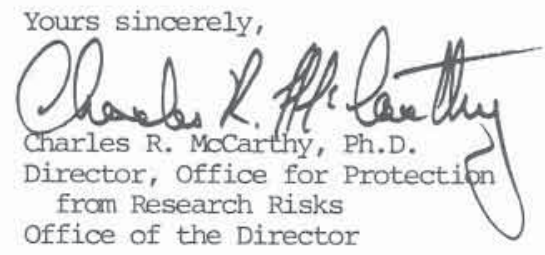

4 Enclosures 
President's Commission for the Study of Ethical Problems

in Medicine and Biomedical and Behavioral Research

Suite 555, 2000 K Street, N.W., Washington, DC 20006 (202) 653-8051

December $8, ' 1981$

Dr. Robert J. Rubin

Assistant Secretary for Planning

and Evaluation

Department of Health and Human Services

Room 415F

Hubert Humphrey Building

200 Independence Avenue, S.W.

Washington, D.C. 20210

Dear Dr. Rubin:

I am pleased that, as a result of the meeting Mr. Abram, Ms. Mishkin and I had on December 3 with Secretary Schweiker, Dr. 'Brandt, yourself and other HHS officials, you will be coordinating the Department's response to the outstanding questions about HHS policies and procedures which have been posed by the Commission over the past fifteen months. I can assure you that we share Secretary Schweiker's view that it should be possible to formulate responses adequate for the Commission's needs in a succinct fashion. We will be glad to do anything we can to assist in this process, and we welcome the suggestion, made by Dr. Brandt, that any formal statements of Departmental policy that emerge be printed in the Federal Register for public comment.

I realize that your schedule is likely to be very busy until FY 82 appropriation (or continuing resolution) issues are laid to rest--and ever thereafter! I w111 look forward to hearing from you at your early convenience about how you wish to proceed. If you need any further background materials, beyond those we provided last week, please let me know. I remain,

With high hopes for a speedy and successful completion of this matter

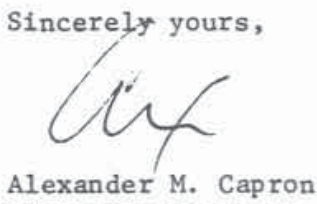

Executive Director

cc: Members of the Commission

The Honorable Richard Schweiker 



\section{HHS Debarment Regulations and Related Rules}

Federal Register / Vol. 45, No. 198 / Thursday, October 9, 1980

67262

\section{DEPARTMENT OF HEALTH AND HUMAN SERVICES}

\section{Office of the Secretary}

\section{CFR Part 78}

Debarment and Suspension From Ellglbillty for Financial Assistance

AOEncr: Department of Health and Human Services.

ACriou Final rule.

sumanar: HHS hereby amends Title 45 by adding a new Part 76 authorizing debarment and suspension of individuals and institutions from eligibility to receive grants or other forms of financial assistance under HHS discretionary programs-. These regulations are necessary because there have been instances of fraud or abuse by persons who are responsible for Federal funds, and the effect of the regulations will be to establish a procedure, with due process safeguards, to rander these persons ineligible to recaive Hirs financial assistance for reasonable periods of time.

urresm Dat: November 10, 1980. ADonens: Requeats for information or a copy of the regulations may be addressed to the Legal Advisor, NIH, Office of the General Counsel, Room 2B50. Building 31, National Institutes of Health, 9000 Rockville Pike, Bethesda, Maryland 20205.

FOn FUnTrea INFOAMañon CONTACT: William G. Ketterer, Senior Attorney, NIH. Address: Same as above; telephone (301) 496-6043.

SUPPLEMENTANY IMFORMATION: On March 19, 1979, the Secretary of Health. Education, and Welfare (now the Secretary of Health and Human Services) published in the Foderal Register (44 FR 16444) a notice proposing regulations governing the debarment and suspension of individuals and institutions from financial assistance for specified causes and subject to due process safeguards.

The notice provided 60 days opportunity for written comment from interested members of the public. Although some comments were received after the expiration date, all comments have been considered in preparation of the final regulations.

\section{Overview of the Commeats}

Thirty-two letters of comment were received from the following sources: 3 local school districts, 5 State 
government agencies, 13 universities or colleges, 9 other educational organizations, and 2 concerned individuals. Although many comments were flatly opposed to any regulations on debarment (generally because they felt that existing procedures were adequate), some letters generally supported the adoption of some form of debarment procedure, but offered specific comments for clarification and improvement. All the comments have been carefully considered in adopting the final regulations.

A discussion of the comments received and the Secretary's action with respect to them follows:

(1) Sufficiency of 5 U.S. Code 8301 as authority. Several comments questioned whether the authority cited for the regulations, 5 U.S. Code 301 , is legally sufficient. Section $\mathbf{3 0 1}$ authorizes the heads of executive agencies to "... prescribe regulations for the government of his department, the conduct of its employees, the distribution and performance of its business, and the custody, use, and preservation of its records, papers, and property." While this authority is general in nature, the Secretary believes that establishment of reasonable debarment and suspension procedures to protect limited public funds for financial assistance is in furtherance of the performance of HHS's "business" of administering financial assistance programs authorized by Congress. The alternative would be to restate separately each statutory authority for every affected program, which is impractical.

(2) Are the Regulations Necessary? Numerous comments questioned whether the regulations are necessary and whether they merely duplicate other HHS regulations and procedures which are presently available to correct fraud and abuse in the assistance area (for example, normal audit procedures, and procedures for termination of ongoing grant awards under 45 CFR Part 74. Subpart M). These procedures deal with fraud and abuse after they have occurred and the Secretary believes that, in order to provide the maximum protection of Federal funds, there should be an across-the-board mechanism for the prevention of fraud and abuse. By excluding irresponsible applicants from the award process, the Secretary believes that limited public funds for assistance purposes will be available where they will be used properly.

With regard to overlapping debarment procedures under particular programs (for example, termination of eligibility of postsecondary institutions for student financial assistance under 45 CFR Part 168), the Secretary agrees that the regulations should take into account and. in response to a comment. \& 76:10(g) [renumbered 76.10(f)] has been revised to include a prior outstanding debarment from financial assistance by a Government agency (including an agency within HHS) as cause for instituting a Department-wide debarment. Conforming changes have also been made to $878.12(\mathrm{~b})$. As in the case of prior contract debarment, the period of debarment would run concurrently with the period of debarment under the particular program concerned. The Secretary believes that it makes little sense for a person debarred from Government contract awards or financial assistance under one program, to continue to be eligible for financial assistance under the other numerous discretionary programs administered by HHS.

(3) Failure to list these regulations in HHS's Semiannual Agenda of Regulations. Two comments pointed out that the debarment regulations were not listed in HHS's Semiannual Agenda of Regulations published in the Federal Register for January 19, 1979 (44 FR 176), which is now required by Executive Order 12044. The Secretary regrets this omission which was entirely inadvertent and due to inadequate "tracking" of the regulations in the course of development. However, the public was not harmed by this omission because the notice provided full 60 days opportunity to comment, as required by the Executive Order and, although numerous comments were received after the expiration of the comment period. all comments received in response to the notice have in fact been considered. 
In this connection, also, one commenter requested a hearing on the issues prior to publishing regulations in the area. The Secretary believes that the 60 day comment period has provided opportunity for public participation, and that such a hearing would only serve to further delay publication of regulations: the request is therefore denied.

(4) $876.10(d)$ and (e) "unsatisfactory performance" and "serious" violations of statutes, regulations, terms and conditions as causes to debar. There were several objections to $\$ 78.10(\mathrm{e})$ authorizing debarment on the basis of "unsatisfactory performance" on a previous award as being ambiguous and subjective. In response, the criterion "as determined under the terms and conditions or specifications the prior awards" has been added to the provision, and, of course, a respondent will be afforded opportunity at a hearing to challenge a proposed debarment for unsatisfactory performance.

In response to a staff comment on paragraph (e), the provision has also been expanded to cover awards of contracts and subcontracts.

Objections on grounds of ambiguity were also raised with regard to the use of the word "serious" at several places in 876.10 . Although clarifying changes have been made, the term has been retained. Because of the numerous programs covered by these regulations, the term was chosen to leave room for administrative discretion, but requires an affirmative finding of seriousness before debarment action may be initiated.

The use of the term "serious" is intended to limit debarment to causes involving matters of importance, or which have important or dangerous possible consequences. The following examples, which are not exhaustive, are given to illustrate this meaning: (1) the misappropriation of grant funds for personal benefit, such as financing personal trips unrelated to the purpose for which the funds were awarded, (2) willful failure to comply with record retention and access requirements of regulations in order to frustrate examination or audit by the
Government, including destruction of relevant documents, and (3) intentional falsification of research reports in order to meet deadlines, comply with the terms of awards, or secure personal or profeesional advantage.

It is believed that the standard thus affords a measure of protection to persons because insubstantial and minor violations would not be basis to debar, and even material violations must be determined to be sufficiently serious in nature to justify debarment action.

(5) $876.10(f)$ Discriminatory practices. Most comments objected to the ground

"discriminatory practices," as introducing a new mechanism and procedures for enforcing civil rights laws, which already have their own specific regulations and procedures for determining discrimination (see, for example, 45 CFR Parts 80 and 81 relating to nondiscrimination under Title VI of the Civil Rights Act of 1964). Others felt that this ground was not consistent with the primary purpose of the regulations. which is to eliminate fraud and fiscal abuses.

Although it would be possible to modify the provisions relating to unlawful discrimination to limit debarment on those grounds to the terms and scope of a previous court or administrative order, this would not constitute a general debarment which is the intention of the regulations, and might lead to confusion. Accordingly, proposed \& 76.10(f) and related provisions of the regulations have been deleted, and debarment for discriminatory practices under the statutes listed below or ur:der Executive Order 11246 is outside the scope of these regulations:

(a) Title VI of the Civil Rights Act of 1964 (42 U.S. Code $\$ 2000$ d et 8eq.);

(b) Title $\mathrm{XX}$ of the Education Amendments of 1972 (20 U.S. Code 81681 et seq.);

(c) Title VII and VIII of the Public Health Service Act (42 U.S. Code $\$ 8292$, 296);

(d) Age Discrimination Act of 1975 (42 U.S. Code 8 6101); and 
(e) Discrimination on the basis of handicap (section 504 of the Rehabilitation Act of 1973; 29 U.S. Code $8794)$.

Debarment from eligibility for financial assistance under the above listed statutes and Executive Order 11246 will be in accordance with the terms of any order issued pursuant to those statutes or Executive Order 11246.

(6) \& $76.10(\mathrm{~h})$ [renumbered \&8 $78.10(\mathrm{~g})]$ "Catch-all" lacks criteria. Many commenters objected to the "catch-all" provision as being ambiguous and encouraging abuse of discretion. The Department does not agree. While the provision is indeed broad, because of the variety of programs covered by these regulations and the myriad of situations which may arise, it is essential to be able to handle unpredictable circumstances.

(7) Should the regulations include a detailed implementing administrative structure, including points of contact? This is viewed as an internal administrative matter which is not appropriate to include in the regulations. All normal channels for receiving and investigating complaints of fraud or abuse in grants would be available, for example, the relevant program office, the Office of the Inspector General, and the Office of the General Counsel. In addition, HHS reserves the right to undertake appropriate investigations of financial assistance programs upon its own initiative.

(8) Are the regulations a penalty or punishment? While the Secretary agrees that the regulations are stringent, the Secretary does not agree that they constitute a penalty or punishment because they are intended and will be used (1) solely to protect the interests of the United States and (2) they apply only to "discretionary programs" which are specifically defined to exclude programs under which an applicant is entitled to assistance as a matter of law. The courts have recognized the nonpunitive nature of debarment actions as follows in Gonzalez v. Freemen, 334 F. 2d 570 at 576, 577 (1964):

The question presented is whother Commodity Credit is powerless to terminate business ralations with irresponsible, defaulting or dishonest contractars. Notwithstanding its severe impact upon e contractor, dabarent is not intended to punish but it is a necessary "meens for accomplishing the congressionsl purpose" of Commodity Credit to "aid ia the development of foreign markets for agricultural commodities." (emphasis added).

(9) 86.13 Imputing conduct of individuals to their institution. It was suggested that \& 76.13(b) (relating to conduct within the scope of one's employment) and (c) (relating to debarrable conduct of individuals) should include the express requirement that the individual be knowingly involved. The comment is accepted with respect to paragraph (c) which deals with circumstances under which an individual may be personally debarred for participating in conduct for which the institution employing that individual may be debarred. Paragraph (b), however, deals solely with the issue of imputing conduct of an individual performed within the scope of employment, to his or her employer, and the key factor here is whether the employer knew or should have known of the conduct in question. To clarify this the word "or" in the sixth line of paragraph (b) has been changed to "and," so as to read "*." "where such conduct was accomplished within the scope of authority or employment and under circumstances in which responsible officials of the institution knew or should have known of the conduct."

Pursuant to another comment, the terminology of paragraph (b) has been improved to read "scope of authority or employment" (in lieu of "course of his or her official duty"). Parallel changes have also been made to 86.21 relating to suspensions.

Other comments questioned the fundamental fairness of changing an institution with the errant conduct of its employees. Holding an employer responsible for the actions of its employees, committed within the scope of employment, has long been accepted for purposes of liability under the general law of agency and this appears 
all the more applicable where, as is the case with financial assistance, the institution often stands to benefit financially from the dishonest acts of its employees. Indeed, it is the institution which is in the best position to take corrective measures and, in response to a comment in this regard, paragraph (b) has been amended to require that remedial action by responsible officials of the institution be taken into account in determining whether institutional debarment is warranted. Also, under \$ 76.12 (c), change of ownership or management, or.correction of the underlying grounds for which debarment was imposed, are grounds to terminate a debarment. Reference to (change of) "responsible personnel" has been added to the provision to make it explicit that this too would constitute a basis to terminate debarment.

(10) Applicability to State and local government agencies. Several comments objected to applicability of the regulations to public institutions, L.e., State and local government agencies, although most comments felt they should be treated the same as private organizations. The Secretary recognizes the serious implications of rendering a State agency subject to debarment for the wrongful conduct of its employees. But in light of the fact that the regulations are limited to discretionary awards, which are awarded solely on the basis of merit or program need, and do not affect nondiscretionary awards, there is no apparent reason why such agencies should not have to compete on an equal basis with, and be subject to the same constraints as, the private sector for the limited Federal dollars available. Also, as previously noted, where the affected individuals are removed from positions of authority, this would be a basis for terminating debarment under 876.12 (c).

A related question was also raised whether violation of the terms and. conditions of a mandatory formula grant (i.e., an entitlement) would theoretically serve as a basis to debar from discretionary awards under $\$ 76.10(d)$. The answer is yes, in light of the broad definition of "financial assistance" (which includes all grants), but this again would not affect the debarred institution's continued eligibility for awards to which it may be entitled as a matter of law.

Also, \& 76.13 has been expanded to make it clear that, when an institution is the subject of a debarment action, the Secretary would normally limit the debarment just to those components of the institution which were involved in or actually responsible for the conduct leading to debarment.

(11) \& 76.17 and \& 76.24 Publication in Federal Register of the results of debarment and suspension actions. Several commenters objected to publication in the Federal Register of the results of debarment and suspension actions, especially publication of the names of persons debarred and suspended. Several felt that this rendered debarment and suspension actions punitive in nature contrary to 8 76.1(a); on the othar hand, others expressed the view that additional information should be so published, including details concerning hearings, periodic lists of names of formerly debarred persons, and the amount of any monies involved. Several comments questioned the need for any public notice concerning debarment and suspension actions.

The purpose of publishing this information in the Federal Register is (1) to inform the public of a significant action taken to protect the public interest, and (2) to provide constructive notice to grantees and others responsible for administering HHS funds so that they can implement the restrictions set forth in $\$ \$ 76.16(\mathrm{c})$ and 76.23(c) barring participation by debarred and suspended individuals under financial assistance programs.

One comment supporting Federal Register publication noted: ". * * secrecy in government is a tool which ts all too often abused. In all likelihood. most cases of debarment are the final result of at least one public hearing." The Secretary agrees that the public has a right to know, through publication in the Federal Register, the results of 
proper governmental actions taken to protect the public interest. Additionally. $876.17(\mathrm{c})$ and $817.24(\mathrm{c})$ provide for the maintenance of a current consolidated list of debarred institutions and individuals for purposes of administering affected discretionary programs.

(12) \& 78.22(f) Suspensions-hearings. Several commenters felt that the regulations failed to provide due process hearings in cases of suspensions. Indeed, one comment stated that there could be a suspension for up to 18 months in cases of criminal indictment without opportunity for a hearing. Postsuspension hearings are guaranteed for all suspensions upon request of the suspended party under $876.22(f)$ and such hearings are required to be conducted, to the extent practical, in accordance with the debarment procedures set forth in $8 \delta 76.14$ and 76.15. Furthermore, although the courts have expressly upheld summary suspensioms for cause for up to one month without any opportunity for a hearing (see Horne Brothers, Inc. v. Laird, 463 F2d 1268 (1972)), the regulations exceed this standard by affording a prompt hearing to suspended persons. However, as proposed, 8 78.21(a) may give the impression that the period and scope of suspensions are determined without reference to the results of any hearing held pursuant to $876.22(f)$, and this has been corrected in the final regulations.

(13) Applicability to persons involved in criminal activity not involving Federal funds; application to affiliates. It was felt by several commenters that the regulations should not apply, as they do, to persons convicted of criminal activity not involving Federal funds (for example, conviction of fraud in connection with attempting to obtain a private contract in \& $78.10(\mathrm{a})$ ).

The Secretary believes that any fraudulent criminal activity in connection with contracts clearly demonstrates a lack of business integrity and therefore may warrant debarment from stewardship over public funds which, in the final analysis, is a public trust. Of course, it should be noted that under the regulations debarment and suspension only preclude future awards during the specific period of debarment or suspension, after which the person would again be eligible to apply for and receive financial assistance. In response to a comment, this point has been clarified in 8 76.1(c).

The suggestion that the regulations set forth required minimum periods of debarment for particular offenses is not accepted, because the Secretary believes the regulations should be as flexible as possible in this regard.

Another comment questioned the fairness of including affiliates at all: but it should be noted that, as defined. affiliates are institutions which control or are controlled by another institution or individual and they are guaranteed the same notice and opportunity for hearing under $878.13(\mathrm{a})$. Similarly, the decision to initiate debarment, which is a drastic remedy, is left to sound discretion of the Secretary in 876.10 , and the suggestion that the Secretary "must", debar all individuals and institutions for the enumerated causes in \& 76.10 is rejected as impractical and umecessarily harsh. For the same reason, other suggestions which would severely limit the discretion of the Secretary to decline action, or unduly restrict the Secretary's choices within the regulatory framework have been rejected.

(14) Hearing procedures. Numerous suggestions have been made to modify the hearing procedures, chiefly to the benefit of the respondent institution or individual. For example: that HHS should bear the full costs of hearings to respondents (including costs of travel expenses and legal counsel, and provision of transcripts without charge), that respondent should choose the place of hearing or that it should always be at the site of the affected institution. that there be more than one hearing examiner, that there be more speciffe thme intervals stated, that there be an appeal as a matter of right to the Secretary and beyond the Secretary. Although $876.18(b)$ has been modified 
to assure respondents a right of appeal to the Secretary, most of these other suggestions are rejected as not necessary to assure due process. In addition, as the result of staff comment, the Secretary has revised the final rule to provide that hearings shall be conducted by a hearing officer (who shall be an officer or employee of HHS not previously involved in the matter), and the notice provisions have been modified to authorize notice by personal service, as well as by registered or certified mail.

(15) Clarifying, technical and editorial changes. In fesponse to a staff comment, the definition of "financial assistance" in 876.2 has been clarified to explicitly cover assistance in the form of property and services, as well as awards of funds.

We have also added clarifying language to 876.11 (d) to remove an apparent inconsistency with 8 76.15(c). While debarment may be based solely on proof of debarment from contracting by another government agency (which is a matter of public record), \& 76.11(d) would permit HHS to develop any additional facts it deems appropriate at the HHS debarment hearing. The fact of prior debarment (as well as any other facts proferred by HHS) will be fully subject to rebuttal by the affected parties at the HHS hearing. The affected parties could also introduce evidence and offer argument on whether the reasons for the prior debarment by another agency warrant debarment under this regulation. Section $76.23(\mathrm{a})$, setting forth general restrictions during suspensions, has been revised in response to a staff comment to conform more closely to the parallel provision \& 78.16(a) governing general restrictions during debarments.

In addition, several other clarifying. technical and editorial suggestions were offered. These have been accepted where possible and are reflected in the final rule.

Title $\mathbf{4 5}$ Code of Federal Regulations is therefore amended by adding a new Part
76, as set forth below:

Dated: August 21, 1880.

Patricia Roberts Harris,

Secretary.

PART 76-DEBARMENT AND SUSPENSION FROM ELIGIBHTY FOR FINANCIAL ASSISTANCE

\section{Subpart A-General}

sec.

76.1 The scope and purpose of these regulations.

76.2 Definitions.

\section{Subpart B-Debarment}

76.10 Causes for debarment.

76.11 Conditions for debarment.

76.12 Period of debarment.

76.13 Scope of debarment.

78.14 Procedures-Hearings.

76.15 Procedures-Determination of hearing officers; review by Secretary.

76.16 Restrictions on debarred institutions and individuals.

76.17 Publication of notice in Federal

Register of results of debarment actions.

\section{Subpart C-Suspendion}

78.20 Causes for suspension.

76.21 Period and scope of suspension.

76.22 Notice of suspension.

76.23 Restrictions during period of suspension

76.2A Publication of notice in Federal

Register of results of suspension actions.

Authority: 5 U.S.C. 301.

\section{Subpart A-General}

\subsection{The scope and purpose of these} regulations.

(a) Debarment. Subpart B prescribes policies and procedures relating to debarment for cause of public and private institutions or individuals (and their affiliates) from eligibility under discretionary programs of financial assistance which are awarded or administered by HHS. Debarment is invoked to exclude institutions and individuals from participation in HHS discretionary programs of financial assistance to protect the interests of the Government, and is not intended to be a penalty or punishment. This measure shall be instituted only for as long as necessary to protect the interests of the 
Government and financial assistance is precluded only during the period of debarment.

(b) Suspension. Subpart C sets forth the procedures for temporary suspension of institutions or individuals (and their affiliates) from eligibility under HHS discretionary programs of financial assistance. Because it is a drastic step taken upon what may be incomplete information, it shall be used cautiously and only when the Secretary believes that grounds for debarment exist (or there is an outstanding indictment for a criminal offense which is grounds for debarment) and there are compelling reasons why immediate action must be taken before debarment proceedings can be completed. In assessing whether adequate evidenoe exists for invoking suspension. consideration shall be given to the evidence available, to the existence or absence of corroboration as to allegations, as well as to the inferences which may properly be drawn from the existence or absence of facts and the irreparable nature of the harm caused by continuing the institution's or individual's eligibility pending debarment proceedings. This assessment shall include an examination of basic documents, such as contracts, grants, inspection reports. and correspondence. A suspension may be terminated or modified whenever it is determined to be in the interest of the Government to do so.

(c) Relationship to other program responsibilities. The regulations of this part deal solely with the debarment and suspension of individuals and organizations for future awards and do not limit the discretion of agency officials to take into account the fiscal and administrative capabilities of applicants in connection with particular applications for financial assistance. Termination and suspension for cause of ongoing grants are separate matters which are governed by HHS's grant administration regulations, 45 CFR Part 74, Subpart M. However, debarment and suspension under this part precludes all future awards during the period of debarment or suspension, including competitive and noncompetitive renewal, supplemental, and continuation awards, of financial assistance for a previously supported activity.

\subsection{Definition:}

As used in this part:

"Affiliate" means an institution which controls, or is controlled by, or is under common control with, another institution or individual. For example, a university foundation and the "parent" university are affiliates if one has the power to control the other with respect to the conduct for which debarment or suspension is sought.

"Discretionary program" means a program of financial assistance which is awarded on the basis of merit or program need and to which an applicant is not entitled as a matter of law.

"Debarment" and "debarred" mean the exclusion from eligibility for financial assistance awarded or administered by HHS under discretionary programs for a reasonable. specified period of time, commensurate with the seriousness of the cause resulting in the debarment.

"Financial assistance" means grants and awards of funds, services, or property (including fellowships, traineeships and National Research Service Awards), cooperative agreements, loans, loan guarantees, and interest subsidies, including competitive and noncompetitive renewal, supplemental, and continuation awards for any of the foregoing.

"HHS" means the Department of Health and Human Services and its operating agencies and component organizations.

"Individual" means a natural person.

"Institution" means any public or private corporation, agency, organization, or institution, which would otherwise be eligible to receive financial assistance under HHS discretionary programs.

"Respondent" means an institutton. individual or affiliate who is the subject of a debarment action under \$ \& 76.14 and 76.15 . 
"Secretary" means the Secretary of Health and Human Services and any officer or employee of HHS to whom the authority involved has been delegated.

"Suspension", unless the context otherwise requires, means an immediate exclusion from eligibility for financial assistance under discretionary programs without prior hearing pending completion of debarment or other proceedings, as applicable.

\section{Subpart B-Debarment}

\section{78.10 Causes for debarment.}

Subject to the conditions set forth in $\$ 76.11$ and the procedural requirements set forth in $\$ 878.14$ and 78.15 , the Secretary may debar an institution or individual, and any affiliate thereof, in the public interest for any of the following causes:

(a) Conviction for any criminal offense committed as an incident to obtaining or attempting to obtain a public or private contract or any form of financial assistance (or subcontract or subgrant thereunder), or as an incident to performance of any contract, or any form of financial assistance (or any subcontract or subgrant thereunder);

(b) Conviction under the Organized Crime Control Act of 1970 , or conviction for embezzlement, theft, forgery, bribery. falsification or destruction of records, receiving stolen property, or any other offense indicating a lack of business integrity or business honesty which seriously and directly affects the question of present responsibility to account for or administer Federal funds;

(c) Conviction under the Federal Antitrust Statutes arising out of the submission of bids, applications or proposals:

(d) Serious violation of the applicable statute, regulations, or other terms and conditions of a previous award of financial assistance;

(e) A record of serious unsatisfactory performance (or failure to perform) under one or more prior awards of financial assistance, contracte or subcontracts, as determined under the terms and conditions or specifications of the prior awards, except that unsatisfactory performance (or failure to perform) caused by acts beyond the control of the institution or individual shall not be considered a basis for debarment:

(f) Debarment from Goternment contracting, subcontracting, or financial assistance, by a Government agency (including an agency within HHS);

(g) Any other cause significantly affecting responsibility as a recipient or participant under a Federal program of sufficiently serious nature as determined by the Secretary to warrant debarment.

\section{78.11 Conditions for deberment.}

(a) General. Unless otherwise required by law, the existence of any of the causes set forth in 878.10 does not effectuate a debarment or necessarily require that an institution or individual be debarred. In each instance, a decision to debar shall be made within the discretion of the Secretary and shall be rendered solely in the best interest of the Government. In addition, mitigating factors, such as the degree of seriousness of the offense, violation. failure, or inadequacy of performance. will be considered in deciding whether debarment is warranted.

(b) The existence of a cause set forth in $876.10(\mathrm{a})$. (b), and (c) (relating to conviction of criminal offenses) shall be established by proof of judgment of criminal conviction by a court of competent jurisdiction. In the event that an appeal taken from such conviction results in a reversal, debarment shall be removed on the Secretary's own motion or upen the written request of the institution or individual concerned (untess other cause for debarment exists).

(c) The existence of causes set forth in $\$ 76.10(\mathrm{~d})$, (e), and (g) (relating to violation of grant terms and conditions. performance, and other causes) shall be established by evidence which the Secretary determines to be clear and convincing in nature.

(d) Debarment on the cause set forth in \$ 76.10(f) (relating to debarment from Government contracting, subcontracting. or financial assistance) may be based entirely on the determination of debarment by the initial debarring 
agency, or upon a combination of this determination and additional facts.

\subsection{Period of debarment.}

(a) General. Debarment for causes other than debarment from contracting. subcontracting or financial assistance under $\$ 76.10$ (i) shall be for a reasonable, definite period of time commensurate with the seriousness of the offense, violation, or failure or inadequacy of performance, as necessary to protect the interests of the Government.

(b) Contract and other prior debarments. Where debarment is based upon prior debarment from contracts, subcontracts or financial assistance, the period of debarment shall run concurrently with the period of the prior debarment.

(c) Termination or reduction of period. Except where prohibited by statute. debarment may be terminated, or the period thereof may be reduced, by the Secretary, on the Secretary's own initiative or upon the submission of an application, supported by documentary evidence, setting forth appropriate grounds for the granting of relief, such as newly discovered material evidence, reversal of conviction, bona fide change of ownership, management, or responsible personnel, or the elimination or correction of the underlying grounds for which the debarment was imposed or other mitigating circumstances. The Secretary may require, as a condition to termination of the debarment period. restitution to HHS by the debarred party for losses sustained by HHS.

(d) Reinstitution of debarment. Except where debarment is based upon conviction of a criminal offense, at the end of the termination period the Secretary may reinstitute debarment, through the debarment procedures set forth in this subpart, if the causes have not been corrected or adequate assurance given that the practices will not be repeated.

876.13 scope of debarment.

(a) Institutions. When an institution is the subject of a debarment action, the Secretary may limit the debarment just to those components of the institution which were involved in the conduct leading to debarment.

(b) Affiliates. A debarment may include affiliates of an institution or individual which have had notice and opportunity for a hearing in accordance with $\$ \S 76.14$ and 76.15 . Each decision to include a known affiliate within the scope of a proposed debarment is to be made on a case-by-case basis, after giving due regard to all the rel ivant facts and circumstances.

(c) Imputing conduct to institution. Conduct of an individual may be imputed to the institution, or responsible component of the institution, with which he or she is associated by employment or otherwise, where such conduct was accomplished within the scope of authority or employment and under circumstances in which responsible officials of the institution knew or should have known of the conduct. However, remedial action taken by responsible officials of the institution shall be taken into account in determining whether debarment of the institution is warranted. The institution shall be entitled to notice and opportunity for a hearing in accordance with $\$ 876.14$ and 76.15 .

(d) Individuals involved in debarable activities. Where an institution is involved in conduct justifying debarment under this part, any individual who was knowingly involved in the commission of the conduct in question may also be debarred. The individual shall be entitled to notice and opportunity for hearing in accordance with $\$ \& 76.14$ and 76.15 .

\section{\$ 76.14 Procedures-Hearings.}

(a) Initiation of action. When the Secretary seeks to debar an institution or individual, or any affiliate thereof (called "respondent" for purposes of $8 \$ 76.14$ and 76.15 ), respondents shall be served with written notice from the Secretary by personal service or registered or certified mail, return reoeipt requested. The notice shall:

(1) State that debarment is being considered;

(2) Set forth the reasons for the 
proposed debarment and the proposed length of time; and

(3) Indicate that the respondent will be accorded an opportunity for a hearing if the respondent so requests and the request is received within 30 days after the date of mailing or service of the notice to the respondent's last know address.

(b) Hearing.-(1) Request for hearing. Any respondent that has been notified of a proposed action is entitled to request an opportunity to be heard and to be represented by counsel. A hearing request shall be made in writing addressed to the Secretary or other official proposing the action. If at the end of the 30 day period referred to in paragraph (a)(3) of this section, no request has been received, it may be assumed that an opportunity to be heard is not desired, and the Secretary shall proceed to make a final determination and so notify the respondent.

(2) Notice of hearing. Upon receipt of a request for an opportunity to be heard, the Secretary shall appoint a hearing officer and the hearing officer shall arrange a prompt and timely hearing. Notice of the time and place of such hearing shall be in writing, transmitted by personal service or registered or certified mail, return receipt requested, and shall include a statement indicating the nature of the proceedings and their purpose. The hearing officer shall determine the place for the hearing. In determining the hearing place, the hearing officer shall consider the convenience of the parties and the public interest.

(c) Hearing procedures. (1) Hearings shall be conducted by the hearing officer, who shall be an officer or employee of HHS not previously involved in the matter.

(2) HHS shall be represented by the General Counsel or designee.

(3) A transcribed record shall be made of the proceedings and a copy shall be made available to the respondent upon request, upon payment of any appropriate fee prescribed under the HHS Freedom of Information Act regulations (45 CFR Part 5).
(4) Formal rules of evidence and procedures applicable to proceedings in a court of law will not be applied.

(d) Scope of hearing; sufficiency of evidence. The scope of the hearing and sufficiency of evidence shall be governed by the applicable provisions of 876.11 .

8576.15 Procedures-Determination of hearing officers; review by Secretary.

(a) After completion of the hearing. the hearing officer shall make a written determination on the evidence presented, including where appropriate the extent to which the determination applies to affiliates named in the action. The hearing officer's determination shall be transmitted to the Secretary, and to all respondents by personal service or registered or certified mail, return receipt requested.

(b) The hearing officer's determination shall be final unless within 60 days the respondent requests the Secretary, or the Secretary decides on the Secretary's own motion or at the request of the General Counsel, to review the findings of the hearing officer.

(c) Where a review is granted, the determination by the Secretary shall be final and shall be based solely on the record of the hearing. It shall fully recite the evidentiary grounds upon which the Secretary's determination is made.

(d) Each determination shall become part of the record.

(e) Notice of the Secretary's decision to review the hearing determination and subsequent determination by the Secretary, shall be given in writing to all respondents by personal service or registered or certified mail, return receipt requested.

\section{76.16 Restrictions on debarred institutione-and individuals.}

(a) General restrictions. Institutions and individuals (and their affiliates) debarred under this subpart shall be ineligible during the period of debarment to receive any form of financial assistance under any discretionary program awarded or administered by HHS; applications or requests for financial assistance 
received under any discretionary program shall not be considered and shall be returned with a statement of the reasons. However, when it is determined essential in the public interest by the Secretary, an exception may be made to permit an institution or individual to apply for and receive support under a particular program on the same basis as other eligible applicants under the program concerned. In addition, where grounds exist, the Secretary may also proceed to terminate or suspend for cause ongoing funded grants avarded to a debarred grantee, as authorized by 45 CFR Part 74. Subpart M.

(b) Suboontracting and sabgranting. Debarred institutions and individaals shall be ineligible to reoeive contracts, suboontracts and subgrants vinder any form of financial asgistance awarded or administered by HHS, and the responsible HHS official and recipients of financial assistance, as applicable, shall decline to approve contracting. subcontracting, or subgranting with that institution or individual, unless it is determined by the Secretary to be essential in the best interests of the Government to grant such epproval.

(c) Individuals. Debarred individuals shall be ineligible to serve or participate under any form of financial assistance awarded or administered by HHS under discretionary programs including service or participation in the conduct or performance of those awards or in the administration of Federal funds. Recipients of financial assistance shall be responsible for compliance with this provision, which constitutes a condition of all awards of financial assistance. Applications for financial assistance proposing debarred individuals to serve as principal investigators, project directors, or those responsible for the administration of Federal funds, or in any other capacity, shall not be considered and saall be returned to the applicant with a statement of the reason therefor.

8ุ 76.17 Publlication of notice in Federal Register of resulte of debarment actions.

(a) Contents. When an institution. individual, or affiliate is debarred under this subpart, HHS shall publish a notice in the Federal Register containing as a minimum the following information:

(1) The names of the debarred institutions, individuals, and affiliates. and their addresses:

(2) The authority under which the action was taken and a brief statement of the reasons for the action:

(3) The extent of restrictions imposed. including effective dates; and

(4) The termination date.

(b) A notice shall also be published in the Federal Register when a debarment is ended prior to its specified termination date.

(c) The Secretary shall also establish and maintain a current, consolidated list of debarred institutions and individuals for purposes of administering affected discretionary programs.

\section{Subpart C-Suepension}

\section{$\$ 76.20$ Cauces for suepension.}

(1) Whenever the Secretary believes that grounds for debarment exist (or there is an outatanding indictment for 8 criminal offense which is grounds for debarment under 78.10), and, in order to protect the interests of the United States, immediate action is necessary. the Secretary may suspend an institution, individual, and any affiliate thereof, in accordance with the applicable procedures of this part. This action shall be taken by the Secretary only where there are compelling reasons why the interests of the United States would be jeoperdized by waiting for completion of debarment proceedings under Subpart B.

8 78.21 Perlod and seope of suspension.

(a) A suspension shall be for a temporary period pending the completion of an investigation or hearing, and any administrative or legal proceedings as may result. Unless earlier terminated as the result of a hearing held pursuant to $86.22(f)$, the period and scope of suspension shall be as follows:

(1) Except where suspension is based on criminal indictment, debarment proceedings shall be initiated within 6 
months after notice of suspension, in accordance with Subpart B, or the suspension shall be terminated automatically. When the debarment proceedings are initiated within the $\theta$ month period, the suspension shall continue in effect pending the completion of debarment proceedings or for a period not to exceed 12 months after the date of the notice of proposed debarment, whichever first occurs.

(2) When suspension is based upon criminal indictment, it may continue until completion of the criminal proceedings, or for 18 months, whichever first occurs.

(b) Suspension may include all known affiliates of an institution or individual who have received notice and opportunity for hearing as set forth in $\$ 78.22$.

(c) A decision to include affiliates in a proposed supsension is a separate determination which shall be made on a case-by-case basis.

(d) The conduct of an individual may be imputed to the institution, or responsible component of the institution, with which he or she is associated by employment or otherwise when the conduct involved was performed within the scope of authority or employment and under circumstances in which responsible officials of the institution knew or should have known of the conduct. However, remedial action taken by responsible officials of the institution shall be taken into account in determining whether suspension of the institution is warranted. The institution shall be entitled to notice and opportunity for a hearing in accordance with $\& 76.22$.

(e) Individuals involved in activities resulting in suspension. Where an institution is involved in conduct justifying suspension under this part, any individual who was knowingly involved in the commission of the conduct in question may also be suspended. The individual shall be entitled to notice and opportunity for a hearing in accordance with \$ 78.22.

\subsection{Notice of suspension.}

When an institution or individual or any affiliate thereof is suspended, the Secretary shall furnish all the affected parties immediately with notice of the suspension by personal service or registered or certified mail, return receipt requested. The notice of suspension shall state that:

(a) The suspension is based on (1) an outstanding indictment for a criminal offense which is grounds for debarment under $\$ 78.10$ or (2) reasonable evidence that the institution or individual has committed irregularities of a serious nature which would be grounds for debarment under $\$ 76.10$ (the notice shall identify the indictment or describe the nature of the irregularities, in general terms, without disclosing the Government's evidence);

(b) The suspension is for a temporary period pending the completion of debarment or other proceedings, as applicable;

(c) Bids, proposals, and applications for financial assistance will not be solicited or accepted from the institution or individua and, if received, will not be considered, and awards of any form of financial assistance under HHS discretionary programs may not be made unless it is determined by the Secretary to be in the best interest of the Government:

(d) The institution or individual will not be eligible for the award of a subcontract or subgrant. Whenever the institution or individual is proposed as a subcontract or subgrantee, the responsible HHS official will decline to approve subcontracting or subgranting with that institution or individual in any instance in which consent is required of the Government before the subcontract or subgrant is made, unless it is determined by the Secretary to be in the best interest of the Govemment to grant approval:

(e) The suspension is effective throughout HHS, and

(f) A hearing as to whether the suspension should be continued will be provided upon request of the institution or individual or any affected affiliate. The hearing shall be conducted, to the, extent practical in accordance with the procedures set forth in $8 \$ 76.14$ and 78.15. 
87 76.23 Restrictions during perlod of suspension.

During a period of suspension of an institution or individual and any affiliate, the following policies and procedures shall be applicable:

(a) General restrictions. Institutions and individuals (and their affiliates) suspended under this subpart shall be ineligible during the period of suspension to receive any form of financial assistance under any discretionary program awarded or administered by HHS; applications or requests for financial assistance received under any discretionary program shall not be considered and shall be returned with a statement of the reasons. However, when it is determined essential in the public interest by the Secretary, and exception may be made to permit an institution or individual to apply for and receive support under a particular program on the same basis as other eligible applicants under the program concerned. In addition, where grounds exist, the Secretary may also proceed to terminate or suspend for cause ongoing funded grants awarded to a suspended grantee, as authorized by 45 CFR Part 74, Subpart M.

(b) Subcontracting and subgranting. Suspended institutions and individuals shall be ineligible to receive contracts, subcontracts and subgrants under any form of financial assistance awarded or administered by HHS, and the responsible HHS official and recipients of financial assistance, as applicable. shall decline to approve contracting. subcontracting or subgranting with that institution or individual, unless it is determined by the Secretary to be essential in the best interests of the Government to grant such approval.

(c) Individuals. Suspended individuals shall be ineligible to serve or participate under any form of financial assistance awarded or administered by HHS under discretionary programs, including service or participation in the conduct or performance of those awards, or in the administration of Federal funds. Recipients of financial assistance shall be responsible for compliance with this provision, which constitutes a condition of all awards of financial assistance. Applications for financial assistance proposing suspended individuals to serve as principal investigators, project directors, or those responsible for administration of Federal funds, $\mathrm{pr}$ in any other capacity, shall not be oonsidered and sball be returned to the applioant with a statement of the reason therefor.

876.24 Publication of notice in Federal Register of results of suspension actions.

(a) When an institution or individual is suspended under this subpart. HHS shall publish a notice in the Federal Register containing as a minimum the following information:

(1) The names of the suspended institutions and individuals, and any affiliates, and their addresses;

(2) The authority under which the action was taken and a brief statement of the reasons for the action;

(3) The extent of restrictions imposed, including effective date; and

(4) Statement that the suspension is for a temporary period of time, pending the completion of debarment or other proceedings, as applicable.

(b) A notice shall also be published in the Federal Register when a suspension is ended.

(c) The Secretary shall also establish and maintain a current, consolidated list of suspended institutions and individuals for purposes of administering affected discretionary programs.

[FR Doc. 80-26916 Filed 10-0-80: 8:45 em]

BuUNo COOE 4110-12-M 
Title 45-Public Welfare

\section{Subtitle A-Department of Health, Education, and Welfare}

Subpart M-Grant and Subgrant Clo-

(3) The grantee shall submit, within seout, Suspension, and Termination 90 days of the date of expiration or termination, all financial, perform.

$\$ 74.110$ Definitions. ance, and other reports required by

"Grant closeout" means the-process the terms of the grant. HEW may by which mines that all applis a tive actions and all required work of the grant have been completed by the grantee and the granting agency.

"Suspension" of a grant means temjorary withdrawal of the grantee's authority to obligate grant funds pend. ing corrective action by the grantee or a decision to terminate the grant.

"Termination" of a grant means pernanent withdrawal of the grantee's a'thority to obligate previously awarded grant funds before that authority would otherwise expire. It also means the voluntary relinquishment of that authority by the grantee. "Termination" does not include:

(a) Withdrawal of funds awarded on the basis of the grantee's underestimate of the unobligated balance in a prior period:

(b) Refusal by the granting agency to extend a grant or award additional funds (such as refusal to make a competing or noncompeting continuation. renewal, extension, or supplemental award):

(c) Withdrawal of the unobligated balance as of the expiration of a grant:

(d) Annulment, i.e., voiding, of a grant upon determination that the award was obtained fraudulently, or was otherwise illegal or invalid from inception.

\$74.111 Closeout.

(a) Each grant shall be closed out as promptly as is feasible after expiration or termination.

(b) In closing out HEW grants, the following shall be observed:

(1) Upon request, HEW shall promptly pay the grantee for any al. lowable reimbursable costs not covered by previous payments.

the grantee, and may waive any report which is not needed.

(4) The granting agency shall make a settlement for any upward or downward adjustment of the Federal share of costs, to the extent called for by the terms of the grant.

(c)(1) The closeout of a grant does not affect the retention period for. or Federal rights of access to, grant records. See subpart D of this part.

(2) If a grant is closed out without audit, the granting agency retains the right to disallow and recover an appro. priate amount after fully considering any recommended disallowances $\mathrm{re}$ sulting from an audit which may be conducted later.

(3) The closeout of a grant does not affect the grantee's responsibilities with respect to property under subpart $O$ of this part, or with respect to any program income for which the grantee is still accountable under subpart $F$ of this part.

\$74.112 Amounts payable to the Federal Government.

For each grant, the following sums shall constitute a debt or debts owed by the grantee to the Federal Govern. ment, and shall, if not paid upon demand, be recovered from the grantee or its successor or assignees by setoff or other action as provided by law:

(a) Any grant funds paid to the grantee by the Federal Government in excess of the amount to which the grantee is finally determined to be entitled under the terms of the grant:

(b) Any interest or other investment income earned on advances of grant funds which is due the Federal Gov. ernment pursuant to $\$ 74.47$;

(2) The grantee shall immediately (c) Any royalties or other special refund or otherwise dispose of, in ac- classes of program income which. cordance with instructions from HEW, under the terms of the grant, are reany unobligated balance of cash ad- quired to be remitted to the Federal vanced to the grantee.

Government (see subpart $F$ of this 
part):

anticipation of suspension or termina.

(d) Any amounts due the Federal tion. At the discretion of the granting Government under subpart $O$ of this agency, third-party in-kind contribupart; and

(e) Any other amounts finally determined to be due the Federal Government under the terms of the grant.

\section{\$74.113 Violation of terms.} tions applicable to the suspension period may be allowed in satisfaction of cost sharing or matching requirements.

(c) Appropriate adjustments to pay.

(a) When a grantee has materially failed to comply with the terms of a grant, the granting agency may suspend the grant, in accordance with $\$ 74.114$, terminate the grant for cause, as provided in $\$ 74.115$, or take such other remedies as may be legally available and appropriate in the circum. stances.

(b) If a project or program is supported over two or more funding periods, a grant may be suspended or terminated in the current period for failure to submit a report still due from a prior period.

\section{$\$ 74.114$ Suspension.} ments under the suspended grant will be made either by withholding subsequent payments or by not allowing the grantee credit for disbursements made in payment of unauthorized obliga. tions incurred during the suspension périod.

\section{\$ 74.115 Termination.}

(a) Termination for cause. The granting agency may terminate any grant in whole, or in nart, at any time before the date of expiration, whenever it determines that the grantee has materially failed to comply with the terms of the grant. The granting agency shall promptly notify the grantee in writing of the determina(a) When a grantee has materially tion and the reasons for the terminafailed to comply with the terms of a tion, together with the effective date. grant, the granting agency may, upon reasonable notice to the grantee, suspend the grant in whole or in part. The notice of suspension will state the reasons for the suspension, any corrective action required of the grantee, and the effective date. The suspension may be made effective at once if a delayed effective date would be unreasonable considering the granting agency's responsibilities to protect the Federal Government's interest. Suspensions shall remain in effect until the grantee has taken corrective action satisfactory to the granting agency, or given evidence satisfactory to the case of partial terminations, the por granting agency that such corrective tion to be terminated. However, if, in action will be taken, or until the grant- the case of a partial termination, the ing agency terminates the grant.

(b) Termination on other grounds. Except as provided in paragraph (a) of this section, grants may be terminated in whole or in part only as follows:

(1) By the granting agency with the consent of the grantee, in which case the two parties shall agree upon the termination conditions, including the effective date and in the case of par. tial terminations, the portion to $t \epsilon$ terminated, or

(2) By the grantee, upon written no. tification to the granting agency, setting forth the reasons for such termi. nation, the effective date, and in the granting agency determines that the

(b) New obligations incurred by the remaining portion of the grant will grantee during the suspension period not accomplish the purposes for which will not be allowed unless the granting the grant was made, the granting agency expressly althorizes them in agency may terminate the grant in its the notice of suspension or an amend- entirety under either paragraph (a) or ment to it. Necessary and otherwise al- paragraph $(b)(1)$ of this section.

lowable costs which the grantee could (c) Termination settlements. When a not reasonably avoid during the sus- grant is terminated, the grantee shall pension period will be allowed if they not incur new obligations for the terresult from obligations properly in-minated portion after the effective curred by the grantee before the effec- date, and shall cancel as many outtive date of the suspension and not in standing obligations as possible. The 
granting agency shall allow full credit informal appeal procedures whicr. to the grantee for the Federal share of must be exhausted before a forma. the noncancellable obligations proper- appeal to the Departmental Board wil: iy incurred by the grantee prior to ter- be allowed. Pursuant to $\$ 16.5(b)(2) 0$ : inination. that Charter, this document provides

\$ 7.116 Applicability to subgrants.

Grantees shall adhere to the same standards regarding closeout, suspension, and termination of subgrants as are prescribed in this subpart for granting agencies.

Title 42-Public Health

\section{Subpart D-Public Health Service Grant Appeals Procedure}

SOURCE: 39 FR 33782, Sept. 19, 1974, unless otherwise noted.

850.401 Purpose.

This subpart establishes an informal cordance with the applicable law anc procedure for resolution of post-award the terms and conditions of such as grant disputes prior to their submis- sistance or for failure of the grantef sion to the Departmental Grant Ap- otherwise to comply with any law, reg. peals Board established in 45 CFR ulation, assurance, term, or conditior Part 16 (38 FR 9906, April 20, 1973).

\$ 50.402 Applicability. applicable to the grant.

(2) A determination that an expendi. ture not allowable under the grant has

This subpart is applicable to all been charged to the grant or that the grant programs which are subject to grantee has otherwise failed to dis 45 CFR Part 16 ("Department Grant charge its obligation to account for Appeals Process") and which are ad- grant funds.

ministered by the National Institutes (3) The disapproval of a grantee's of Health, the Health Services Admin- written request for permission to incur istration, the Health Resources Ad- an expenditure during the term of a ministration, the Center for Disease grant.

Control, the Alcohol, Drug Abuse and (4) A determination that a grant is Mental Health Administration, or the void.

Food and Drug Administration, or by the Public Health Service Regional Offices. For the scope of 45 CFR Part 16 , see 45 CFR 16.2 and the appendices to such part.

[41 FR 49987, Nov. 12, 1976]

850.403 Policy.

(b) A determination described in paragraph (a) of this section may not be reviewed by the review committee described in \$ 50.405 unless an officer or employee of the agency or the Regional Office has notified the grantee in writing of such determination. Such notification shall set forth the reasons for the determination in sufficient

The Secretary of Health and Human detail to enable the grantee to respond Services has established a Depart- and shall inform the grantee of his opmental Grant Appeals Board for the portunity for review under this subpurpose of reviewing and providing part. In the case of a determination hearings upon post-award disputes under paragraph (a)(3) of this section, which may arise in the administration the failure of an agency or a Regional of certain grant programs by constitu- Office to approve a grantee's request ent agencies of the Department. Sec- within a reasonable time, which shall tion $16.5(b)(2)$ of the Charter (45 CFR be no longer than 30 days after the Part 16) which establishes such Board postmark date of the grantee's request authorizes DHHS agencies to establish shall be deemed by the review commit- 
tee a notification for purposes of this paragraph.

(c) Prior to submission to the Departmental Grant Appeals Board of an issue covered by paragraph (a) of this section, the grantee must exhaust the procedure set forth in $\$ 50.406$ of this subpart.

\subsection{Review committees.}

The head of each agency or his designee shall appoint review committees for reviewing appeals of adverse determinations made by Headquarters officials in his agency. For adverse determinations made by Regional Offices the Assistant Secretary for Health or his designee shall appoint review committees. A minimum of three employees shall be appointed (one of whom shall be designated as chairman) either on an ad hoc, case-by-case basis, or as regular members of review committees for such terms as may be des. ignated. None of the members of the review committee reviewing any given appeal may be from the office of the responsible official whose determination is being appealed.

\subsection{Procedure.}

(a) A grantee with respect to whom an adverse determination described in $\S 50.404(a)$ above has been made and who desires a review of such determination must submit a request for such review to the head of the appropriate agency or his designee (or in the case of Regional Office determinations to the Assistant Secretary for Health or his designee) no later than thirty (30) days after the written notification of such determination is received: Provided, That

(1) An extension of time may be granted for good cause shown, and

(2) Where the determination is one described in $\$ 50.404(a)(3)$, the grantee's request for review must be postmarked no later than 90 days after the postmark date of the grantee's request for permission to incur an expenditure.

(b) Although the request for review need not follow any prescribed form, it shall contain a full statement of the grantee's position with respect to the determination being appealed and the pertinent facts and reasons in support of such position. Except in the case of a determination described in the last sentence of $\$ 50.404(\mathrm{~b})$, the grantee shall attach to this submission a copy of the notice of adverse determination.

(c) When a request for review has been filed under this subpart with respect to a determination, no action may be taken by the awarding agency or Regional Office pursuant to such determination until such request has been disposed of, except that the filing of the request shall not affect the authority which the agency or Regional Office may have to suspend assistance or otherwise to withhold or defer pay. ments under the grant during proceedings under this subpart.

(d) Upon receipt of such a request. the head of the agency or his designee (or, if the adverse determination was made in a Regional Office, the Assistant Secretary for Health or his designee) will immediately notify the office responsible for the adverse determina. tion.

(e) The agency or Regional Office involved will provide the review committee appointed pursuant to $\S 50.405$ with copies of all background materials (including application, award, summary statements, and correspondence) and any additional information availa. ble.

(f) The review committee may, at its discretion, invite the grantee, the agency or Regional Office staff, or both to discuss with the review committee pertinent issues, and to submit such additional information as it deems appropriate.

(g) Based on its review, the review committee will prepare a written response to be signed by the chairman. This written response shall be sent to

the grantee, with a copy to the official responsible for the adverse determination. If such response is adverse to the grantee's position, the correspondence shall state the grantee's right to appeal to the Departmental Grant Appeals Board, pursuant to 45 CFR Part 16. 
Federal Register / Vol. 48. No. 168 / Monday, August 31, 1981

43816

\section{DEPARTMENT OF HEALTH ANO HUMAN SERVICES}

Office of the Secratary

\section{CFR Parts 16 and 74}

Grant Appeals Board; Process for Appeals From Final Written Decisions

AGENCY: Department of Health and Human Services.

Action: Final rule.

SUMMARr: The Department of Health and Human Services (HHS) revises 45 CFR Part 16 to substitute new requirements and procedures applicable to disputes arising under certain HHS grant and cooperative agreement programs. HHS also adds certain related provisions to 45 CFR Part 74, which contains general requirements applicable to all HHS grant and cooperative agreement programs. The provisions will improve the Department's capability to provide a fair, quick and flexible process for appeals from final written decisions. DATE: Effective September 30, 1981. FCA FURTHEF INFOMMATION CONTACT: John Settle, Chair, Departmental Grant Appeals Board. Room 2004, Switzer Building, 330 C Street, S.W., Washington, D.C. 20201; Telephone: (202) 245-0222.

SUPPLEMENTARY INFOAMATIONE

\section{Background}

On January 6, 1981, HHS published a Notice of Proposed Rulemaking in the Federal Register containing proposed new requirements and procedures apolicable to the Departmental Grant Appeals Board and those who use the Board's dispute resolution services ( 46 FR 1644). The rules below contain changes made in response to comments received.

II. Summary of comments and changes

Overail, the comments were very supportive of the proposed procedures.
The few criticisms are discussed below. Small cases. We invited comment on whether we should eliminate Board review of small cases, suggesting a threshold of $\$ 5,000$. Comments were negative; furthermore, since we receive few cases under $\$ 5,000$, the savings of time by the Board would be minimal. We therefore have not eliminated small cases from Board jurisdiction. The procedures do contain an expedited review process for cases of $\$ 25,000$ or less ( $\S 16.12$ ).

Subgrantees. One commenter argued that subgrantees of HHS grantees should have a right to appeal to the Board. We have not provided such a general right of access. The Board's primary responsibility is to deal with disputes between $\mathrm{HHS}$ and its grantees, and Board resources are not great enough to permit us to substantially expand our role. Furthermore, HHS has no direct relationship with the subgrantee, and disputes between the subgrantee and the grantee generally should be resolved between those parties. The rules do contain a provision (\$ 16.16) under which a subgrantee which is the real party in interest can intervene if the appellant does not object, and any party with an identifiable interest in a case may, in the discretion of the Board, participate in the process in some lesser manner (for example, by submitting a brief).

Standard of review. One commenter suggested that the Board adopt a standard of review, such as a "substantial evidence" test. We have not done so because the wide range of programs the Board serves, and the complexity of issues within those programs, cannot be adequately covered by a single standard of review or burden of proof statement.

Conflict of interest. One commenter felt that the proposed rules were weak concerning potential conflicts of interest on the part of Board personnel. We have modified the provisions to state an effirmative but general standard, based on the Code of Judicial Conduct and case law such as-Cinderella Career \& 
Finishing Schools, Ine v. FTC, 425 F.2d 583, 391 (D.C. Cir. 1970). This case states that the test for disqualification is whether a disinterested observer could conclude that the decisionmaker "has in some measure adjudged the facts as well as the law of a particular case in advance of hearing it" Canon 3.C.(1) of the Code says that "a judge should disqualify himself in a proceeding in which his impartiality might reasonably be questioned." and lists examples of circumstances. The Board will use the Code and relevant case law as guidance in applying its rule (see \$ 16.5(d)).

Filing time limits. Three commenters felt the time frames in $\$ \$ 16.7$ and 16.8 were too short. We bave not modified these provisions, because we believe that the commenters failed to realize that the new-provisions actually represent a substantial expansion of front-end filing time over existing regulations. Under provisions currently in effect. the grantee is required to file an application for review within 30 days after the adverse agency decision. The application for review contains both notice of an appesl and the appellant's substantive argument. Linder the new rule, an appellant has 30 days to file a notice of appeal (which can be very brief land then has a further 30 days to prepare its argument after the Board acknowledges the notice of appeal. Thus, $\$ \$ 16.7$ and 16.8 more than double the amount of front-end time the appellant has to prepare its position.

In return for this expanded time at the beginning of the appeal, the Board expects greater completeness in grantee briefing. so that the Board will save time later by avoiding successive requests for information or briefing.

Uses of conferences. Section 18.10 has been modified slightly to clarify that the conference is provided not only to elicit answers to specific questions from the Board, but also to give the parties an opportunity to make an oral presentation. The Board still intends to keep the scope of the conference, to the maximum extent practicable, restricted to consideration of material in the appeal file. The conference is not an evidentiary hearing.
Electing a hearing. One commenter found $\$ 16.11$ (a) too restrictive, reading it to mean that unless a party specifically requesterl a hearing at the outset of a case, none would be granted. regardless of the issues involved. The commenter suggested this would lead tn pro forma requests for hearings in all cases. This interpretation was not intended, and we have added lánguage to make it clear that the Board can respond to a later request for a hearing or can schedule one on its own.

Prehearing conferences and the record. One commenter stated that it was "uneasy" about \$16.11(b), which states that the Board, "after consulting with the parties," may reduce the results of an informal prehearing conference to writing in a document which would be made part of the record. The commenter felt that both parties should be given the opportunity of reviewing and commenting on what the Board proposes to include in the record. The Board intends to provide precisely that opportunity, and that is how the Board will interpre! the "consulting" phrase.

Sanctions. Two commenters felt the provisions of $\xi 16.15(\mathrm{~b})$, providing for possible dismissal of an appeal for failure to meet deadlines, were too severe or unfair compared to penalties applicable to the HHS component. The procedures give the Board ample authority to accommodate the legitimate needs of grantees which need extensions for valid reasons, but we cannot allow unreasonable delays. The reason the procedures do not contemplate dismissal against the HHS component for failure to meet desdlines is that there is a substantial legal and policy question whether the Board could or should take an action effectively precluding HHS from recouping funds which HHS determined the grantee possesses or claims illegally, by virtue. for example, of having incurred an unallowable cost. If the HHS component does unreasonably delay, the Board can treat the HHS case as submitted for decision based on the record assembled to that point.

Secretorial review. The provision which provoked the most comments was 
proposed § 16.21 (c), which provided that Board decisions would not be final and would be subject to modification in whole or part at the discretion of the Secretary. The Department continues to study whether Board decisions should be "final" or should be subject to Secretarial review. In order to avoid further delay in implementing the other provisions, these procedures are being published without $\xi 16.21(\mathrm{c})$, and that section is reserved for the addition of a provision dealing with the matter of the finality of Board decisions. In the interim, the decisions of the Board will be the final administrative action of the Department on the matter in dispute.

Staying agency action. Several commenters objected to $\$ 16.22(\mathrm{~b})$, on the basis that it gives an HHS component too much authority to take action pending the outcome of the appeal. The range of actions an HHS component may take under the provisions of $\$ 16.22$ (b) (1) through (3) are reasonably limited; the broadest authority is contained in $\$ 16.22(\mathrm{~b})(4)$, which provides for any other action "specifically authorized by statute or regulation." The latter provision merely restates what would be the rule even if this provision were not included here. and we believe that commenters' attention-generally should focus on the adequacy or desirability of any specific provision of law or regulation that may be proposed by an HHS component to authorize or require predecision action. However, we have clarified $816.22(\mathrm{~b})(3)$. It is intended to apply only to certain Social Security Act programs in situations where a disallowance is taken, based on a report of actual expenditures, before the disallowed claim has ever been approved.

Provisions related to jurisdiction. The final rule adds disallowances under Title III of the Older American Act. Under a final rule published by the Social Security Administration (46 FR 29190, May 29, 1981), the Board will also review certain audit determinations, and provide a hearing on a proposed finding of "substantial failure," in disputes arising under-section 221 of the Social
Security Act.

One commenter expressed "disappointment" that the Board would rely so heavily on HHS component input in situations where Board jurisdiction is unclear, since we will be bound by an HHS opinion that is not clearly erroneous (Appendix A, Paragraph G). The determination that the Board should have jurisdiction for certain programs reflects a policy decision by Departmental managers. Thus, it would be inappropriate for the Board to extend jurisdiction to cases where we did not clearly have it. Furthermore, it is important to bave a rapid decisionforcing mechanism in these unclear cases, to let the grantee and the agency involved know quickly what their review options are.

"Final" agency decisions. Concerning proposed \$ 74.304 , one commenter observed that there can be a problem with an HHS component delaying a final decision, so that failure to provide a final decision should trigger a right to appeal. We have not included such a provision. It is administratively very difficult to determine the scope of an undefined dispute, and thus in most cases virtually impossible to adjudicate it. The Board's regulation does indicate that an agency should issue a decision "promptly." Board personnel who participate in agency training sessions continually try to impress upon agency personnel the need to issue timely final decisions, both to reduce legal and political risk and to foster good grantee/ grantor relationships.

Minor wording changes. A number of other minor changes have been made to assure consistent terminology, to clarify meaning without substantial change, and to improve grammar and style.

\section{Continuing comments invited}

Although this is a final rule, we invite comment and criticism on a continuing basis, and we will make modifications in the future as they are meeded. Please communicate with the Chair, Departmental Grant Appeals Board. Room 2004, Switzer Building, 330 C Street, S.W., Washington, D.C. 20201 (telephone 202/245-0222). 


\section{Implementation}

These procedures apply to all appeals filed on and after the effective date. These procedures also apply to all appeals pending on the effective date, to the extent practicable and not inconsistent with faimess to the parties. The Board will conduct all hearings and conferences in pending appeals in accordance with the new $\$ \S 16.5,16.10$ and 16.11, but the parties in these cases are not required to duplicate earlier effort by developing the appeal file under new $\$ 16.8$. Unless the parties otherwise agree, the expedited process in $\$ 16.12$ does not apply to pending appeals. The Board will consult with the parties in each pending appeal concerning the transition to the new procedures, and will apply the old procedures where a party shows why they would be fairer in that appeal.

Accordingly, the Department amends 45 CFR as follows:

1. By revising Part 16 as follows:

PART 16-PROCEDURES OF THE DEPARTMENTAL GRANT APPEALS BOARD

Sec.

16.1 What this part does.

16.2 Definitions.

16.3 When these procedures become available.

16.4 Summary of procedures below

16.5 How the Board operates.

16.6 Who represents the parties.

16.7 The first steps in the appeal process: the notice of appeal and the Board's response.

16.8 The next step in the appeal process: preparation of an appeal file and written argument.

16.9 How the Board will promote development of the record.

16.10 Using a conference.

16.11 Hearing.

16.12 The expedited process.

16.13 Powers and responsibilities.

16.14 How Board review is limited.

16.15 Failure to meet deadlines and other requirements.

16.16 Parties to the appeal.

16.17 Ex parte communications

(communications outside the record).

16.18 Mediation.

16.19 How to calculate deadlines.

18.20 How to submit material to the Board.
16.21 Record and decisions.

16.22 The effect of an appeal.

16.23 How long an appeal takes.

Appendix A-What Disputes the Board Reviewe.

Authority: 5 U.S.C. 301 and sections 1, 5, 6, and 7 of Reorganization Plan No. 1 of 1953, 18 FR 2053, 67 Stat. 631 and authorities cited in the Appendix.

816.1 What this part does.

This part contains requirements and procedures applicable to certain disputes arising under the HHS programs described in Appendix A. This part is designed to provide a fair, impartial, quick and flexible process for appeal from uritten final decisions. This part supplements the provisions in Part 74 of this title.

\subsection{Definitions.}

(a) "Board" means the Departmental Grant Appeals Board of the Department of Health and Human Services. Reference below to an action of "the Board" means an action of the Chair, another Board member, or Board staff acting at the direction of a Board member. In certain instances, the provisions restrict action to particular Board personnel, such as the Chair or a Board member assigned to a case.

(b) Other terms shall have the meaning set forth in Part 74 of this title, unless the context below otherwise requires.

\section{§ 16.3 When these procedures become available.}

Before the Board will take an appeal, three circumstances must be present:

(a) The dispute must arise under a program which uses the Board for dispute resolution, and must meet any special conditions established for that program. An explanation is contained in Appendix A.

(b) The appellant must have received a final written decision, and must appeal that decision within 30 days after receiving it. Details of how final decisions are developed and issued, and what must be in them, are contained in 45 CFR 74.304.

(c) The appellant must have exhausted any preliminary appeal 
process required by regulation. For example, see 42 CFR Part 50 (Subpart D) for Public Health Service programs and Part 75 of this title for rate determinations and cost allocation plans. In such cases, the "final written decision" required for the Board's review is the decision resulting from the preliminiary review or appeal process. Appendix A contains further details.

\$16.4 Summary of procedures below.

The Board's basic process is review of. a written record (which both parties are given ample opportunity to develop), consisting of relevant documents and statements submitted by both parties (see \$ 16.8). In addition, the Board may hold an informal conference (see $\S 16.10)$. The informal conference primarily involves questioning of the participants by a presiding Board member. Conferences may be conducted by telephone conference call. The written record review also may be supplemented by a hearing involving an opportunity for examining evidence and witnesses, cross-examination, and oral argument (see $\$ 18.11$ ). A hearing is more expensive and time-consuming than a determination on the written record alone or with an informal conference. Generally, therefore, the Board will schedule a hearing only if the Board determines that there are complex issues or material facts in dispute, or that the Board's review would otherwise be significantly enhanced by a hearing. Where the amount in dispute is $\$ 25,000$ or less, there are special expedited procedures (see $\$ 16.12$ of this part). In all cases, the Board has the flexibility to modify procedures to ensure fairness, to avoid delay, and to accommodate the peculiar needs of a given case. The Board makes maximum feasible use of preliminary informal steps to refine issues and to encourage resolution by the parties. The Board also has the capability to provide mediation services (see \& 16.18).

\section{16.5 How the Board operates.}

(a) The Board's professional staff consists of a Chair (who is also a Board member) and full- and part-time Board members, all appointed by the Secretary; and a staff of employees and consultants who are attorneys or persons from other relevant disciplines, such as accounting.

(b) The Chair will assign a Board member to have lead responsibility for each case (the "presiding Board member"). The presiding Board member will conduct the conference or hearing. if one is held. Each decision of the Board is issued by the presiding Board member and two other Board members.

(c) The Board staff assists the presiding Board member, and may request information from the parties; conduct telephone conference calls to request information, to clarify issues, or to schedule events; and assist in developing decisions and other documents in a case.

(d) The Chair will assure that no Board or staff member will participate in a case where his or her impartiality could reasonably be questioned.

(e) The Board's powers and responsibilities are set forth in \$16.13.

s 16.8 Who represents the parties.

The appellant's notice of appeal, or the first subsequent submission to the Board, should specify the name, address and telephone number of the appellant's representative. In its first submission to the Board and the appellant, the respondent (i.e., the federal party to the appeal) should specify the name, address and telephone number of the respondent's representative.

8 16.7 The Nrst steps in the appeal process: the notice of appeal and the Board's response.

(a) As explained in 45 CFR 74.304, a prospective appellant must submit a notice of appeal to the Board within 30 days after receiving the final decision. The notice of appeal must include a copy of the final decision, a statement of the amount in dispute in the appeal, and a brief statement of why tl.e decision is wrong.

(b) Within ten days after receiving the notice of appeal, the Board will send an acknowledgment, enclose a copy of these procedures, and advise the 
appellant of the next steps. The Board will also send a copy of the notice of appeal, its attachments, and the Board's acknowledgment to the respondent. If the Board Chair has determined that the appeal does not meet the conditions of 816.3 or if further information is needed to make this determination, the Board will notify the parties at this point.

816.8. The next atep in the appeal proceses: preparation of an appeal file and written argument.

Except in expedited cases (generally those of $\$ 25,000$ or less; see $\$ 16.12$ for details), the appellant and the respondent each participate in developing an appeal file for the Board to review. Each also submits written argument in support of its position. The responsibilities of each are as follows.

(a) The appellant's responsibility. Within 30 days after receiving the acknowledgment of the appeal, the appellant shall submit the following to the Board (with a copy to the respondent):

(1) An appeal file containing the documents supporting the claim, tabbed and organized chronologically and accompanied by an indexed list identifying each document. The appellant should include only those documents which are important to the Board's decision on the issues in the case.

(2) A written statement of the appellant's argument concerning why the respondent's final decision is wrong (appellant's brief).

(b) The respondent's responsibility. Within 30 days after receiving the appellant's submission under paragraph (a) of this section, the respondent shal' submit the following to the Board fwith a copy to the appellant):

(1) A supplement to the appeal file containing any additional documents supporting the respondent's position. organized and indexed as indicated under paragraph (a) of this section. The respondent should avoid submitting duplicates of documents submitted by the appellant.

(2) A written statement (respondent's brief responding to the appellant's brief. (c) The appellant's reply. Within 15 days after receiving the respondent's submission, the appellant may submita short reply. The appellant should avoid repeating arguments already made.

(d) Cooperative efforts. Whenever possible, the parties should try to develop a joint appeal file, agree to preparation of the file by one of them. agree to facts to eliminate the need for some documents, or agree that one party will submit documents identified by the other.

(e) Voluminous documentation. Where submission of all relevant documents would lead to a voluminous appeal file (for example where review of a disputed audit finding of inadequate documentation might involve thousands of receipts), the Board will consult with the parties about how to reduce the size of the file.

\subsection{How the Board will promote} development of the record.

The Board may, at the time it acknowledges an appeal or at any appropriate later point, request additional documents or information; request briefing on issues in the case; issue orders to show cause why a proposed finding or decision of the Board should not become final; hold preliminary conferences (generally by telephone) to establish schedules and refine issues: and take such other steps as the Board determines appropriate to develop a prompt, sound decision.

\section{16.10 Using a conference.}

(a) Once the Board has reviewed the appeal file, the Board may, on its own or in response to a party's request. schedule an informal conference. The conference will be conducted by the presiding Board member. The purposes of the conference are to give the parties an opportunity to make an oral presentation and the Board an opportunity to clarify issues and question both parties about matters which the Board may not yet fully understand from the record.

(b) If the Board has decided to hold a conference, the Board will consult or correspond with the parties to schedul 
the conference, identify issues, and discuss procedures. The Board will identify the persons who will be allowed to participate, along with the parties' representatives, in the conference. The parties can submit with their briefs under $\$ 18.8$ a list of persons who might participate with them, indicating how each person is involved in the matter. If the parties wish, they may also suggest questions or areas of inquiry which the Board may wish to pursue with each participant.

(c) Unless the parties and the Board otherwise agree. the following procedures apply:

(1) Conferences will be recorded at Department expense. On request, a party will be sent one copy of the transcript. The presiding Board member will insure an orderly transcript by controlling the sequence and identification of speakers.

(2) Only in exceptional circumstances will documents be received at a conference. Inquiry will focus on material in the appeal file. If a party finds that further documents should be in the record for the conference, the party should supplement the appeal file, submitting a supplementary index and copies of the documents to the Board and the other party not less than ten days prior to the conference.

(3) Each party's representative may make an oral presentation. Generally, the only oral communications of other participants will consist of statements requested by the Board or responses to the Board's questions. The Board will allow reply comment, and may allow short closing statements. On request, the Board may allow the participants to question each other.

(4) There will be no post-conference submissions, unless the Board. determines they would be helpful to resolve the case. The Board may require or allow the parties to submit proposed findings and conclusions.

\section{16.11 Hearing.}

(a) Electing a hearing. If the appellant believes a hearing is appropriate, the appellant should specifically request one at the earliest possible time (in the notice of appeal or with the appeal file). The Board will approve a request (and may schedule a hearing on its own or in response to a later request) if it finds there are complex issues or material facts in dispute the resolution of which would be significantly aided by a hearing, or if the Board determines that its decisionmaking otherwise would be enhanced by oral presentations and arguments in an adversary, evidentiary hearing. The Board will also provide a hearing if otherwise required by law or regulation.

(b) Preliminary conference before the hearing. The Board generally will hold a prehearing conference (which may be conducted by telephone conference call) to consicier any of the following: the possibility of settlement; simplifying and clarifying issues; stipulations and admissions; limitations on evidence and witnesses that will be presented at the hearing: scheduling the hearing; and any other matter that may aid in resolving the appeal. Noimally, this conference will be conducted informally and off the record; however, the Board, after consulting with the parties, may reduce results of the conference to writing in a document which will be made part of the record. or may transcribe proceedings a id make the transcript part of the record.

(c) Where hearings are held. Hearings generally are held in Washington, D.C. In exceptional circumstances, the Board may hold the hearing at an HHS Regional Office or other convenient facility near the appellant.

(d) Conduct of the hearing. (1) The presiding Board member will conduct the hearing. Hearings will be as informal as reasonably possible, keeping in mind the need to establish an orderly record. The presiding Board member generally will admit evidence unless it is determined to be clearly irrelevant, immaterial or unduly repetitious, so the parties should avoid frequent objections to questions and documents. Both sides may make opening and closing statements, may present witnesses as agreed upon in the prehearing 
conference, and may cross-examine. Since the parties have ample opportunity to develop a complete appeal file, a party may introduce an exhibit at the hearing only after explaining to the satisfaction of the presiding Board member why the exhibit was not submitted earlier (for example, because the information was not available).

(2) The Board may request the parties to submit written statements of witnesses to the Board and each other prior to the hearing so that the hearing will primarily be concerned with crossexamination and rebuttal.

(3) False statements of a witness may be the basis for criminal prosecution under sections 287 and 1001 of Title 18 of the United States Code.

(4) The hearing will be recorded at Department expense.

(e) Procedures after the hearing. The Board will send one copy of the transcript to each party as soon as it is received by the Board. At the discretion of the Board, the parties may be required or allowed to submit posthearing briefs or proposed findings and conclusions (the parties will be informed at the hearing). A party should note any major prejudicial transcript errors in an addendum to its post-hearing brief (or if no brief will be submitted, in a letter submitted within a time limit set by the Board).

\subsection{The expedited process.}

(a) Applicability. Where the amount in dispute is $\$ 25,000$ or less, the Board will use these expedited procedures, unless the Board Chair determines otherwise under paragraph (b) of this section. If the Board and the parties agree, the Board may use these procedures in cases of more than $\$ 25,000$.

(b) Exceptions. If there are unique or unusually complex issues involved, or other exceptional circumstances, the Board may use additional procedures.

(c) Regular expedited procedures. (1) Within 30 days after receiving the Board's acknowledgment of the appeal (see \$ 16.7), each party shall submit to the Board and the other party any relevant background documents (organized as required under $\$ 16.8$ ), with a cover letter (generally not to exceed ten pages) containing any arguments the party wishes to make.

(2) Promptly after receiving the parties' submissions, the presiding Board member will arrange a telephone conference call to receive the parties' oral comments in response to each other's submissions. After notice to the parties, the Board will record the call. The Board member will advise the parties whether any opportunities for further briefing, submissions or oral presentations will be established. Cooperative efforts will be encouraged (see \& 16.8(d)).

(3) The Board may require the parties to submit proposed findings and conclusions.

(d) Special expedited procedures where there has already been review. Some HHS components (for example, the Public Health Service) use a board or other relatively independent reviewing authority to conduct a formal preliminary review process which results in a written decision based on a record including documents or statements presented after reasonable notice and opportunity to present such material. In such cases, the following rules apply to appeals of $\$ 25,000$ or less instead of those under paragraph (c) of this section:

(1) Generally, the Board's review will be restricted to whether the decision of the preliminary review authority was clearly erroneous. But if the Board determines that the record is inadequate, or that the procedures under which the record was developed in $\mathbf{a}$ given instance were unfair, the Board will not be restricted this way.

(2) Within 30 days after receiving the Board's acknowledgment of appeal (see $\$ 16.7)$, the parties shall submit the following:

(i) The appellant shall submit to the Board and the respondent a statement why the decision was clearly erroneous. Unless allowed by the Board after consultation with the respondent, the appellant shall not submit further documents. 
(ii) The respondent shall submit to the Board the reccrd in the case. If the respondent has reason to believe that all materials in the record already are in the possession of the appellant, the respondent need only send the appellant a list of the materials submitted to the Board.

(iii) The respondent may, if it wishes, submit a statement why the decision was not clearly erroneous.

(3) The Board, in its discretion, may allow or require the parties to present further arguments or information.

8 16.13 Powers and responsibilities. In addition to powers specified elsewhere in these procedures, Board members have the power to issue orders (including "show cause". orders); to examine witnesses; to take all steps necessary for the conduct of an orderly hearing: to rule on requests and motions, including motions to dismiss; to grant extensions of time for good reasons; to dismiss for failure to meet deadlines and other requirements; to close or suspend cases which are not ready for review; to order or assist the parties to submit relevant information; to remand a case for further action by the respondent; to waive or modify these procedures in a specific case with notice to the parties; to reconsider a Board decision where a party promptly alleges a clear error of fact or law; and to take any other action necessary to resolve disputes in accordance with the objectives of these procedures.

8 16.14 How Board review is limited. The Board shall be bound by all applicable laws and regulations.

ริ 16.15 Failure to meet deadlines and other requirements.

(a) Since one of the objectives of administrative dispute resolution is to provide a decision as fast as possible consistent with fairness, the Board will not allow parties to delay the process unduly. The Board may grant extensions of time, but only if the party gives a good reason for the delay.

(b) If the appellant fails to meet any filing or procedural deadlines, appeal file or brief submission requirements, or other requirements established by the Board, the Board may dismiss the appeal, may issue an order requiring the party to show cause why the appeal should not be dismissed, or may take other action the Board considers appropriate.

(c) If the respondent fails to meet any such requirements, the Board may issue a decision based on the record submitted to that point or take such other measures as the Board considers appropriate.

\section{$\$ 16.16$ Parties to the appeal.}

(a) The only parties to the appeal are the appellant and the respondent. If the $\mathrm{BC}$ ard determines that a third person is a real party in interest (for example. where the major impact of an audit disallowance would be on the grantee's contractor, not on the grantee), the Board may allow the third person to present the case on appeal for the appellant or to appear with a party in the case, after consultation with the parties and if the appellant does not object.

(b) The Board may also allow other participation, in the manner and by the deadlines established by the Board, where the Board decides that the intervenor has a clearly identifiable and substantial interest in the outcome of the dispute, that participation would sharpen issues or otherwise be helpful in resolution of the dispute, and that participation would not result in substantial delay.

\section{\$1 16.17 Ex parte communications (communications outside the record).}

(a) A party shall not communicate with a Board or staff member about matters involved in an appeal without notice to the other party. If such communication occurs, the Board will disclose it to the other party and make it part of the record after the other party has an opportunity to comment. Board members and staff shall not consider any information outside the record (see $\$ 16.21$ for what the record consists of ] about matters involved in an appeal.

(b) The above does not apply to the following: communications among Board 
members and staff; communications concerning the Board's administrative functions or procedures; requests from the Board to a party for a document (although the material submitted in response also must be given to the other party); and material which the Board includes in the record after notice and an opportunity to comment

8ิ 16.18 Modiation.

(a) In cases pending before the Board. If the Board decides that mediation would be useful to resolve a dispute, the Board, in consultation with the parties, may suggest use of mediation techniques and will provide or assist in selecting a mediator. The mediator may take any steps agreed upon by the parties to resolve the dispute or clarify issues. The results of mediation are not binding on the parties unless the parties so agree in writing. The Board will internally insulate the mediator from any Board or staff members assigned to handle the appeal.

(b) In other cases. In any other grants dispute, the Board may, within the limitations of its resources, offer persons trained in mediation skills to aid in determinations of award amount or disposition of unobligated balances, or selection in the award document of an option for disposition of program-related income.

(2) A termination for failure to comply with the terms of an award.

(3) A denial of a noncompeting continuation award under the project period system of funding where the denial is for failure to comply.with the terms of a previous award.

(4) A voiding (a decision that an award is invalid because it was not authorized by statute or regulation or because it was fraudulently obtained).

(b) Where an HHS component uses a preliminary appeal process (for example, the Public Health Service), the "final written decision" for purposes of Board review is the decision issued as a result of that process.

\section{Cost allocation and rate disputes.}

The Board reviews final written decisions in disputes which may affect a number of HHS programs because they involve cost allocation plans or rate determinations. These include decisinns related to cost allocation plans negotiated with State or local governments and negötiated rates such as indirect cost rates, fringe benefit rates. computer rates, research patient care rates; and other special rates. The "final written decision" for purposes of Board review of these disputes is the decision issued as a result of the preliminary appeal process at Part 75 of this title.

\section{E. SSI agreement disputes.}

The Board reviews disputes in the Supplemental Security Income (SSI) program arising under agreements for Federal administration of State supplementary payments under section 1616 of the Social Security Act or mandatory minimum supplements under section 212 of Pub. L 93-66. In these cases, the Board provides an opportunity to be heard and offer evidence at the Secretarial level of review as set out in the applicable agreements. Thus, the "final written decision" for purposes of Board review is that determination appealable to the Secretary under the agreement.

\section{F. Where Board review is not available.}

The Board will not review a decision if a hearing under 5 U.S.C. 554 is required by statute, if the basis of the decision is a violation of applicable civil rights or nondiscrimination laws or regulations (for example, Title VI of the Civil Rights Act), or if some other hearing process is established pursuant to statute.

G. How the Board determines whether it will review a case.

Under \& 16.7, the Board Chair determines whether an appeal meets the requirements of this Appendix. If the Chair finds that there is some question about this, the Board will request the written opinion of the HHS component which issued the decision. Unless the Chair determines that the opinion is clearly erroneous, the Board will be bound by the opinion. If the HHS component does not respond within a 
time set by the Chair, or cannot determine whether the Board clearly does or does not have jurisdiction, the Board will take the appeal.

\section{PART 74-ADMINISTRATION OF GRANTS}

2. Part 74 of Title 45 of the CFR is amended as set forth below:

a. Subparts $\mathbf{R}$ and $\mathrm{S}$ are reserved as follows:

\section{Subpart R-[Reserved]}

\section{Subpart S-[Reserved]}

b. The table of contents is revised by adding entries for a new Subpart $T$, as follows:

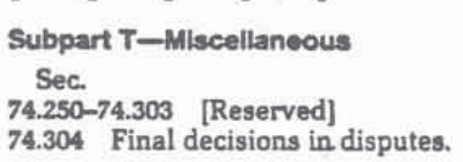

\section{Subpart T-Miscellaneous}

\$\$ 74.250-74.303 [Reserved]

\$74.304 Final decisions in disputes.

(a) Granting agencies and other Departmental components attempt to promptly issue final decisions in disputes and in other matters affecting the interests of grantees. However, they do not issue a final decision adverse to the grantee until it is clear that the matter cannot be resolved informally through further exchange of information and views.

(b) Under various HHS statutes or regulations, grantees have the right to appeal from, or to have a hearing on. certain final decisions by Departmental components. (See, for example, Subpart D of 42 CFR Part 50 and 45 CFR Parts 16 and 75.) Paragraphs (c) and (d) of this section set forth the standards the Department expects its components to meet in stating a final decision covered by any of the statutes or regulations.

(c) The decision is brief but contains-

(1) A complete statement of the background and basis of the component's decision, including reference to the pertinent statutes, regulations, or other governing documents; and

(2) Enough information to enable the grantee and any reviewer to understand the issues and the position of the HHS component.

(d) The following or similar language (consistent with the terminology of the applicable statutes or regulations) appears at the end of the decision: "This is the final decision of the [title of grants officer or other official responsible for the decision]. It shall be the final decision of the Department unless. within 30 days after receiving this decision, you deliver or mail (you should use registered or certified mail to establish the date) a written notice of appeal to [name and address of appropriate contact; e.g., the Departmental Grant Appeals Board. Department of Health and Human Services, Washington, D.C. 20201]. You shall attach to the notice a copy of this decision, note that you intend an appeal, state the amount in dispute, and briefly state why you think that this decision is wrong. You will be notified of further procedures."

(e) If a decision does not contain the statement, information, and language described in paragraphs (c) and (d) of this section, the decision is not necessarily the granting agency's final decision in the matter. The grantee should notify the granting agency that it wishes a formal final decision following any further exchange of views or information that might help resolve the matter informallv.

Dated: August 3, 1981.

Richard Schweiker,

Secretary.

[FR Doc 81-75315 Filed 8-25-81: 8:45 am]

BILLNG COOE 4110-12-M 

Correspondence with the Deputy Director, OMB 


\section{President's Commission for the Study of Ethical Problems in Medicine and Biomedical and Behavioral Research}

Suite 555, 2000 K Street, N.W., Washington, DC 20006 (202) 653-8051

August 24,1981

Edwin L. Harper

Deputy Director

Office of Management and Budget

Washington, D.C. 20503

Dear Mr. Harper:

In a recent conversation with Patricia Szervo, your Associate Administrator for Procurement Law and Legislation, I was told that the proposed government-wide debarment procedures, published July 22 for public comment ( 46 Federal Register 37832) will be applicable only to government contractors. This letter is to inquire whether there is any consideration being given to establishing conforming regulations for grantees of Executive agencies. A member of your staff suggested that in your capacity as Chairman of the President's Council on Integrity and Efficiency, you might be 1nterested in exploring the possibility of developing government-wide debarment and suspension regulations that would be applicable to both grantees and contractors. In the area of concern to this Commission (described below) there would appear to be no relevant differences between grantees and contractors with respect to debarment and suspension from receipt of government funds.

The President's Commission for the Study of Ethical Problems in Medicine and Biomedical and Behavioral Research was established by Title III of Public Law 95-622 in November 1978. Section 1802(c) provides:

(c) REPORT ON PROTECTION OF HUMAN SUBJECTS. The Commission shall biennially report to the President, the Congress, and appropriate Federal agencies on the protection of human subjects of biomedical and behavioral research. Each such report shall include a review of the adequacy and uniformity (1) of the rules, policies, guidelines, and regulations of all Federal agencies regarding the protection of human subjects of biomedical or behavioral research which such agencies conduct or support, and (2) of the implementation of such rules, policies, guidelines, and regulations by such agencies, and may include such recommendations for legislation and administrative action as the Commission deems appropriate. 
A copy of the Commission's mandate is enclosed.

In response to the first part of this mandate, we are currently completing an analysis of the rules and regulations of over twenty Federal agencies that conduct or support biomedical or behavioral research with human subjects. Virtually all of those agencies adopt the policies and procedures set forth in the regulations of the Department of Health and Human Services (HHS), codified at 45 CFR 46.

In an attempt to evaluate the adequacy of the implementation of those rules, the Commission has been examining the response of funding agencies to allegations that a grantee or contractor has materially failed to comply with the applicable regulations or has otherwise placed human subjects at rlsk. Although we are still in the process of gathering information and receiving testimony on this issue, it would appear that a scientist disqualified by FDA from conducting research in support of new drug applications remains eligible to receive research grants from the National Institutes of Health (NIH). Similarly, a scientist debarred from receiving research grants from the NIH remains eligible to receive similar grants and contracts from the National Sclence Foundation, the Department of Defense, and other Executive agencies that support biomedical research through such mechanisms.

My question, therefore, is whether your office has contemplated or would consider extending the government-wide debarment procedures and consolidated lists to include individual biomedical and behavioral scientists debarred from receiving research grants and contracts for serious fallure to comply with the terms of a current award or for violation of applicable regulations. I note in this regard that the debarment rules of the Department of Health and Human Services

(45 CFR 76), published on October 9, 1980 (45 Federal Register 67262), provide standards and procedures for debarment and suspension consistent with those proposed in the OMB policy letter with the exception that the HHS regulations apply to recipients of research grants as well as contracts.

The Commissioners w11 be reviewing the OMB policy letter at its meeting on September 11-12, 1981. It would assist in their discussion if we could have a preliminary indication from you of the possibility of expanding the applicability of the proposed regulations for the Commissioners' review and consideration. I would be happy to discuss this with members of your staff and to provide further materials relevant to this portion of the Commission's mandate, should you so desire.

Thank you for your assistance.

Sincerely yours,

Barbara Mushkin Barbara Mishkin

Enclosures

Deputy D1rector

cc: Melissa Allen

Donald Moran 


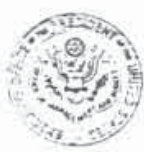

\section{EXECUTIVE OFFICE OF THE PRESIDENT} OFFICE OF MANAGEMENT AND BUDGET

WASHINGTON, D.C. 20503

OCT 301981
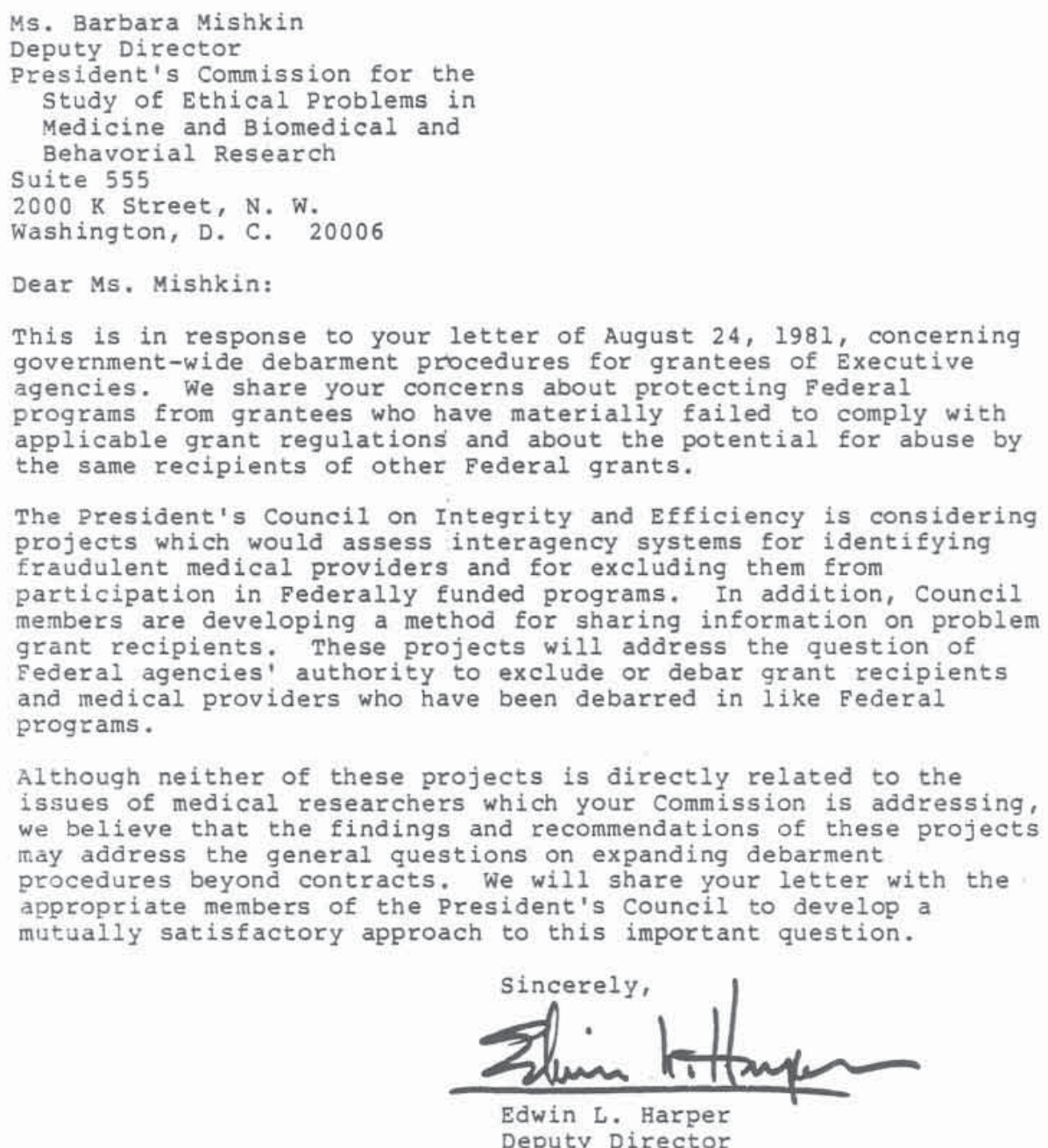


\section{Witnesses Who Testified at Commission Hearings}

\section{Federal Regulation of Behavioral and Social Science Research}

July 12,1980 Washington, D.C.

Ithiel de Sola Pool, Ph.D.

Professor of Political Science

Massachusetts Institute of Technology

Judith Swazey, Ph.D.

Professor of Socio-Medical Sciences

Boston University School of Medicine

Joan Cassell, Ph.D.

Senior Research Associate Center for Policy Research

J. W. Peltason, Ph.D.

President

American Council on Education
Virginia O'Leary, Ph.D.

Administrative Officer for Social and Ethical Responsibility

American Psychological Association

Russell Dynes, Ph.D,

Executive Officer

American Sociological Association

Donna E. Shalala

Assistant Secretary for Policy Development and Research

Department of Housing and Urban Development

David Kefauver

Associate Administrator for Extramural Programs

Alcohol, Drug Abuse and

Mental Health

Administration 
Policies and Procedures for Responding to Reports of Misconduct in Federally Supported Research

June 5, 1981, Boston, Massachusetts

\section{Invited Witnesses:}

Norman G. Levinsky, M.D. Physician-in-Chief

Boston University Hospital

Robert J. Polackwich, M.D.

Tampa, Florida

(former member of the B.U. Oncology Research Unit)

Leonard Glantz, J.D.

Assistant Professor

Boston University Medical School and School of Public Health

(member, IRB, B.U. Medical Center)

Judith Watkins

Boston, Massachusetts

(lay member, IRB, B.U. Medical Center)

James F. McDonough, M.D. Chairman

Massachusetts Board of Registration and Discipline in Medicine

Marc J. Straus, M.D.

Chief, Division of Neoplastic Diseases

New York Medical College

Valhalla, New York

(former Chief, B.U.

Oncology Research Unit)

accompanied by Andrew Good, Esq.

Ruth Moran, Ph.D.

Head, Cell Kinetics Laboratory

New York Medical College

Valhalla, New York

(former head of Cell Kinetics Laboratory, B.U. Oncology Research Unit)
Ms. Jody Fleit

Women and Infants Hospital

Providence, Rhode Island

(former head nurse, B.U. Oncology Research Unit)

Thomas Zipoli, M.D.

Head, Oncology Clinic

St. Luke's Hospital

Bedford, Massachusetts

(referring physician for B.U. Oncology Research Unit)

Kenneth J. Ryan, M.D.

Chairman

Department of Obstetrics and Gynecology

Harvard Medical School and

Chairman, National Commission for the Protection of Human Subjects of Biomedical and Behavioral Research (1974-1978)

Public Witnesses:

Arthur Schneider

(husband of a patient of Dr. Marc Straus)

Frank Musinsky

(former patient at B.U. Hospital)

Dr. Stephen Straus

National Institute of Allergy and Infectious Diseases, $\mathrm{NIH}$

(brother of Dr. Marc Straus) 
The Role of the IRB in Responding to Reports of Misconduct in Federally Supported Research

September 11, 1981 Los Angeles, California

Jerry Mashaw, LL.B., Ph.D.

Professor of Law

Yale University

Virginia Davis Nordin, LL.B.

Director, Institute of

Administrative

Advancement

University of Wisconsin

Robert I. Lehrer, M.D.

Professor of Medicine

University of California, Los Angeles

(Vice-Chairperson, IRB, UCLA School of Medicine)

Robert Sparkes, M.D.

Professor of Medicine

University of California, Los Angeles

(member, IRB, UCLA School of Medicine)

John F. Schacher, Ph.D.

Division of Epidemiology

University of California, Los Angeles

(Chairman, IRB, UCLA's Schools of other health sciences)
The Rev. Charles W. Doak

University Religious

Conference

University of California, Los Angeles

(lay member, IRB, UCLA School of Medicine)

Robert P. Gale, M.D.

Department of Microbiology and Immunology

University of California, Los Angeles

Albert A. Barber, Ph.D.

Vice Chancellor-Research Programs

University of California, Los Angeles

Harold W. Horowitz, S.J.D.

Vice Chancellor-Faculty Relations

University of California, Los Angeles

Sherman Mellinkoff, M.D.

Dean, School of Medicine

University of California, Los Angeles 



\section{Participants in the}

Workshop on

Whistleblowing in Biomedical Research

September 21-22, 1981

Washington, D.C.

Sponsored By

The President's Commission for the Study of Ethical

Problems in Medicine and Research (Washington, D.C.)

The American Association for the Advancement of Science, Committee on Scientific Freedom and

Responsibility (Washington, D.C.)

Medicine in the Public Interest (Boston, MA and

Washington, D.C.)

\section{Workshop Organizers}

Barbara Mishkin, M.A., J.D. Deputy Director

President's Commission for the Study of Ethical

Problems in Medicine and Research

Washington, D.C.

Rosemary Chalk, B.A.

Program Head

Committee on Scientific

Freedom and Responsibility

AAAS

Washington, D.C.
Judith P. Swazey, Ph.D. Executive Director

Medicine in the Public Interest

Boston, Massachusetts 


\section{Participants}

Charlotte B. Cloutier, M.A., M.P.A.

Medicine in the Public Interest

Boston, Massachusetts

Spencer Foreman, M.D.

President

Sinai Hospital of Baltimore

J. Richard Gaintner, M.D.

Vice President and Deputy Director

Johns Hopkins Hospital

Leonard Glantz, J.D.

Department of SocioMedical Sciences

Boston University School of Medicine and Public

Health

Frank P. Grad, LL.B.

Professor of Law

Columbia Law School

Robert J. Levine, M.D.

Yale University School of Medicine

Donald Medearis, M.D.

Chief of the Children's Service

Massachusetts General Hospital

(Member, The President's Commission)

Stuart Nightingale, M.D.

Acting Associate Commissioner for Health Affairs

Food and Drug Administration
Virginia Davis Nordin, LL.B.

Director

Institute of Administrative

Advancement

University of Wisconsin

Andra N. Oakes, Esq.

Dobrovir, Oakes and

Gebhardt

Washington, D.C.

William F. Raub, M.D.

Associate Director for Extramural Research and Training

National Institutes of Heatlh

Peter Raven-Hansen, J.D.

National Law Center

The George Washington University

(Member, AAAS Committee on Scientific Freedom and Responsibility)

John Robertson, J.D.

Schools of Law and Medicine

University of Wisconsin

Stephen Scher, J.D., Ph.D.

Medicine in the Public Interest

Boston, Massachusetts

Deena Weinstein, Ph.D.

Professor of Sociology

De Paul University

Alan Westin, LL.B., Ph.D.

Department of Political Science

Columbia University 


\section{Observers}

\begin{tabular}{ll} 
Alfred Feliu & National Institutes of Health \\
Legal Research Associate & Vijaya L. Melnick, Ph.D. \\
Educational Fund for & Special Assistant for \\
Individual Rights & Bioethics \\
New York, New York & National Institute on Aging \\
Rachelle Hollander & Vanessa Merton, J.D. \\
Acting Program Manager, & Associate for Law \\
Program on Ethics and & Hastings Center \\
Values in Science and & Elena Nightingale, M.D. \\
Technology & Institure of Medicine \\
National Science & National Academy of \\
Foundation & Sciences \\
Thomas Kennedy, M.D. & (Member, AAAS Committee \\
Department of Planning and & on Scientific Freedom and \\
Policy Development & Responsibility) \\
Association of American & Joan Rachlin, J.D. \\
Medical Colleges & Executive Director \\
Washington, D.C. & PRIM\&R \\
Bonnie Lee & Dorothy Rasinsky, M.D., J.D. \\
Office of Health Affairs & Associate Director \\
Food and Drug & Medical Legal Affairs \\
Administration & Veterans Administration \\
Richard T. Louttit, Ph.D. & Richard J. Riseberg \\
Division Director for & Chief, NIH Branch \\
Behavioral and Neural & Office of General Counsel \\
Sciences & Department of Health and \\
National Science & Human Services \\
Foundation & Nancy Sempolsky \\
Bernard M. Malloy, M.D. & University of Kansas \\
Office of Medical Services & \\
Central Intelligence Agency & \\
Charles R. McCarthy, Ph.D. & \\
Chief, Office for Protection & \\
from Research Risks & \\
\hline
\end{tabular}


